INEL-96/0386

April 1996

\title{
Experimental Critical Parameters of Enriched Uranium Solution in Annular Tank Geometries
}

National

Engineering

Laboratory
By

Dr. Robert E. Rothe

Consultant

DE6 19930

오 $S T$

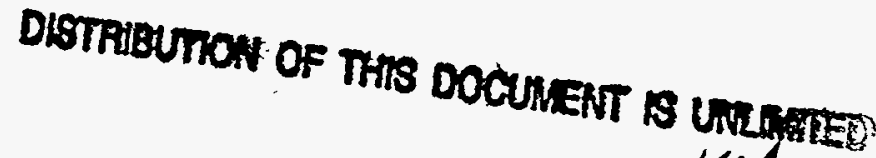

\section{MASTER}

LOCKHEED MARTIN 


\section{DISCLAIMER}

This report was prepared às? an account of work sponsored by an agency of the United States Government. Neither the United States Government nor any agency $\because \quad, \quad$ assumes any legal liability or responsibility for the accuracy, completeness, or use$\therefore$ fulness of any information, apparatus, product, or pröcess disclosed, or represents that its use would not infringe privately owned rights. Reference herein to any specifie-cothitriéreiel-product, process, or service by trade name, trademark, manufacturer, or otherwise does not necessarily constitute or imply its endorsement, recommendation, or favoring by the United States Government or any agency thereof. The views and opinions of authors expressed herein do not necessarily state or reflect those of the United States Government or any agency thereof. 


\title{
EXPERIMENTAL CRITICAL PARAMETERS
}

\author{
of
}

ENRICHED URANIUM SOLUTION

in

ANNULAR TANK GEOMETRIES

by

Dr. Robert E. Rothe

Associate Scientist

April 30, 1996

This paper is written under contracts \#DE-AC07-56IDO1570 and C96-175866 with the United States Department of Energy, administered by the Idaho National Engineering Laboratory, although the work was performed at Rocky Flats, Colorado 


\section{ABSTRACT}

A total of 61 critical configurations are reported for experiments involving various combinations of annular tanks into which enriched uranium solution was pumped. These experiments were performed at two widely separated times in the 1980s under two programs at the Rocky Flats Plant's Critical Mass Laboratory. The uranyl nitrate solution contained about $370 \mathrm{~g}$ of uranium per liter; but this concentration varied a little over the duration of the studies. The uranium was enriched to about $93 \%{ }^{235} \mathrm{U}$ All tanks were typical of sizes commonly found in nuclear production plants. They were about $2 \mathrm{~m}$ tall and ranged in diameter from $0.6 \mathrm{~m}$ to $1.5 \mathrm{~m}$. Annular thicknesses and conditions of neutron reflection, moderation, and absorption were such that criticality would be achieved with these dimensions. Only 13 of the entire set of 74 experiments proved to be subcritical when tanks were completely filled with solution. Single tanks of several radial thicknesses were studied as well as small line arrays $(1 \times 2$ and $1 \times 3)$ of annular tanks. Many systems were reflected on four sides and the bottom by concrete but none were reflected from above. Many experiments also contained materials within and outside the annular regions that contained strong neutron absorbers. One program had such a thick external moderator/absorber combination that no reflector was used at all. 


\section{CONTENTS}

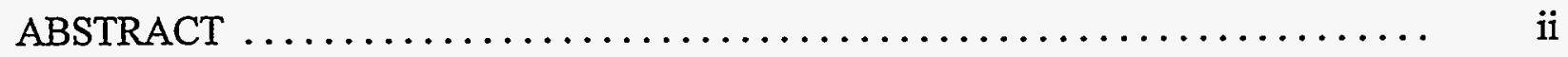

TABLE OF CONTENTS $\ldots \ldots \ldots \ldots \ldots \ldots \ldots \ldots \ldots \ldots \ldots \ldots \ldots \ldots \ldots \ldots \ldots \ldots \ldots$ iii

LIST OF FIGURES $\ldots \ldots \ldots \ldots \ldots \ldots \ldots \ldots \ldots \ldots \ldots \ldots \ldots \ldots \ldots \ldots \ldots \ldots \ldots \ldots \ldots$ vi

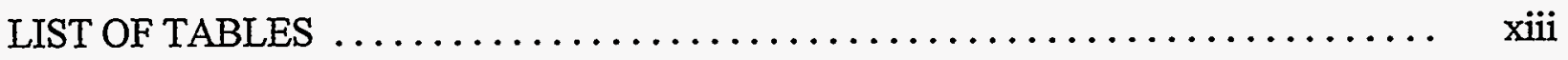

INTRODUCTION $\ldots \ldots \ldots \ldots \ldots \ldots \ldots \ldots \ldots \ldots \ldots \ldots \ldots \ldots \ldots \ldots \ldots \ldots \ldots$

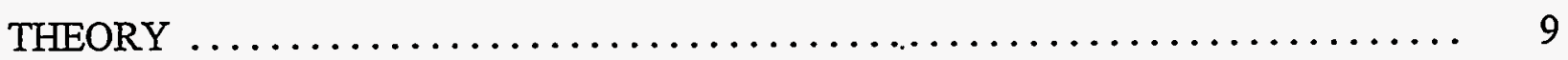

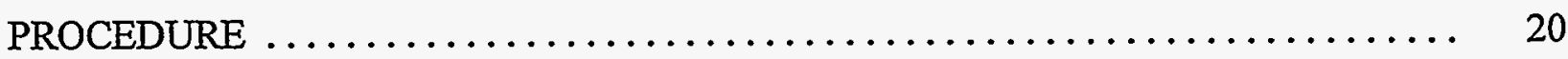

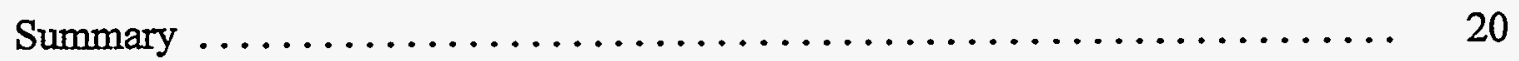

Solution Flow $\ldots \ldots \ldots \ldots \ldots \ldots \ldots \ldots \ldots \ldots \ldots \ldots \ldots \ldots \ldots \ldots \ldots \ldots, 22$

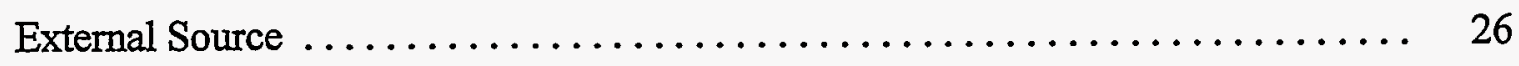

Normal Shutdown $\ldots \ldots \ldots \ldots \ldots \ldots \ldots \ldots \ldots \ldots \ldots \ldots \ldots \ldots \ldots \ldots \ldots, 28$

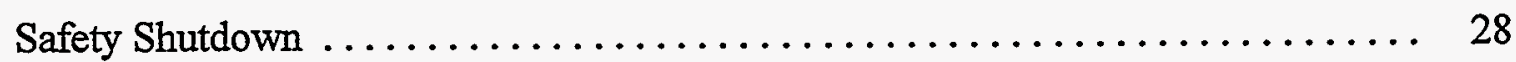

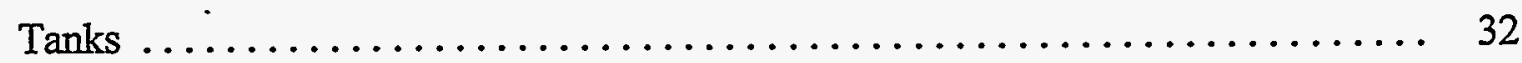

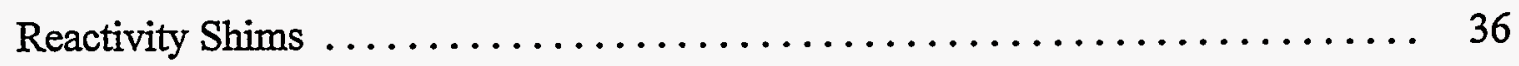

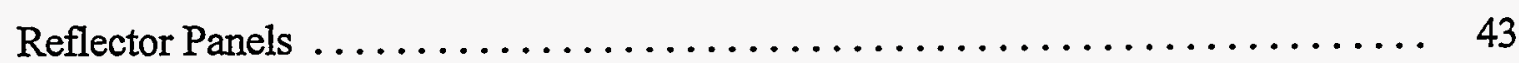

Neutron Moderators \& Absorbers ....................... 43

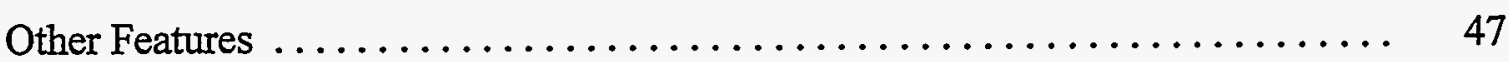

Radiation Detection ................................ 48

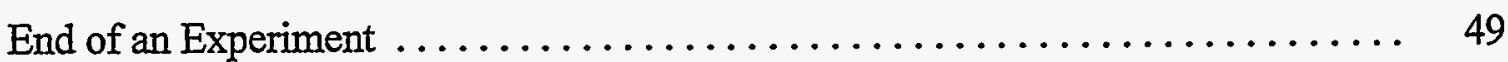

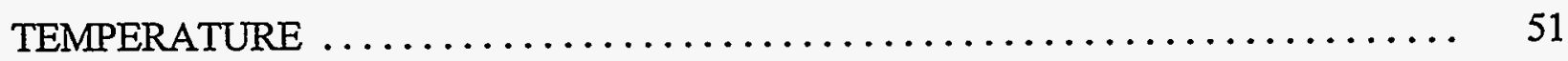

URANIUM SOLUTION $\ldots \ldots \ldots \ldots \ldots \ldots \ldots \ldots \ldots \ldots \ldots \ldots \ldots \ldots \ldots \ldots \ldots \ldots \ldots \ldots$

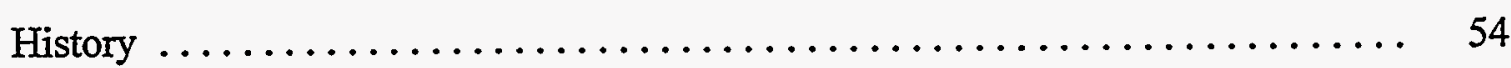

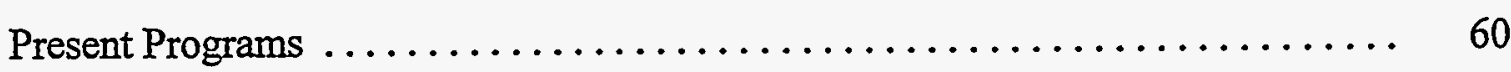




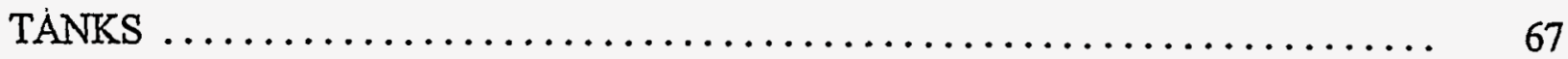

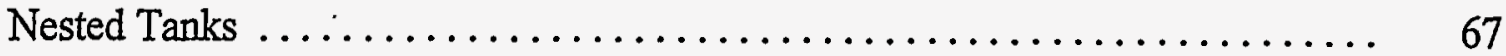

Shielded Annular Tank $\ldots \ldots \ldots \ldots \ldots \ldots \ldots \ldots \ldots \ldots \ldots \ldots . . . \ldots 1$

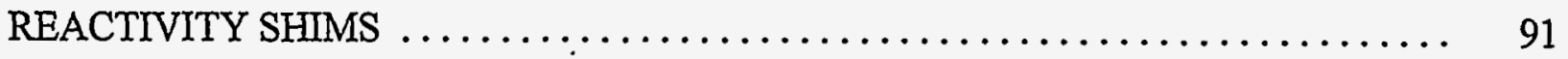

MODERATORS and ABSORBERS $\ldots \ldots \ldots \ldots \ldots \ldots \ldots \ldots \ldots \ldots \ldots \ldots, 102$

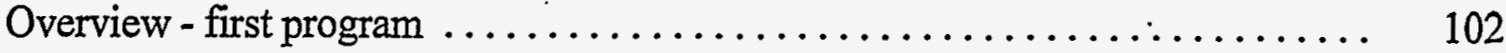

Overview - second program $\ldots \ldots \ldots \ldots \ldots \ldots \ldots \ldots \ldots \ldots \ldots, 108$

Internal Moderation and Absorption - first program $\ldots \ldots \ldots \ldots \ldots \ldots \ldots, 111$

External Moderation and Absorption - first program ............... 138

Internal and External Moderation and Absorption - second program ......... 141

Moderator $\ldots \ldots \ldots \ldots \ldots \ldots \ldots \ldots \ldots \ldots \ldots \ldots \ldots \ldots \ldots, 141$

Absorber ................................... 146

CONCRETE REFLECTOR PANELS $\ldots \ldots \ldots \ldots \ldots \ldots \ldots \ldots \ldots \ldots \ldots \ldots \ldots \ldots \ldots \ldots \ldots \ldots$

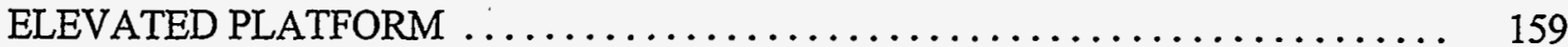

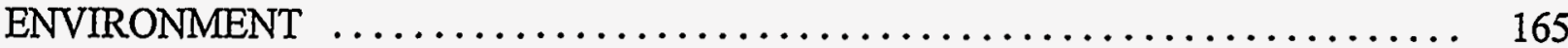

Assembly Room $\ldots \ldots \ldots \ldots \ldots \ldots \ldots \ldots \ldots \ldots \ldots \ldots \ldots \ldots, 166$

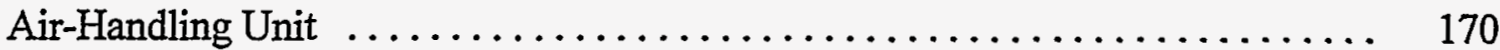

Horizontal Split Table $\ldots \ldots \ldots \ldots \ldots \ldots \ldots \ldots \ldots \ldots \ldots \ldots \ldots . . . \ldots \ldots \ldots$

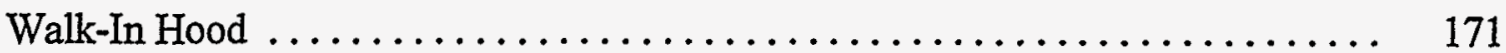

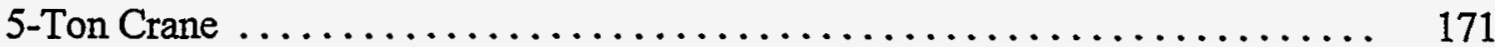

SOLUTION HEIGHT $\ldots \ldots \ldots \ldots \ldots \ldots \ldots \ldots \ldots \ldots \ldots \ldots \ldots \ldots \ldots \ldots \ldots \ldots \ldots$

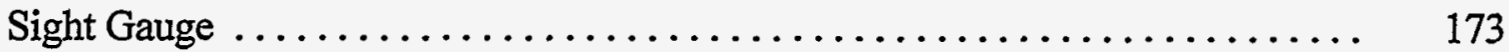

Level Detector ................................... $\quad 175$

Mass Flow Meter $\ldots \ldots \ldots \ldots \ldots \ldots \ldots \ldots \ldots \ldots \ldots \ldots \ldots . \ldots \ldots \ldots$

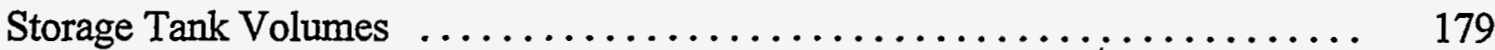

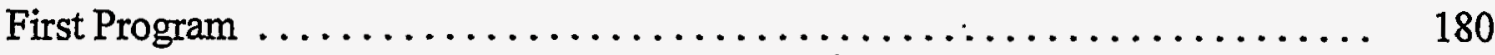

iv 


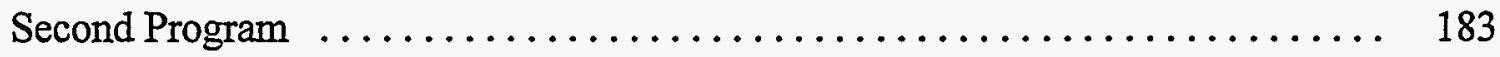

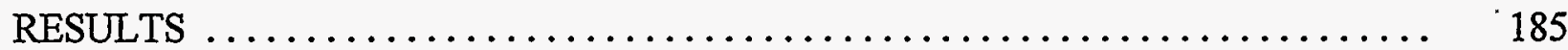

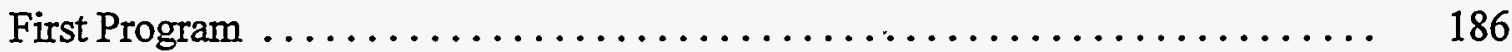

Single Tank $\ldots \ldots \ldots \ldots \ldots \ldots \ldots \ldots \ldots \ldots \ldots \ldots \ldots \ldots \ldots \ldots \ldots$

1x3 Array of Nested Pairs . ....................... 198

1x2 Array of Nested Triples $\ldots \ldots \ldots \ldots \ldots \ldots \ldots \ldots \ldots \ldots . \quad 215$

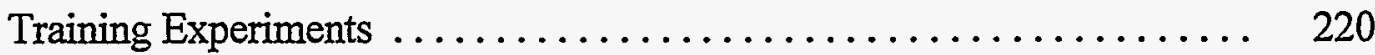

"High Power" Study .......................... 223

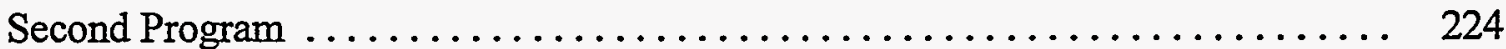

Radial Thickness Search $\ldots \ldots \ldots \ldots \ldots \ldots \ldots \ldots \ldots \ldots \ldots . . \ldots \ldots$

Absorber/Moderator Variations $\ldots \ldots \ldots \ldots \ldots \ldots \ldots \ldots \ldots .233$

UNCERTAINTIES ....................................... 243

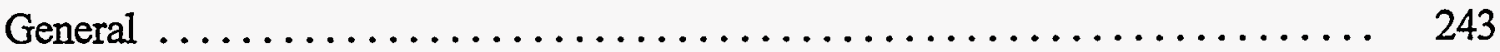

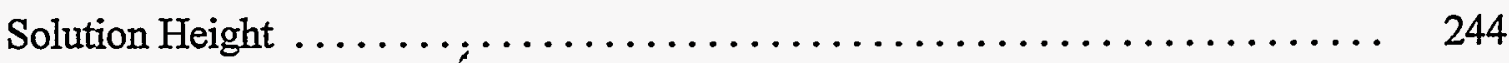

Elemental Composition $\ldots \ldots \ldots \ldots \ldots \ldots \ldots \ldots \ldots \ldots \ldots \ldots . \ldots \ldots \ldots$

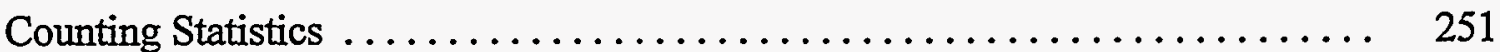

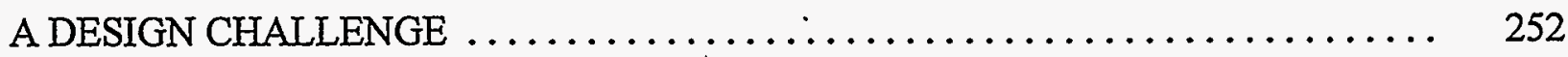

Theoretical ........................................ 252

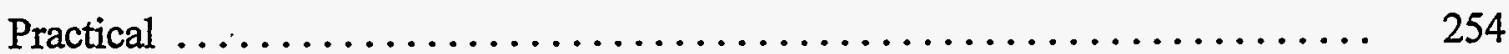

PREPARATION OF A NEUTRON-ABSORBING CONCRETE $\ldots \ldots \ldots \ldots \ldots .259$

A NON-DESTRUCTIVE ASSAY METHOD . . . . . . . . . . . . . . . . . 263

ACKNOWLEDGMENTS ................................... 266

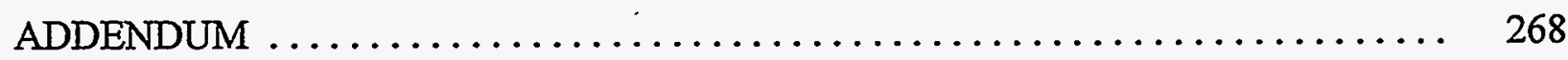

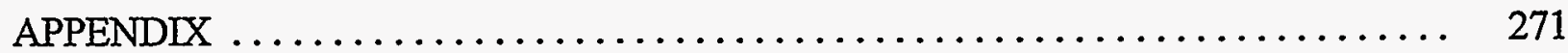




\section{FIGURE CAPTIONS}

Figure 1. A typical reciprocal multiplication curve. Data from two detectors $(\theta$ and $\mathrm{x})$ provided redundancy (safety). The inset table shows how the extrapolated height

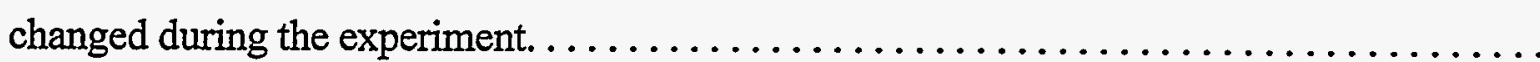

Figure 2. Logarithm of the neutron population vs. time (right to left) during the near-critical phase of an experiment. The experiment actually began far to the right. Alternating source movements and solution additions yield the irregular curve near the center. The rising sloped trace to the left of that corresponds to a

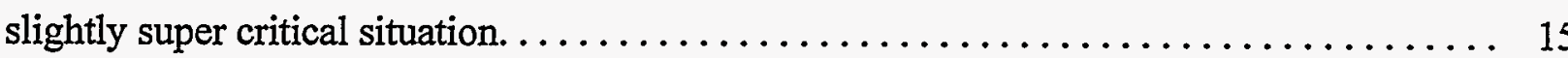

Figure 3. Interpolation of a critical height from slightly super critical and subcritical data (the two dots).

Figure 4. Available fissile solution delivery rates.

Figure 5. Schematic drawing of the uranium solution storage and handling system.

Vertical scaling is approximately accurate; but horizontal placements are not.

Connections for both experimental programs are shown at top left (one as an inset). 
Figure 6. Tanks of the first program had air gaps between them.

Figure 7. The inner tank of the Shielded Annular Tank is to the left of the outer one prior to assembly.

Figure 8. A sturdy cross kept the inner tank from floating when filled with uranium solution. It was also used for lifting components. .

Figure 9. This 4.86-mm-thick reactivity shim would be pressed against the inner wall of the outer tank to reduce the thickness of the radial region, DR.

Figure 10. This 6.23-mm thick free-standing reactivity shim would be placed in the midst of the solution annulus to achieve a subcritical system.

Figure 11. A pie-wedge section of the Shielded Annular Tank program. 46

Figure 12. In 1965, the shipment of $55.7 \mathrm{~kg}$ of enriched uranium required little paperwork. 
Figure 13. Measurements over 25 years assure a linear relationship between concentration and density for this uranium solution. Later data (x's), added years after the linear regression fit (line and equation) to the original data (dots) was calculated, demonstrate a continued fit.

Figure 14. The historical evolution of solution concentrations at Rocky Flats from receipt to the last measurement (1989). Dates of the two experimental programs are indicated..$: \ldots \ldots \ldots \ldots \ldots \ldots \ldots \ldots \ldots \ldots \ldots \ldots \ldots \ldots \ldots, 61$

Figure 15. Vertical section of one of the Nested Tanks.................. 71

Figure 16. Deviations in annular thicknesses from the 38.1-mm design goal (vertical lines) for the six Nested Tanks. Undersized thicknesses are to the left. .

Figure 17. Rolled tanks were not perfectly circular in cross section. Deviations for the largest tank are shown at one height. 
Figure 19. Measured variations in the radial thickness of the Shielded Annular

Tank at 3 heights. Deviations from the $109.22 \mathrm{~mm}$ design goal are shown. ............

Figure 20. Three reactivity shims are clamped against the inner tank and one is expanded against the outer wall. ............................... 94

Figure 21. Detail of the method used to expand the $4.86-\mathrm{mm}$-thick shim. .......... 96

Figure 22. Neutron moderation and absorption were combined into one earthen material for the first program. These were called "plugs". The top two photos show stages of manufacture, the bottom, six finished plugs.

Figure 23. A $1 \times 3$ line array of nested pair of tanks have absorber/moderator slabs between sets of tanks and plugs interior. 106

Figure 24. One plug collapsed during casting and was saved as explained in the text. The assumed cross section is shown. $\ldots \ldots \ldots \ldots \ldots \ldots \ldots \ldots \ldots \ldots$

Figure 25. Cross section of the plaster slabs used between tanks in the Nested

Tank study 140 


\section{DISCLATMER}

Portions of this document may be illegible in electronic image products. Images are produced from the best available original document. 
Figure 26. Plastic moderating cylinders were cut apart to allow assembly but then welded back together for strength. $\ldots \ldots \ldots \ldots \ldots \ldots \ldots \ldots \ldots \ldots \ldots \ldots \ldots \ldots \ldots \ldots$

Figure 27. Moderator cylinders were notched to fit around tank flanges........... 145

Figure 28. Cross section of the annular tank for the second program showing the polyethylene moderator but not the absorber. $\ldots \ldots \ldots \ldots \ldots \ldots \ldots \ldots \ldots \ldots \ldots, 147$

Figure 29. The innermost absorber was wrapped onto a paper tube............ 150

Figure 30. Concrete loses water for a long time after being mixed. Water content of a test concrete block over several months is shown.

Figure 31. The myriad of plastic hoses directing solution from a single fill line into four or six tanks are not thought to contribute significant reactivity because they are outside the reflector boundary. One panel was raised by a concrete block to connect lines to tanks. 
Figure 32. The Assembly Room of the Rocky Flats Critical Mass Laboratory was built in the summer of 1964 . This historic photograph reveals several stages

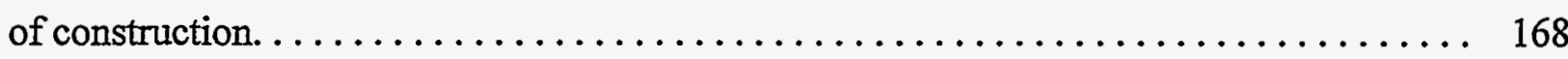

Figure 33. Not all reflector panels were needed to surround four nested tanks of the first configuration. Cast panels did not always fit perfectly; so measured dimensions should be used instead of adding nominal values.

Figure 34. The first configuration viewed from above.

Figure 35. All wall panels were insufficient to surround the $1 \times 3$ array of the second configuration.

Figure 36. The second configuration without any neutron absorber/moderator components. 203

Figure 37. The second configuration with both plugs and slabs within the array. 
Figure 38. The critical height for one experiment had to be inferred from an extrapolation of the reciprocal multiplication data because the supply of high-concentration uranyl nitrate solution had been exhausted. Criticality corresponds to the ordinate equals zero.

Figure 39. The most complicated case for the $1 \times 2$ array of the third configuration included two plugs and four slabs. Other experiments simply had components removed. .

Figure 40. The first three experiments yielded critical heights (dots) less than one meter. Reasonable curves extrapolating these data formed the shaded region and suggested a 6.29-mm-thick shim (upward arrow) was still required. That shim and the next case (downward arrow) proved too thick. The ideal shim fell between 98 and $100 \mathrm{~mm}$.

Figure 41. An infinite slab of fissile solution with a thicker region over a large but finite area has criticality determined by that thickness regardless of the thickness of the slab. A similar slab with a large - but thinner - area is unaffected by the depression. Criticality is determined by the thickness of the infinite slab. 
Figure 42. A reactivity shim reduces reactivity of a slab or annulus because it reduces the solution thickness; but half that decrease is offset by the increased reflection of the thicker wall.

Figure 43. The first attempt to include boron in cast concrete was a dismal failure.

Boron oxide can not replace sand (silicon dioxide) as an ingredient. The top half shows a test cast of various compositions; the bottom illustrates the result of rough handling the set concrete with bare hands!. 


\section{TABLE TITLES}

Table I. Uranium Inventory Results at Rocky Flats Between 1965 (Solution Received) and 1989 (Last Measured).

Uranium Solution 57

Table II. Isotopic Composition of Uranyl Nitrate Solution

Uranium Solution 63

Table III. Impurity Analyses of Rocky Flats' Uranium Solution over its Lifetime.

Uranium Solution 65

Table IV. Composition of the Six Nested Annular Tanks.

Tanks

68

Table V. Dimensions of the Six Nested Annular Tanks.

Tanks

Table VI. Detailed Radial Thicknesses for the Six Nested Annular Tanks. 
Table VII. Radial Map of the Six Nested Annular Tanks to Determine the "Best" Diameter.

Tanks

Table VIII. Equations for the Six Nested Annular Tanks in Various Coordinate Systems.

Tanks

Table IX. Elemental Composition of the Stainless Steel of the Shielded Annular Tank.

Tanks

Table X. Weights and Dimensions of Earthen Plugs.

Mod/Abs

Table XI. Weights and Dimensions of Steel Lifting Disks for Plugs.

Mod/Abs 123

Table XII. Impurity Analysis of the Earthen Ingredients for the Concrete Plugs.

Mod/Abs 128

Table XIII. Elemental Composition of Gerstley Borate. 
Table XIV. Elemental Composition of Plaster Components.

Mod/Abs

Table XV. Measured Dimensions for the First Configuration.

Results

190

Table XVI. Experimental Critical Heights for the First Configuration.

Results

Table XVII. North/South Reflector Enclosure Dimensions for the Second Configuration.

Results

Table XVIII. Precise Tank Locations for the Second Configuration.

Results 204

Table XIX. Experimental Critical Heights for the Second Configuration.

Results

Table XX. Tank Locations Within Reflector Enclosure for the Third Configuration.

Results

xvi 
Table XXI. Experimental Critical Heights for the Third Configuration.

Results

Table XXII. Experimental Critical and Other Solution Heights by Two Methods Due to Changes in the Radial Solution Thickness Through Use of Reactivity Shims.

Results

Table XXIII. Experimental Critical and Other Solution Heights by Two Methods Due to Changes in Placement of Components.

Results

Table XXIV. Changes in Components Referred to in Table XXIII.

Results 236 


\section{INTRODUCTION}

The Rocky Flats Environmental Technology Site (RFETS) has used large-sized production tanks for the storage of fissile solutions since the 1950s. These tanks are only critically safe because they were first filled with borosilicate glass cylinders called "Raschig rings". The glass occupies about one-third of the tank's volume, leaving the remainder for the critically safe storage of plutonium and enriched uranium solutions. The boron in the glass absorbs a sufficient fraction of fission neutrons to render the composite configuration of glass plus solution well subcritical. In recent years, difficulty in meeting the rather strict requirements of the relevant national standard ${ }^{1}$ led plant management to seek alternate methods of storage. That Standard also made Rasching ring usage costly because of the frequent need to handle heavily contaminated items. The switch from that method therefore, became a cost avoidance matter.

The "Annular Tank" was one possibility considered. An annular tank may be understood as a large-diameter tank with coaxial inner and outer walls. The solution is housed only in the annular region between. The height and diameter of such a tank is unrestricted; only the annular thickness is limited to assure criticality safety. An annular tank may also be viewed for some

1 American National Standard: "Use of Borosilicate-Glass Raschig Rings as a Neutron Absorber in Solutions of Fissile Material", ANSI/ANS-8.5-1986. 
purposes as a large, flat, rectangular slab rolled into a circular geometry around an axis parallel to the slab but a distance away from it such that opposite ends of the rolled slab meet.

An annular tank is very inefficient in the use of available floor space. Those in use at Rocky Flats only house solution in about $10 \%$ of a room's floor area. This is in comparison to the Raschig-ring-filled tank's much-more-efficient $65 \%$.

One reason the annular region must be kept thin is that neutrons from one tank interact neutronically with fissile nuclei in neighboring tanks and also with other regions of itself. The critically safe thickness of the annular region could be about doubled if that interaction were eliminated. Toward that goal, neutron moderators in combination with neutron absorbers have been proposed both inside and outside the annulus. This modification is called the "Shielded Annular Tank".

Critical and critical approach experiments were performed to investigate this. These occurred at the Rocky Flats Critical Mass Laboratory (CML) located northwest of Denver, Colorado. That plant was operated for the Department of Energy (DOE) by Rockwell International Incorporated during these experimental programs, although it was subsequently operated by EG\&G Rocky Flats Incorporated and is now operated by Kaiser Hill Incorporated. 
The 74 experiments were conducted in two programs widely separated in time. The first studied a single tank, two side-by-side tanks, and a line array of three annular tanks. It also introduced the concept of reducing neutronic interaction between and within tanks. with shielding. The second concentrated on the control of neutron interactions through a selected combination of neutron moderating and absorbing materials.

The first study ran from August, 1980, through April, 1983. The majority of the data was collected in the first seven months; but, afterward, two ancillary studies merely used the annular tank equipment already set up. One of these later series was a short set of six experiments which spanned the month of May, 1982, and were performed specifically to train a new employee. The other consisted of only three experiments in the spring of 1983 to study criticality detection devices. For these experiments, the neutron flux at criticality was operated about a factor of ten greater than most other experiments in the history of the facility. The second program ran from January through October, 1987. It was specifically tailored to investigate the improved floor-space efficiency of a shielded annular tank. Sadly, that series was halted before the planned program could be completed because of a number of safety concerns which plagued the entire plant. Rocky Flats never recovered from those problems; and that, in turn, signaled the end of experimental research at the CML.

Both programs measured critical uranium solution heights for a tank geometry that could be described, perhaps loosely, as "annular". Dimensions of the tanks used in both programs were 
quite representative of typical production tanks found at Rocky Flats. The solution region was over $2 \mathrm{~m}$ tall; and the outside diameter of the largest tank was more than $1 \mathrm{~m}$. In the first study, a set of six annular tanks of four different diameters was fabricated. All six had the same nominal (38 mm) annular thickness. Four different diameters could be nested inside one another forming an equivalent single tank four times the thickness $(152 \mathrm{~mm})$ of one. The middle two sizes were the ones repeated as the fifth and sixth tanks of the set. With these six tanks, then, one could construct:

- a single "tank" composed of four nested tanks (152 mm),

- two "tanks" each composed of three nested tanks (114 mm), and

- three "tanks" each composed of two nested tanks (76 mm).

One defect of this design was that each "tank" had a number of stainless steel tank walls and the tolerance air gaps between them interrupting the fissile solution region; but these were needed for assembly in this design.

Although six tanks were employed in the first study, just one was fabricated for the second. This one tank was much more carefully manufactured than the first six. Surfaces were machined to be truly circular whereas the earlier set had merely been rolled plate material welded at the seams. Rolled tanks are not very precise in their manufactured geometry. This one was quite precisely a right-circular cylindrical annulus. Its thickness was carefully selected to be just thick enough to achieve criticality with solution near the top of the tank considering the 
moderating and absorbing materials inside and outside the tank. This was a very difficult goal to achieve as will be explained later.

All experiments in the first program were reflected by concrete wall panels. This, too, was intended to simulate conditions at Rocky Flats where solution storage tanks might be located close to concrete walls of a building. No close-fitting reflector was used in the second study because the exterior șhielding was so thick and such a good reflector. Experiments of both programs were reflected at the bottom; but they were essentially unreflected at the top.

The uranium solution used in these studies was uranyl nitrate. The uranium was highly enriched in the isotope ${ }^{235} \mathrm{U}$; and the concentration was close to that yielding optimum moderation. Uranium was chosen for these studies in spite of the fact that RFETS is primarily a plutonium processing facility because the CML already housed a large inventory of uranium solution; ranium experiments are easier, safer, and less expensive to perform; the physics of systems involving both materials are expected to be quite similar; and plutonium solution in such a large quantity was not available.

These experiments were not published at the time they were completed because of a management decision to proceed onto the next experimental study. The reasoning was that Rocky Flats had the data and could use it internally without taking the time and effort to publish 
the results for others to use. Although these particular experiments were never published, the concept of an annular tank for storage of fissile solution was. ${ }^{2}$

Fortunately, the once-bypassed data is being published in this paper under a DOE contract administered by the Idaho National Engineering Laboratory (INEL). It is included within the purview of the Criticality Safety Benchmark Evaluation Project. A similar paper, reporting critical parameters of plutonium metal arrays in water, was completed in 1994 under that same contract.

Composing a technical paper a decade or more after the work was performed is difficult at best. Written records may sometimes be ambiguous. Remembered facts become less certain. Writing the same paper over more than 18 months compounds the difficulty. Data gleaned with difficulty because of the lost decade are not always easy to organize systematically in a sensible fashion over the long writing time. A consequence of these complications is the Addendum at the end of this paper. The reader is advised early to peruse that section for any additional information pertaining to any other section of immediate interest.

Many annular tanks have been used at Rocky Flats since sometime during the 1980 s. Experimental data from the Shielded Annular Tank program was used right away, however, to

2 Jerry N. McKamy, "A Shielded Annular Tank for the Storage of Plutonium Solutions". Transactions of the American Nuclear Society, $\frac{54}{6}, 207$ (1987). 
validate calculational methods associated such a design. Rocky Flats planned to replace its Raschig-ring-filled tanks gradually over a long period of time with annular or shielded annular tanks. Whether all or which selected tanks would be exchanged was not firm at the time of validation (1987). Based in large part on this validation ${ }^{3}$, Rocky Flats built its first prototype shielded annular tank to be used in Building 371 . It was partially built but not completed before other problems besieged Rocky Flats. In 1996, Rocky Flats criticality safety engineers approved use of a shielded annular tank for the caustic waste treatment facility in the same building.

This validation document is not published in any retrievable form. A copy has been retained by this author for almost a decade. Fearful that a possibly important document could be lost, the text is included as an appendix to this document. The text has not been modified in any way; and it even contains non-standard units of measure.

${ }^{3}$ Robert E. Rothe, Robert E. Miles, Jerry N. McKamy, R. David Sachs, and James N. Wu, "The Validation of a Fissile Solution Storage Method for Use at Rocky Flats -- The Shielded Annular Tank", Rockwell International (Critical Mass Laboratory), Rocky Flats Plant. September, 1987. 
Criticality safety aspects of an annular tank are not new. Other papers on the subject have appeared in the literature since $1985^{45678}$.

${ }^{4}$ Robert E. Rothe, "A Survey of Fissile Solution Storage Methods: Champion the Poisoned Tube Tank", Proceedings of a Topical Meeting, American Nuclear Society, Jackson, Wyoming. September, 1985.

${ }^{5}$ John E. Tanner, "Critical Experiments for Large Scale Enriched Uranium Solution Handling", Proceedings of a Topical Meeting, American Nuclear Society, Jackson, Wyoming. September 1985.

${ }^{6}$ T. Kitano and M. Ono, "Criticality Safety Design of the Cylindrical Annular Tanks of NUCEF", Proceedings of ICNC"91，Oxford, United Kingdom. September, 1991.

${ }^{7}$ Gary R. Smolen, Raymond C. Lloyd, and Hideyuki Funabashi, "Criticality Data and Validation Studies of Plutonium-Uranium Nitrate Solutions in Cylindrical and Slab Geometry", NUCLEAR TECHNOLOGY: 107 (1994).

${ }^{8}$ Robert E. Rothe, "Experimental Parameters of Enriched Uranyl Nitrate Solution Contained in Annular Tanks", Proceedings of ICNC'95, Albuquerque, New Mexico. September, 1995. 


\section{THEORY}

Approaches to criticality were monitored by a method called the Reciprocal Multiplication technique to ensure safety. Here, the fact is used that the neutron count rate everywhere within a system increases as criticality is approached. The ratio of this increase over the initial count rate is called the Multiplication of the system? ${ }^{9}$. At the critical height, $\mathrm{H}_{c}$, this count rate, $\mathrm{C}\left(\mathrm{H}_{\mathrm{c}}\right)$, will be many orders of magnitude greater (essentially infinite) than the beginning, $\mathrm{C}_{0}$. The inverse of this multiplication is the reciprocal multiplication already mentioned, mathematically, $\mathrm{C}_{\mathrm{o}} / \mathrm{C}(\mathrm{H})$. This ratio tends toward zero as criticality is approached, an attractive feature for graphing. For safety, reciprocal multiplication curves should have all parameters fixed save one. In this program, that one was the uranium solution height in the one or more tanks with all other features held constant.

Another important definition is that of the neutron reproduction factor, $\dot{k}$. It and the true multiplication, $\mathrm{M}$, are related by the following equation:

$$
\mathrm{k}=\mathrm{M} /[\mathrm{M}+1]=[1+(1 / \mathrm{M})]^{-1} \text {. }
$$

Here, the last term on the right hand side is very close to the reciprocal multiplication already defined.

9 Actually, this empirical ratio is only an approximation to the true multiplication because of other complications to the theory which are explained later. 
The increasing neutron flux is related to the increase in reactivity of the system. Reactivity, $r$, and the reproduction factor are related by:

$$
\mathrm{r}=[\mathrm{k}-1] / \mathrm{k} .
$$

The term really pertains to the state of the system relative to criticality but is often loosely applied to the physical addition of that one parameter being varied, solution height in this case. Adding more uranium solution to these tanks, then, adds "reactivity" to the system through increased fissions due to the additional nuclear fuel in this example.

In practice, the reciprocal multiplication technique began with the completely assembled tank configuration securely positioned within the reflector walls but with no uranium solution yet introduced. Any neutron absorbing or moderating materials, likewise, were already secured in place. The neutron count rate, $\mathrm{C}_{0}$, was noted for each of several very sensitive neutron detectors called proportional counters positioned nearby. These counters detect a constant percentage (usually about $25 \%$ ) of the neutrons incident upon them, even at quite low counting rates. Clearly, at the start of an experiment when the tank is empty ( $\mathrm{H}=0)$, this reciprocal multiplication ratio is unity by definition.

Enriched uranium is not, itself, a good source of neutrons; and a sea of these in and around the components of the experiment are necessary to the reciprocal multiplication technique for safety. An external source is needed to assure that any addition of solution (reactivity) is immediately manifested by an increased neutron count rate. If no neutrons are present to start 
the fission process, an increment of reactivity could be made with no outward manifestation ${ }^{10}$. Accordingly, an external source of neutrons was also positioned at some pre-selected location within the tanks before uranium solution was introduced. In these two studies, a sealed ${ }^{252} \mathrm{Cf}$ neutron source was used.

As the first uranium solution was introduced into the tanks, the change in count rate was only due to improved thermalization of source neutrons by moderation from the hydrogen within the solution. Not nearly enough true reactivity had been added to increase the count rate any appreciable amount. This moderation alters the energy spectra seen by the detectors and, therefore, the instrument's detection efficiency, not the absolute number of neutrons incident upon them.

The reciprocal multiplication technique continued by graphing the reciprocal multiplication, $\mathrm{C}_{\mathrm{d}} \mathrm{C}(\mathrm{H})$, against the critical approach parameter. This was the height, $\mathrm{H}$, of uranium solution within the tank in this case. Eventually, solution additions really did increase

10 An experimental system known as "Godiva" provides a good example. This uranium metal system, designed to be prompt critical, has been so assembled in the controlled absence of extraneous neutrons. The configuration existed, in one reported case, for about 17 seconds before some stray neutron initiated the chain reaction. In the next instant, a very large amount of energy was released, shutting down the excursion; but, in those 17 seconds, one could have approached the prompt critical system receiving no radiation. 
the reactivity of the system; and the reciprocal multiplication ratio truly decreased in some fashion characteristic of neutronic changes within the configuration under study.

The reciprocal multiplication technique ensures safety by allowing experimenters a continually improving estimate of the height at which criticality is projected to occur if the uranium solution height were to increase. At frequent intervals during the approach, solution additions were interrupted to measure the current value of $\mathrm{C}_{0} / \mathrm{C}(\mathrm{H})$. This was graphed on the reciprocal multiplication curve. Its shape and linearity was used to extrapolate to the greater height, $\mathrm{H}_{\mathrm{c}}$, at which criticality would be predicted to occur. Based on this extrapolation, both experimenters agreed upon the next increment of solution to be added and the rate at which it could be added safely. Figure 1 shows a typical reciprocal multiplication curve generated through this procedure. The inset table gives the extrapolated critical heights inferred from the data collected up to the height shown in the left hand column. Generally, the curve was quite linear throughout this program; so the extrapolated values tended to remain close to the final, measured, critical height.

During this procedure, the possibility always existed that some curve might decrease more swiftly than expected. This would suggest a lower critical height than predicted by previous data. This would-be unsafe feature was guarded against by a simple administrative expedient. During the addition of each increment, the next data point was to be taken before the 


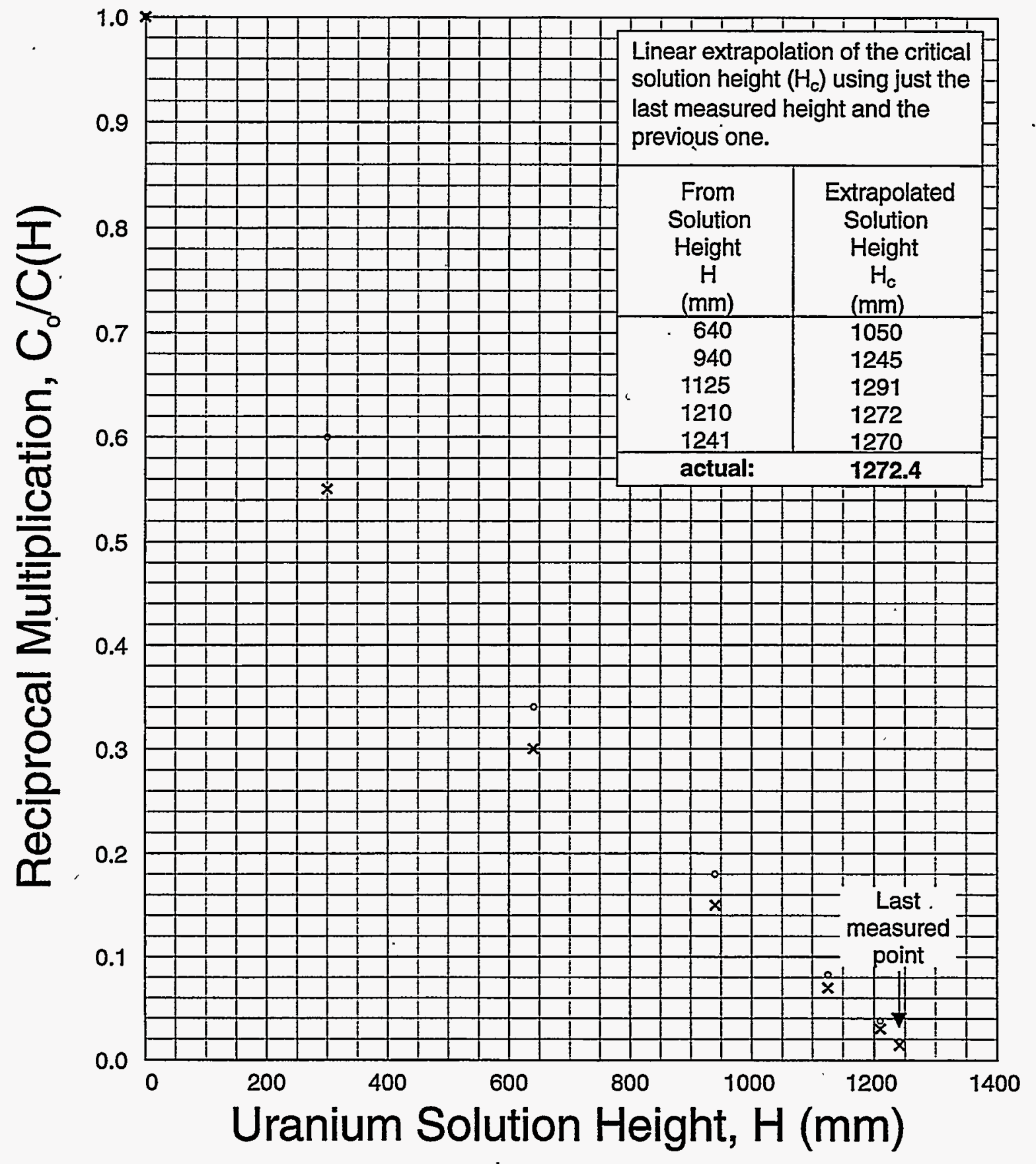

Figure 1. A typical reciprocal multiplication curve. Data from two detectors ( $\mathrm{o}$ and $\mathrm{x}$ ) provided redundancy (safety). The inset table shows how the extrapolated height changed during the experiment. 
neutron flux had increased a factor of $\mathrm{e}(\approx 2.718)$, even if that occurred at a solution height lower than agreed upon. This was possible because both experimenters had continual knowledge of the instantaneous neutron flux for each detector.

This administrative limit (e-folding) was, itself, conservatively protected by administratively adopting an even smaller factor before taking the next reciprocal multiplication data point. Only doubling the count rate, instead of e-folding, became the operational goal.

This procedure continued until the system under study was very close to critical but still slightly subcritical. The neutron population had grown several orders of magnitude over that at the start of the experiment, as illustrated in the figure. A sufficient number of neutrons existed throughout the system that the external source was no longer needed; so it was removed from the vicinity of the experimental system. That is why no data exists above $1240 \mathrm{~mm}$ in the same figure. The source was removed and very small amounts of uranium solution were added in alternating incremental steps. The neutron flux decreased with each source withdrawal but was essentially restored by small solution additions. This procedure kept the neutron population roughly constant. The first very small withdrawal produced a large decrease and required a significant solution addition to recover the population. In time, even large source movements produced only small changes in flux; and very small solution additions were needed. Figure 2 is 


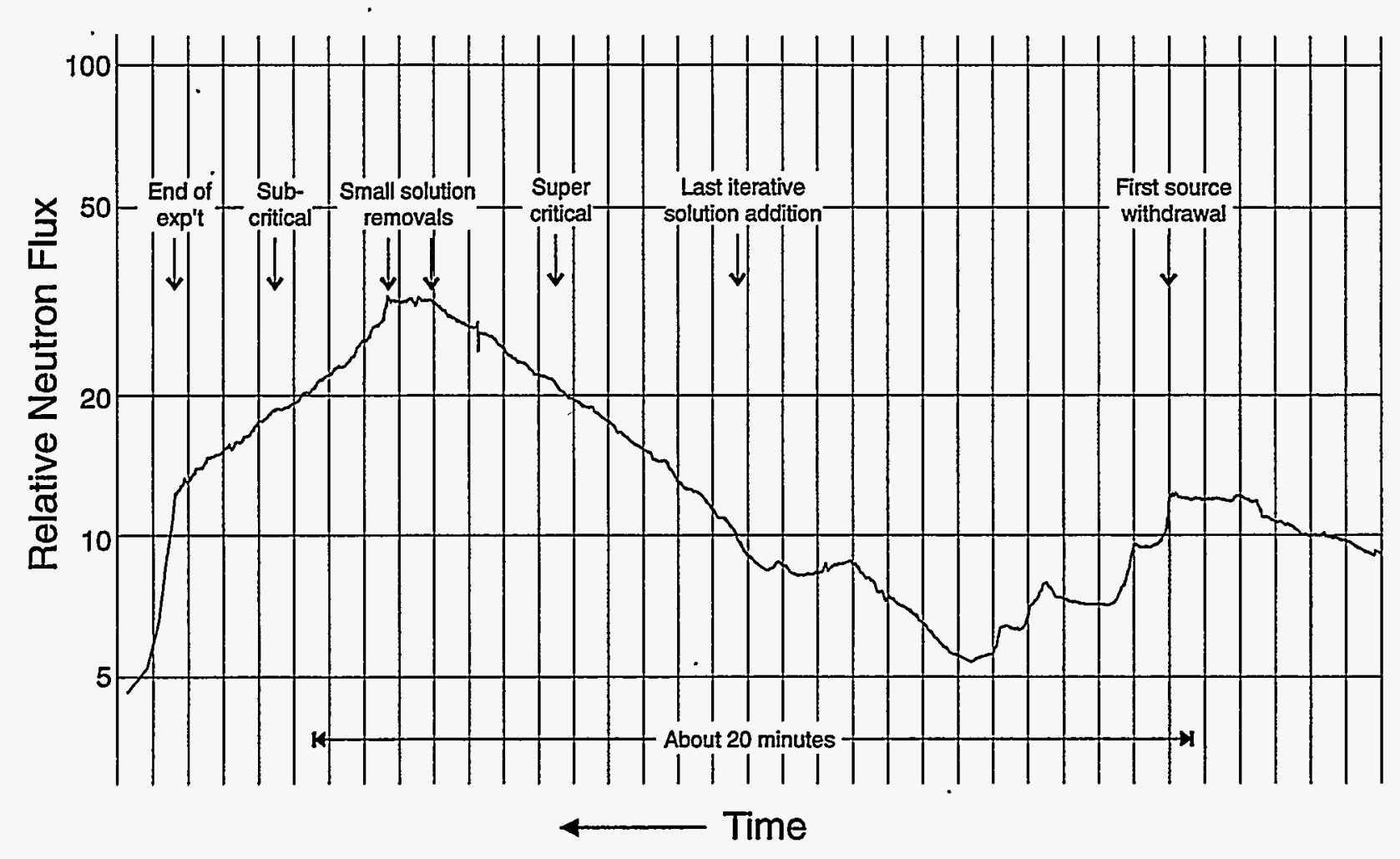

Figure 2. Logarithm of the neutron population vs. time (right to left) during the near-critical phase of an experiment. The experiment actually began far to the right. Alternating source movements and solution additions yield the irregular curve near the center. The rising sloped trace to the left of that corresponds to a slightly super critical situation. 
an example of an actual case showing these iterative steps. The procedure ended when the source was removed an effectively infinite distance away.

During these last, small, solution additions, the neutron flux became so large that proportional counters began to suffer dead-time losses in their observed counting rates. Detectors can not physically count the same percentage of neutrons incident upon them that they did at the start of the experiment. This physical defect is non-conservative from a safety perspective. The actual multiplication extant would be larger than indicated.

This well-understood flaw was obviated by abandoning the reciprocal multiplication technique in favor of another method for the final attainment of criticality. Other radiation detectors, known as ionization chambers, produce a quasi-DC current proportional to the instantaneous neutron flux incident upon them. These are known not to experience dead time losses until neutron fluxes many orders of magnitude greater than those encountered in these experiments are reached. These same detectors, however, are not sufficiently sensitive to neutron fluxes early in an experiment. Thus, ionization chambers, alone, can not be used for a safe critical approach. In anticipation of this, ionization chambers had been placed in the vicinity of the experimental apparatus, in many cases right alongside the proportional counters. 
Both ionization chambers and proportional counters were equally viable beginning somewhere about the middle of the experiment. Both yielded nearly identical extrapolated predictions of the critical solution height. Both were followed by both observers; so the transition from the reciprocal multiplication technique to ionization chamber data was no compromise of safety.

- By the time the external neutron source was fully removed and the last of the incremental solution additions had about returned the neutron population to its previous level, the precise proximity to criticality could be controlled by the addition or removal of very small quantities of fissile solution ${ }^{11}$. Indeed, an experimental system may be maintained very close to criticality alternating between slightly subcritical and slightly super critical - for many hours by these changes.

Slightly super critical systems were attained by adding solution until the neutron count rate continued to rise slowly even after the addition had ceased. It was delayed critical but not prompt critical because nearly all the delayed neutrons were needed to keep the neutron flux increasing. This exponential growth defined the positive reactor period, mathematically, the time required to increase the neutron flux by a factor of $\mathrm{e}(\approx 2.72)$. This super critical height would be maintained only long enough to measure it accurately. Then, a very small amount of solution was

11 Still, the neutron population is so.large that any unexpected change in the reactivity of the essentially critical system would be seen immediately. 
returned to storage rendering the system very slightly subcritical and producing a negative reactor period. This height would also be maintained just long enough to measure it accurately.

All critical heights quoted in this paper are the result of a linear interpolation between the reciprocal periods at these slightly super critical and slightly subcritical solution heights. An example of this interpolation is shown in Fig. 3 for one experiment from this study. The validity of this interpolated critical height was demonstrated in the literature ${ }^{12}$.

After all this, the experiment was terminated. Keeping the system at or near criticality any longer only increased the risk of an accident and added to the (very small) fission product inventory. The solution was simply allowed to flow back to storage. As expected, the ionization chamber currents returned to their initial near-zero level; but the proportional counters did not return to $C_{0}$ because the external neutron source had been moved.

12 Robert E. Rothe, NUCLEAR SCIENCE AND ENGINEERING: 35 (1969). 


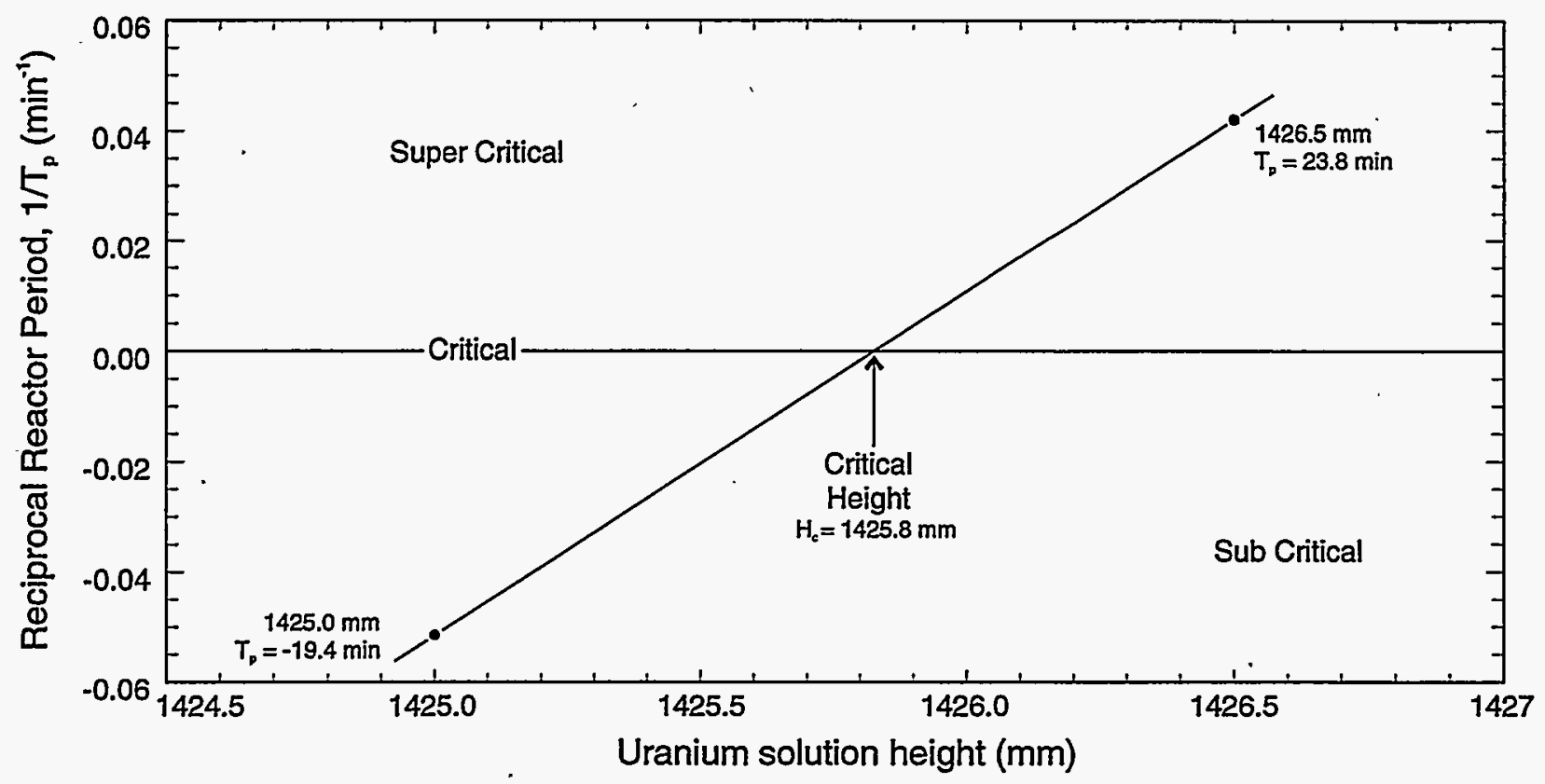

Figure 3. Interpolation of a critical height from slightly super critical and subcritical data (the two dots). 


\section{PROCEDURE}

Summary:

Apparatus used in either program was first securely assembled at the desired location. This included multiple tanks, reflector wall panels, and plaster components containing both neutron moderating and absorbing materials in the first program. In the second, it included a single tank plus separated moderating and absorbing materials. The exact way this assembly was done differed with the two series of experiments; but the end result was the same -- a set of stainless steel, concrete, plaster, plastic, and/or rubber components securely fastened with respect to one another such that they would not move during the experiment $t^{13}$.

The experimental tank or tanks were connected to a storage tank farm which housed a large inventory of enriched uranium in the form of uranyl nitrate solution. The holding contained two concentrations; but only the high concentration solution was used in these experiments. The initially empty experimental tanks were filled with this solution until criticality was achieved. A set of three pumps performed this function.

13 Uranium solution added during the experiment would add considerable weight to preassembled components. That had to be considered during assembly to assure they remained stationary. 
Experiments began with an external source of neutrons flooding the system under study; but this was withdrawn as the configuration reached a point just short of criticality. The source was needed at the start to assure the system's appropriate neutronic response to additions of solution; but it was no longer needed late in an experiment when large numbers of neutrons existed through the fission process in a nearly critical configuration.

The last increment of reactivity (solution) was added very slowly until a very slightly super critical system existed. Generally, positive reactor periods of +3 and +10 minutes were the goal, although slightly shorter and considerably longer periods were sometimes obtained. The administrative safety limit was +30 seconds. This solution height was recorded as precisely as possible. Moments later, a very small amount of solution was returned to storage rendering the system just slightly subcritical; and the amount of solution returned was just as carefully recorded. Generally, negative reactor periods of between -3 and -20 minutes were the goal. In a few instances, a little more solution was added to the first (super critical) system to produce an even shorter reactor period. This was done, rather than establishing a negative reactor period, because the physical process of draining a small amount of solution occasionally shut down the experiment. This is explained later. The critical uranium solution heights quoted in this paper were interpolated from these two near-critical heights, either one positive and one negative or two positive ones. This concluded the experiment and the solution was returned to storage. The apparatus was then re-configured for the next case. 
Solution Flow

Reactivity was introduced through the addition of enriched uranyl nitrate solution. Here, reactivity increased because of increased fissions within the ever-increasing fuel present. The solution was stored in a 9-tank tank farm in another room. Those tanks were critically safe because they contained thousands of borosilicate glass cylinders known as Raschig rings. The solution was pumped into the experimental setup through a single line connecting the storage tanks with a simple distribution manifold for the first program. It passed through the same line but connected directly to the single tank in the second.

The distribution manifold used in the first program merits some discussion. Critical heights were sought for many combinations of multiple tanks. This could have been done over a number of days by constantly shuffling tanks and connecting flexible fill lines. A more efficient procedure was to valve the several tanks for a remote selection of which tanks were to be filled. This was accomplished via the remotely controlled distribution "manifold". This manifold consisted of four branches each consisting of a manual on/off valve and a remotely controlled valve in series. With this manifold, up to four tanks could be connected at one time to the storage farm. Experimenters would simply open appropriate remote-control valve(s) to admit solution into the desired $\operatorname{tank}(\mathrm{s})$. If more than four tanks were to be filled at the same time, as in the case of both array studies, two of the branches would each be plumbed to feed two tanks. If less than 
four tanks were included in any particular configuration, one or more of the manual valves would be left closed.

For example, several very efficient experiments yielded critical heights for four, three, and two tanks without access to the experimental room between critical configurations. In these cases, the critical height in four nested tanks was determined first. Then, solution was drained from only the outer tank but left at the previous height in the inner three. This, of course reduced reactivity to well subcritical. The fourth tank's remote valve was closed and the experiment continued by adding solution to the inner three only. The reciprocal multiplication curve safely began at that already established subcritical height. After the (greater) critical height for three tanks was determined, one of the three was drained, its supply valve closed, and criticality achieved at an even greater height in just two tanks.

Three different flow rates were available for safe control over reactivity addition rates. The fastest was used at the beginning of an experiment and added about one liter per second to the experiment. This flow rate, itself, was remotely adjustable and could be slowed as the initial rate affected the indicated neutron reactor period ${ }^{14}$ too strongly. An administrative safety limit

14 The indicated neutron reactor period is the e-folding time for the growth of the neutron flux in response to the actual addition of fissile solution. This differs from the slightly super critical or slightly subcritical neutron reactor period which measures the e-folding time at a constant uranium solution height very near to precise criticality. 
existed on that parameter: +30 seconds. This same pump could continue to be used a while longer by activating the pump in ever-shorter bursts with ever-longer pauses between bursts. The time-averaged reactivity addition rate over several seconds would still fall within that administrative limit.

At some time during an experiment, even this routine would add solution too fast to stay comfortably below the administrative limit. At this juncture, that pump was rendered physically unable to be used again ${ }^{15}$. A second pump, capable of a slower delivery rate, was used until even that rate became too fast for safe operation. The second pump was also variable in delivery rate. Occasionally, the intermittent pumping procedure was employed with this pump, too; but its lower range nicely overlapped that of the last pump, capable of adding only about $20 \mathrm{~mL} / \mathrm{min}$ at its maximum rate. It, too, was variable but only by a factor of two over its full range. This wide variety of available flow rates enabled every experiment to remain easily within the administrative reactor period limit.

Figure 4 shows the available solution delivery rates. The first pump was a centrifugal design using a rotating impeller, a common design. The other two added solution in pulses. Here,

${ }^{15}$ A nuclear accident could quickly evolve from an inadvertent operation of a pump capable of high-speed solution delivery when experimental conditions called for a much slower addition rate. 


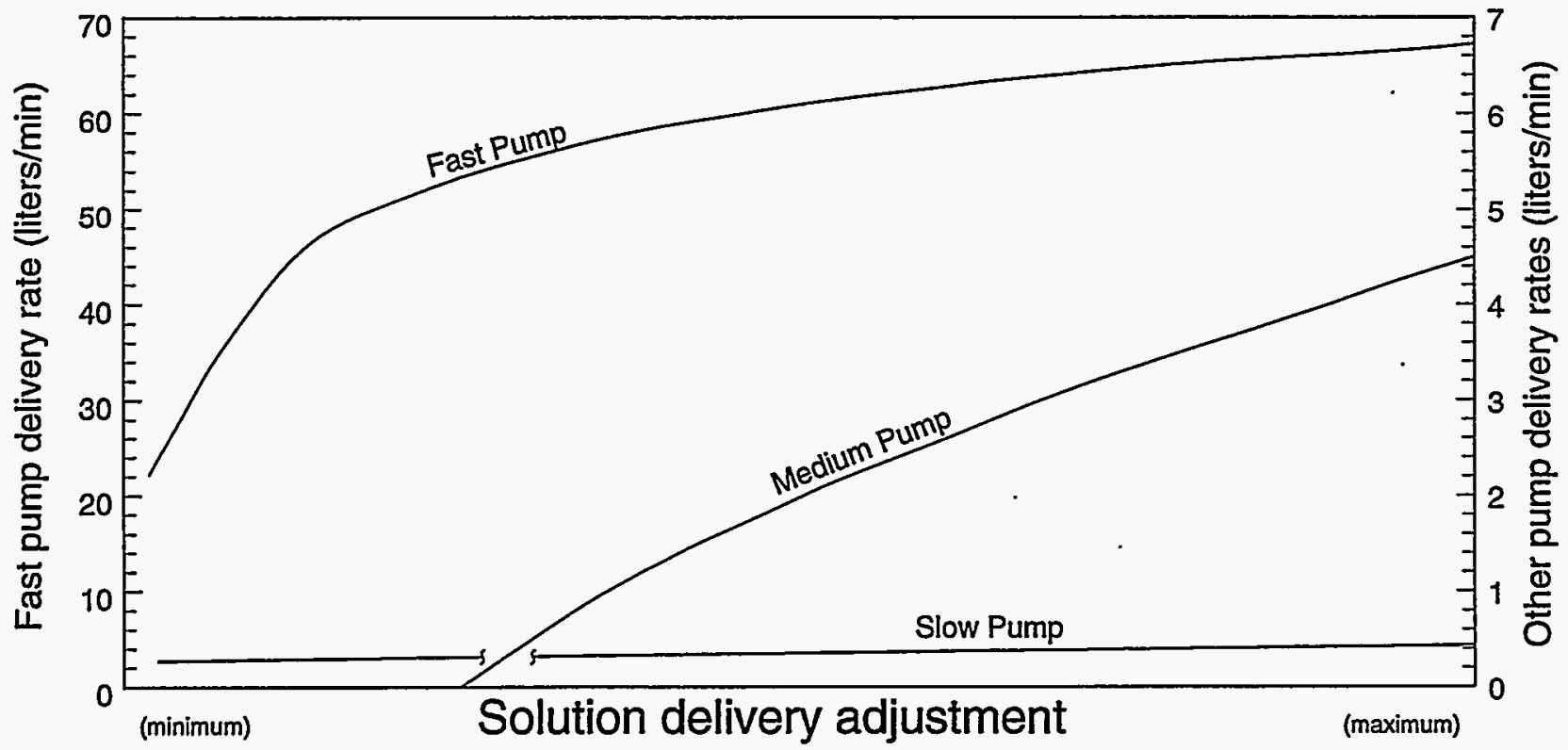

Figure 4. Available fissile solution delivery rates. 
a stainless steel diaphragm separated the uranium solution chamber from one containing hydraulic fluid. A reciprocating ram applied pressure to the oil and then released it in a cyclic fashion. This variation caused the diaphragm to flex. This movement, in turn, alternately expelled solution out of the pump (its delivery) and then sucked more solution into that chamber. All three pumps were very dependable during their 30 years of use.

\section{External Source:}

Throughout most of an experiment, the system under study was bathed in a continuous flux of neutrons from an external source. A very small (few $\mathrm{mg}$ ) speck of ${ }^{252} \mathrm{Cf}$, encapsulated for safety, provided these neutrons. The purpose was to assure that any addition of solution would immediately produce the corresponding change in neutron flux. Uranium, itself, is not a good source of spontaneous neutrons; so the external source was necessary. Just before criticality was attained, this source was no longer needed. In fact, its continued presence would only increase the power level of the near-zero-power reactor unnecessarily. The resulting increase in neutron flux, fission density, and fission fragment inventory was undesirable. For this reason, when an adequate supply of fission neutrons existed because the system was very close to criticality, the

neutron source was removed from the vicinity. This was accomplished in alternating incremental steps with solution additions as explained elsewhere. The result of this iterative procedure was a very slightly delayed critical system with a measurable positive reactor period. 
Critical systems were allowed to remain very slightly super delayed critical for several minutes while the height of the uranium solution was carefully measured. Four methods were used to measure this important parameter; and these are discussed in detail in another section. After that, a very small amount of solution was allowed to drain back to storage. This yielded a very slightly subcritical condition (measurable negative reactor period). The amount of solution returned was also carefully measured and converted to a change in height. The critical heights quoted in this paper are interpolated from these two near-critical heights.

Precise criticality was never attained because that state is characterized by an infinite reactor period. A very long time would be required to demonstrate that situation had been attained; and, if not quite, hours more would be required after a scarcely noticeable change in height. During these hours, unnecessary and unwanted numbers of fission fragments would be forming.

Another theoretical argument speaks against attempting to achieve this "mythical" state. The fission process is statistical in nature. At any given time, even a hypothetical configuration that had been adjusted to be precisely critical when averaged over a long time, would be constantly alternating between various states of being slightly subcritical and slightly super critical. This phenomenon is called reactor noise. 


\section{Normal Shutdown:}

Once both near-critical heights had been determined, the experiment was considered all but ended. Only the safe and systematic shutdown followed. At that point, the solution was allowed to flow back to storage. The experimental tank was not routinely covered to prevent evaporation except for long periods of inactivity. Annular tanks were considered deep enough that the humid atmosphere within an annular region had little chance to escape. Experience revealed this to be a reasonable assumption because laboratory analyses of samples taken before, during, and after a number of other, similar, open-topped experimental studies showed no measurable change in concentration. Much longer temporary stoppages of a week or more occasionally found the tank covered with a plastic drape, more to preclude dust from the solution. The few programs involving exposed, large, slab-like geometries proved the question worth considering. Here, overnight evaporation would sometimes result in a thin crust, similar to yellow ice, forming of the surface of the residual liquid.

\section{Safety Shutdown:}

A delayed critical system is never very far from an accidental prompt-critical situation, sometimes called an excursion. This unplanned condition should be avoided because of its severe consequences -- an intense burst of radiation, lethal to anyone in the immediate vicinity, and the formation of a large inventory of very radioactive nuclides with very long half-lives. If such an event were to occur, it ought to be terminated as quickly as possible to mitigate consequences. 
One of these consequences is the tendency for second, and sometimes more, excursion spikes to develop ${ }^{16,17}$. Quick action can prevent these repeated criticalities. Toward this goal, all critical experiments ever performed at the Rocky Flats laboratory had at least two (redundant) safety shut down mechanisms. These are called SCRAM ${ }^{18}$ devices.

The SCRAM devices for the present experiments consisted of two stainless steel, largediameter, fast-acting, normally-open valves in that line which connected the experimental tank with the set of critically safe holding tanks, termed the dump tanks. Had there been an excursion, the solution would have been highly radioactive; and one would not have wanted to mix that with the non-irradiated solution. A simplified schematic drawing of the valve system is shown in Fig. 5. Only one of several storage tanks and one of three pumps represent the entire tank farm. Four parallel branches to the left center show (right to left) two fill routes through Mass Flow

16 William R. Stratton, "A Review of Criticality Accidents", PROGRESS IN NUCLEAR ENERGY, SERIES IV, VOL. 3, Pergamon Press (1960).

17 William R. Stratton (revised by David R. Smith), "A Review of Criticality Accidents", NUCLEAR CRITICALITY INFORMATION SYSTEM: DOE/NCT-04 (March, 1989).

${ }^{18}$ The word SCRAM comes from the early days of nuclear research. Dr. Enrico Fermi led a team in the assembly of the world's first nuclear reactor in 1942 at the University of Chicago. Dr. Norman Hilberry, later the Director of the Argonne National Laboratory, was given a hand axe and instructed to chop a rope which would then allow a boron plug, called "Zip", to fall under gravity into the core. This rapid addition of negative reactivity was hoped adequate to render the reactor subcritical if some accident had happened. Dr Hilberry was referred to as the Safety Control Rod Axe Man, or "SCRAM". 


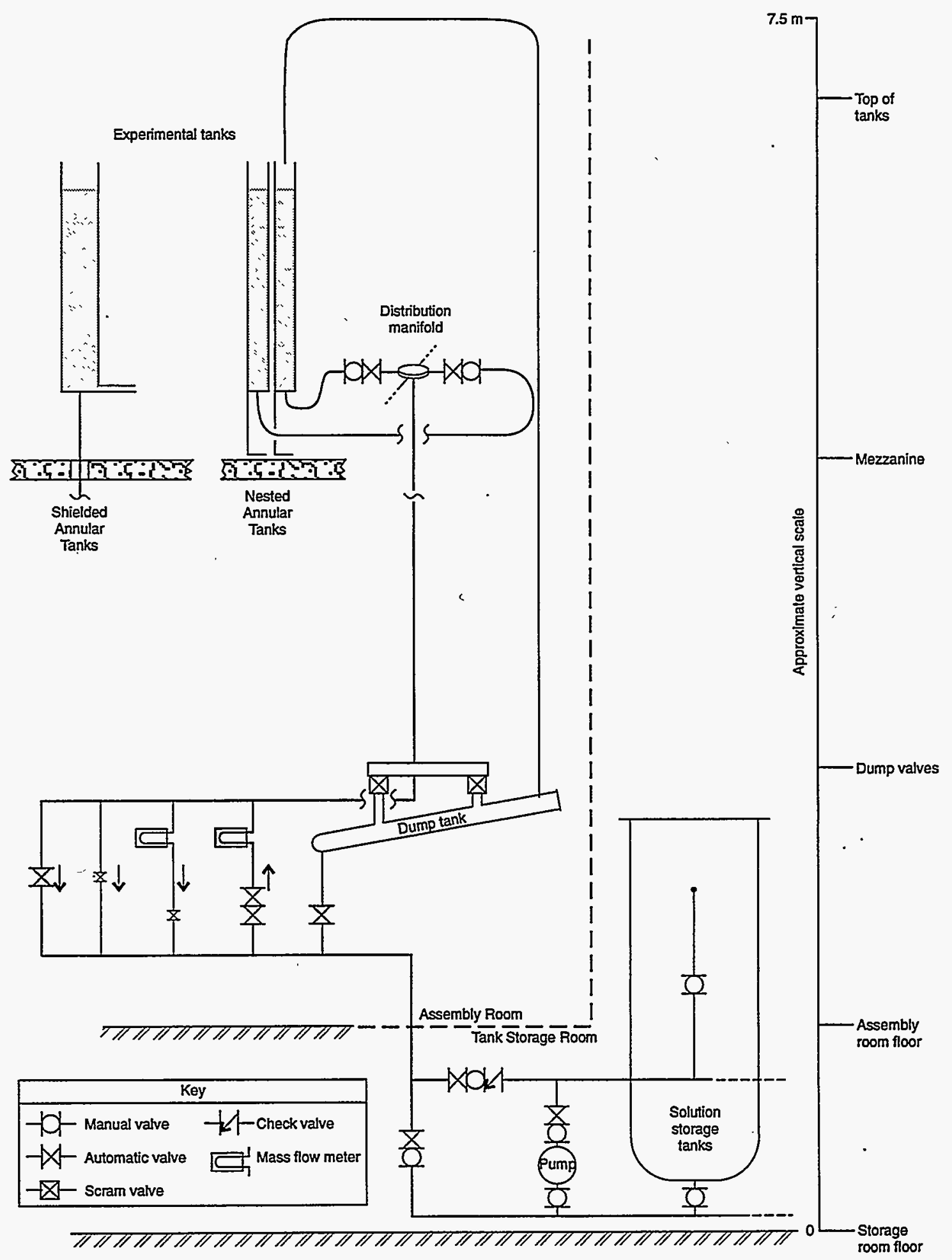

Figure 5. Schematic drawing of the uranium solution storage and handling system. Vertical scaling is approximately accurate; but horizontal placements are not. Connections for both experimental programs are shown at top left (one as an inset). 
Meters and two return routes, one for incremental removals to subcriticality and one for normal return. The dump tank is shown connected to the two SCRAM valves coupled, in turn, to a pancake manifold. Connections to the experimental tanks for both programs are shown at top left, one as an inset.

Each SCRAM valve was electrically operated and had to be energized to keep closed. This is the fail-safe mode. The de-energized state would pass any solution directly into the dump tanks. Only when closed could solution enter the experimental tank.

One important safety feature was that the SCRAM valves were sized large enough to permit uranium solution to flow away from the tank through only one valve faster than the fastest possible solution addition rate. The failure mode assumed that one SCRAM valve fails to function and that the pump feeding the tank fails to turn off. This solution removal rate was verified periodically throughout both programs.

Solution was always pumped upwards against the force of gravity. The weight of the solution within the tank applied a hydrostatic pressure against the head surfaces of the SCRAM valves. The solenoid closure had to be strong enough to overcome that pressure. The valves, themselves, were heavy and operated vertically; so the solenoid had to overcome that weight, 
too. Finally, an ordinary screen door spring tugged against the solenoid. These three conditions (hydrostatic head, weight, and the spring) all contributed to the fail-safe design.

This concept functioned flawlessly in every other program at Rocky Flats; but proved borderline in the current study. The experimental tanks sat too high above the heads of the dump valves ( 3 to $4 \mathrm{~m}$ ). This additional hydrostatic pressure occasionally caused solution to leak through "closed" valves. Only a small amount of leakage was necessary to initiate an automatic SCRAM of the experiment. The pressure head due to platform height was about $4 \mathrm{~m}$ in contrast to the more typical $2.5 \mathrm{~m}$ (same density solution).

The problem seemed worse for the very small returns which changed a slightly super critical system to a slightly subcritical one. Apparently, the downward movement of even this small volume of solution introduced enough momentum that the sudden stoppage of this return increased the force against these solenoids beyond their limit. Often, an automatic SCRAM followed a few seconds after such a return. That is why some critical heights are extrapolated from two different super critical heights rather than the usual method described above.

\section{Tanks:}

In the first program, three configurations were studied using the set of six nesting tanks: 
1) a single tank formed from two to four nesting tanks,

2) a $1 \times 2$ array of three nested tanks, and

3) a $1 \times 3$ line array of nested pairs of tanks.

An oblique overhead view of two of these tanks from the $1 \times 3$ array is shown in Fig. 6 . The photograph reveals some of the shortcomings of rolled tanks and of nesting tanks. Rolled tanks lack dimensional tolerances to fit closely together. In addition, nesting placed regions of stainless steel in the midst of solution regions. In the second study, only a single annular tank having a much thicker annular region was used.

Whatever $\operatorname{tank}(\mathrm{s})$ were to be used were positioned on a mezzanine elevated above the floor of the room. This mezzanine was, effectively, a thick concrete slab; so it resembled a floor all by itself. Tanks were stable by themselves and not fastened to the floor. In fact, the tank of the second series sat on a stout wooden platform.

The single tank of the second experimental program was actually composed of two opentopped cylindrical tanks. The smaller fit inside the larger leaving the desired annular region between. They were formed by rolling and welding much thicker stainless steel stock and then machining these surfaces to the desired thickness. Figure 7 shows the two before assembly. It also shows one edge of the elevated platform. The inner tank was shorter by the thickness of the 


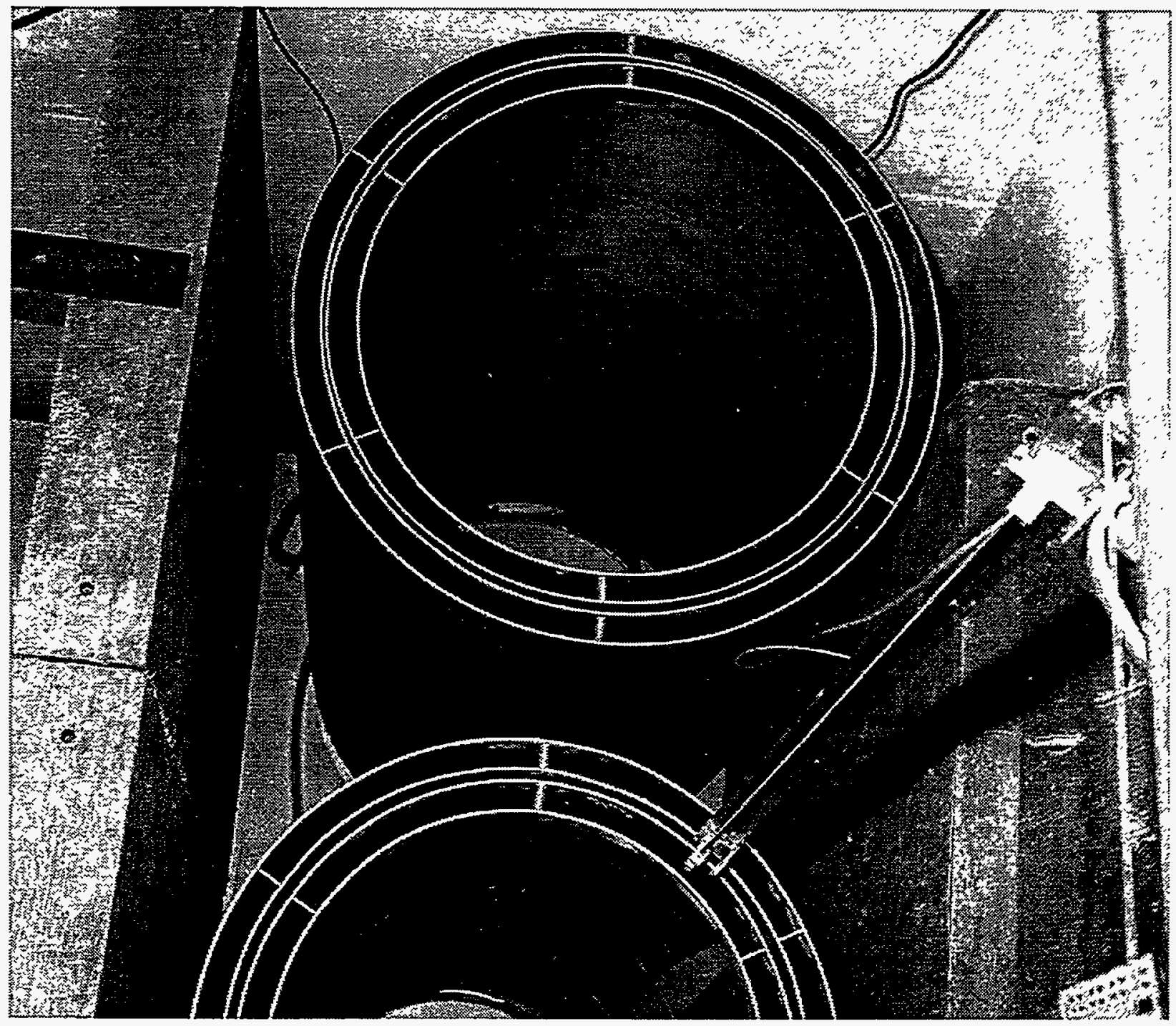

Figure 6. Tanks of the first program had air gaps between them. RFP photo \# 26692-9. 


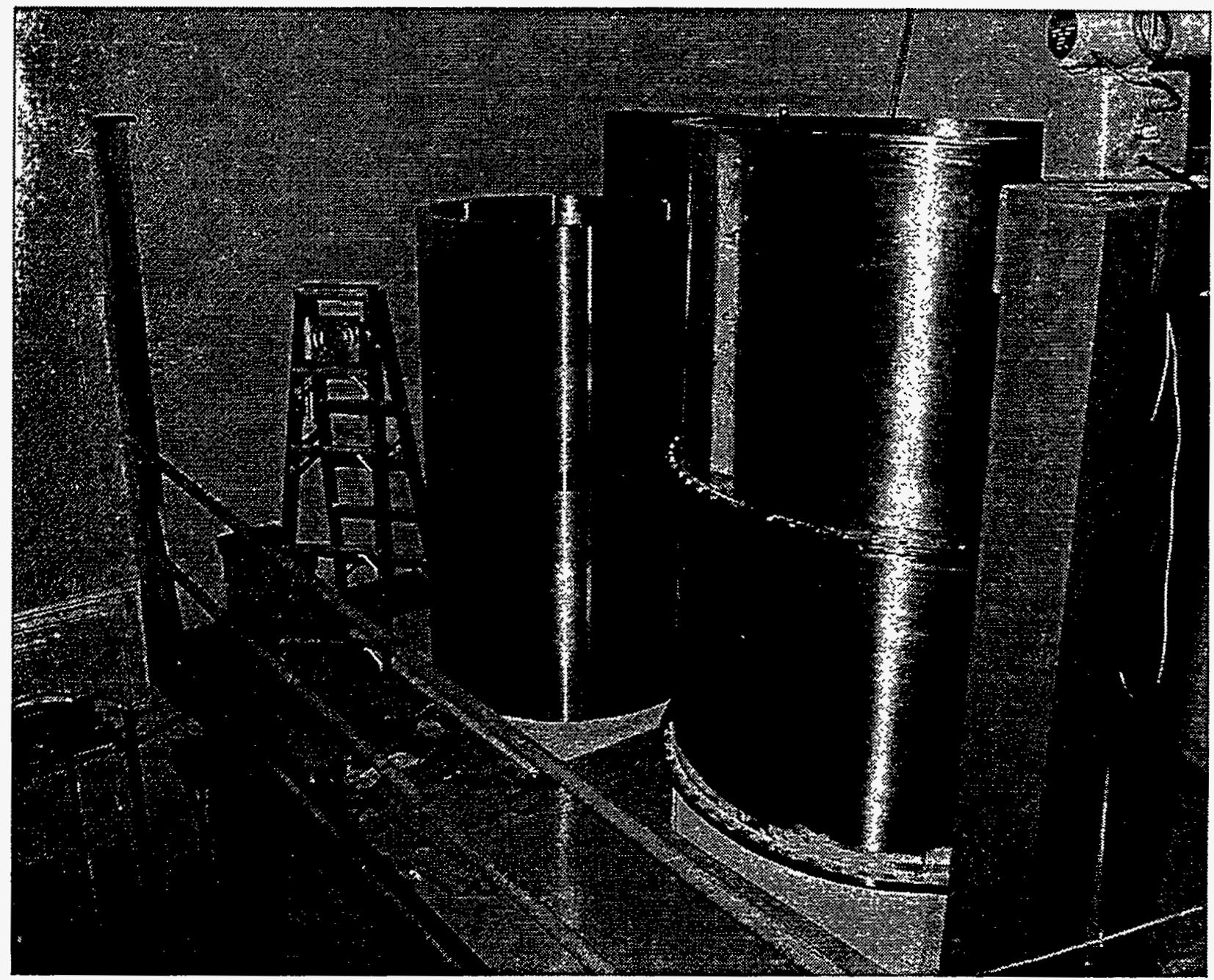

C185-WHT-396-07

Figure 7. The inner tank of the Shielded Annular Tank is to the left of the outer one prior to assembly.

RFP photo \# 35823-17 [12/10/86]. 
outer tank's bottom plate; so both tops were co-planar. A machined annular disk on the floor of the larger assured the inner would be centered.

The inner tank would float due to buoyancy when solution filled the annulus. A heavyduty cross welded from I-beam stock was bolted to both top flanges to prevent that, Fig. 8 . The cross was also used to lift the entire assembly.

\section{Reactivity Shims:}

The annular thickness of the solution region in the second program was intentionally set large. Too thin an annulus would not allow criticality; and the entire study would have been a waste of time. An excessively thick region, on the other hand, would produce criticality at heights lower than desired. The "perfect" radial thickness to manufacture was very difficult to select.

The plan was to add thin sheets of stainless steel to an interior surface of the annulus, thereby reducing the effective annular thickness. The shim thickness was to be adjusted until criticality was achieved with fissile solution somewhere near the top of the tank. These sheets are referred to as reactivity shims. The wisdom of this plan and the challenge of ever obtaining "the perfect tank" is discussed in another section. 


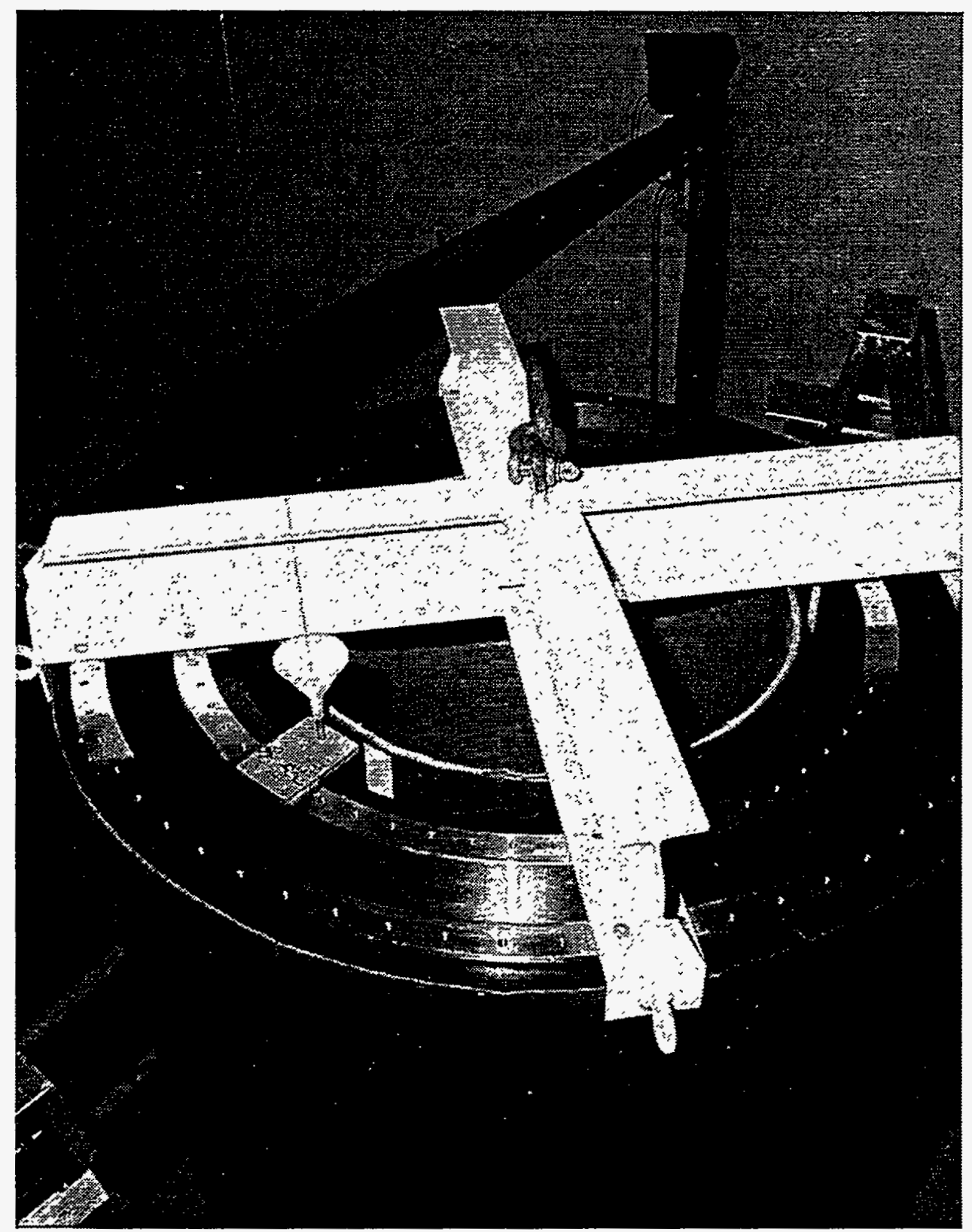

C185-WHT-396-08

Figure 8. A sturdy cross kept the inner tank from floating when filled with uranium solution. It was also used for lifting components. RFP photo \# 35957-06 [1/30/87]. 
Thin shims of three thicknesses were originally fabricated in anticipation of this use. One thickness, any two, or all three could be used to reduce the effective radial thickness of the annular region as necessary. Each thickness was fabricated from flexible sheet stock and sheared to length to just match the circumference of the inner wall. Two sheets, one above the other, were necessary to cover the full height of the tank. These flexible sheets were to be wrapped around the outside of the inner wall of the annular tank and held in place with stainless steel banding material. The plan was to install these only with considerable forethought because, once in position, they would be contaminated with uranium and require greater care in handling.

The first experiment with no reactivity shims in place yielded a critical height much lower than expected. An evaluation revealed that even the sum of all three shims $(3.63 \mathrm{~mm})$ would probably still leave too thick an annular region. They were set aside and a single, much thicker (4.86 mm), shim was bought, rolled into a cylindrical shell, and slipped inside the tank. It was neither machined nor welded along its seam. It was expanded outward against the inside surface of the outer wall to achieve the best fit possible. This was accomplished by a bolt-drive system seen to the left in Fig. 9 which left a small gap. Only half of the shim is shown in the figure; the three tabs were used to connect the two halves.

Even the installation of this unplanned thick shim did not produce the anticipated increase in critical height. This mystery was not at first understood any better than the unexpectedly low 
[L8/L L/Z] I0-966S\&\# 010पd dHY

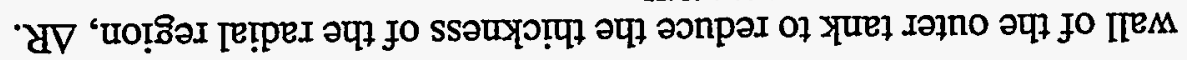

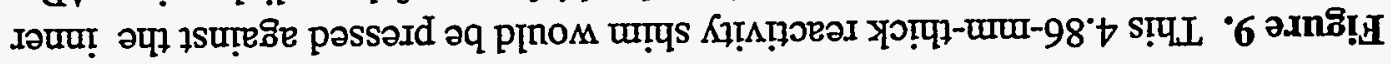

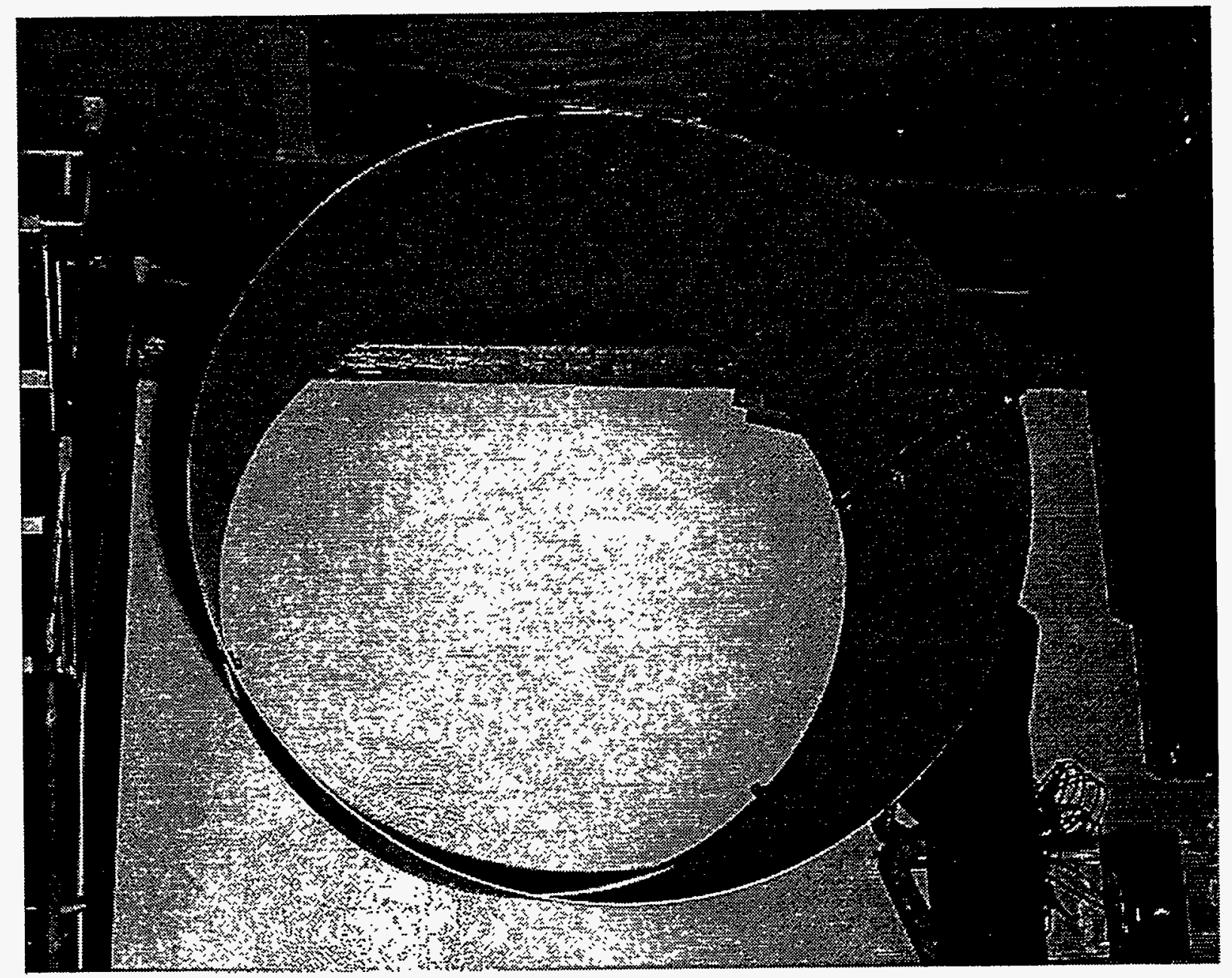


critical height for the shim-free case. In an effort to obtain greater critical heights, all three thin shims were added. These were installed as explained above. At this stage, then, the initial radial thickness was reduced by three shims against the inner wall and one thick shim expanded against the outer wall of the tank. This proved to be an unwise decision because all shims became heavily contaminated and could not be cleaned before removal; so disposal became a significant problem. A total of five contaminated shims still await disposal.

Even this effort - far beyond the initial plan - did not produce a critical height anywhere close to the top of the tank. This was mysterious. Still another shim $(6.23 \mathrm{~mm}$ thick!) was fabricated and installed; but this was rolled to a diameter such that it would become a freestanding cylindrical shell about centered in the solution. It, too, was made in two sections bolted together to cover the full height but was welded along vertical seams. Use of this shim was a drastic measure to achieve criticality that went far beyond initial planning and introduced three concerns:

1) The location of the shim within the solution region needed to be measured. Results were expected to differ if the shim was perfectly centered or tangent to another metal surface at some element.

2) The finished shim was not perfectly circular. Instead, it was a little "egg-shaped".

3) Its bottom edge was notched to permit free flow of liquid away from the annulus in case of a SCRAM, see Fig. 10. 


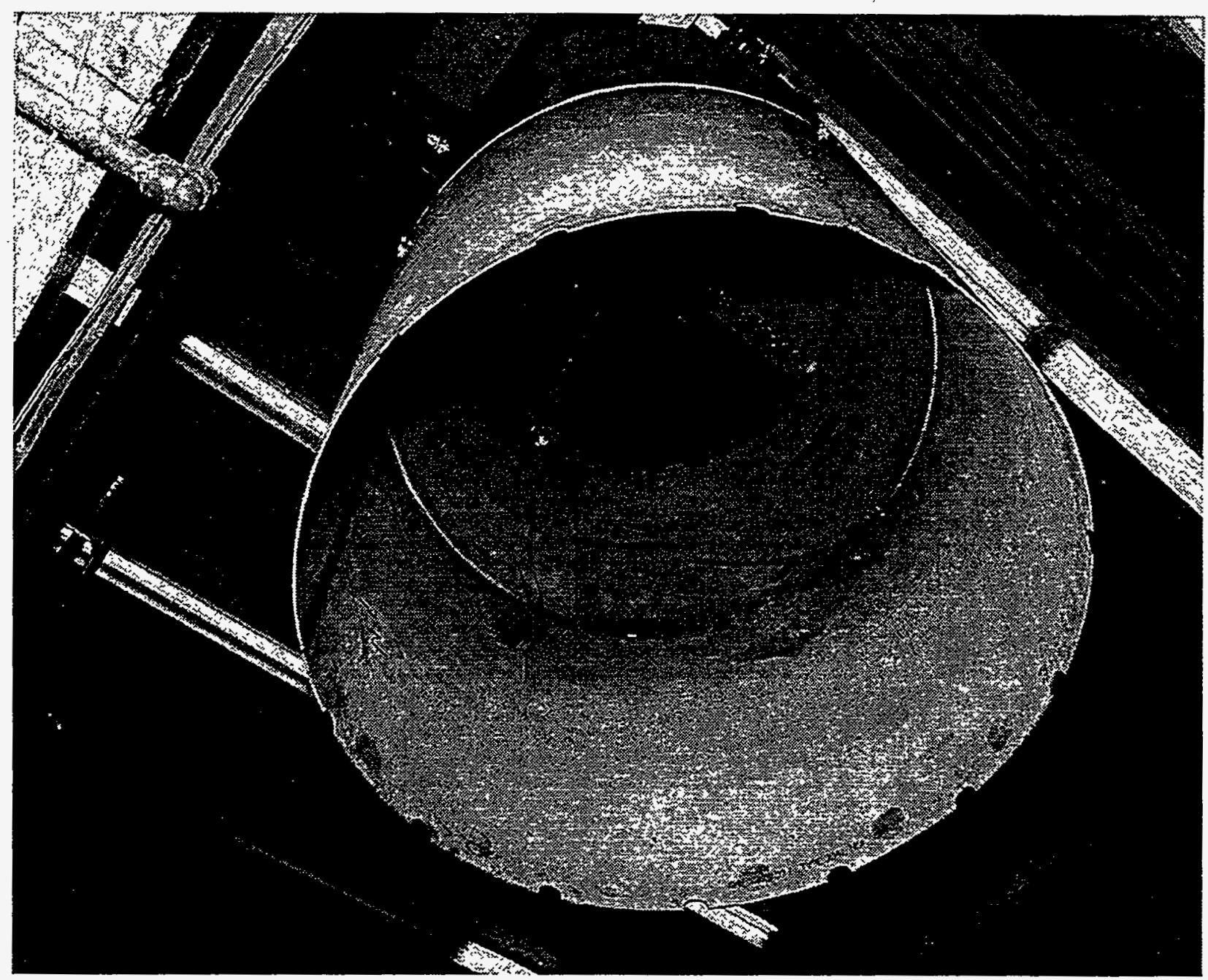

C185-WHT-396-10

Figure 10. This 6.23-mm thick free-standing reactivity shim would be placed in the midst of the solution annulus to achieve a subcritical system. RFP photo \# 36103-10 [2/25/87]. 
Finally, a situation was achieved that did not yield an unexpectedly low critical height. In fact, the reverse was true. That experiment proved to be far from critical; the multiplication at a little over $1.6 \mathrm{~m}$ solution height was only 1.4 ! The desired radial thickness of the perfect solution annulus had been only very roughly bounded.

The sets of three thin shims were removed leaving the thick shim against the outside wall and the even thicker shim in the solution region; but, surprisingly, even this configuration remained well subcritical. Evidently, either the location of the thicker shim in the midst of the solution region or the small differences in shim thicknesses for the various cases was sufficient to change a system with a very low critical height to one that was very unreactive. Nonetheless, all subsequent experiments retained the configuration of two fairly thick shims. Changes to achieve criticality involved the external components.

In summary, the following list illustrates the delicate dilemma of selecting a suitable reactivity shim thickness:

No shims installed

$4.86 \mathrm{~mm}$ shim in place

$3.63+4.86=8.49 \mathrm{~mm}$ shims

All shims $(14.84 \mathrm{~mm})$ in place

$4.86+6.35=11.21 \mathrm{~mm}$ shims
Very low critical height

Low critical height

Still, low critical height

Subcritical, low reactivity

Still, well subcritical

That is, $8.49 \mathrm{~mm}$ worth of shim stock yielded a quite low critical height; but only $2.92 \mathrm{~mm}$ additional rendered the system very unreactive. The task of choosing the right thickness was 
truly difficult. The experimental program was terminated before this question could be answered satisfactorily.

Reflector Panels:

All experiments in the first program were reflected by thick-walled concrete panels; but no such reflection appeared in the second. These panels were intended to simulate the concrete walls of a production facility; and they were configured around the tank(s) such that they resembled a "room". The panels were the thickness of typical walls and about as tall as the tanks. They rested by their own weight on the floor of the mezzanine; but they were rigidly braced at their top to some nearby structural support. No such bracing existed elsewhere. The bottom stayed in place because of friction with the floor and the pressure of neighboring panels pressing against one another. The elemental composition of the concrete was not measured in detail because it was common, ordinary concrete. Impurities, however, were carefully determined to verify the absence of strong neutron absorbers.

Neutron Moderators \& Absorbers:

Later experiments in the first program and all of the second employed non-fissile materials near the tanks to purposefully moderate and absorb neutrons. These were mostly cylindrical in geometry in both programs. Only those neutron absorbers between tanks in an array of tanks in the first program were slab-like in geometry. 
Cylindrical units in the first study were called plugs and they were manufactured at Rocky Flats from concrete and plaster. Many contained a boron compound, but some did not. The chemically compatible boron compound replaced part of the aggregate in the concrete and was blended into the dry plaster before adding water. A total of 19 plugs were made, although not all were used. Two levels of boron loading were so manufactured. Some plugs were solid cylinders while others were cylindrical annuli of various thickness. All were cast inside paper forms, designed for use in casting bridge columns and other structural pillars. Annular units had the inner diameter defined by another (smaller) paper tube or by a corrugated metal cylinder.

The slabs used between tanks in the first program were cast in two thicknesses but at only one boron loading. By design, the material was similar to the boron-loaded plaster plugs. Their forms were made of plywood faces with the wet mix poured within a wood border. Overall, they were the same height as the reflector panels (the bottom $305 \mathrm{~mm}$ contained no plaster); but, when used, they rested $38 \mathrm{~mm}$ above the floor to clear plastic hoses which passed solution into tanks. Thus, these slabs extended that same $38 \mathrm{~mm}$ above the tops of the reflector panels. Photos show that they were wedged in place at the top using the tanks themselves to wedge against; but they rested on the floor, relying upon friction to prevent movement. 
The neutron absorber and neutron moderator materials in the second program were distinct from one another. This was in contrast to the first where the concrete and plaster performed the moderating function and the uniformly distributed boron within absorbed neutrons. Thick polyethylene cylindrical annuli provided moderation and suitably thick rubber layers provided absorption. The rubber contained boron, a strong thermal neutron absorber. It was composed of $50 \%$ silicone rubber and $50 \%$ boron carbide. One such combination was inside the annular tank to affect neutrons moving between regions of the same tank. A similar combination was outside and designed to affect neutrons travelling from one tank to another. The rubber existed in four laminations: inside and outside the inner and outer plastic cylinders. For ease of assembly, the rubber was affixed to the outside of convex surfaces rather than to the inside of concave surfaces. Thus, the outermost layer was stapled to the outer plastic annulus; and the second layer was taped onto the outside of the outer tank wall. The first layer inside the solution region was, again, stapled to the inner plastic moderator; and, finally, the innermost layer was taped to a paper cylinder left over from the first program. This multi-regioned construction is illustrated in Fig. 11 where the inside of the entire geometry is to the left of the figure.

The goal of this shielded annular tank design was to make each tank essentially isolated from any potential neighboring tank or wall. That is why experiments in the second series were not reflected by concrete panels. 

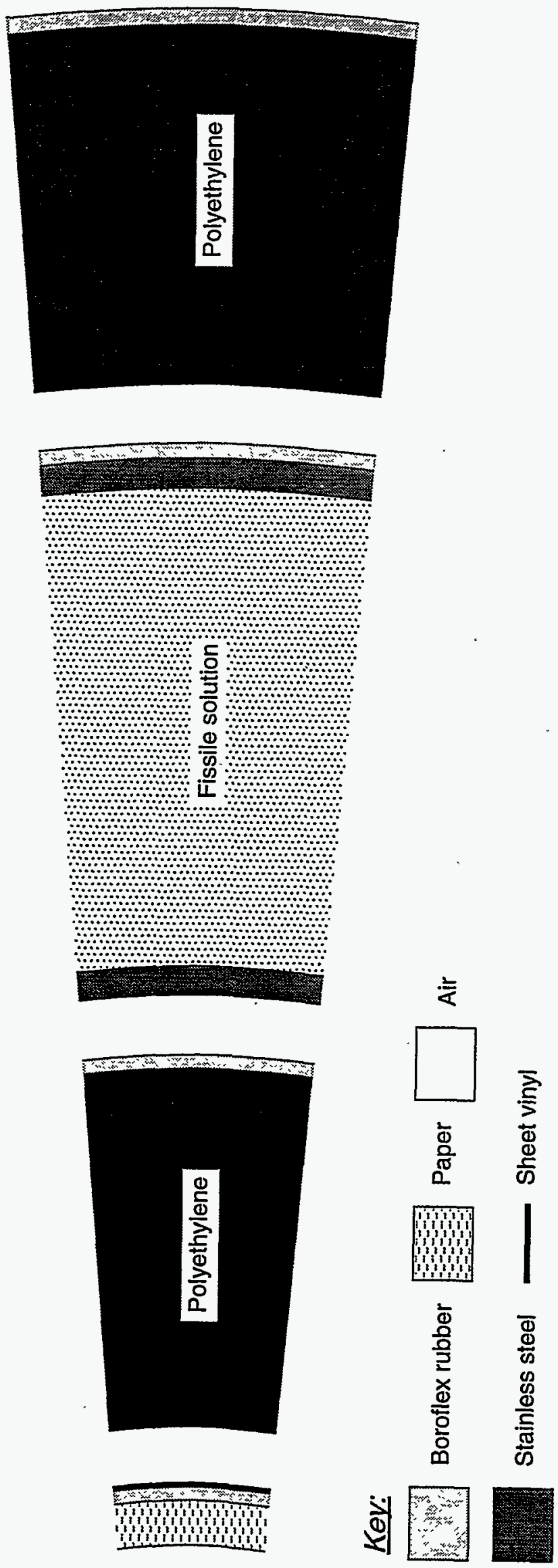

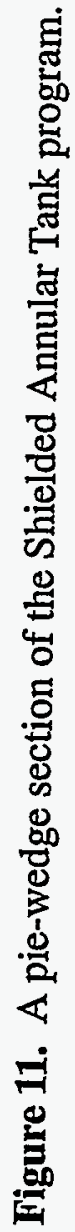


The use of absorbers both inside and outside a moderator might be questioned. Each absorber region plays a different role. A neutron created deep within the solution would be moderated by the solution and absorber by the first layer of rubber. The additional moderation of the plastic would be superfluous. On the other hand, a neutron created near the surface would pass through the first absorber region relatively unscathed only to be moderated by the plastic and absorbed by the outer absorber.

Other Features:

The only other hardware that needs to be described briefly is the external sight gauge used to read the solution height during the experiment, a vent line from the dump tanks, and the hollow tube designed to hold the Californium neutron source in its suitable location during the experiment.

The sight gauge was one or more vertical length(s) of clear plastic tubing. In the first program they were outside the reflector panels. In the second, it was suspended in space a distance from the tank. Data from these were transmitted to the experiment Control Room via closed-circuit television. Sight gauges vented into the tops of the tanks. Solution levels were also determined by a Level Detector device in the first program but not at all in the second. The device, itself, is described later and seen in several figures. 
The dump tanks also needed to be vented. Otherwise solution entering them would be inhibited by trapped air. Still, this air could carry contamination; so these vents were tied together and also vented into the top of the experimental tanks.

The external neutron source moved vertically up or down in close proximity to the uranium solution by passing through a long stainless steel tube with the bottom end welded shut. That tube was internal to one of the annular tanks in the first program but external to the tank, between the innermost absorber and the inner plastic cylinder, in the second. The tube caused no effect in the second program other than a very small neutron reflection; but it excluded solution from a very slender region of one tank in the first. The tube extended above the tops of the tanks and was fitted with a plastic funnel. This allowed the neutron source to be re-admitted if desired.

\section{Radiation Detection:}

Several neutron detectors were located near every experiment. These included both proportional counters and ionization chambers as discussed in the Theory Section. These detectors were always sufficiently far away from the critical assembly that they would not reasonably be considered to reflect neutrons. Generally, they were under the mezzanine floor.

One of these ionization chambers was especially configured to yield a continuous measure of the natural logarithm of the instantaneous neutron flux. This was convenient because, with a slight super criticality, this flux would increase exponentially; and the resulting trace would be a 
straight line. A straight line is easier to determine than a fit to an exponential growth. The slope of this line equalled the positive reactor period. Figure 2 illustrates this nicely.

The final radiation detection instrument was a g-ray-sensitive ionization chamber. This unit was mounted on a wall about $8 \mathrm{~m}$ from the experiment. This distance always proved acceptable because the g-flux within the room was relatively unaffected by equipment. It would respond with increased levels well before the multiplication exceeded ten. This was true for all experiments performed at Rocky Flats, not just the present programs.

\section{End of an Experiment:}

The experiment was considered ended when either the critical uranium solution height had been determined or when the asymptotic reciprocal multiplication revealed that the system under study was subcritical. Under these normal conditions, uranium solution was simply drained back to the storage farm. Sometimes, the decision was made to just SCRAM the experiment intentionally. Other experiments ended of their own accord when system perturbations produced a SCRAM automatically. This often related to solution seeping past the SCRAM valve seats as discussed above. 
Whenever a SCRAM did occur, the radiation level in the room was observed to prove that a criticality accident had not occurred. Then, the solution was recovered from the dump tank system and returned to storage in preparation for the next experiment. 


\section{TEMPERATURE}

These experiments were performed at nominal room temperature. This varied between about 18 and $22^{\circ} \mathrm{C}$, depending upon the season. The fissile solution was stored in one room but used in another. The latter, the Assembly Room, was large and thick-walled; and it tended to respond to outside temperatures quite slowly. Room heating was available; but it was noisy and caused air turbulence. It was operated only in the coldest weather; and, then, it would be shut down during an experiment.

Often, the Assembly Room felt cool in the morning but would warm up to the day's ambient temperature by the time the experiment was performed. This explains the fairly large range in room temperature within a temperature-controlled facility. On the other hand, the room in which the solution was stored followed the building's comfortable temperatures very closely.

Solution temperatures during experiments were never recorded because "room temperatures" were expected. Still, experience over the lifetime of the Rocky Flats Critical Mass Laboratory suggests the above range as a valid assumption for the present programs. For example, several liquid temperatures, logged for a variety of other programs in this room over two decades, fell well within that range; and air temperatures did likewise. These liquids included water, oil, and fissile solution. 
The solution always had ample time to come into equilibrium with the temperature in the experimental room. This is so because experiments took over an hour to perform and the initial difference would have been small.

Even though critical experiments were performed, the solution is not expected to have heated up through that avenue. The power levels generated were just too small, even impossible to measure. Typical experiments at Rocky Flats probably operated in the tens to hundreds of milliwatts range. This, in such a large thermal mass, would produce no measurable temperature increase. 


\section{URANIUM SOLUTION}

The fissile solution was uranyl nitrate solution. The uranium was highly enriched in ${ }^{235} \mathrm{U}$; and the uranium concentration used was very close to that for which the critical spherical volume would be its minimum. The solution was formed from a high-purity uranyl nitrate hexahydrate salt,

$$
\mathrm{UO}_{2}\left(\mathrm{NO}_{3}\right)_{2} \cdot 6 \mathrm{H}_{2} \mathrm{O}
$$

dissolved in dilute nitric acid.

This solution has a unique feature that instills confidence in its chemical stability. The same solution has been housed in the same set of tanks in the same building and used for a single purpose over the full quarter of a century of its useful life there (1965 - 1989). The solution has only passed from these storage tanks into various experimental components and then returned to storage to await the next study. The solution has been involved in about 1000 critical or critical approach experiments over that time. The only other significant operations performed with this solution is the occasional measurement of its uranium weight. This was done for material accountability purposes; but associated laboratory analyses can prove useful in reporting experimental results. 
History:

All these experiments have been low-power critical studies. The fission product inventory has remained low because of this low power and the short time that criticality was maintained.

This solution, shipped as "Uranium Feed Solution", was prepared at Rocky Flats in 1965 in Building 81 (now, 881). The first ten 55-gallon stainless steel drums were shipped between buildings at the rate of 2 to 4 drums per day. Drums were, of course, Raschig ring filled for criticality safety. An example of the only documentation to accompany each drum is shown in Fig. 12; and this represents almost $56 \mathrm{~kg}$ of enriched uranium! Shipments came on an enclosed truck with a canvas-covered back. Each drum was lowered to the ground on the tailgate and wheeled into the building and through the office area on a 2-wheeled hand cart. The method of transferring the solution from the drums to the already volume-calibrated tanks is not recalled.

Ten drums were shipped at an estimated 106 liters each. The average concentration claimed was $483.4 \mathrm{gU} / \mathrm{liter}$. Thus, this initial delivery should have transferred $512.404 \mathrm{~kg}$ of uranium; but the quantity measured immediately upon receipt was 1030 liters at an average concentration of $465 \mathrm{gU} /$ liter $(478.95 \mathrm{~kg}$ ). This shipper $/$ receiver difference (almost $33.5 \mathrm{~kg}$ ) was later traced to liquid held up in the drums, a badly calibrated slab tank in the manufacturer's building, and concentration measurement errors by the analytical laboratory. (They had never 


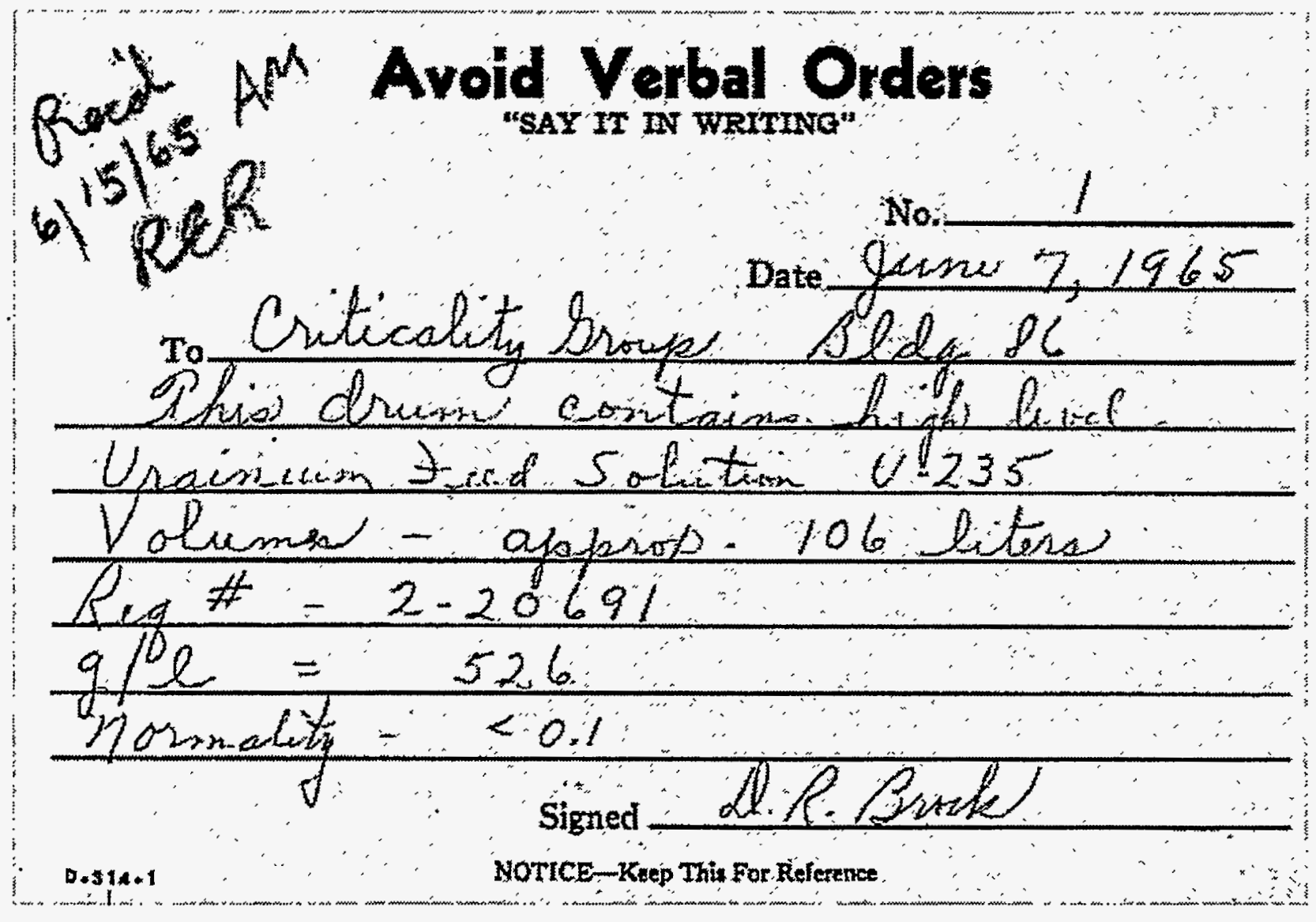

Figure 12. In 1965, the shipment of $55.7 \mathrm{~kg}$ of enriched uranium required little paperwork. 
measured such high concentrations before.) The technique employed was a g-counting method; and this contained unrecognized self-shielding errors for such rich solutions.

A final shipment (11th drum) of feed solution came to the laboratory August 25, 1965. The sum of the two shipments and small administrative adjustments led to a governmentapproved reconciliation of $569.711 \mathrm{~kg}$ in the fall of 1965 . The uranium weight has been measured periodically since then for material accountability purposes. Results of these "inventories" are shown in Table I. Uncertainties are not given; but they were typically about $\pm 8 \mathrm{~kg}$ at the $95 \%$ confidence level ( $2 \mathrm{~s}$ ) required by the government. (Elsewhere in this report, uncertainties in other parameters are the more-common one standard deviation of an assumed Gaussian distribution unless otherwise explained.) The last column gives the difference between the just-measured value and the previous inventory adjusted for small estimated or measured additions or removals since the previous measurement.

Measurement techniques have improved markedly over the decades; and the 1989 inventory measurement was performed using nearly state-of-the-art procedures. One interesting new feature was the incorporation of a "densitometer". This was a commercial device that would report the instantaneous density of the liquid it contained. The meter served two purposes. It was used to assure homogeneity, claimed when the density ceased to fluctuate in the 4 th or 5th decimal point as the solution flowed through the device. It was also used to confirm the 
Table I. Uranium Inventory Results at Rocky Flats Between 1965 (Solution Received) and 1989 (Last Measured).

\begin{tabular}{|c|c|c|}
\hline $\begin{array}{c}\text { Inventory } \\
\text { Year }\end{array}$ & $\begin{array}{c}\text { Uranium } \\
\text { Weight } \\
(\mathrm{g})\end{array}$ & $\begin{array}{c}\text { Inventory } \\
\text { Difference } \\
(*)\end{array}$ \\
\hline 1965 & 569711 & +446 \\
\hline 1967 & 562983 & -6113 \\
\hline 1969 & 561280 & -644 \\
\hline 1972 & 559294 & -747 \\
\hline 1975 & 563606 & +5287 \\
\hline 1979 & 564268 & +346 \\
\hline 1982 & 562473 & -892 \\
\hline 1989 & 568834 & +6816 \\
\hline
\end{tabular}

* Difference between previous measured inventory adjusted for measured or estimated additions or deletions and the just-measured inventory weight. 
concentration obtained from a sample of the solution by the analytical laboratory by noting the quantitative measure of this density. Over two decades of comparing measured densities against corresponding measured uranium concentrations has established a tight linear relationship between the two as shown in Fig. 13. Thus, the density may always be used to infer the concentration for this well-known solution.

The densitometer, in fact, is probably a better method of determining concentration in this . case at least. Analytical laboratory measurements are subject to sampling errors and biases associated with the analytical method and with the technician; and they are measures on, at best, a very small sample of the entire stock of solution. Densitometer measurements, on the other hand, measure the density over the entire holding of solution since it measures that parameter while the solution passes through the device. There are no sampling errors. The only errors are inherent to the device itself.

A few years after initial receipt, the first volume-based calibration of contaminated tanks resulted in creation of significant volumes of solution at lower concentrations. This unintended action was later recognized to be advantageous; and, in 1973, useful volumes of three concentrations were formed for continued use in the laboratory. The highest was still close to the minimum-critical-volume concentration. The lowest was a concentration a few times richer than that for which an infinite volume would have been critical. The third was somewhere between 


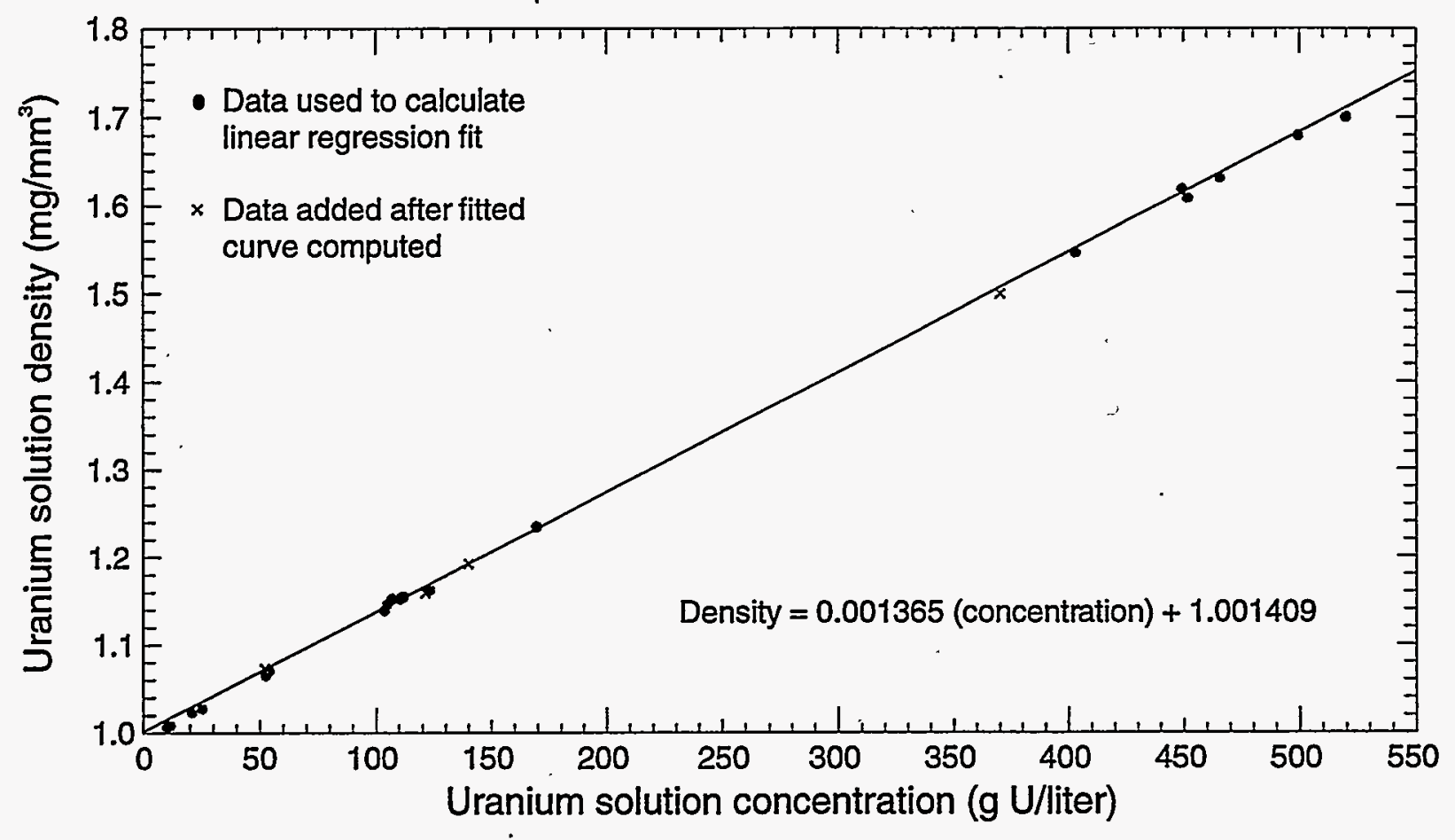

Figure 13. Measurements over 25 years assure a linear relationship between concentration and density for this uranium solution. Later data ( $x$ 's), added years after the linear regression fit (line and equation) to the original data (dots) was calculated, demonstrate a continued fit. 
the two. This holding allowed any study to be parametric in solution concentration. This ideal state was maintained until the 1989 inventory at which time the decision was made to blend the lower two. This history is displayed in Fig. 14. The decrease in concentration of the richest solution in 1971 reflects the influence of the then new American National Standard pertaining to Raschig rings. The Standard simply did not address solutions in excess of $400 \mathrm{gU} / \mathrm{liter}$. The high concentration solution has drifted only a little over the last 20 years. This is due to unavoidable intermixing with lower concentration solution remaining in the lines after other operations and to evaporation.

\section{Present Programs:}

The uranium solution used in the first series of experiments was reported by an analytical laboratory at Rocky Flats to contain $357.4 \pm 0.7 \mathrm{gU} / \mathrm{liter}$. The actual uncertainty is probably greater than reported. That is more the precision of a specific small number of measurements, not the accuracy of the concentration which would reflect sampling errors and technician's bias. The overall uncertainty (accuracy plus precision) in analytical laboratory results is probably about $\pm 0.9 \%$, or $\pm 3.2 \mathrm{~g} /$ liter in this case. This concentration is the average of duplicate analyses of multiple samples from each of the three configurations studied. The single tank result stemmed from four samples, the $1 \times 2$ array of neșted triples came from three, and the $1 \times 3$ array of nested pairs of tanks was the result of two samples. 


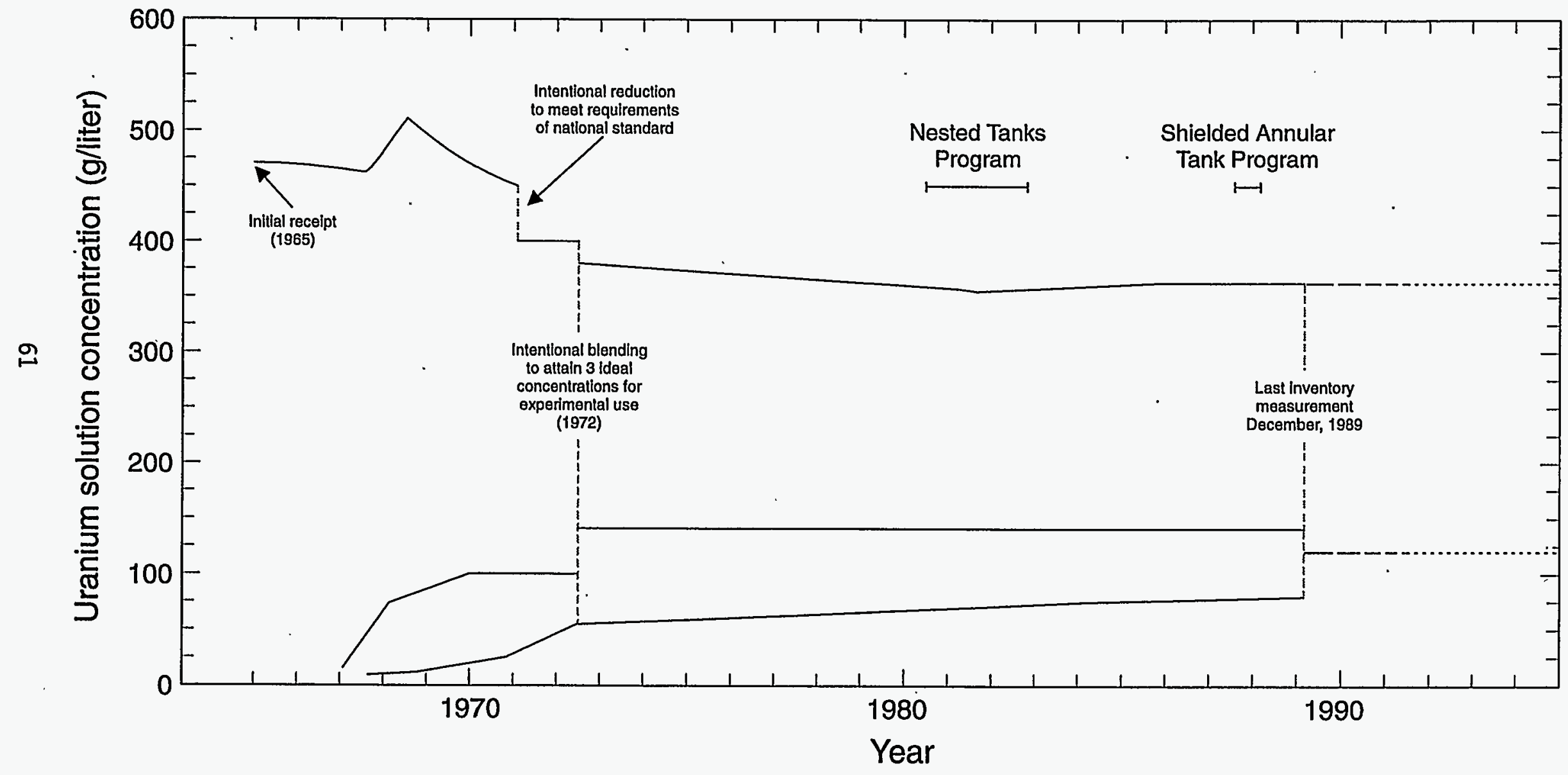

Figure 14. The historical evolution of solution concentrations at Rocky Flats from receipt to the last measurement (1989). Dates of the two experimental programs are indicated. 
The concentration was determined by a method called Gravimetric Titration, generally recognized as a high-precision method. The density of the solution was $1.4982 \pm 0.0011$ $\mathrm{mg} / \mathrm{mm}^{3}$; and this was measured by weighing a temperature calibrated $25 \mathrm{~mL}$ picnometer. The excess acid content, also called free nitric acid, was $0.5751 \pm 0.0115 \mathrm{~N}$. The isotopic composition of the solution, based on a single mass spectrometry measurement of the composite from the above samples, is presented in Table II.

The average elemental impurities measured on this one set of samples are expressed below in parts per million by weight relative to the uranium weight:
$\mathrm{Al}, 350 \pm 190$
$\mathrm{B}, 4.4 \pm 1.7$
$\mathrm{Bi}, 6.8 \pm 5.1$
$\mathrm{Cd}, 7.8 \pm 2.6$
$\mathrm{Cu}, 81 \pm 26$
$\mathrm{Fe}, 515 \pm 200$
$\mathrm{Mg}, 250 \pm 150$
$\mathrm{Mn}, 27 \pm 10$
Mo, $75 \pm 27$
$\mathrm{Ni}, 69 \pm 37$
$\mathrm{Pb}, 44 \pm 11$
$\mathrm{Si}, 43 \pm 20$
$\mathrm{Sn}, 280 \pm 190$
and
$\mathrm{Zn}, 230 \pm 100$

Concentration measurements for the first program are in good agreement with similar measurements on the same solution made as part of uranium weight inventories of the solution holding both before and after the experimental program. Samples were not taken for the second experimental program because the program was terminated early. Instead, the results from inventory measurements several months earlier and a few months later will be assumed. Fortunately, they are in excellent agreement with one another. Therefore, the concentration and 
Table Il. Isotopic Composition of Uranyl Nitrate Solution.

\begin{tabular}{|c|c|c|}
\hline Isotope & $\begin{array}{c}\text { Weight } \\
\text { Percent }\end{array}$ & $\begin{array}{c}\text { Standard } \\
\text { Deviation }\end{array}$ \\
\hline${ }^{234} \mathrm{U}$ & 0.982 & \pm 0.010 \\
\hline${ }^{235} \mathrm{U}$ & 93.219 & \\
\hline${ }^{235} \mathrm{U}$ & 0.432 & \pm 0.002 \\
\hline${ }^{239} \mathrm{U}$ & 5.367 & \pm 0.025 \\
\hline
\end{tabular}


density claimed for the second experimental program is $368 \pm 4 \mathrm{~g} /$ liter and $1.508 \pm 0.005$ $\mathrm{mg} / \mathrm{mm}^{3}$.

No record was found for the free nitric acid content of the solution either during the second program or either inventory. Long-standing experience, however, shows this parameter, also, to be remarkably linear with respect to the concentration. This is so because both intentional dilutions and small increases in concentration through limited evaporation always involved just water gains and losses. Based upon this argument, the free acid content of this solution would have been $0.59 \mathrm{~N}$.

Metallic impurities, also, could not be found; but, because the solution has been so stable over its 25-year lifetime, this data may me inferred with good confidence. Impurity data spanning many years are presented in Table III. Values are expressed in parts-per-million by weight. Calculated mathematical averages are not given because the method used to obtain the data was very imprecise (see next paragraph). Most of the data was obtained by methods called Spark Source Mass Spectroscopy and Optical Emission Spectrometry. For lower levels of impurities, measured values may be in error by factors of 2 or 3 . The methods are intended for materials having greater impurities. The "average" given in the third column is a visual estimate over many scores of measurements, not a calculated average. To illustrate the extremely wide range of results by these methods, the minimum and maximum values reported over the full set are also given. 
Table III. Impurity Analyses of Rocky Flats' Uranium Solution over its Lifetime.*

\begin{tabular}{|r|r|r|r|r|r|r|r|r|r|}
\hline Date & $\mathrm{Al}$ & $\mathrm{B}$ & $\mathrm{Ca}$ & $\mathrm{Cd}$ & $\mathrm{Cr}$ & $\mathrm{Fe}$ & $\mathrm{Mg}$ & $\mathrm{Ni}$ & $\mathrm{Si}$ \\
\hline 1965 & 240 & 9 & 198 & 26 & 30 & 393 & 1000 & 58 & 611 \\
\hline 1967 & 197 & 2 & 75 & 30 & 23 & 100 & 490 & 27 & 30 \\
\hline 1968 & 188 & 6 & 343 & 21 & 42 & 390 & 804 & 75 & 263 \\
\hline 1969 & 284 & 7 & 462 & 44 & 22 & 606 & 631 & 46 & 63 \\
\hline 1970 & 284 & 16 & 558 & 31 & 73 & 938 & 834 & 82 & 92 \\
\hline 1971 & 204 & 6 & 200 & 44 & 61 & 1117 & 450 & 93 & 49 \\
\hline 1972 & 193 & 5 & 257 & 44 & 75 & 1059 & 416 & 84 & 59 \\
\hline 1978 & 240 & 13 & 200 & 37 & 48 & 440 & 260 & 76 & 140 \\
\hline 1982 & 149 & 7 & 75 & 15 & 41 & 149 & 298 & 70 & 45 \\
\hline 1988 & 200 & 5 & 300 & 30 & 60 & 600 & 650 & 80 & 60 \\
\hline
\end{tabular}

* Values are expressed in parts-per-million by weight. 
Even this coarse estimate of impurity levels was important. It was used to adjust uranium concentrations a little during the laboratory analysis procedure. Here, the solution was evaporated to the dry salt, uranyl nitrate hexahydrate. This was calcined at a high temperature to drive off the water of hydration and the oxides of nitrogen. The result was uranium oxide, specifically, $\mathrm{U}_{3} \mathrm{O}_{8}$ combined with the oxides of all impurity metals. This weight, then, equaled the sought for weight of the uranium oxide plus the weight of oxide states of all of impurity elements. This latter correction was so small that errors of a factor of 2 or 3 in impurity content made little difference.

This discussion on the exact concentration of the solution is probably somewhat unnecessary. The solution is so close to its optimum moderation concentration that concentration errors of, perhaps, a few percent might go unnoticed. 


\section{TANKS}

Six tanks were manufactured for the first experimental program and only one for the second. The six came in four diameters such that four could be nested within one another. The other two were identical to the middle two. This allowed nesting into one set of four tanks, two 3-unit tanks, or three 2-unit tanks. For reference, the six tanks are referred to as \#1 (largest), \#2, $\# 2 *$, \#3,\#3*, and \#4 (smallest). The single tank of the second program was actually composed of two large-diameter cylindrical tanks. The smaller rested within the larger leaving an annular region between. All tanks of both programs were close to $2.1 \mathrm{~m}$ tall, typical of production tanks found at Rocky Flats. Wall thicknesses were nominally $6.4 \mathrm{~mm}$ thick; and all tanks were open topped.

Nested Tanks:

All six were composed of Type 304L, SA-240, stainless steel. A laboratory analysis of these metals is given in Table IV; but the nominal composition might also be assumed. This is probably a better assumption anyway for such a common material because its composition is well-defined and would be expected for any purchased stock. On the other hand, a few small samples from selected regions would be subject to both analytical errors and possible inhomogeneity of the sheet. 
Table IV. Elemental Composition in Weight Percent of the Six Nested Annular Tanks.

\begin{tabular}{|c|c|c|c|c|c|c|c|}
\hline & \multicolumn{6}{|c|}{ Tank } & \multirow[b]{2}{*}{$\begin{array}{l}\text { Analytical Method and } \\
\text { Nominal Relative Error }\end{array}$} \\
\hline & $\begin{array}{c}\# 1 \\
\text { (largest) }\end{array}$ & $\# 2$ & $\# 2 *$ & \#3 & $\# 3 *$ & $\begin{array}{c}\# 4 \\
\text { (smallest) }\end{array}$ & \\
\hline Co & 0.18 & 0.18 & 0.20 & 0.20 & 0.21 & 0.20 & \multirow{6}{*}{$\begin{array}{l}\text { Plasma } \\
\pm 5 \%\end{array}$} \\
\hline $\mathrm{Cr}$ & 19 & 19 & 21 & 21 & 20 & 20 & \\
\hline $\mathrm{Mn}$ & 2.5 & 2.2 & 2.3 & 2.3 & 1.7 & 2.2 & \\
\hline Mo & 0.18 & 0.18 & 0.20 & 0.21 & 0.21 & 0.21 & \\
\hline $\mathrm{Ni}$ & 10 & 10 & 11 & 11 & 11 & 10 & \\
\hline V & 0.086 & 0.087 & 0.091 & 0.089 & 0.092 & 0.091 & \\
\hline$C$ & 0.012 & 0.013 & 0.012 & 0.015 & 0.014 & 0.009 & \multirow{5}{*}{$\begin{array}{c}\text { Furnace } \\
\pm 3 \%\end{array}$} \\
\hline$S$ & 0.002 & 0.002 & 0.002 & 0.002 & 0.002 & 0.002 & \\
\hline $\mathrm{N}$ & 0.074 & 0.074 & 0.076 & 0.077 & 0.077 & 0.078 & \\
\hline 0 & 0.044 & 0.008 & 0.008 & 0.009 & 0.007 & 0.010 & \\
\hline $\mathrm{H}$ & 0.0004 & 0.0003 & $<0.0001$ & 0.0006 & 0.0007 & 0.0005 & \\
\hline $\mathrm{Al}$ & & & 0.015 & & & & \multirow{4}{*}{$\begin{array}{c}\text { Emission }^{\mathrm{a}} \\
\text { spectrographic } \\
\pm 50 \%\end{array}$} \\
\hline $\mathrm{Pb}$ & & & & 0.05 & & & \\
\hline Sn & & & & 0.01 & 0.01 & 0.01 & \\
\hline$\pi$ & & & & 0.01 & & & \\
\hline $\mathrm{Fe}$ & \multicolumn{6}{|c|}{ Major component (all the rest) } & By difference \\
\hline
\end{tabular}

a. Blank entries in this region of the table and almost all other impurity metals were found to be less than $0.01 \%$ of the sample. $\mathrm{Bi}$ and $\mathrm{In}$ were not determined; and both $\mathrm{U}$ and $\mathrm{W}$ were found to be less than $0.05 \%$ for all 6 cases. 
The six tanks of the first experimental program were manufactured to nominal dimensions and measured weights presented in Table V. A section view is shown in Fig. 15. Each tank was formed by rolling 6.4-mm-thick sheet stock into two cylinders of the desired diameter and welding the side seam. Then, the smaller was concentrically positioned within the larger and welded to an annular disk that formed the bottom of the annular tank. The manufacturing goal was to maintain an annular region $38.1 \mathrm{~mm}$ thick in every case. The manufacturing tolerance on this reference dimension was $\pm 0.8 \mathrm{~mm}$ even though the tolerance on the diameters was a much larger $\pm 6 \mathrm{~mm}$. The overriding requirement was that the tanks shall nest within one another.

The bottom disk provided that annular dimension at the bottom; but 18 small-diameter rods were welded between the two walls to maintain this spacing above. Six of these rods were located very near the top of the tank and azimuthally spaced $60^{\circ}$ apart. Two other sets of six rods were located at one-third and two-thirds the height of the tank and at the same azimuthal angles. All rods but two were $6.4 \mathrm{~mm}$ in diameter. Two diametrically opposed rods at the top were $19 \mathrm{~mm}$ in diameter and were used for lifting the tank.

The bottom of the tank was sloped at a gentle $2^{\circ}$ angle to facilitate drainage. The greatest height of the annular region for all six tanks was $2.13 \mathrm{~m}$. The slope combined with differing diameters from Table V means that the diametrically opposite side of the four different tanks were $36,32,28$, and $24 \mathrm{~mm}$ shorter, respectively. 
Table V. Nominal Dimensions and Measured Weight and Air Gaps of the Nested Annular Tanks.

\begin{tabular}{|c|c|c|c|c|c|c|c|c|}
\hline Tank & \multicolumn{3}{|c|}{$\begin{array}{c}\frac{\text { Outside Diameter }}{\text { Inside Diameter }} \\
(\mathrm{mm})\end{array}$} & \multicolumn{2}{|c|}{$\begin{array}{c}\text { Capacity } \\
(\ell)\end{array}$} & $\begin{array}{l}\text { Short } \\
\text { Height } \\
(\mathrm{mm})\end{array}$ & \multicolumn{2}{|c|}{$\begin{array}{l}\text { Measured } \\
\text { Weight } \\
(\mathrm{kg})\end{array}$} \\
\hline$\# 1$ & & $\frac{1041}{940}$ & & \multicolumn{2}{|c|}{253} & 2097 & \multicolumn{2}{|c|}{742.1} \\
\hline $\begin{array}{l}\# 2 \\
\# 2 *\end{array}$ & & $\frac{924}{822}$ & & \multicolumn{2}{|c|}{223} & 2101 & \multicolumn{2}{|c|}{$\begin{array}{l}643.1 \\
648.1\end{array}$} \\
\hline $\begin{array}{l}\# 3 \\
\# 3 *\end{array}$ & \multicolumn{3}{|c|}{$\frac{806}{705}$} & \multicolumn{2}{|c|}{193} & 2105 & \multicolumn{2}{|c|}{$\begin{array}{l}565.1 \\
561.9\end{array}$} \\
\hline$\# 4$ & & $\frac{689}{587}$ & & \multicolumn{2}{|c|}{163} & 2110 & \multicolumn{2}{|c|}{484.9} \\
\hline \multicolumn{7}{|c|}{$\begin{array}{l}\text { Annular solution region thickness }(\mathrm{mm}) \\
\text { Wall thickness }(\mathrm{mm}) \\
\text { Tall height, all } 6 \text { tanks }(\mathrm{mm}) \\
\text { Displacement above floor by skirting }(\mathrm{mm})\end{array}$} & \multicolumn{2}{|c|}{$\begin{array}{r}38.1 \\
6.4 \\
2134 \\
305 \\
\end{array}$} \\
\hline \multirow{2}{*}{$\begin{array}{l}\text { Between } \\
\text { Tanks } \\
\text { Numbered }\end{array}$} & \multicolumn{8}{|c|}{$\begin{array}{c}\text { Gaps Between Tanks (mm) Measured Near } \\
\text { the Top for Various Nestings of Tanks }\end{array}$} \\
\hline & $0^{\circ}$ & $45^{\circ}$ & $90^{\circ}$ & $135^{\circ}$ & $180^{\circ}$ & $225^{\circ}$ & $270^{\circ}$ & $315^{\circ}$ \\
\hline $1 \& 2$ & 14 & 18 & 8 & 2 & 0 & 7 & 10 & 7 \\
\hline $2 \& 3$ & 4 & 7 & 13 & 12 & 9 & 7 & 3 & 5 \\
\hline $3 \& 4$ & 11 & 11 & 11 & 7 & 0 & 2 & 5 & 11 \\
\hline $1 \& 2 *$ & 8 & 5 & 5 & 8 & 2 & 13 & 14 & 10 \\
\hline $2 * \& 3$ & 3 & 5 & 5 & 11 & 18 & 17 & 10 & 6 \\
\hline $3 \& 4$ & 2 & 8 & 13 & 14 & 8 & 4 & 1 & 2 \\
\hline $1 \& 2$ & 8 & 11 & 6 & 5 & 4 & 9 & 14 & 7 \\
\hline $2 \& 3 *$ & 4 & 3 & 13 & 18 & 15 & 12 & 5 & 2 \\
\hline $3 * \& 4$ & 1 & 0 & 2 & 2 & 6 & 12 & 14 & 14 \\
\hline $1 \& 2 *$ & 8 & 2 & 5 & 9 & 4 & 13 & 14 & 8 \\
\hline $2 * \& 3 *$ & 7 & 6 & 8 & 13 & 15 & 13 & 4 & 0 \\
\hline $3 * \& 4$ & 1 & 7 & 10 & 9 & 7 & 8 & 8 & 6 \\
\hline
\end{tabular}

a. Tank height opposite low-point drain connection due to $2^{\circ}$ slope to bottom. 


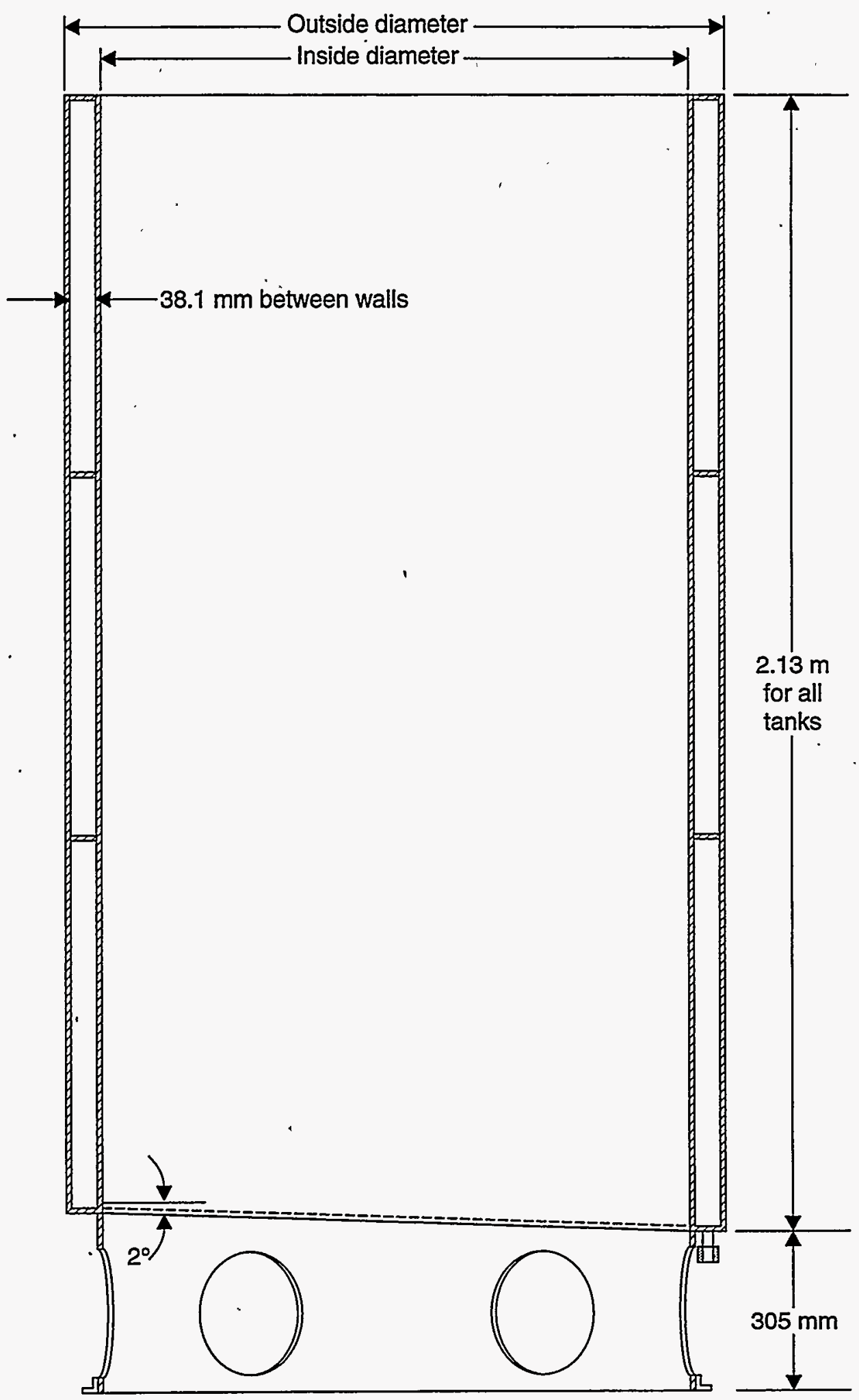

Figure 15. Vertical section of one of the Nested Tanks. 
The inner wall of each tank was extended below the annular region to form a support skirt which would elevate the solution region $305 \mathrm{~mm}$ above the floor at the lowest point. A stiffening flange was rolled and welded to the outside of this extended wall to form a stable base to support the tank. Six 250-mm-diameter holes were cut in this skirting. These holes were used for access to fill line connections to inner tanks of a nested set and as a criticality safety drain in the event of a solution leak. These holes were centered in the same vertical alignment as the spacer rods above.

A 102-mm length of threaded commercial stainless steel pipe (nominal _" size) was welded at the low point as the fill/drain connection. Finally, two of the tanks $\left(2^{*}\right.$ and $\left.3^{*}\right)$ were fitted during manufacture with triangular fillets on the inside of the annular region at the bottom. The purpose was to prevent accumulation of precipitates due to questionable laminar flow. This concern was never realized because the solution did not tend to precipitate. The side length of this fillet was $13 \mathrm{~mm}$.

The radial thickness was selected so one tank, alone, could never achieve criticality. Tanks would have to be nested for that to occur. They were tall enough to resemble production tanks; but these conservatively thin annular thicknesses yielded the capacities listed in Table V. Tanks were never volume-calibrated; so these capacities are calculated. 
The idealized geometry is that described above; but delivered tanks were far from ideal. Diameters varied significantly due to the rolling process, although they did nest one within another - an obvious requirement. The radial thickness appeared to be well maintained; but cross sections were not perfectly circular. This resulted in unexpectedly large variations in air gaps between adjacent tanks. Not only did this vary azimuthally from near zero (almost touching) to $18 \mathrm{~mm}$ but probably vertically as well. Gaps for one nesting, measured only near the top, are presented in the bottom portion of Table V. This data would not necessarily apply on subsequent assemblies nor different heights.

In spite of this, considerable effort was expended in attempting to describe the actual tanks. Each tank was filled with water and an ultrasonic thickness measurement device used to obtain radial measurements. A 72-point grid was defined for each tank consisting of 6 equally spaced heights avoiding the weld at the bottom and the top edge and 12 azimuthal intervals $\left(30^{\circ}\right)$ avoiding the welded side seam. The annular thickness and the outer wall thickness was measured at each point of that grid. The ultrasonic gauge was calibrated by measuring the thickness of the annular region at one arbitrary point near the top of the tank but well below the top edge two ways. A machinist's inside micrometer was used first. Then, the ultrasonic instrument was used to read the same thickness at that same point. 
Average radial thicknesses for the annular regions are presented in Table VI in bold face. This average and its standard deviation were obtained from all 72 points. The maximum and minimum thicknesses are also given as bounds to the measurement. Similar data for the thickness of the outer stainless steel wall is given except that the statistical data was derived from only 18 of the 72 grid points. The inner wall's thickness was not measured by this device. A scan of these data reveal that the vertical profiles were really quite irregular.

Figure 16 displays measured annular region thickness for the six tanks. Two widely separated vertical profiles out of the measured 12 are shown for each by hand-drawn lines joining measured points. The thin, vertical lines mark the nominal 38.1-mm thickness. Thinner regions appear to the left and thicker to the right. The top and bottom of the tanks are represented by horizontal lines. The two scale factors for orthogonal directions are vastly different; so surface departures from a simple mathematical cylinder are greatly exaggerated.

All these detailed measurements characterize each tank as to its radial annular thickness; but they did little to address the tank's actual diameter at that same locale. This was attempted by carefully positioning each tank, one at a time, on a sturdy surface capable of being slowly rotated. The tank's centerline was coaxial with the axis of rotation of the table. This table was close to a steel wall that was precisely vertical such that a magnetically clamped machinist's Dial 
Table VI. Detailed Radial Thicknesses in $\mathrm{mm}$ for the Six Nested Annular Tanks.

\begin{tabular}{|c|c|c|c|c|c|}
\hline \multirow{2}{*}{$\begin{array}{c}\text { Tank } \\
\text { Number }\end{array}$} & \multicolumn{2}{|c|}{ Annular Region Thickness } & \multicolumn{2}{c|}{ Outer Wall Thickness } \\
\cline { 2 - 6 } & Average $\pm \sigma$ & Max & Min & Max & Min \\
\hline 1 & $38.38 \pm 0.64$ & 39.40 & 37.01 & 6.50 & 6.20 \\
\hline 2 & $38.48 \pm 1.17$ & 41.96 & 36.63 & 6.55 & 6.15 \\
\hline $2 *$ & $37.41 \pm 1.17$ & 39.98 & 33.88 & 6.60 & 6.20 \\
\hline 3 & $38.46 \pm 0.51$ & 39.95 & 36.91 & 6.40 & 6.07 \\
\hline $3 *$ & $37.72 \pm 0.79$ & 39.22 & 35.79 & 6.60 & 6.17 \\
\hline 4 & $37.82 \pm 0.48$ & 39.19 & 36.63 & 6.63 & 6.27 \\
\hline
\end{tabular}

a. Wall thickness of the inner tank not measured by this method. 

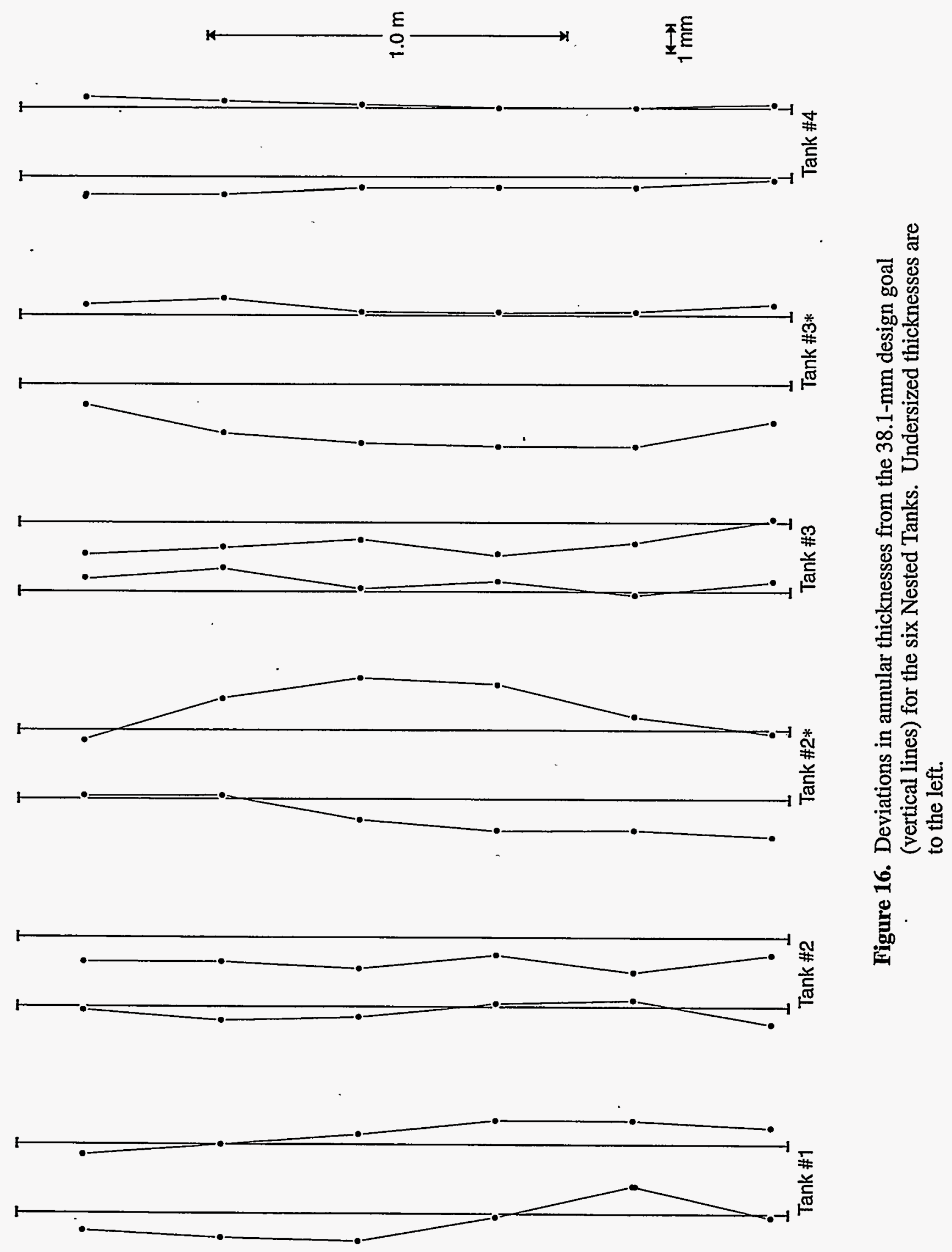
Indicator ${ }^{19}$ could be attached to the wall and still contact the tank. The distance between was set so that the dial indicator would move in and out as the tank was slowly rotated. The same $72-$ point grid used with the ultrasonic device was mapped for each tank in this manner.

Even this surface contour study mapped only deviations of the surface from a circle of some arbitrary and undefined radius because the distance from the null on the dial indicator to the axis of rotation could not be measured. For that reason, the actual "diameter"20 across the tank was measured at two orthogonal azimuths and this at several heights using a large caliper. This data was used to estimate "best" diameters using equations [1] and [2]. The reader is cautioned that circles so obtained at different heights may not be precisely concentric. Figure 17 illustrates this complicated evaluation for one example. The circle (light line) is concentric with the axis of rotation of the tank; and the four small displacements at compass points give the movement of the dial indicator relative to that circle. Clearly, the radius of the circle corresponding to null is not necessarily the radius of the tank. Still, the diameter of that "null" circle can be estimated from the north/south data as:

19 This is a common tool found in machine shops. The dial moves in response to surface variations. The tool is usually calibrated to the nearest $0.025 \mathrm{~mm}$.

${ }^{20}$ The word appears in quotation marks because the measurement was not actually a diameter. It was the sum of two co-linear radii both measured from the axis of rotation. Only if the dial indicator read zero at both points $180^{\circ}$ apart across which the "diameter" was measured would the value equal the true diameter. 


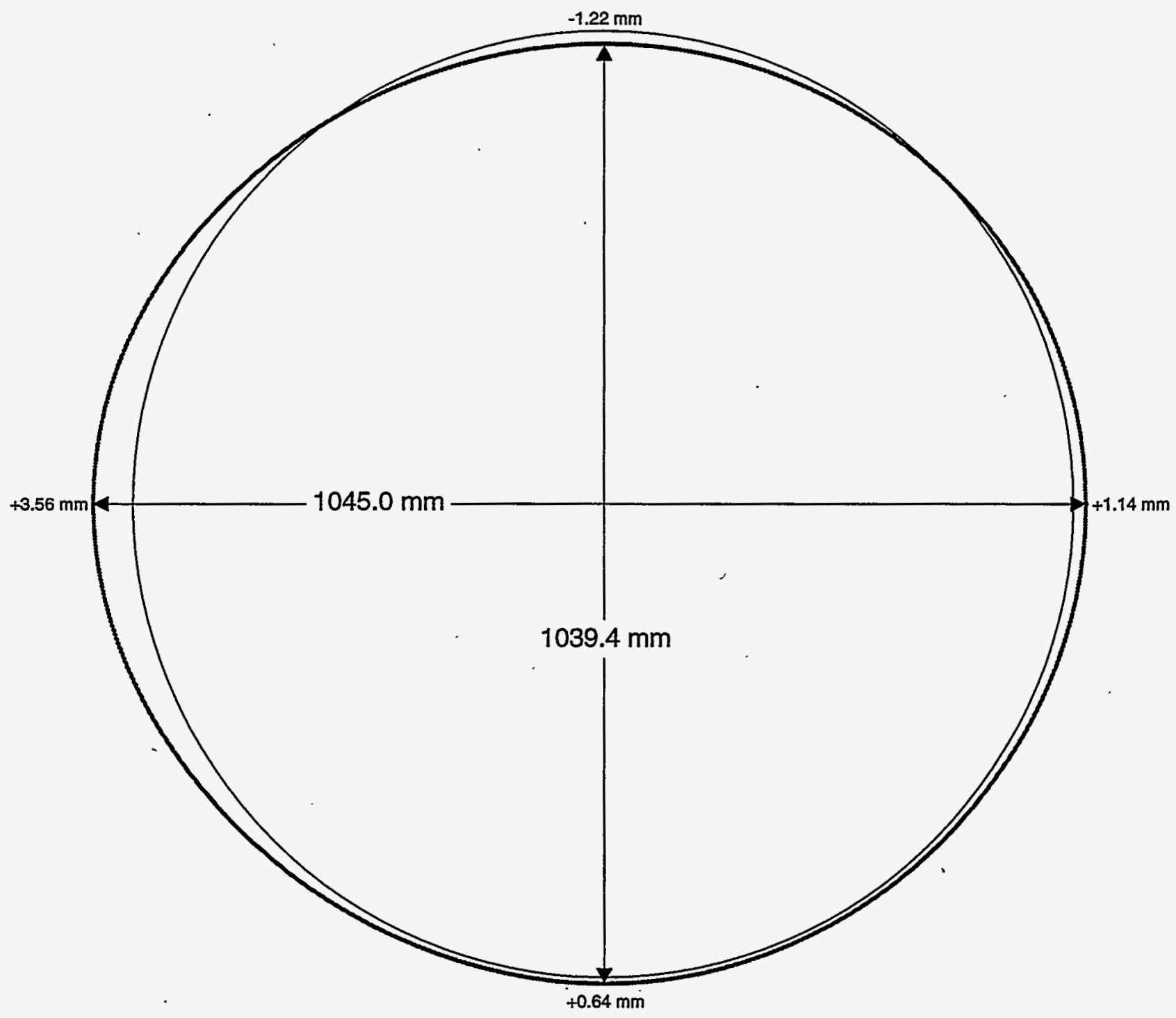

Figure 17. Rolled tanks were not perfectly circular in cross section.

Deviations for the largest tank are shown at one height. 


$$
\text { diameter }=1039.4-(0.64)-(-1.22)=1039.98 \mathrm{~mm} ;
$$

and, from the east/west data:

[2] diameter $=1045.0-(3.56)-(1.14)=1040.31 \mathrm{~mm}$.

The average of these is $1040.14 \mathrm{~mm}$ and yields one estimate of the diameter of that unknown circle.

Table VII tabulates a wealth of data which may be used in this manner, with the example of Fig. 17 shown bold. Both "diameters" are listed as well as deviations from that unknown circle at quadrants; and all this is tabled for several heights. Still, this represents only one-third of the data actually taken for each tank. This procedure may be repeated several times for each tank using the data from Table VII. Each line yields two estimates of the diameter of this unknown circle using equations [1] and [2].

The actual sought-for diameter of the tank itself can be obtained from this diameter of this unknown circle by correcting for the average of the 12 equally spaced dial indicator readings around the tank. For tank \#1 at this one height, that average was $1.19 \pm 1.30 \mathrm{~mm}$. Combining all this yields a measure of the outside diameter of this one tank at the height under consideration of $1041.3 \pm 1.3 \mathrm{~mm}$. The nominal diameter for this tank was $1041.4 \mathrm{~mm}$. This remarkably good agreement is only fortuitous; elsewhere it was a little worse. 
Table VII. Detailed Map of the Six Nested Tanks to Obtain their "Best" Diameters in $\mathrm{mm}$.

\begin{tabular}{|c|c|c|c|c|c|c|c|}
\hline \multirow[b]{2}{*}{ Tank } & \multirow{2}{*}{$\begin{array}{l}\text { Height Above } \\
\text { Bottom of Tank }\end{array}$} & \multicolumn{2}{|c|}{ "Diameters" } & \multicolumn{4}{|c|}{ Deviations from Circle } \\
\hline & & North/South & East/West & North & East & South & West \\
\hline \multirow{6}{*}{$\# 1$} & 2083 & & & -2.03 & +0.25 & -1.02 & +7.42 \\
\hline & 1676 & 1036.7 & 1047.3 & -2.69 & +0.08 & -0.56 & +6.60 \\
\hline & 1270 & 1037.0 & 1046.5 & -2.03 & +0.71 & -0.38 & +5.21 \\
\hline & 864 & 1038.0 & 1044.2 & -2.16 & +0.13 & 0.00 & +3.94 \\
\hline & 457 & 1039.4 & 1045.0 & -1.22 & +1.14 & +0.64 & +3.56 \\
\hline & 51 & & & -2.29 & +0.20 & -0.58 & -0.76 \\
\hline \multirow{6}{*}{ \#2 } & 2083 & & & +1.52 & -4.45 & -0.81 & +2.41 \\
\hline & 1676 & 927.2 & 924.9 & +1.32 & -4.24 & -0.25 & +2.34 \\
\hline & 1270 & 925.9 & 924.1 & +0.81 & -4.44 & -1.07 & +1.57 \\
\hline & 864 & 925.3 & 924.7 & +0.30 & -2.16 & -0.97 & +1.65 \\
\hline & 457 & 926.3 & 924.9 & +0.13 & -2.08 & 0.00 & +0.89 \\
\hline & 51 & & & +2.67 & -2.54 & -1.02 & -2.67 \\
\hline \multirow{6}{*}{ \#2* } & 2083 & & & +3.81 & +1.37 & +3.78 & -4.70 \\
\hline & 1676 & 929.8 & 921.9 & +3.12 & +0.51 & +1.15 & -3.81 \\
\hline & 1270 & 928.8 & 922.2 & +2.82 & & +0.91 & -3.33 \\
\hline & 864 & 927.3 & 923.4 & +2.41 & +0.18 & +0.46 & -1.91 \\
\hline & 457 & 926.1 & 922.7 & +1.45 & -0.20 & 0.00 & -1.37 \\
\hline & 51 & & & -1.37 & -2.16 & -2.08 & -1.83 \\
\hline \multirow{6}{*}{$\# 3$} & 2083 & & & -1.78 & +2.29 & -0.33 & -2.16 \\
\hline & 1676 & 805.9 & 810.0 & -1.02 & +2.29 & -0.28 & -1.52 \\
\hline & 1270 & 805.6 & 808.9 & +0.51 & +3.56 & -0.33 & +1.78 \\
\hline & 864 & 805.7 & 804.6 & -0.81 & +1.57 & -0.20 & -0.89 \\
\hline & 457 & 806.6 & 807.2 & -0.25 & +1.02 & 0.00 & -0.43 \\
\hline & 51 & & & -1.02 & -0.64 & -0.64 & -2.03 \\
\hline \multirow{6}{*}{$\# 3 *$} & 2083 & & & -5.33 & -1.57 & +1.65 & -0.23 \\
\hline & 1676 & 807.8 & 807.6 & -4.45 & -1.27 & +2.03 & -0.25 \\
\hline & 1270 & 808.0 & 806.1 & -3.71 & -1.60 & +1.37 & -1.32 \\
\hline & 864 & 806.9 & 805.3 & $-3: 30$ & -1.91 & +0.56 & -1.27 \\
\hline & 457 & 807.3 & 805.7 & -2.03 & -1.78 & 0.00 & -1.27 \\
\hline & 51 & & & -1.88 & -2.18 & -1.35 & -1.80 \\
\hline \multirow{6}{*}{$\# 4$} & 1930 & 689.1 & 688.8 & -1.52 & -0.76 & +0.64 & 0.00 \\
\hline & 1549 & 688.8 & 689.9 & -0.97 & -0.18 & +0.48 & +0.25 \\
\hline & 1168 & 689.0 & 690.5 & -0.90 & +0.51 & -0.05 & +0.38 \\
\hline & 889 & 689.3 & 689.4 & -0.38 & +0.25 & +0.13 & -0.51 \\
\hline & 432 & 689.3 & 688.3 & +0.10 & -0.25 & 0.00 & -0.81 \\
\hline & 51 & 689.0 & 686.1 & +0.15 & -1.85 & +2.03 & -1.37 \\
\hline
\end{tabular}


This analysis was repeated at other levels over the height of the tank. The lowest, only about $50 \mathrm{~mm}$ above the bottom weld bead, was always considerably smaller than the average and was discarded from calculating the final average. It was probably smaller because of being "drawn in" during the welding operation. Estimates of tank \#1's outer diameter. by this procedure were (in millimeters), from top to bottom: $1041.2 \pm 3.4,1041.2 \pm 3.0,1040.6 \pm 2.4,1040.9 \pm 2.1$, and the $1041.3 \pm 1.3$ from above. The grand average of these estimates yielded: $1041.0 \pm 5.7 \mathrm{~mm}$.

Data from this mapping was turned over to the Statistical Analysis Group at Rocky Flats. They fit the wealth of data to three geometrical models. One assumed a right circular cylinder with no "out-of-roundness" nor any vertical functional dependence. Here, the constant on the right side of the equation is a best estimate of the outside diameter of the experimental tank in question. The second fit the data to an elliptical cross section having no Z-dependance. This proved to be a statistically good fit for all tanks but two. These exhibited some Zdependance. These two (tanks \#2* and \#4) required fit to a quadratic surface in three dimensions. Equations for these models are presented in Table VIII.

\section{Shielded Annular Tank:}

The single annular tank for the second experimental program was actually composed of two tanks, one positioned inside the other. Uranium solution would be allowed to occupy the space between. Both were right circular cylinders with full bottoms but no top. This design 
Table VIII. "Best" Equations for the Nesting Annular Tanks.

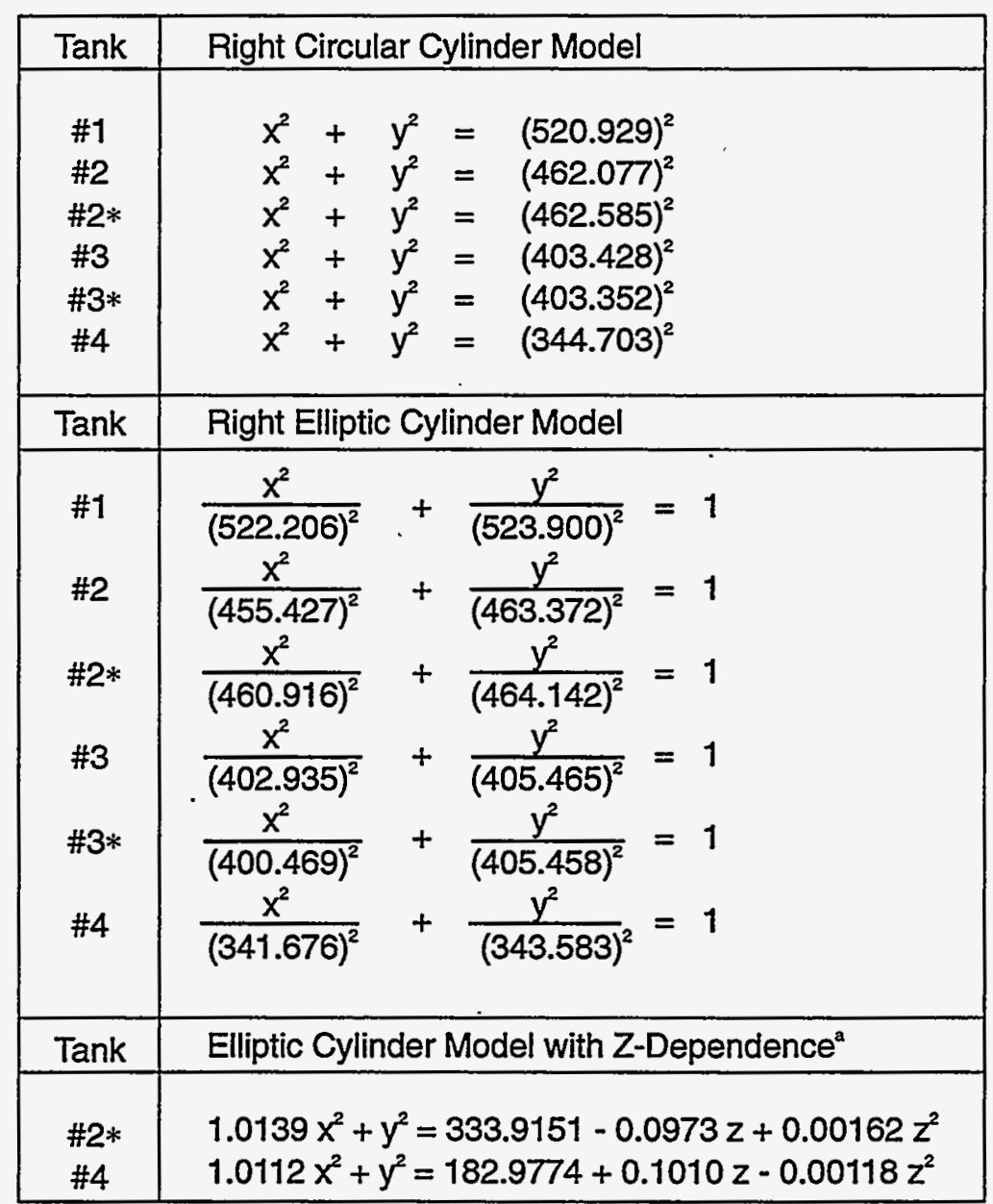

a. Both $x$ and $y$ in the upper two sets of six equations are expressed in millimeters; but the last two equations, which have $z$-dependence, are expressed in inches. 
presented two safety problems. The inner tank would tend to float unless it was securely clamped in place during the experiment; and a leak through a defective weld into the central region could result in a criticality because the volume contained in even a well subcritical annulus might yield a critical slab at the bottom of a leaky tank.

The design goal of this program was to achieve criticality near the top of production-sized tank. This would be one to two meters in diameter and a little over two meters tall. After much consideration; a radial thickness, $\mathrm{DR}$, of $109.22 \pm 0.25 \mathrm{~mm}$ was selected for the solution annulus. Early on, the challenge to design such a tank was recognized. The radial thickness would be a very sensitive parameter affecting criticality. This is discussed more in a later section. The manufacturing uncertainties associated with rolling, such as those encountered in the first program, would never be acceptable in this case. The present tank, instead, was to be rolled of 13-mm-thick stainless steel (type 304L), full-penetration welded along its side seam, and then machined to the final wall thickness. Even the machining was staged such that the final cuts removed less material. The purpose of this was to reduce heat generation during machining which might distort the finished product. The surface finish specified was a "63 finish", generally regarded as twice as smooth as the common machine shop practice. The elemental compositions of the metals used in various regions of the tank are presented in Table IX. 
Table IX. Elemental Composition of Stainless Steel in the Shielded Annular Tank.

\begin{tabular}{|c|c|c|c|c|c|c|c|c|c|c|c|c|}
\hline \multirow[b]{2}{*}{ Component } & \multicolumn{12}{|c|}{ Weight-Percent of Element } \\
\hline & $\mathrm{Cr}$ & $\mathrm{Ni}$ & C & $\mathrm{Mn}$ & $P$ & $S$ & $\mathrm{Si}$ & Mo & Co & $\mathrm{Cu}$ & $\bar{N}$ & $\mathrm{Fe}$ \\
\hline Tank walls & 18.40 & 8.84 & 0.02 & 1.72 & 0.03 & 0.01 & 0.39 & 0.25 & 0.12 & 0.17 & 0.10 & \\
\hline Flanges & 18.82 & 9.82 & 0.02 & 1.52 & 0.04 & 0.03 & 0.42 & 0.10 & 0.04 & 0.10 & 0.09 & - \\
\hline $\begin{array}{l}\text { Bottom and } \\
\text { spacer ring }\end{array}$ & 18.18 & 8.11 & 0.05 & 1.68 & 0.02 & 0.02 & 0.49 & 0.20 & 0.16 & 0.52 & 0.07 & $\overline{\mathbb{x}}$ \\
\hline
\end{tabular}


The tanks were to be quite tall and large in diameter; and access into the experimental room was limited to smaller objects. Each of the two tanks (inner and outer) was, in turn, composed of two sections (lower and upper) which would, in fact, fit through doorways. Lower sections were right circular cylinders each with a full bottom but only a stiffening flange at the top. Upper sections were simply right circular cylindrical shells with tôp and bottom stiffening flanges. The four components were moved into the experimental room and assembled into two full-height tanks. This stage is shown in Fig. 7. Flat gaskets of Viton A rubber separated the two halves of each tank. Diameters of these gaskets were cut to equal the inside diameter of the outer tank and the outside diameter of the inner tank. The rubber was 3.2-mm thick. Sixty-four stainless steel bolts fastened the matching flanges to assure a leak tight assembly; and an engineered torquing procedure assured the tank would not warp during assembly.

The important final dimensions of the two tanks were certified by the manufacturer and are given below. They were verified by Rocky Flats personnel upon receipt. The radial thickness is so important that even the shipping season and route from California to Colorado was chosen to prevent effects from thermal shocks. The inside diameter of the larger tank was $1511.3 \mathrm{~mm}$ with zero lower tolerance and a tight $0.13 \mathrm{~mm}$ positive tolerance. The lower component stood $1041 \mathrm{~mm}$ tall including its $12.7 \pm 0.1-\mathrm{mm}$-thick bottom. The upper unit was also $1041 \mathrm{~mm}$ tall over both flanges. The outside diameter of the inner tank was $1292.9 \mathrm{~mm}$ with no positive tolerance and a tight $0.13 \mathrm{~mm}$ undersize tolerance. The upper component was the 
same $1041 \mathrm{~mm}$ tall; but the lower was only $1028.7 \mathrm{~mm}$ to account for the bottom thickness of the larger tank.

Wall thickness was $6.4 \pm 0.1 \mathrm{~mm}$ thick for all four sections. The six flanges were all 12.7 $\pm 0.1 \mathrm{~mm}$ thick by $50.8 \mathrm{~mm}$ in the radial direction. The three flanges of the inner tank extended inward and the reverse was true for the outer tank.

This construction, drawn in Fig. 18, yielded two very smooth cylindrical surfaces exposed to the uranium solution. That quality for one surface is confirmed by looking, again, at Fig. 7.

The smaller tank was located within the larger via a precisely machined stainless steel ring. This was lowered into the outer tank with close slip fit. Later, the inner tank was positioned inside the ring. This was a delicate operation because of the close tolerances involved; but it formed a well characterized annular tank. The installation was made somewhat easier by machining large chamfers on both inner and outer edges of the ring without altering its limiting diameters. This was done at Rocky Flats prior to assembly. The ring was $1511.2 \mathrm{~mm}$ in outside diameter, only $0.13 \mathrm{~mm}$ smaller than the tank's diameter. The inside diameter of the ring was 1293.0, the same amount larger than the inner tank's outer diameter. Both diameters had zero tolerance in the direction that would preclude a fit and a $0.13-\mathrm{mm}$ tolerance the other direction. 


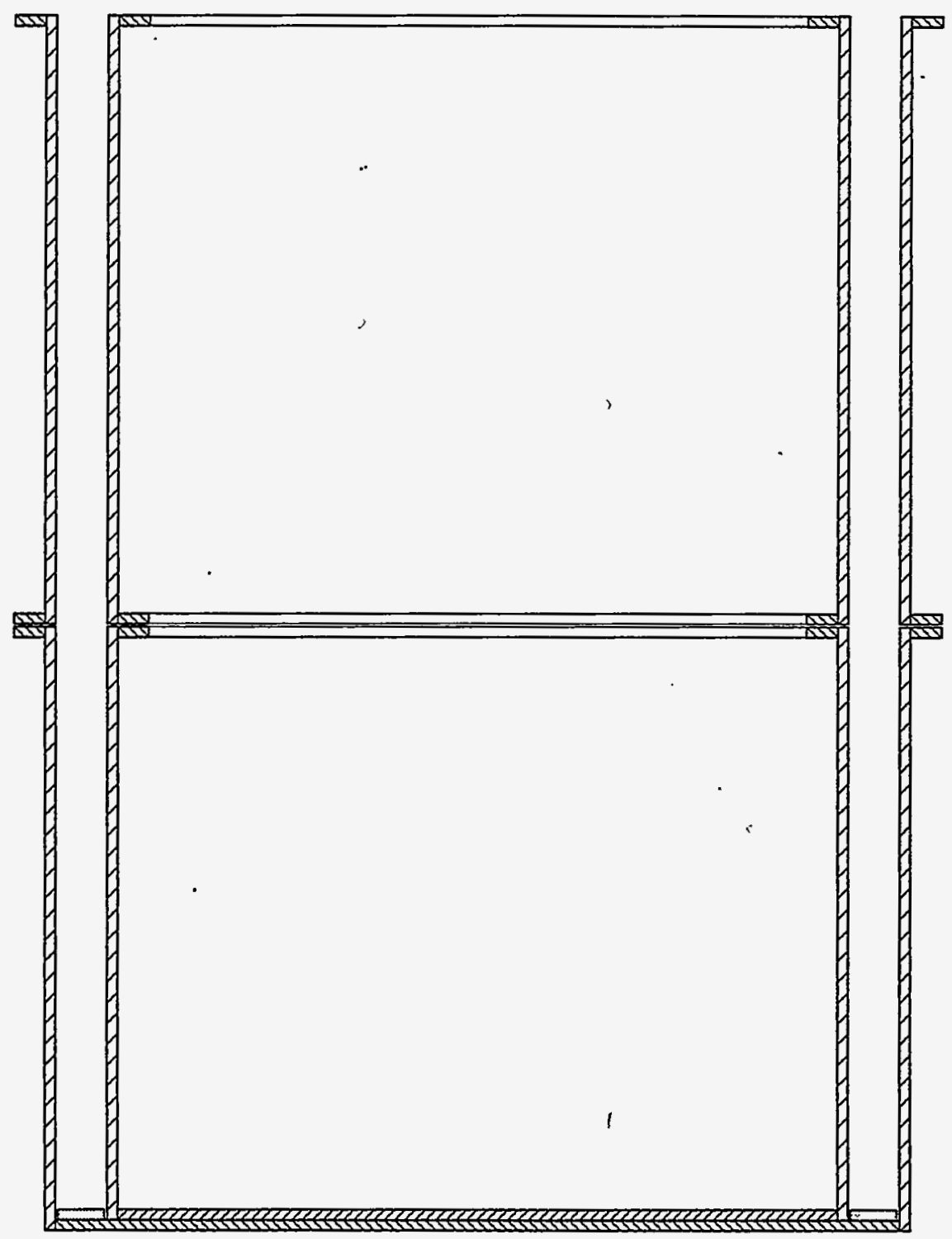

Figure 18. Vertical section of the Shielded Annular Tank. 
The ring was $12.7 \pm 0.1 \mathrm{~mm}$ thick and weighed $51.9 \mathrm{~kg}$. The ring was drilled and tapped for lifting eye bolts; but these were removed before installing the inner tank. A hole was drilled in the ring to accommodate the solution fill line into the annular region.

This fill line, itself, was a length of stainless steel pipe screwed into the bottom of the outer tank. It was long enough to extend through a hole in the mezzanine floor. There, the pipe was connected to the fill line from the storage tank farm.

The final annular region was carefully measured after assembly was completed. Results are graphically represented in Fig. 19. Sixteen equally spaced radial measurements were made at three heights. The top was measured easily; and this was repeated a day later in case any settling took place - curves (1) and (2), respectively, in Fig. 19. The next lower height was in a plane 508 $\mathrm{mm}$ below the top of the upper tank section; it is curve (3). The lowest measurement was in a plane just below the joint between tank sections; so it was in the lower tank segment. It is curve (4).

A qualitative study of Fig. 19 suggests that the upper tank may have had a decreased annular thickness by about $1.5 \mathrm{~mm}$ in the west region of the tank; but the reverse may have existed to the south in the lower tank. Both tanks seemed to exhibit a slightly increased thickness by perhaps a millimeter or so to the east. 


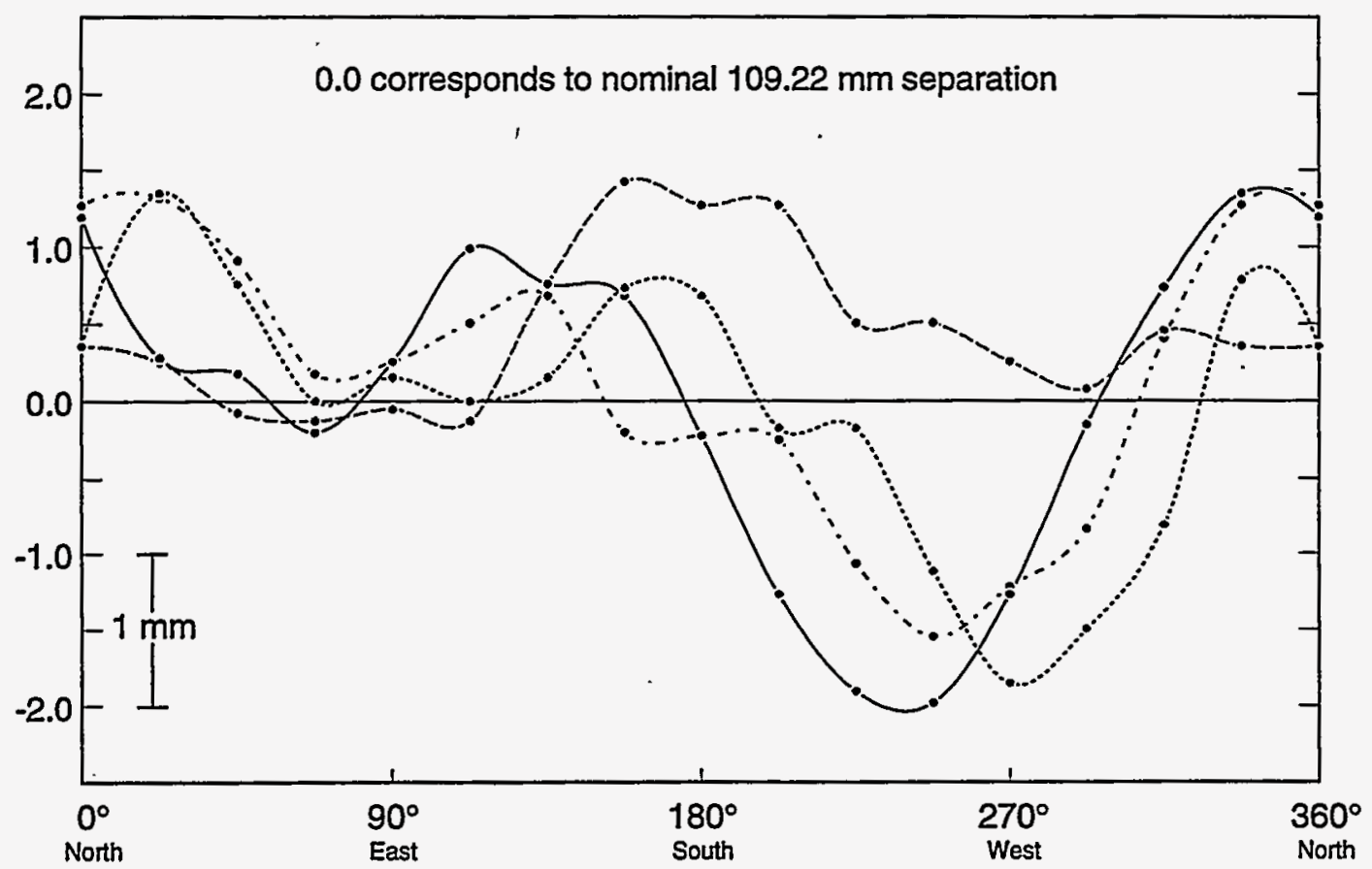

Key

Original measurement at top of tank

Next day measurement at same place but after movement

Measurement after movement, $0.5 \mathrm{~m}$ down from top

Measurement after movement, $1.07 \mathrm{~m}$ down from top

Figure 19. Measured variations in the radial thickness of the Shielded Annular Tank at 3 heights. Deviations from the $109.22 \mathrm{~mm}$ design goal are shown. 
Increases in thickness contribute greater change' in reactivity than decreases; but this point is discussed in a later section.

These radial measurements were probably measured using a machinist's Telescoping $T$ Gauge near the top of the assembly; but the method used lower is not recalled. Care would have been taken to assure the measurement was along a radius and not canted at an angle. Such an error would have yielded values larger than the true radial thickness. How this orientation control was achieved is not recalled either.

The entire tank assembly rested on a sturdy wooden platform. This was $1.32 \mathrm{~m}$ square and placed the bottom of the tank $0.38 \mathrm{~m}$ above the mezzanine floor. The platform was framed with six meters of $90-\mathrm{mm}$ square wood (fence posts) sheathed with 19-mm-thick plywood on top and three sides. The south side was unsheathed to permit access under the tank and as a safety drain. The platform was painted white with fire retardant paint. 


\section{REACTIVITY SHIMS}

The optimum thickness of the annular region, $\mathrm{DR}$, for the second experimental program was impossible to select. Choosing this thickness would be analogous to selecting the critical thickness of an infinite slab for a particular fissile solution. Combining this theoretical difficulty with the practical need to allow manufacturers some reasonable tolerance meant that one could not order a commercial tank with $\mathrm{DR}$ so precisely specified that criticality would predictably occur close to the top of the tank.

This difficulty was addressed by purchasing a tank whose radial thickness was intentionally a little too large. Criticality would, of course, occur at a relatively low height. Then, subsequent experiments would attain criticality at greater heights by decreasing the effective radial thickness through the use of reactivity shims. These would be thin wraps of the same metal as the tank itself added to the inside of the annular region. This procedure would decrease the effective DR by the thickness of the shim stock.

Three thin stainless steel shims of different thicknesses were purchased for this purpose. This approach proved quite inadequate for reasons explained in a later section. To compensate, two additional - and much thicker - reactivity shims were hastily purchased, bringing to five the total number of reactivity shims added at one time or another to the solution region. These five 
are described below. Their sequence of use and associated problems are explained in later sections.

The initial three thin shims were fabricated from commercial 16-, 18-, and 22-gauge Type 304 stainless steel sheet stock. These thicknesses were $1.51,1.22$, and $0.90 \mathrm{~mm}$ thick, respectively. The plan had been to use one or more shims in any combination until a critical height near the top of the tank was attained. Seven different thicknesses were possible with this set. The maximum would be $3.63 \mathrm{~mm}$ when all three were laminated together.

This stock came in 1.22-m-wide sheets. Three sheets of each thickness were purchased and cut and welded together to form two rectangles each. One would be wrapped around the lower half of the tank, the other, the upper. Together, the two wraps of whatever thickness would form a thin cylindrical shell extending the full height of the tank, reducing the annular solution region's thickness by the thickness of the shim.

The lower shim was the full height $(1.22 \mathrm{~m})$ of the commercial sheet stock. The length of a commercial sheet, however, was not long enough to cover the full circumference. A second piece was tack-welded to the end of the first to form a length equal to the circumference of the inner $\operatorname{tank}(4.06 \mathrm{~m})$. 
The upper shim was fabricated to the same length, again, by tack-welding two sheets together. This, however, was sheared to be only $0.81 \mathrm{~m}$ high. Installed, the two shims stood $2.03 \mathrm{~m}$ tall $(1.22 \mathrm{~m}+0.81 \mathrm{~m})$ and completely encircled the outside surface of the inner tank.

The installation was nearly perfect because of the flexibility of this thin stock. The left side of the annular region in Fig. 20 illustrates this good fit. Only a gap of a few millimeters existed where the two ends met inside the tank. This was measured at only $1 \mathrm{~mm}$ for the innermost shim. The gap would understandably be larger if two or all three shims were sandwiched together because the circumferences would be larger for each lamination. This was indeed found to be the case. When all three shims were used, the gap for the middle shim was 8 $\mathrm{mm}$ and $17 \mathrm{~mm}$ for the outermost one.

The sheets were held in place by two bands for the lower shims and two more for the upper. These bands were home-made and consisted of small bits of stainless steel angle stock welded to 25-mm-wide lengths of thin stainless steel sheet. Each band, then, was a narrow strip of thin metal just slightly shorter than the circumference of the tank; and both ends of each band had the angle stock welded in place. A long screw through the angle stock provided the tightening, similar to an ordinary hose clamp. The actual thickness of these bands was not measured. Memory recalls that they may have been formed from residual stock from the fabrication of the shims themselves; but this point is not certain. The vertical location of these 


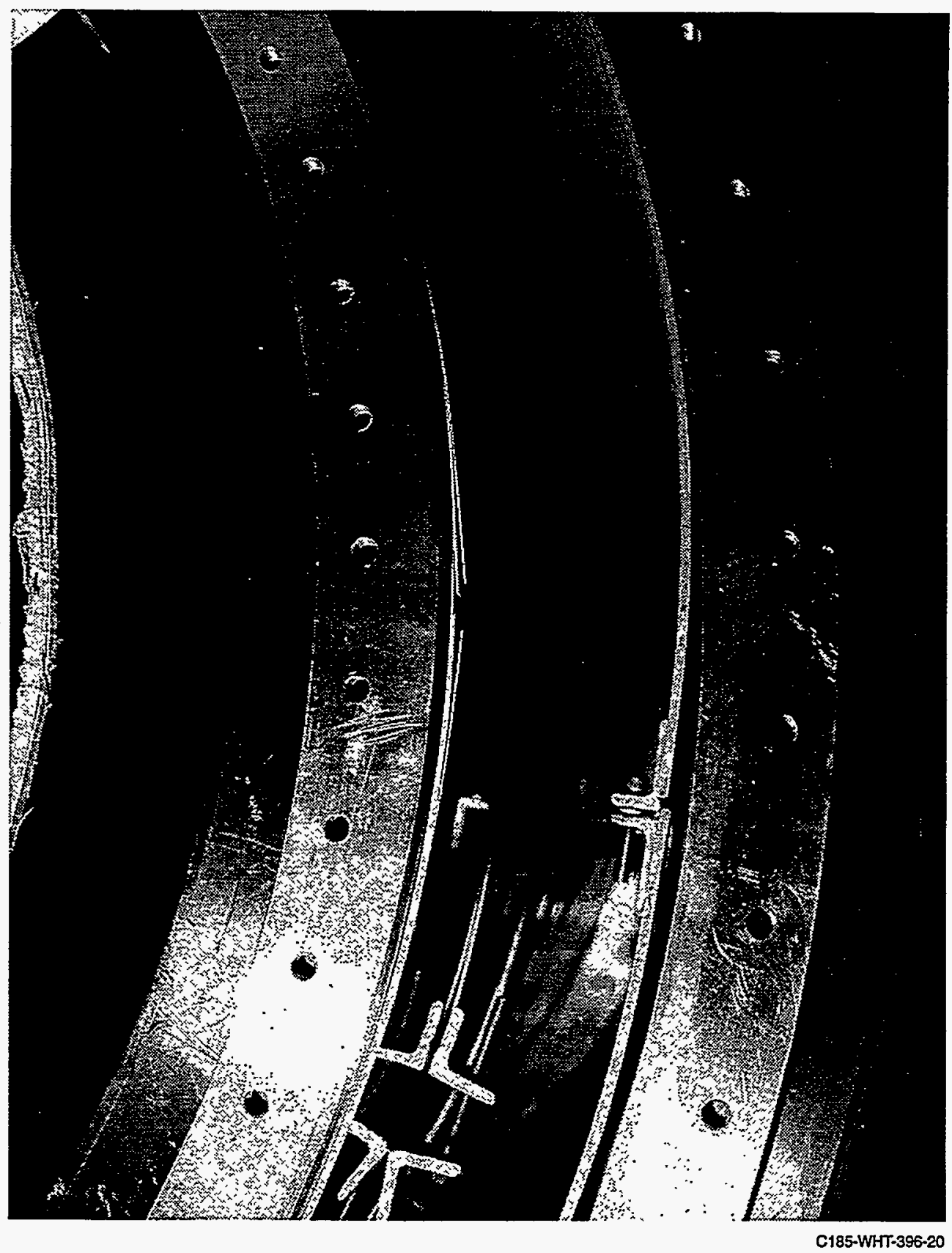

Figure 20. Three reactivity shims are clamped against the inner tank and one is expanded against the outer wall. RFP photo \# 36045-17 [2/16/87]. 
bands also was not recorded; however the author recalls that they may have been about a quarter in... of the way up from the bottom and down from the top of each set of shims.

The fourth reactivity shim was also composed of commercial stainless steel stock (Type 304L). The nominal thickness of the plate material ordered was $4.76 \mathrm{~mm}$; and the delivered sheets measured that around the perimeter. After fabrication, however, eleven measurements around the perimeter of the plate ranged from 4.78 to $4.92 \mathrm{~mm}$ with an average of $4.86 \mathrm{~mm}$. This value is suggested as "best" for this paper.

This shim was designed to be lowered into the annular region and then expanded outward such that it would press against the inside surface of the outer tank. This thicker material was very stiff and was expected not to press as well against the tank wall as the thinner shims. That proved to be an accurate prediction as illustrated to the right in Fig. 20.

As before, the finished shim was a composite of a lower piece and an upper one. Each was formed by welding two flat rectangles together, grinding the weld beads smooth, and rolling them into a right circular cylindrical shell. The two ends of each rolled shell were not welded together. Instead brackets were attached to allow the cylinder to be expanded outward by a set of adjusting screws. One of these brackets is shown in Fig. 21; but three such adjusting brackets were used on top and bottom portions. Brackets were formed from short lengths of $25 \mathrm{~mm}$ angle 


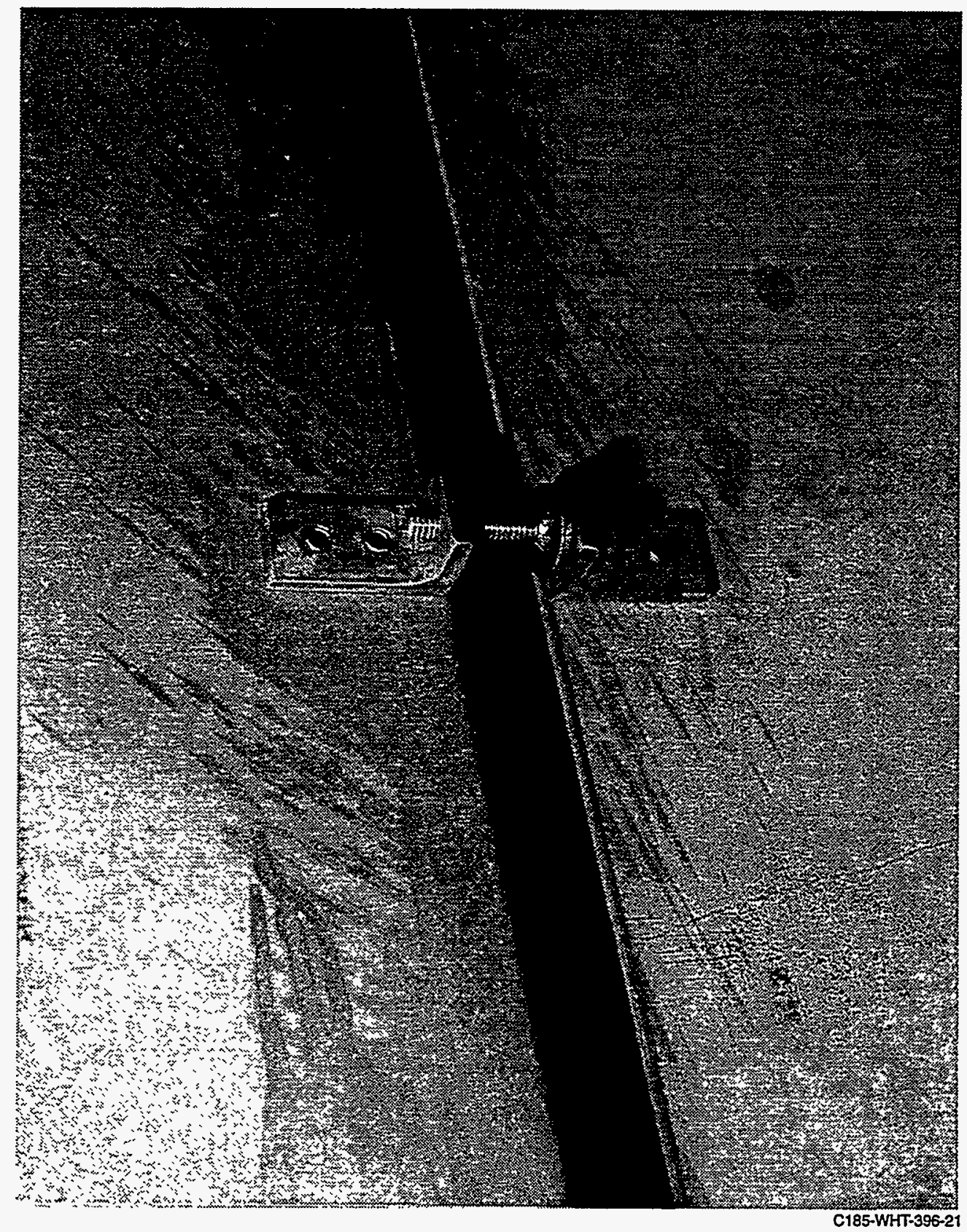

C185-WHT-396-21

Figure 21. Detail of the method used to expand the 4.86-mm-thick shim. RFP photo \# 35996-03 [2/11/87]. 
stock; and the adjusting screw was a standard $6.4 \mathrm{~mm}$ cap screw. All components were made of stainless steel.

The length of both lower and upper shims, before rolling, was cut less than the circumference $(4.75 \mathrm{~m})$ of the inside surface of the outer tank. Such a design would leave a small gap between the two vertical ends when the rolled cylindrical shell was later expanded. Unfortunately, the actual cut length of each piece was never recorded. Figure 20, however, shows that the "expansion" joint near the top was nearly zero. Such a smaller-than-expected gap is difficult to explain.

This stiff material did not roll perfectly; so a perfect press against the wall did not exist. When the lower half was expanded against the wall, two azimuthal segments (about $30^{\circ}$ each) revealed a gap between wall and shim. The maximum was about $12 \mathrm{~mm}$ near its center; but this tapered off to zero on both sides. The upper piece also left a few places where the shim did not press perfectly against the wall. The worst gap was a $90^{\circ}$ segment that had a maximum space of about $6 \mathrm{~mm}$ between shim and tank. These azimuthal gaps may explain why not much outward expansion of the adjusting screws was required.

The lower half was $1.02 \mathrm{~m}$ tall to match the joint in the two tank segments. This lower shim weighed $188.6 \mathrm{~kg}$. The upper was $1.04 \mathrm{~m}$ high and weighed $192.6 \mathrm{~kg}$. The sum of the 
heights was designed to stay a little below the top of the tank, although the actual construction ended up about even with the top of the tank. The difference is assumed to be due to imperfections in fit. The upper piece may not have rested perfectly upon the lower one; and the bottom shim may not have contacted the floor of the annular tank around its entire circumference.

Top and bottom sections were fastened to each other before being lowered into the experimental tank. Thus, this shim (unlike the set of three) was nearly the full height of the tank when installed. Three pair of small angle bracket sets on $120^{\circ}$ intervals tied top and bottom together. One trio was welded near the bottom of the top half while a matching three was welded near the top of the bottom one. The two sections were probably bolted together; but this detail is not certain.

The final reactivity shim was designed to be free-standing somewhere in the middle ${ }^{21}$ of the radial solution region. It's nominal diameter would be $1.40 \mathrm{~m}$. It, too, was fabricated in lower and upper sections. The commercial material was nominally 6.4-mm-thick Type 304L stainless

${ }^{21}$ Use of this interstitial shim was based on the following argument. The annular solution region may be viewed as simply an infinite, flat, solution slab rolled into an effective largediameter cylinder. A truly infinite slab of some thickness is known to have the same critical thickness, $T$, as the sum of the thicknesses of two, parallel, infinite slabs separated by any thickness of vacuum. That is, the critical thickness of the two separated solution slabs equals the original critical thickness $\mathrm{T}$. This interstitial shim, with stainless steel in the midst of the annular region, would follow the same reasoning except for the scattering and absorption introduced by the material itself. This argument, also, proved to be somewhat flawed. 
steel plate. Actual measured thicknesses averaged $6.22 \pm 0.03 \mathrm{~mm}$ at the bottom and $6.24 \pm 0.03$ $\mathrm{mm}$ at the top. The overall average, $6.23 \pm 0.05 \mathrm{~mm}$, is the value suggested for use. The bottom section of the finished right circular cylindrical shell weighed $226 \mathrm{~kg}$ and the top, $227 \mathrm{~kg}$.

Each section was formed of two lengths welded together end to end. This was then sheared to $4.4 \mathrm{~m}$ such that, when rolled, it could be welded along its vertical seam forming a rigid nearly right circular cylindrical shell $1.40 \mathrm{~m}$ in diameter. The height of each half was never measured for some reason; but the finished shim is known to have been almost exactly co-planar with the top of the annular tank. This reasoning places the height of the two segments at 2.07 m., although this simple parameter was not recorded.

Before joining the two halves together, each one was quite rigid and had no gap at the vertical seam because it was welded there. When the upper section was lowered onto the lower, their "circular" cross sections didn't match closely. The two were temporarily clamped, squeezed, and forced into better (still, not perfect) circular alignment. Then, they were securely tack-welded all the way around. The result is the single free-standing cylinder shown in Fig. 10. That view ${ }^{22}$ is from below the suspended shim before being lowered into the experimental tank.

${ }^{22}$ Four small metal bars can be seen in the figure. These held the top and bottom segments together before tack welding. The two were tack welded to preserve the best achievable circular cross section. The four temporary bars were simply left in place. 
This thick and rigid interstitial shim was still not perfectly circular in cross section; that was obvious to the naked eye. Two measurements were made on two different occasions to measure this eccentricity. The shim had been moved between the two; so the two sets of data should not be expected to be the same. The measurement was the radial separation between the inside edge of this egg-shaped shim and the outside surface of the three thin shims wrapped around the inner tank. The latter surface, even with the shims, can be expected to be very close to a truly circular cross section. This separation was determined at eight equally spaced $\left(45^{\circ}\right)$ locations, clockwise, around the azimuth:

\section{$\begin{array}{llllllll}86.3 & 69.5 & 56.3 & 52.4 & 43.8 & 37.5 & 38.9 & 54.5\end{array}$ \\ $\begin{array}{llllllll}69.3 & 45.7 & 45.7 & 56.7 & 74.9 & 75.8 & 73.3 & 66.7\end{array}$}

All measurements are in millimeters. The first is to the north, third-east, fifth - south, and so on.

These measurements were made in the plane of the top of the tank only. The observed eccentricity varied slowly over the full height of the interstitial shim. That was also visible to the naked eye. Unfortunately, no details of this vertical change in eccentricity were recorded. One measurement hints at this matter. When this interstitial shim was intentionally placed tangent to one vertical element of one tank wall, the top edge warped $13 \mathrm{~mm}$ away from that tangent.

This shim in the midst of the solution region would slow down the removal of fissile solution at the end of an experiment; so a set of 14 semi-circular notches were cut into its bottom. 
These permitted more rapid movement of solution from one side to the other of the now-divided solution annulus. The dimensions of these notches can be estimated from Fig. 10. Onefourteenth of the circumference is about $314 \mathrm{~mm}$; and the figure can be used to scale the width of the notches: about $50 \mathrm{~mm}$. 


\section{MODERATORS and ABSORBERS}

Neutrons were slowed down and exposed to potential absorbers differently in the two programs. In the nested annular tank study, this was accomplished by common earthen materials which contained a selected amount of a strong neutron absorber. The earthen material provided thermalization of neutrons. The second study used common plastic to slow neutrons and laminations of flexible, boron-loaded, rubber sheet to provide absorption. Neutrons both inside and outside the annular solution region need to be absorbed for criticality control. Fission neutrons would interact between tanks in a farm of closely spaced tanks; and they would also move across internal chords of a single tank.

\section{Overview - first program:}

The common earthen materials were concrete and plaster. Both are readily availability, low cost, easily formed, and strong. Two materials were chosen (rather than just one) to determine the practical suitability of one compared with the other. Concrete is a little more common; but it loses moisture (hydrogen) slowly over many years. Plaster, on the other hand, comes to a fixed and predictable moisture (hydrogen) content for the finished product.

Neutrons moving along chords of a given tank were both moderated and absorbed by concentric cylindrical annuli, called plugs, positioned interior to the annular solution region. 
These were prepared in various radial thicknesses and with three different loadings of the absorber element. All were the full height of the solution region in a tank. That is, they did not rest on the floor because the solution did not start at floor level. The solution region was elevated by the tank's skirting; so the earthen unit rested upon a wooden platform the same height.

These earthen components were cast by pouring wet mixes of the dry ingredients into cylindrical forms. The outer form was always a thin-walled, cylindrical, plastic-coated paper shell commonly used to cast bridge supports and similar columns. These are called Sonotubes ${ }^{23}$ in the construction industry. Figure 22 shows two stages of the casting process and a half-dozen finished plugs. Some plugs had no inner form; so they were simply solid cylinders. Those with inner forms resulted in the annular geometry. Paper tubes were used for this application, too, in all cases but three. For these, commercial corrugated steel culvert stock was used for the inner form. These products, normally used to pass water under highways, were cut to length for the present application.

Absorber units between tanks in an array were cast as thin, flat slabs. Only plaster was used for four slabs made for this purpose. Two thicknesses were cast. All four contained the same mix of ingredients. The slabs were cast inside ordinary plywood; and this was not removed

${ }^{23}$ Sonotubes are a registered trademark of the Sonoco Products Company of Hartsville, SC. At the time, they were distributed in the Denver, $\mathrm{CO}$, area by Gates Mold Company . 


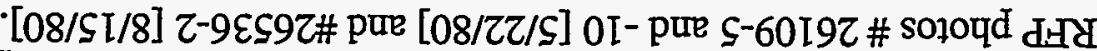

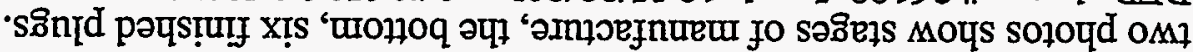

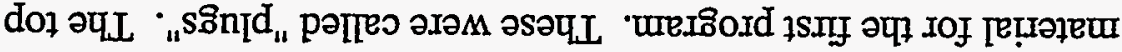

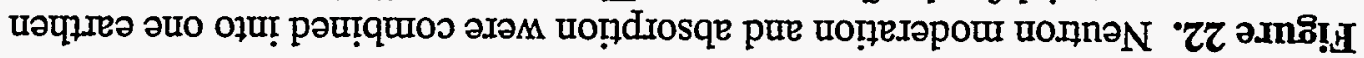
टZ-968-LHM-S8เ5
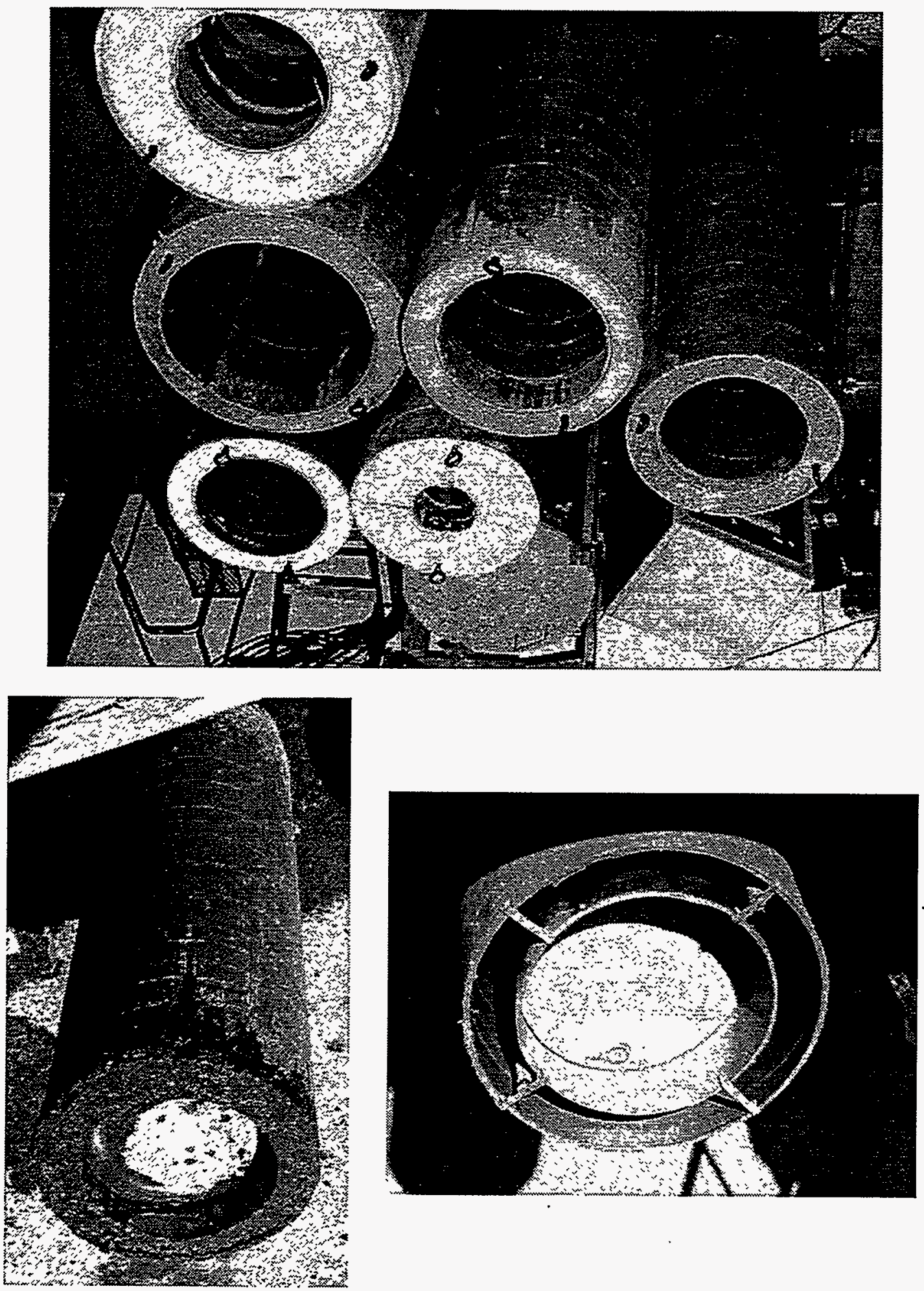
for use. Thus, the plaster slabs also contained some plywood. The width of these units was such as to provide an easy slip fit between parallel walls of the concrete neutron reflector panels (discussed in a later section) when the array of tanks was in a line formation. The height, again, about equalled the height of the solution region in a tank. That is, even though the plywood form extended to the floor, the plaster within the form began at the same height as the skirting on the tanks themselves. Figure 23 shows two of these slabs between sets of tanks. The photo also shows one thick and one thin plug, some reflector wall panels, and all six tanks.

The neutron absorbing ingredient added to both earthen materials was a boron-rich product mined in California. It is called Gerstley Borate ${ }^{24}$ and is an unrefined natural mixture of Colmanite, a calcium borate $\left[\mathrm{Ca}_{2} \mathrm{~B}_{6} \mathrm{O}_{11} \bigcirc 5 \mathrm{H}_{2} \mathrm{O}\right]$, and Ulexite, a sodium-calcium borate $\left[\mathrm{NaCaB}_{5} \mathrm{O}_{9} \diamond 2-8 \mathrm{H}_{2} \mathrm{O}\right]$. This product varied in particulate size from fine sand to chips a few millimeters on a side. It was homogenized as a dry ingredient into other dry ingredients before adding water. The finished products were believed to contain homogeneously distributed solids of small size, although homogeneity was never proven by detailed analysis. The theoretical concern is that one component might separate from others once water was added.

24 Gerstley borate is a commercial product solely distributed by U. S. Borax, Inc., of Valencia, CA. 


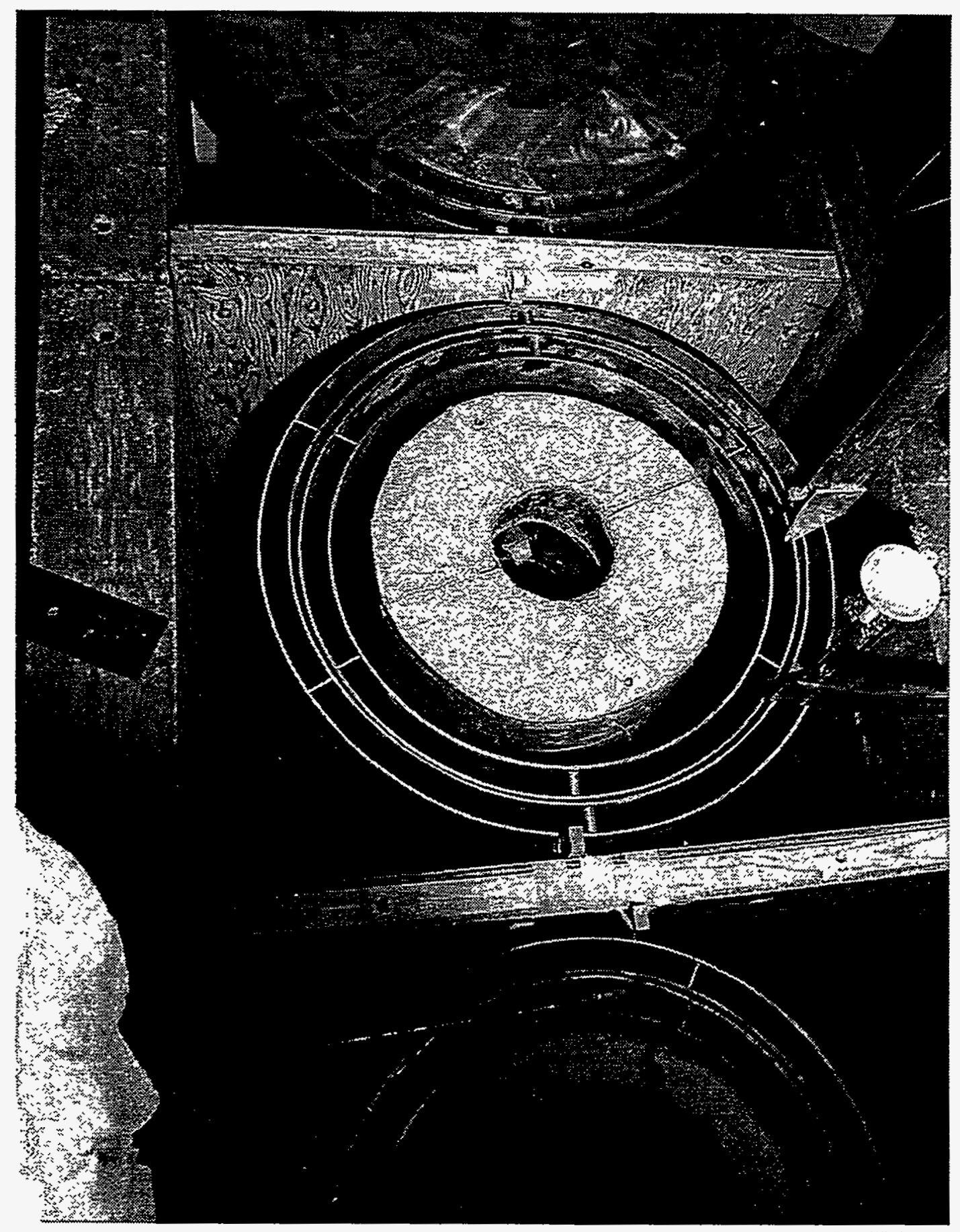

C185-WHT-396-23

Figure 23. A 1x3 line array of nested pair of tanks have absorber/moderator slabs between sets of tanks and plugs interior. RFP photo \# 27021-9 [1/15/81]. 
The concrete was a very common mix of dry ingredients: Portland cement (mostly Type II), ordinary moist sand direct from outdoor storage .bins, and the dry aggregate, an ordinary washed river rock nominally $10 \mathrm{~mm}$ on a side. Ordinary tap water was used; but a very small amount of Pozzolith was added as a water-reducing agent designed to produce a given consistency (called "slump" in the industry) with less water. Pozzolith is a lignin and also a defloculating agent.

The plaster was a commercial gypsum product called Hydrostone Super $\mathrm{X}^{25}$. It was a fine powder similar to other plasters and was mixed with the Gerstley borate chips while still dry. Ordinary tap water was added to this to form the wet mix for casting.

Both concrete and plaster components were cast only weeks to months before use; so the water content existing a few weeks after setting can be assumed for these experiments. Concrete especially would have lost a significant fraction of its moisture content if the experiments were to have been performed many years later.

${ }^{25}$ Hydrostone Super X is a registered trademark of the U. S. Gypsum Company of Southard, OK. 
Overview - second program:

Neutron moderating and absorbing materials were separate from one another on this program wherein they were homogenized for the first. The same composition and geometry, on the other hand, were similar inside and out for this program whereas the first employed cylinders inside and slabs outside. Here, moderator and absorber materials were "sandwiched" together into three layers of two different materials. These sandwiches became free-standing cylindrical annuli. The inner sandwich fit loosely inside the inner tank. The outer sandwich, likewise, fit loosely around the outside of the outer.

The moderator of each sandwiched layer was a thick region of high density .polyethylene. This was flanked on both surfaces by thin laminates of absorber. This plastic was spiral wound by the manufacturer as a nearly molten continuous filament. When cooled, this winding procedure produced a rigid, thick, free-standing, cylindrical shell of polyethylene. It was free of air bubbles, a little longer than the height of the experimental tanks, and thick enough to thermalize fission-energy neutrons. Winding was done on a heated mandrel, slightly smaller than the needed inside diameter; and the winding continued until the cylinder was slightly too thick. When cool, the slightly oversized polyethylene blank was slid off the mandrel and shipped to Rocky Flats. 
These blanks were then machined at Rocky Flats to desired diameters and length. The inside diameter of the outer piece was only several millimeters greater than the outside diameter of the outer wall of the tank; and the outside diameter of the inner one was only several millimeters smaller than the inside diameter of the tank's inner wall. Thus, even with a few millimeters of absorber material between plastic and tank walls, an air gap of only a few millimeters existed.

The stainless steel tanks had stiffening flanges at the top and middle. Machining the plastic blanks to clearance diameters so large that they could have slipped over these flanges would have created unnecessarily large air gaps between components. To avoid that, both inner and outer plastic cylinders were sawed vertically into segments so the cylindrical geometry could be re-assembled closer to the tank. The outer shell needed only be cut in half. The inner shell had to be cut into more pieces for subsequent re-assembly. Mechanical rigidity was regained by "welding" ${ }^{26}$ these segments back together once in place.

Another machining operation concerned the height. They needed to be the full height of the tank; but this would have made them too tall and unwieldy for easy handling. Consequently,

${ }^{26}$ Plastic welding is an uncommon art worthy of some explanation. A heat gun is used to melt local regions of the plastic while a rod of the same plastic is fed into the melted area. When cooled, the two pieces are welded together much the same as metals are welded. 
each shell was also cut in half horizontally, forming lower and an upper components. The result of all this machining was a set of cylindrical sectors that were later reassembled into cylindrical annuli inside and outside the solution tank.

The neutron absorbing material was a flexible rubber sheet a few millimeters thick. It was manufactured as an equal mix of boron carbide $\left(\mathrm{B}_{4} \mathrm{C}\right)$ grit and silicone rubber. The commercial product was called Rad-Stop ${ }^{27}$. This Rad-Stop was placed on both sides of both polyethylene regions. That is, one layer was outside the larger plastic shell. Another existed between this shell and the outer wall of the stainless steel tank. A third existed between the inner surface of tank and the outside of the inner plastic piece. The fourth and final sheet was inside the smaller plastic shell. Refer, again, to Fig. 11 for a pie-wedge section drawing for the Shielded Annular Tank program.

In all cases, the rubber was wrapped around the nearest convex surface. This was done for safety to ensure that a sheet would not peel away and fall to the floor during an experiment. The consequences of such an unplanned event could have been a criticality accident. The outermost rubber layer was stapled to the polyethylene using steel carpenter's staples. The second layer of rubber was wrapped and banded around the exterior surface of the outer stainless steel tank wall.

${ }^{27} \mathrm{Rad}-$ Stop is a registered trademark of Bisco Products of Park Ridge, IL. 
The third layer of rubber was, again, stapled to the outside of the inner plastic shell. Because this rubber had to be added before assembly and welding, it was cut to size and stapled to each segment. When assembled, the finished rubber sheet covered the same area as the polyethylene. The final and smallest diameter of sheet rubber was wound on another Sonotube. This paper tube was just a little smaller than the inside diameter of the inner plastic shell. Sheet vinyl ensured this rubber would not peel away at the wrong time.

Internal Moderation and Absorption - first program

Most materials used to manufacture the plugs were cast into the concrete and plaster; so their weights, dimensions, and compositions need to be included in any calculational model of these experiments. The paper forms were available only in certain sizes and would be used both inside and out; so sizes were selected to yield close fits to tanks and reasonable radial thicknesses. Throughout this paper, plugs are named by the nominal outside and inside diameters of their casting forms, expressed in inches, such as "30x18".

A total of 19 plugs were made. All but two were concrete. Both plaster plugs contained $1.1 \%$ natural boron and were sized to fit inside the smallest stainless steel tank. One plaster plug was quite thick, the other, thinner. The 17 concrete plugs were cast in three boron concentrations: no boron, $1.2 \% \mathrm{~B}$, and $2.5 \% \mathrm{~B}$. The smallest of these fit the smallest tank; 
middle sized ones fit tanks \#3 and \#3*, but the largest fit easily inside either second largest tank. The radial thickness of plugs ranged from fairly thin $(71.7 \mathrm{~mm})$ down to zero, solid cylinders.

Only 11 of the 19 plugs made were actually used in critical experiments. The full set was designed to cover all experimental contingencies; but the coarse of the study dictated the smaller number. Table $\mathrm{X}$ gives both the dimensions and weights of all 19 plugs. These weights include the finished plug at different times because weights change as water leaves during the setting process. Weights of other components cast into the plug are also given. Parameters for the 8 plugs not used are included because the weight change with time data may be useful in evaluating water contents.

All 19 plugs were about $2.14 \mathrm{~m}$ tall, although precise heights are contained in the table. If stood on the floor, plugs would not be tall enough to reach the tops of the tanks because the height of each plug equalled the height of the potential solution region in the tanks. An earlier section describes how these solution regions were elevated above the floor by a tank skirting. Thus, the plugs, themselves, also needed to be elevated above the floor the same amount. This was done with wooden stands strong enough to support the weight. They were low-mass to minimize reflection. Stands resembled an open square frame when viewed from above. Corners were vertical $89-\mathrm{mm}$-square wood members $305 \mathrm{~mm}$ tall, the load-bearing components. These posts were tied together by four 250-mm-wide strips of $13-\mathrm{mm}$-thick plywood glued and 
Table X-A. Dimensions of the Interior Neutron Absorber/Moderator Cylinders (Plugs ${ }^{\star}$ ) for the Nested Annular Tank Program.

\begin{tabular}{|c|c|c|c|c|c|c|}
\hline \multirow[b]{2}{*}{$\begin{array}{l}\text { Plug } \\
\text { Namea }\end{array}$} & \multirow[b]{2}{*}{ 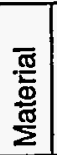 } & \multirow{2}{*}{$\begin{array}{c}\text { Boron } \\
\text { Content } \\
(\%)\end{array}$} & \multicolumn{4}{|c|}{ Plug Diameters (mm) } \\
\hline & & & $\begin{array}{c}\text { Paper } \\
\text { OD }\end{array}$ & \multicolumn{2}{|c|}{$\begin{array}{cc}\text { Earthen } & \text { Material } \\
\mathrm{OD} & \mathrm{ID}\end{array}$} & $\begin{array}{c}\text { Paper } \\
\text { ID }\end{array}$ \\
\hline $22 \times 0$ & \multirow{17}{*}{ 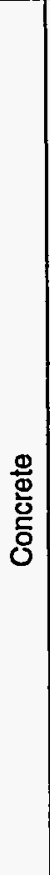 } & & 570.2 & 558.8 & 0 & 0 \\
\hline $22 \times 8$ & & & 570.2 & 558.8 & 209.6 & 203.2 \\
\hline $22 \times 16$ & & & 570.2 & 558.7 & 415.3 & 406.4 \\
\hline $24 \times 10$ & & & 621.0 & 609.6 & 261.6 & 254.0 \\
\hline $24 \times 18$ & & & 621.0 & 609.6 & 467.4 & 457.2 \\
\hline $30 \times 16$ & & & 777.2 & 762.0 & 415.3 & 406.4 \\
\hline $30 \times 24$ & & & 777.2 & 762.0 & 621.0 & 609.6 \\
\hline $22 \times 8^{h}$ & & \multirow{6}{*}{1.2} & 570.2 & 558.8 & 209.6 & 203.2 \\
\hline $22 \times 16$ & & & 570.2 & 558.8 & 415.3 & 406.4 \\
\hline $24 \times 10^{h}$ & & & 621.0 & 609.6 & 261.6 & 254.0 \\
\hline $24 \times 18$ & & & 621.0 & 609.6 & 467.4 & 457.2 \\
\hline $30 \times 0^{9}$ & & & 777.2 & 762.0 & \multicolumn{2}{|c|}{ Nearty solid ${ }^{9}$} \\
\hline $30 \times 24$ & & & 777.2 & 762.0 & 621.03 & 609.6 \\
\hline $22 \times 16$ & & \multirow{4}{*}{2.5} & 570.2 & 558.8 & 415.3 & 406.4 \\
\hline $30 \times 12$ & & & 777.2 & 762.0 & \multirow{3}{*}{\multicolumn{2}{|c|}{$\begin{array}{l}\text { Fluted } \\
\text { interior } \\
\text { see text - }\end{array}$}} \\
\hline $30 \times(18)$ & & & 777.2 & 762.0 & & \\
\hline $30 \times 24$ & & & 777.2 & 762.0 & & \\
\hline $22 \times 8$ & $\frac{\mathbf{\Phi}}{\Phi}$ & & 570.2 & 558.8 & 209.6 & 203.2 \\
\hline $22 \times 16$ & $\frac{\mathscr{m}}{0}$ & 1.1 & 570.2 & 558.8 & 415.3 & 406.4 \\
\hline
\end{tabular}

See Table X-D for footnotes. 
Table X-B. Component Weights for the Interior Neutron Absorber/Moderator Cylinders (Plugs*) for the Nested Annular Tank Program.

\begin{tabular}{|c|c|c|c|c|c|c|}
\hline \multirow[b]{2}{*}{$\begin{array}{c}\text { Plug } \\
\text { Name }\end{array}$} & \multirow[b]{2}{*}{ 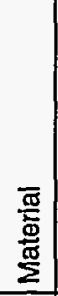 } & \multirow[b]{2}{*}{$\begin{array}{c}\text { Boron } \\
\text { Content } \\
(\%) \\
\end{array}$} & \multicolumn{4}{|c|}{ Component Weights Before Casting $(\mathrm{kg})$} \\
\hline & & & \begin{tabular}{|c|} 
Plug \\
Height \\
to top of \\
Earthen \\
Material \\
$(\mathrm{mm})$ \\
\end{tabular} & $\begin{array}{c}\text { Paper } \\
\text { Sonotubes }^{\mathrm{b}} \\
\end{array}$ & $\begin{array}{c}\text { Steel } \\
\text { Bottom } \\
\text { Disk + } \\
4.32 \mathrm{~kg} \text { in } \\
2 \text { Rods \& } \\
\text { Anchors } \\
\end{array}$ & $\begin{array}{c}3 \text { Wooden } \\
\text { Disks }{ }^{c} \text { or } \\
\text { [Steel Culvert] }\end{array}$ \\
\hline $22 \times 0$ & & & 2124 & (15.1) & 16.48 & 0 \\
\hline $22 \times 8^{0}$ & & & 2127 & 18.82 & 14.75 & $(0.99)$ \\
\hline $22 \times 16$ & & & 2127 & 23.59 & 9.47 & $(3.50)$ \\
\hline $24 \times 10$ & & 0 & 2127 & 20.59 & 15.93 & $(1.56)$ \\
\hline $24 \times 18$ & & & 2134 & 27.27 & 9.94 & (2.37) \\
\hline $30 \times 16$ & & & 2121 & 34.93 & 20.20 & (3.50) \\
\hline $30 \times 24$ & & & 2127 & 42.32 & 11.85 & $(7.83)$ \\
\hline $22 \times 8^{h}$ & & & 1956 & 18.82 & 14.75 & 0.99 \\
\hline $22 \times 16$ & & & 2127 & 23.59 & 9.47 & (3.50) \\
\hline $24 \times 10^{h}$ & $\overline{\mathrm{g}}$ & & 1975 & 20.59 & 15.93 & 1.56 \\
\hline $24 \times 18$ & రํ & 1.2 & 2130 & 27.27 & 9.94 & 2.37 \\
\hline $30 \times 0^{9}$ & & & $2124^{k}$ & 34.93 & 20.20 & 3.50 \\
\hline $30 \times 24$ & & & 2127 & 42.32 & 11.85 & (7.83) \\
\hline $22 \times 16$ & & & 2121 & 23.59 & 9.47 & $3.50(6)$ \\
\hline $30 \times 12$ & & & 2108 & (26.5) & 27.02 & [33.4] \\
\hline $30 \times(18)$ & & 2.5 & 2121 & $(26.5)$ & 20.20 & [48.7] \\
\hline $30 \times 24$ & & & 2134 & (26.5) & 11.85 & [65.2] \\
\hline $22 \times 8$ & $\frac{\overline{\mathbf{g}}}{\mathrm{s}}$ & & 2134 & 18.82 & 14.75 & $(0.99)$ \\
\hline $22 \times 16$ & $\frac{\pi}{0}$ & 1.1 & 2127 & 23.59 & 9.47 & $(3.50)$ \\
\hline
\end{tabular}

See Table X-D for footnotes. 
Table X-C. Weights of the Interior Neutron Absorber/Moderator

Cylinders (Plugs ${ }^{\star}$ ) for the Nested Annular Tank Program.

\begin{tabular}{|c|c|c|c|c|c|c|c|}
\hline \multirow[b]{4}{*}{$\begin{array}{l}\text { Plug } \\
\text { Name }^{a}\end{array}$} & \multirow[b]{4}{*}{ 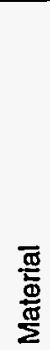 } & \multirow[b]{4}{*}{$\begin{array}{c}\text { Boron } \\
\text { Content } \\
(\%)\end{array}$} & \multicolumn{5}{|c|}{ Cast Weights $(\mathrm{kg})$ of Plugs } \\
\hline & & & \multicolumn{5}{|c|}{ After Casting Earthen Material } \\
\hline & & & \multirow[b]{2}{*}{$\begin{array}{c}\text { Fresh } \\
\text { Cast }+ \\
\text { Pallet and } \\
\text { Spillage }\end{array}$} & \multicolumn{3}{|c|}{ Plug Only (as Used) ${ }^{d}$} & \multirow[b]{2}{*}{$\begin{array}{l}\text { Earthen } \\
\text { Density } \\
\left(\mathrm{mg} / \mathrm{mm}^{3}\right)\end{array}$} \\
\hline & & & & $\begin{array}{c}1 \\
\text { Month } \\
\text { after } \\
\text { Casting } \\
\end{array}$ & $\begin{array}{c}3 \\
\text { Months } \\
\text { after } \\
\text { Casting }^{m} \\
\end{array}$ & $\begin{array}{c}\text { Just } \\
\text { Prior } \\
\text { to } \\
\text { Use } \\
\end{array}$ & \\
\hline $22 \times 0$ & \multirow{17}{*}{ 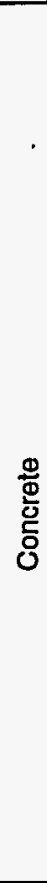 } & \multirow{7}{*}{0} & $1251.6^{t}$ & 1223.6 & & 1220.3 & 2.29 \\
\hline $22 \times 8$ & & & 1101.4 & 1062.2 & & & 2.29 \\
\hline $22 \times 16$ & & & 602.9 & 562.5 & & 554.9 & 2.24 \\
\hline $24 \times 10$ & & & $121 \dot{9} .2$ & 1182.3 & & & 2.26 \\
\hline $24 \times 18$ & & & 647.2 & 615.3 & & & 2.25 \\
\hline $30 \times 16$ & & & 1630.1 & 1598.0 & & & 2.27 \\
\hline $30 \times 24$ & & & 842.1 & 793.7 & & & 2.27 \\
\hline $22 \times 8^{h}$ & & \multirow{6}{*}{1.2} & 1032.5 & 965.5 & 985.9 & 984.3 & 2.30 \\
\hline $22 \times 16$ & & & $580.7^{\circ}$ & 509.0 & 528.0 & 525.0 & 2.11 \\
\hline $24 \times 10^{h}$ & & & 1164.8 & 1101.1 & 1115.1 & & 2.22 \\
\hline $24 \times 18$ & & & 624.8 & 528.1 & 574.2 & & 2.09 \\
\hline $30 \times 0^{9}$ & & & 1616.1 & 1557.3 & 1589.8 & & $1.58^{g}$ \\
\hline $30 \times 24$ & & & 808.2 & 701.8 & 742.8 & & 2.11 \\
\hline $22 \times 16$ & & \multirow{4}{*}{2.5} & & & 489.4 & 458.61 & 1.94 \\
\hline $30 \times 12$ & & & & 1599.? & 1594.5 & & 1.91 \\
\hline $30 \times 18$ & & & & 1249.5 & $968.8^{i}$ & & 1.94 \\
\hline $30 \times(24$ & & & & 741.5 & 733.3 & & 1.99 \\
\hline $22 \times 8$ & $\frac{\frac{1}{\omega}}{0}$ & & 918.0 & 888.7 & & 882.8 & 1.89 \\
\hline $22 \times 16$ & $\frac{\pi}{a}$ & 1.1 & 492.3 & 475.5 & & 468.4 & 1.86 \\
\hline
\end{tabular}

See Table X-D for footnotes. 
Table X-D. Footnotes to Tables X-A, -B, and -C.

a. Ordinary font type corresponds to plugs actually used in one or more experiments. Italic entries were prepared in anticipation of use but were not needed. The numbers in the names actually correspond to the nominal $O D$ and ID in inches. Circled entries correspond to inner forms made of steel culvert stock.

b. Both tubes except for four cases (parentheses) wherein only an outer tube was paper.

c. Circular disks were used to strengthen the inner paper form. The weight of these are included in the weight of the fresh casting. Weights enclosed in parentheses are not included in later measurement because the disks had been removed. In the $22 \times 16$ case at the highest boron . loading, six wooden disks were used but only the top one could be removed after the concrete set.

d. Weight includes set earthen material, paper form(s), inner culvert (3 cases), baseplate, two lifting rods, and anchor inserts, and those plywood disks that could not be removed from the finished plug.

e. Weighed again 100 minutes later and lost $2.05 \mathrm{~kg}$ as water loss during setting.

f. Weighed again 70 minutes later and lost $1.09 \mathrm{~kg}$ as water loss during setting.

g. Intended to be a $30 \times 16$ plug; but the inner paper form collapsed during manufacture. The plug was salvaged by filling it as though it was $30 \times 0$. See text for discussion of void; and note reduced density. The collapsed paper tube was not removed.

$h$. These two forms sagged a small amount during the casting process probably due to inward bulges of the inner paper form. Note the lower heights compared to the rest of the plugs.

i. This weight is questionable. It corresponds to a concrete density of $1.51 \mathrm{mg} / \mathrm{mm}^{3}$, much smaller than other similar plugs.

j. Last measured weight of plug minus weight of embedded steel, paper, and wood (if any) divided by the volume of the cylindrical earthen shell.

k. Actual height not measured.

1. 31 days $(0 \%) ; 24$ days ( $1 \%) ; 21$ days ( $3 \%) ; 29$ days (plaster).

m. 92 days $(1 \%)$ and 89 days $(3 \%)$. 
screwed vertically to them. These webs touched neither floor nor plug. Five stands were made in three sizes. The largest two would fit easily inside tanks \#2 and \#2*. The next two fit inside tanks \#3 and \#3*; and the fifth fit within the smallest tank.

Table $\mathrm{X}$ separates into three sections. Various diameters are given to the left. Thicknesses of paper forms can be obtained from this section of the table. Center columns specify weights of non-earthen components as measured before casting. Columns to the right present weights of the cast plug at various times after casting and the density of the earthen material. This density is not merely the weight of the plug divided by its volume. Rather, the gross weight has been reduced by the weight of steel, paper, and (sometimes) wood components embedded in the plug; so it more accurately measures the density of the set concrete or plaster.

The paper Sonotubes are designed for such casting. They are spirally constructed of laminated plies of recycled pulp paper (newspapers, cardboard boxes, etc.). An adhesive derived from sodium silicate is used to bond together the $150-\mathrm{mm}$-wide plies of fiber. The interior surface is coated with a plastic to aid form removal if that is to be done. This is some sort of polyethylene or poly urethane; but the detailed composition of the material is proprietary information. The exterior surface is impregnated with ordinary beeswax to provide limited protection against rain. 
This beeswax did not always protect the outer surface of the inner forms adequately. This caused some problems. One was that the softened paper would swell during setting. This swelling did not always allow the removal of the plywood disks, intentionally placed at three heights inside the inner paper form to brace it during the pour. The plan was to remove them after the concrete had set. The table identifies which plugs ended up with plywood disks wedged in place because those weights are not enclosed in parentheses.

The worst problem occurred while casting the $1.2 \% \mathrm{~B}$ concrete plug intended to be named 30x16. The inner tube collapsed at some unknown height during the pouring operation. The still-wet concrete slumped down considerably; and a hasty decision was made to continue filling as though the plug were a solid cylinder; thus, this plug was later named 30x0. The collapsed paper tube was not removed. Consequently, the set plug had the outward appearance of a solid cylinder of concrete but really had a cavity within it. That cavity was about the diameter of the inner form by some unknown height and was at the bottom of the cylinder. That height was estimated by assuming the concrete would have the same average density as the rest of the $1.2 \%$ B concrete. The weight was known; so the volume could be calculated. Figure 24 is almost certainly a huge simplification of the actual cross section. The upper portion is probably not as smooth as shown; and some rubble probably exists at the bottom. Still, the cylindrical annulus is so thick that these imperfections are presumed of little consequence. 


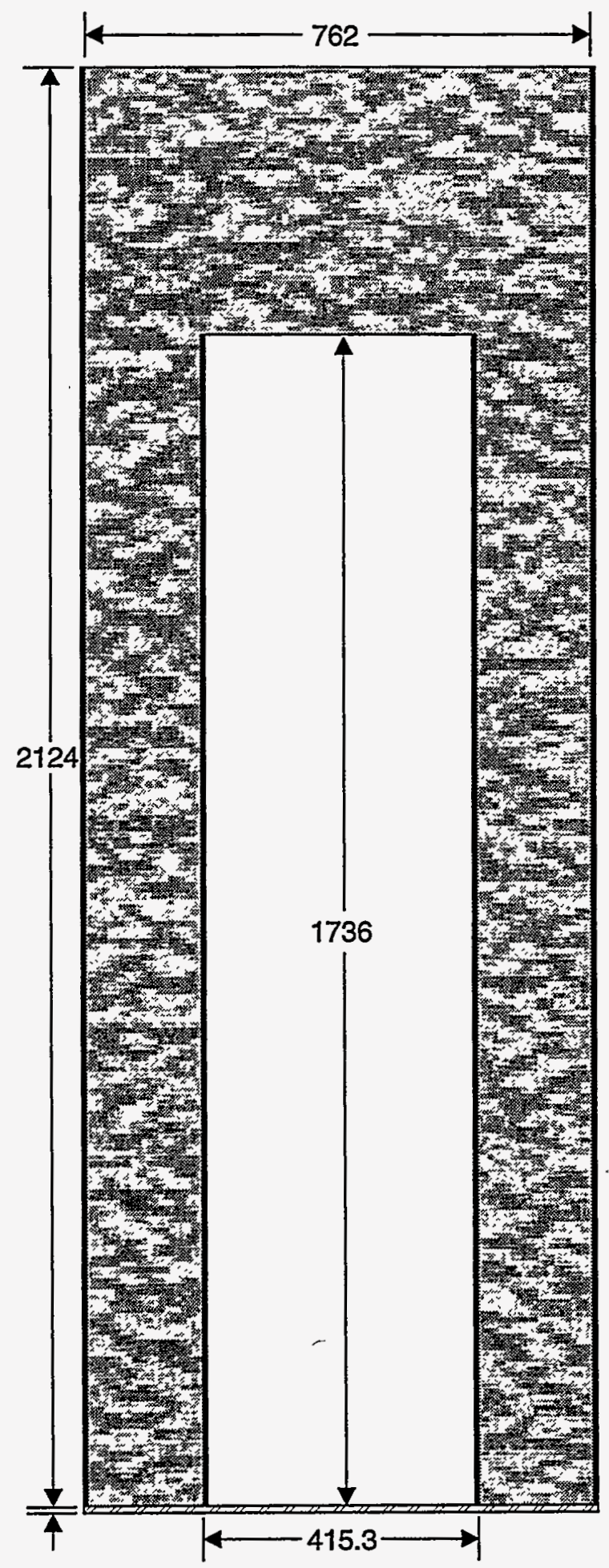

Figure 24. One plug collapsed during casting and was saved as explained in the text. The assumed cross section is shown. 
Two other plugs ( $22 \times 8$ and $24 \times 10$ at $1.2 \%$ B concrete) sagged a little during casting but were not filled further. The earthen material for these two are many millimeters shorter than the paper tube outside form. The outside of these plugs was unaffected; probable the inner tubes softened and bulged enough to produce the observed sag.

One final problem caused by water on a paper form was a little humorous when it happened. When casting a $22 \times 0$ concrete plug at $2.5 \% \mathrm{~B}$, a considerable amount of wet concrete leaked out the bottom. This was discarded as waste. The damaged cylinder was bound with rope and refilled with fresh concrete of similar composition. An hour later, gas generated within the setting cylinder caused it to "blurp" wet concrete out of the top. Moments later, the soggy cylinder slowly laid over on its side. It was lost to further use.

The problem of moisture soaking through unprotected paper was taken into consideration before casting the $2.5 \% \mathrm{~B}$ concrete plugs. That concrete would contain even more water; so the problem would have been even worse. The thinnest one was cast by the old method; but paper was not used as the inner form of the remaining three. Commercial steel culvert stock was used instead. This is the corrugated tubular product used in the construction industry to divert ground water such as under roadways. Three sizes were available at Rocky Flats; and all were used. These are referred to as "12 inch", "18 inch", and "24 inch" culverts in the roadwork industry. They were cut to the same length as the paper tubes. The ASTM A-444 steel stock is $1.5 \mathrm{~mm}$ 
thick ${ }^{28}$. The "clearance" inside diameters (minimum diameter across flutes) were 305,457 , and $610 \mathrm{~mm}$, respectively; and the greatest inside diameter across flute valleys was always $25 \mathrm{~mm}$ greater. Both surfaces were galvanized to a thickness of $0.31 \mathrm{mg} / \mathrm{mm}^{2}$. The distance between spiral flutes was $68 \mathrm{~mm}$. Use of these culverts formed plugs with corrugated interiors; but this shape was accepted because the plugs were so thick that the detailed geometry of the inner surface was considered unimportant.

Before casting, small-scale tests were performed on concrete containing boron to determine any effect of the additive on strength. This is discussed in greater detail in a later section; but the conclusion was that strength was lessened. The decision was made not to lift the concrete by lifting anchors cast into the top of a plug because these might pull out. Instead, each plug was fitted with a steel bottom plate to which two steel rebars, the full height of the plug, were welded vertically. These were diametrically opposite one another and about midway in a plug's radial thickness. The rebar was welded to the bottom plate and to the steel lifting anchors. It was nominal 13-mm-diameter fluted stock; and the cut-to-length pair weighed $4.07 \mathrm{~kg}$. The commercial lifting anchors weighed $123 \mathrm{~g}$ each. This procedure allowed the weight of each plug to be borne by the bottom plate.

${ }^{28}$ This was never measured; it is a handbook thickness. Measured weights of the actual lengths used are given in the table. 
Steel bottom plates were $6.4 \mathrm{~mm}$ thick and turned to match the inside diameter of the outer paper tube. An inside hole was also turned for those plugs having a hollow center. This equalled the outside diameter of the inner form. Eight sizes were made and their weights and diameters are given in Table XI. These assured the desired dimensions of the finished plug at its bottom. Four temporary light-weight metal spacers at quadrants around the top assured this dimensional stability between outer and inner form during casting. These were removed and discarded after the raw mix was poured.

Plywood disks were $19 \mathrm{~mm}$ thick and were removed from the set plugs by breaking them in all cases but five. Wood weights are given in Table $\mathrm{X}$ whether the disks were removed or not because some plug weights include these weights. Entries enclosed in parentheses correspond to cases where wood disks were successfully removed. The number of wooden disks in the $2.5 \% \mathrm{~B}$ concrete $22 \times 16$ plug was doubled to six because the mix was so wet. The top disk was successfully removed; but the other five were too firmly held in place. This one plug contained five wooden disks when used.

The boron-free concrete plugs were made on May 5, 1980, a few months before use. The truckload of concrete used to make all plugs of this boron content contained:

$\begin{array}{ll}\text { Portland Type II Cement } & 1059 \mathrm{~kg} \\ \text { Moist Sand (7.1\% absorbed water) } & 3034 \mathrm{~kg} \\ \text { Moist Gravel chips (1\% water) } & 3511 \mathrm{~kg}\end{array}$


Table XI. Steel Bottom Lifting Disks ${ }^{a}$ for the Plugs of the First Program.

\begin{tabular}{|c|c||c|c||c|c|}
\hline \multicolumn{2}{|c||}{$\mathrm{OD}=558.0 \mathrm{~mm}$} & \multicolumn{2}{c||}{$\mathrm{OD}=609.6 \mathrm{~mm}$} & \multicolumn{2}{|c|}{$\mathrm{OD}=762.0 \mathrm{~mm}$} \\
\cline { 1 - 5 } $\begin{array}{c}\text { ID } \\
(\mathrm{mm})\end{array}$ & $\begin{array}{c}\text { Weight } \\
(\mathrm{kg})\end{array}$ & $\begin{array}{c}\text { ID } \\
(\mathrm{mm})\end{array}$ & $\begin{array}{c}\text { Weight } \\
(\mathrm{kg})\end{array}$ & $\begin{array}{c}\text { ID } \\
(\mathrm{mm})\end{array}$ & $\begin{array}{c}\text { Weight } \\
(\mathrm{kg})\end{array}$ \\
\hline 0 & 12.0 & 261.6 & 11.7 & 0 & 22.3 \\
209.6 & 10.3 & 467.4 & 5.9 & 415.3 & 15.7 \\
415.3 & 5.4 & & & 621.0 & 7.5 \\
\hline
\end{tabular}

a. $6.4 \mathrm{~mm}$ thick (mild steel). 
Tap Water at plant

Add'l water after pouring $1450 \mathrm{~kg}$

Add'l water after pouring $4940 \mathrm{~kg}$

Pozzalith water-reducing agent

Total weight fresh $0 \%$ B concrete
$511 \mathrm{~kg}$

$15 \mathrm{~kg}$

$4 \mathrm{~kg}$

$2 \mathrm{~kg}$

$8136 \mathrm{~kg}$

A concrete expert, present during the casting of these plugs, judged that the mix was a little too dry midway through the process. He suggested the addition of another $15 \mathrm{~kg}$ of water after $18 \%$ of the wet concrete had been poured. Later, another $4 \mathrm{~kg}$ of water was added after $60 \%$ of the truckload had been used up.

The concrete plugs containing $1.2 \%$ boron were made on May 19,1980 , only two weeks later. The truckload of concrete used to make all plugs of this boron content contained:

$\begin{array}{lc}\text { Portland Type II Cement } & 1196 \mathrm{~kg} \\ \text { Moist Sand (6.9\% absorbed water) } & 1668 \mathrm{~kg} \\ \text { Moist Gravel chips (1\% water) } & 2291 \mathrm{~kg} \\ \text { Gerstley Borate (7.6\% boron) } & 1053 \mathrm{~kg} \\ \text { Tap Water at plant } & 694 \mathrm{~kg} \\ \text { Pozzalith water-reducing agent } & 2 \mathrm{~kg} \\ \text { Total weight fresh 1.1\% B concrete } & \overline{\mathbf{6 9 0 4}} \mathbf{~ k g}\end{array}$

The boron contained in the Gerstley Borate was $80 \mathrm{~kg}$; so the boron content in the finished freshcast concrete plug was $1.16 \%$ B (7.6\% of $1053 \mathrm{~kg}$ divided by $6904 \mathrm{~kg}$ of wet concrete). A more accurate analysis would take into account the water loss experienced by freshly cast concrete over many months. Some water was certainly lost during the setting process. A boron content of $1.2 \% \mathrm{~B}$ is assumed throughout this paper. If as much as $500 \mathrm{~kg}$ of water were lost, the boron content would increase to only $1.3 \% \mathrm{~B}$. The concrete is not likely to have lost that much water. 
More water was required for this $1.2 \% \mathrm{~B}$ concrete than for the similar casting of the boron-free plugs. For this composition, $10 \%$ of the weight was water; the first casting had only $6.5 \%$ water. This concrete was also weakened by the addition of the boron minerals as discussed elsewhere.

The concrete plugs containing $2.5 \%$ boron were made on May 22, 1980, the same month as the other two kinds. The truckload of ingredients, as mixed at their plant, contained only Portland Type II cement, gravel chips, water and Pozzalith. No sand or Gerstley Borate was present at this stage. When this very runny partial mix arrived at Rocky Flats, the planned amount of Gerstley Borate $(1864 \mathrm{~kg}$ ) was added; but the mix was still much too fluid to pour. An additional $286 \mathrm{~kg}$ of the borate was added along with $271 \mathrm{~kg}$ more cement. Rocky Flats did not have Type II cement so Portland Type I cement was substituted. To this, $270 \mathrm{~kg}$ of moist sand was also added; the moist sand was assumed to contain $7 \%$ water. This proved to be an unwise sequence of adding ingredients as discussed later. This complicated recipe yielded the following still very wet and runny mix:

$\begin{array}{lc}\text { Portland Type II Cement } & 1542 \mathrm{~kg} \\ \text { Portland Type I Cement } & 271 \mathrm{~kg} \\ \text { Moist Sand (assume 7\% water) } & 270 \mathrm{~kg} \\ \text { Moist Gravel chips (1\% water) } & 1539 \mathrm{~kg} \\ \text { Gerstley Borate (7.6\% boron) } & 2150 \mathrm{~kg} \\ \text { Tap Water at plant } & 1289 \mathrm{~kg} \\ \text { Pozzalith water-reducing agent } & 3 \mathrm{~kg} \\ \text { Total Weight fresh 2.4\% B concrete } & \mathbf{7 0 6 4} \mathbf{~ k g}\end{array}$


The boron contained in the Gerstley Borate was $161 \mathrm{~kg}$; so the boron content in the finished fresh-cast concrete plug was $2.3 \%$ B ( $7.6 \%$ of $2150 \mathrm{~kg}$ divided by $7064 \mathrm{~kg}$ of wet concrete). A more accurate analysis would take into account the water loss experienced by freshly cast concrete over many months. If $500 \mathrm{~kg}$ of water were lost, the boron content would increase to $2.5 \% \mathrm{~B}$. This is the boron content assumed for these plugs throughout this paper.

One additional complication entered this particular casting operation. Because the Gerstley Borate was added to the mix after the water, some amount of "balling" occurred. Spheres of unmixed Gerstley Borate were surrounded by thin shells of wet concrete, preventing the homogenization of some borate material. These clumps were picked out of the mix by hand and collected. About one-third of these clumps were lost; but the remaining two-thirds weighted $117 \mathrm{~kg}$. Thus, about $176 \mathrm{~kg}$ of clumps had been picked out of the mix. Six of these clumps (between 200 and $700 \mathrm{~g}$ each) were studied further and found to contain $20 \%, 31 \%, 2 \%, 27 \%$, $0 \%$, and $46 \%$ unmixed Gerstley Borate. The average borate content of a ball, based on that sampling, was $21 \pm 18 \%$; and the composition for the $2.5 \%$ B concrete may be adjusted for these removed clumps by subtracting $37 \mathrm{~kg}$ of the borate and $176 \mathrm{~kg}$ of wet mix from the above table. This small correction only changes the boron content of the wet mix a negligible amount.

The possibility exists that all ingredients are not homogeneous within these castings. Undetected clumps may have existed within vast regions of otherwise well-mixed concrete. Still, 
weights of ingredients given above and adjusted for removed clumps are known to have been contained within the plugs even if not homogeneously so.

Even more water was required for this $2.5 \% \mathrm{~B}$ concrete than for the other two compositions. Here, $18 \%$ of the weight was water. This concrete was also greatly weakened by the addition of the boron minerals as discussed elsewhere.

The complete and balanced (to 100\%) composition of these concretes was, unfortunately, not attempted. Ingredients were ordinary materials commonly used to make familiar objects such as walls, floors, and sidewalks. So, lacking further detail, the elemental composition of these standard concrete ingredients (Portland cement, sand, and rock aggregate) described in the literature is suggested. Then, a specific elemental analysis for this program can be derived from the mixtures of ingredients specified above. Although major elements were not adequately measured, samples of the raw materials were analyzed to detect any surprising levels of metallic impurities. These analyses also proved the absence of any strong neutron absorbers such as boron and cadmium. Impurity analyses are presented in Table XII and the bottom section of Table XIII.

The moisture content of these raw materials was important because that moisture contributed hydrogen; and this is important to the thermalization of neutrons. These materials 
Table XII. Impurity Analysis for the Concrete Plugs.

\begin{tabular}{|c|c|c|c|c|c|c|c|}
\hline \multirow{2}{*}{$\begin{array}{l}\text { Element } \\
\text { or } \\
\text { Compound }\end{array}$} & \multirow{2}{*}{$\begin{array}{l}\text { Type II } \\
\text { Portland } \\
\text { Cement }^{\text {C }}\end{array}$} & \multicolumn{3}{|c|}{ Moist Sand } & \multicolumn{3}{|c|}{ Aggregate } \\
\hline & & $0 \% B$ & $1.2 \% \mathrm{~B}$ & $2.5 \% \mathrm{~B}$ & $0 \% B$ & $1.2 \% B$ & $2.5 \% B$ \\
\hline$\overline{A l}$ & 2.5 & 6.2 & 6.1 & 5.8 & 8.1 & 6.5 & 7.4 \\
\hline $\mathrm{Ba}$ & 0.06 & 0.1 & 0.1 & 0.1 & 0.1 & 0.1 & 0.1 \\
\hline$c$ & 0.02 & 0.004 & 0.006 & 0.005 & 0.005 & 0.005 & 0.006 \\
\hline $\mathrm{Ca}$ & 43.4 & 0.2 & 0.2 & 0.2 & 0.7 & 0.2 & 0.3 \\
\hline $\mathrm{Fe}$ & 2.9 & 3.2 & 2.4 & 1.5 & 4.0 & 1.8 & 2.6 \\
\hline K & 0.6 & 0.2 & 0.2 & 0.2 & 0.5 & 0.2 & 0.3 \\
\hline $\mathrm{Mg}$ & 1.2 & 0.2 & 0.2 & 0.2 & 0.7 & 0.2 & 0.5 \\
\hline $\mathrm{Mn}$ & 0.1 & 0.0 & $\#$ & $\#$ & 0.1 & 0.0 & 0.0 \\
\hline $\mathrm{Na}$ & 0.2 & 0.0 & 0.1 & 0.0 & 0.1 & 0.0 & 0.1 \\
\hline $\mathrm{Ni}$ & 0.01 & & & & & & \\
\hline$R b$ & 0.02 & 0.01 & 0.0 & 0.0 & 0.01 & 0.0 & 0.0 \\
\hline$S$ & 0.11 & 0.0 & & & & & \\
\hline $\mathrm{Si}$ & 7.0 & 23 & $*$ & 25 & 24 & $*$ & * \\
\hline $\mathrm{SiO}_{2}$ & $*$ & $*$ & $72.8 \pm 0.5$ & * & $*$ & $71.0 \pm 0.5$ & $74.6 \pm 0.5$ \\
\hline $\mathrm{Sr}$ & 0.2 & 0.0 & 0.0 & 0.0 & 0.0 & 0.0 & 0.0 \\
\hline $\mathrm{Ta}$ & 0.1 & & 0.1 & 0.1 & & 0.1 & 0.1 \\
\hline$\pi$ & 0.1 & 0.2 & 0.3 & 0.3 & 0.5 & 0.3 & 0.4 \\
\hline V & 0.1 & & & & & & \\
\hline $\mathrm{Zn}$ & $<0.01$ & 0.0 & 0.0 & 0.0 & 0.0 & 0.0 & 0.0 \\
\hline $\mathrm{Zr}$ & 0.01 & & & & & & \\
\hline $\begin{array}{l}\text { Absorbed } \\
\text { moisture }\end{array}$ & 0.7 & 6.0 & 3.8 & 1.9 & 0.0 & 0.0 & 1.8 \\
\hline
\end{tabular}

a. Ordinary font implies a relative error of about $\pm 5 \%$ or better. Smaller light-face font implies about $\pm 50 \%$ relative error from emission spectroscopy. The asterisk means that either $\mathrm{Si}$ or $\mathrm{SiO}_{2}$ was measured but not both. The \# means that Mn was not reported in this case. A blank entry means that the observed amount was below the detection limit.

b. $15 \%$ of the cement used in the $2.5 \%$ B concrete was Type I Portland cement; and this was found to contain $45.8 \% \mathrm{Ca}$. 
Table XIII. Distribution of Gerstley Borate ${ }^{a}$ by Particle Size Resulting from Passing through Successive Mesh Sizes (right to left) and a Partial Elemental Composition by Size.

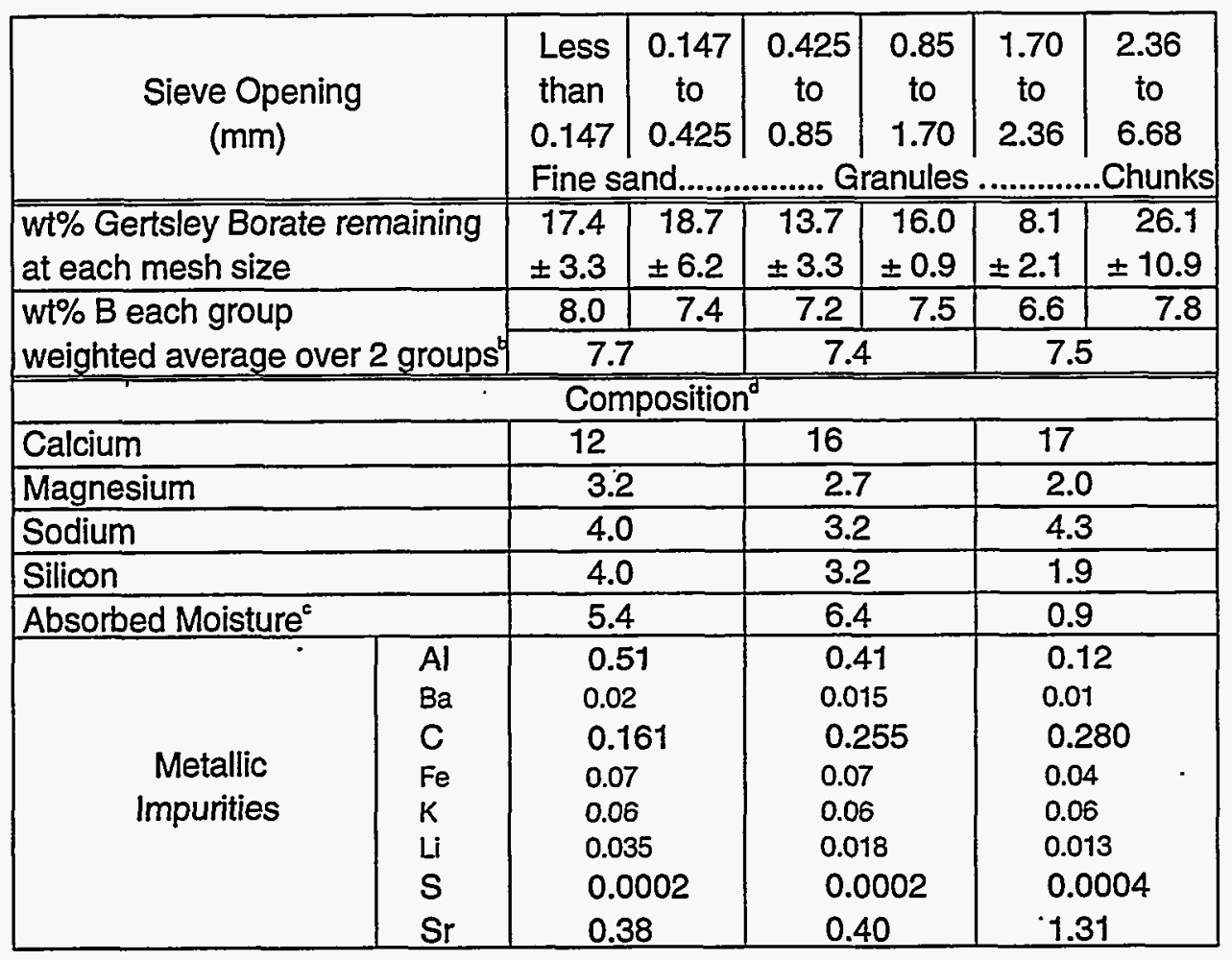

a. Average of four samples from different bags.

b. The grand weighted average for the boron ontent of the Gerstley Borate is $7.55 \%$ B with an expected relative error of $\pm 5 \%$. The rounded value of $7.6 \% \mathrm{~B}$ will be used throughout this paper.

a. The weighted average for the absorbed moisture content of this one sample is $4.1 \%$ water.

d. Ordinary font means the relative error is about $\pm 5 \%$. Smaller, light-face font has a relative error of about $\pm 50 \%$. 
were stored out-of-doors and might vary in moisture depending on recent weather conditions. The water content of these ingredients was measured by thermogravimetric analysis (TGA) wherein the weight loss is monitored as the temperature is raised slowly. Most moisture listed in the two tables was absorbed moisture. The TGA analysis of Portland cement was complicated.

Gerstley Borate was a major component of this experimental program. Its boron content was the sole reason for adding it to plugs. Because of its importance, this unrefined mineral was analyzed more thoroughly than other materials. Still, a complete and balanced elemental analysis is sadly lacking.

The unrefined product is believed to be some unknown mixture of three minerals: Ulexite, Colemanite, and ordinary sand. Ulexite is a sodium-calcium borate $\left[\mathrm{NaCaB}_{5} \mathrm{O}_{9} \diamond(2-8) \mathrm{H}_{2} \mathrm{O}\right]$. Its molecular weight is 351 (choosing 5 waters of hydration). Pure Ulexite would contain $15.4 \%$ boron, $11.4 \%$ calcium, $6.6 \%$ sodium, $2.8 \%$ hydrogen, and $63.8 \%$ oxygen. Colemanite is a much simpler borate: calcium borate $\left[\mathrm{Ca}_{2} \mathrm{~B}_{6} \mathrm{O}_{11} \cdot 6 \mathrm{H}_{2} \mathrm{O}\right]$. Its molecular weight is 410.8 ; and the pure mineral would contain $15.8 \%$ boron, $19.5 \%$ calcium, $2.4 \%$ hydrogen, and $62.3 \%$ oxygen. Sand, of course, is simply $\mathrm{SiO}_{2}$, has a molecular weight of 60 , and contains $46.7 \%$ silicon and $53.3 \%$ oxygen. 
A detailed analysis of Gerstley Borate showed the product contained only $7.55 \%$ boron, about half that of either mineral. The precision of this measurement is only about $\pm 5 \%$; so the value chosen for this important parameter is: Gerstley Borate contains 7.6\% natural boron.

Bags of the unrefined material showed a wide range of particle size. The distribution by size was measured using a standard set of mesh sieves. Four samples were selected from random bags and passed through successively smaller sieves. All material passed through the sieve with $6.68 \mathrm{~mm}$ holes. Various amounts remained, for each of the four samples, after passing through six other sieves of progressively smaller size. The smallest had $0.147 \mathrm{~mm}$ holes; and further segregation was not attempted. Table XIII shows that the commercial product contained a fairly uniform distribution from larger chunks down to fine sand. The uncertainty for each size group reflects the variation over the four samples. The boron content was determined for each of the six particle size groupings and are reported in the same table. The range was only $6.6 \%$ to $8.0 \%$ $\mathrm{B}$; and the grand weighted average over all available samples was the $7.55 \%$ reported above.

The boron content was so constant over six sizes and the distribution of material was so uniform over these same bins that adjacent pairs were blended for further analyses. The resulting bins may reasonably be labeled "sand", "granules", and "chunks". 
These three bins were analyzed for metallic impurities and moisture content. These results are also contained in Table XIII. The weighted average for calcium across the three bins suggests that Gerstley Borate contains $14.9 \%$ calcium. A similar consideration for sodium and silicon suggests $3.9 \%$ and 3.0\%, respectively. These data, combined with simple assumptions, can be used to estimate the relative abundance of Colemanite, Ulexite, and sand in the Gerstley Borate.

Sand: Assuming all silicon comes from sand (silicon does not appear in either Colemanite or Ulexite), the amount of sand in Gerstley Borate could be reasoned as follows: (fraction of silicon in sand) $x$ (fraction of sand in borate) equals (fraction of sand observed).

$$
46.7 \% \times \text { (fraction of sand in borate) }=3 \% \text {. }
$$

This model suggests $6.4 \%$ of the borate is sand.

Sodium: That element is found only in Ulexite. The amount of Ulexite in Gerstley Borate could be reasoned as follows: (fraction of sodium in Ulexite) $\mathrm{x}$ (fraction of Ulexite in borate) equals (fraction of sodium observed).

$$
6.6 \% \times \text { (fraction of Ulexite in borate) }=3.9 \% \text {. }
$$

This model suggests $59 \%$ of the borate is Ulexite.

Calcium: Calcium appears in both minerals but not in sand. The amount of Colmanite in Gerstley Borate could be reasoned as follows: (fraction of calcium in Ulexite) $x$ (fraction of Ulexite in borate) + (fraction of calcium in Colmanite) $x$ (fraction of Colmanite in borate) $=$ (fraction of calcium observed). 


$$
11.4 \% \times 59 \%+19.5 \% \times \text { (fraction of Colmanite in borate) }=14.9 \% \text {. }
$$

This model suggests $42 \%$ of the borate is Colmanite.

This simplistic model exhibits some flaws. On the one hand, the amount of calcium calculated by difference from $100 \%$ should compose $34.6 \%$ of the unrefined product. This is in fair agreement with the $42 \%$ just calculated. The model breaks down badly when extended to boron. If Gerstley Borate were composed of $59 \%$ Ulexite containing $15.4 \%$ boron and $34.6 \%$ Colemanite containing $15.8 \%$ boron and $6.4 \%$ sand containing no boron, then the boron content of this simple mixture should be $14.6 \%$ :

$$
[15.4 \% \times 59 \%+15.8 \% \times 34.6 \%+0.0=14.6 \%] .
$$

The measured boron content, however, of the Gerstley Borate is about one-half that value (7.6\%). The two minerals appear to be diluted by $48 \%$ sand, obtained by equating boron contents:

$$
7.6 \% \text { (boron minerals }+ \text { sand })=14.6 \% \text { (boron minerals })
$$

This simple assumption must be wrong; $48 \%$ is a lot different than $6.6 \%$. This incomplete characterization of Gerstley Borate is probably not a great detriment to criticality calculations based on this program. The most important element, boron, has been well established at $7.6 \%$ by weight. Other major components such as calcium, sodium, impurity metals, and oxygen have been coarsely, but adequately, identified. These major elements are relatively unimportant in neutronic calculations. Hydrogen is a fairly small component of both 
minerals as water of hydration even though it is an efficient moderator. The tables also report absorbed water which would, in turn, contribute hydrogen to the finished plug.

The plaster plugs containing $1.1 \%$ B were made on May 7,1980 , the same month as the concrete plugs. Hydrostone Super X Plaster, Gerstley Borate, and ordinary tap water were added in incremental batches during mixing until a sufficient quantity of wet mix was prepared. Mixing was accomplished using a hand-held electric motor which drove a long shaft fitted with a propeller at its bottom. Mixing was done in a 55-gallon drum previously modified with a largediameter drain valve in the center of the bottom. Wet mix could later be drained into the form through this valve. This operation was carried out on a platform lifted above the paper form by a fork lift truck. After mixing, the valve was opened allowing mix the consistency of very heavy cream to flow into the form.

The $22 \times 8$ plaster plug contained 13.25 bags of plaster $(602 \mathrm{~kg})$ added in 8 increments. To this, $121 \mathrm{~kg}$ of Gerstley Borate and $161 \mathrm{~kg}$ of water were added over the same 8 increments. This composition suggests that the wet mix contained $1.0 \% \mathrm{~B}$; but this was expected to change some as the plaster set. The literature states that plaster sets to about 18.34 parts of water for ever 100 parts of plaster; so the finished plug was expected to contain: 
Plaster

Gerstley Borate (7.6\% boron)

Water - after setting!

Total set weight expected
$602 \mathrm{~kg}$

$121 \mathrm{~kg}$

$110 \mathrm{~kg}$

$833 \mathrm{~kg}$

The boron content of this plug would be $1.1 \% \mathrm{~B}$; and this is the value adopted for this parameter. The hydrogen content would be $1.5 \%$.

This plaster plug contained $18.82 \mathrm{~kg}$ of paper as inner and outer forms and $14.75 \mathrm{~kg}$ of steel in the form of a bottom lifting plate, two rods and the lifting anchors. Adding this weight to the anticipated weight of the set plaster $(833 \mathrm{~kg})$ implies that the finished plug was expected to weigh $866.6 \mathrm{~kg}$. It was observed to weigh $882.8 \mathrm{~kg}$ the day before its use. This small difference (16.2 kg) may be assumed to be water trapped in the plaster matrix. This assumption does not affect the boron content much; but it does affect the assumed hydrogen content. If the assumption were correct, the hydrogen content of this plug would be $1.6 \%$.

The second plaster plug (22x16) contained $311.4 \mathrm{~kg}$ of plaster added in 5 increments. To this, $62.4 \mathrm{~kg}$ of Gerstley Borate and $85.4 \mathrm{~kg}$ of water were added over the same increments. This wet second wet mix also contained $1.0 \% \mathrm{~B}$ but was expected to change some as the plaster set. The finished plug was expected to contain:

Plaster

Gerstley Borate (7.6\% boron)

Water - after setting!

Total set weight expected
$311.4 \mathrm{~kg}$

$62.4 \mathrm{~kg}$

$57.1 \mathrm{~kg}$

$430.9 \mathrm{~kg}$. 
The boron content of this plug would also be $1.1 \% \mathrm{~B}$; so both plaster plugs possessed the same boron concentration: $1.1 \% \mathrm{~B}$.

This plug contained $23.59 \mathrm{~kg}$ of paper as inner and outer forms and $9.47 \mathrm{~kg}$ of steel. Adding this weight to the anticipated weight of the set plaster $(430.9 \mathrm{~kg})$ implies that the finished plug was expected to weigh $464.0 \mathrm{~kg}$. It was observed to weigh $468.4 \mathrm{~kg}$ the day before its use. This very small difference $(4.4 \mathrm{~kg})$ may, again, be assumed to be water trapped in the plaster matrix. This assumption does not affect the boron content much; but it does affect the assumed hydrogen content. If the assumption were correct, the hydrogen content of this plug would be $1.5 \%$.

One laboratory analysis of one piece of set plaster produced a boron content of $1.2 \pm$ $0.06 \%$, in good agreement with the above value. The later is recommended because it reflects measurements made over the entire process of making the cylinders, not one sample from one part of one plug.

The elemental composition of plaster plugs is presented in the left column of Table XIV. The upper portion describes the raw gypsum product itself (no borate or water); the lower represents the finished plaster plugs. Unlike concrete, these are much more complete analyses; still, columns do not add up to $100 \%$ (not balanced). This simply reflects the results of 
Table XIV. Elemental Composition in Weight Percent of Plaster Components for the First Program.

\begin{tabular}{|c|c|c|c|}
\hline & $\begin{array}{l}\text { Element } \\
\text { or } \\
\text { Jompound }\end{array}$ & Plugs & Slabs \\
\hline & Al & 0.06 & 0.06 \\
\hline & $\mathrm{C}$ & 0.55 & 0.54 \\
\hline $\bar{\Phi}$ & $\mathrm{Ca}$ & $28.04 \pm 0.1$ & $28.21 \pm 0.1$ \\
\hline 늘 & $\mathrm{Fe}$ & 0.016 & 0.025 \\
\hline$\frac{1}{3}$ & $\mathrm{~K}$ & 0.07 & 0.07 \\
\hline $\overrightarrow{\bar{E}}$ & $\mathrm{Mg}$ & 0.17 & 0.17 \\
\hline 产 & $\mathrm{Na}$ & 0.07 & 0.07 \\
\hline$\frac{\bar{g}}{\mathbb{\Phi}}$ & $\mathrm{SO}_{4}^{--}$ & $62.25 \pm 0.1^{c}$ & $61.84 \pm 0.1$ \\
\hline$\frac{a}{3}$ & $\mathrm{Si}$ & 0.52 & 0.54 \\
\hline ⿷匚ّ & $\mathrm{Sr}$ & 0.03 & 0.05 \\
\hline & Moisture $^{b}$ & 6.7 & 6.8 \\
\hline & Total & 98.476 & 98.375 \\
\hline & $\overline{\mathrm{Al}}$ & 0.12 & 0.21 \\
\hline & B & 0.9 & 1.2 \\
\hline$\frac{\mathbf{m}}{\mathbf{n}}$ & C & 0.629 & 1.1 \\
\hline$\frac{\frac{m}{0}}{0}$ & $\mathrm{Fe}$ & 0.035 & 0.035 \\
\hline $\mathbf{g}$ & $\mathrm{K}$ & 0.36 & 0.08 \\
\hline 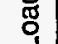 & $\mathrm{Mg}$ & 0.42 & 0.75 \\
\hline $\overrightarrow{\underline{c}}$ & $\mathrm{Ca}$ & $27.47 \pm 0.1$ & $28.86 \pm 0.1$ \\
\hline 高 & $\mathrm{Na}$ & 0.44 & 0.40 \\
\hline$\vec{\Phi}$ & $\mathrm{SO}_{4}^{--}$ & $30.09 \pm 0.1^{\circ}$ & $54.51 \pm 0.1$ \\
\hline & $\mathrm{Si}$ & 0.59 & 0.92 \\
\hline & $\mathrm{Sr}$ & 0.06 & 0.19 \\
\hline & Moisture & 18.3/2.3 & Not reported \\
\hline & Total & 81.714 & $88.255+$ water \\
\hline
\end{tabular}

a. Relative error about $\pm 5 \%$ unless specified except for low-level impurities determined by emission spectroscopy to about $\pm 50 \%$ (smaller light-face font).

b. Absorbed moisture in raw plaster.

c. Gravimetric result. Also measured by turbidimetric method: $72.6 \pm 0.5 \%$

d. Absorbed/hydrated moisture in set plaster.

e. Large difference between two otherwise similar set plaster components not understood. 
independent measurements made on separate materials. Possibly, the weights of the oxide of the metallic impurities should have been used to bring the sum closer to $100 \%$. The relative error expected for most results are about $\pm 5 \%$; entries in light-face font are less precise $\biguplus 50 \%)$. The lower portion also sums to much less than $100 \%$. Results for the sulphate radical are questionable because a similar analysis of an otherwise similar casting yielded vastly different results. That measurement in this case is probably low. The recommended method of calculating elemental compositions of finished plaster components used in this program is to assume the compositions of individual ingredients in Tables XIII and XIV and then to proportion these according to the percentage of that material in the final product.

\section{External Moderation and Absorption - first program}

Whenever the nested tanks were configured in an array, neutron interactions between them were just as important as when neutrons moved across a chord of one tank. These neutrons should be moderated and absorbed in a similar fashion. Slabs of boron-loaded plaster were inserted between tanks for this purpose.

Only four slabs were made and all were plaster containing the same combination of ingredients as the plaster plugs. Therefore, these plaster slabs also contained $1.1 \%$ natural boron. Two thicknesses were cast on December 9, 1980, several months after the plugs were made. Two were $51 \mathrm{~mm}$ thick and two were $19 \mathrm{~mm}$. 
All four were cast inside wooden forms; and the wood was left in place during use for safety. Each slab was laminated between two sheets of 13-mm-thick plywood measuring $1.17 \mathrm{~m}$. wide by $2.44 \mathrm{~m}$ high and framed around its perimeter with construction-grade lumber. Thicker slabs were framed with $38 \mathrm{~mm}$ by $51 \mathrm{~mm}$ wood, thinner ones, $38 \mathrm{~mm}$ by $19 \mathrm{~mm}$. A final framing cross member near the bottom formed a plaster-free region $305 \mathrm{~mm}$ above the floor. Figure 25 illustrates this framing. In summary, this construction formed 1.1\% B plaster släbs either 19 or $51 \mathrm{~mm}$ thick that were $1.09 \mathrm{~m}$ wide by $2.10 \mathrm{~m}$ tall. The plaster slab, itself extended from 305 $\mathrm{mm}$ to $2.40 \mathrm{~m}$ above the floor.

Slabs were cast flat; and flat surfaces the desired thickness were assured by drawing a metal straight edge across the slightly over-filled form before nailing the last sheet of plywood. Weights were measured a month later. Thick slabs weighed 276 and $266 \mathrm{~kg}$, and thin ones, 122 and $117 \mathrm{~kg}$. A week later, both thin slabs were weighed again and showed no change. Even though slight differences in weight existed, no distinction was made as to which thin slab or which thick slab was placed where in an experiment.

Table XIV also presents the elemental composition of these slabs. The upper portion of this table represents raw plaster and the lower, the set slab. The sum of the individual elements adds to less than $100 \%$; and this simply reflects the results of independent measurements made on separate materials. Again, using weights of oxides would bring the sum closer to $100 \%$. The 


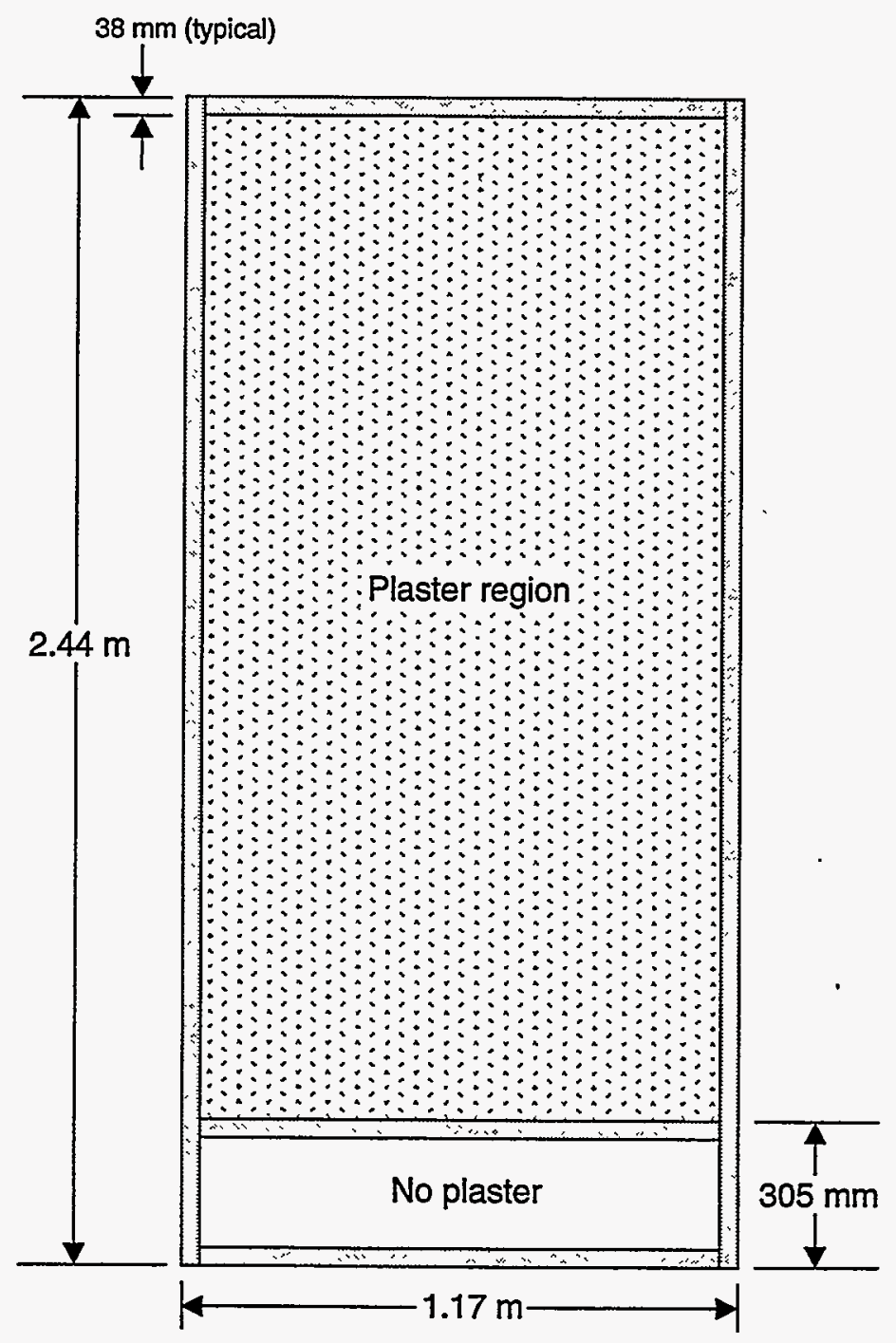

Figure 25. Cross section of the plaster slabs used between tanks in the Nested Tank study. 
expected water content (a little over 18\%) brings the total to over $100 \%$; so the sulphate content may be a little high. The relative error expected for most of the results are about $\pm 5 \%$. Entries in light-face font are less precise $\biguplus 50 \%)$.

Internal and External Moderation and Absorption - second program

The second program dealt with neutrons differently than the first. Components interior and exterior to the tank were geometrically similar to one another (concentric cylinders) rather than being a mix of cylindrical and slab geometries. Moderating and absorbing materials were distinct from one another unlike the first program. Moderator and absorber materials are discussed separately.

\section{Moderator}

Neutron moderation was accomplished by thick cylinders of high-density polyethylene plastic. The specific material was never analyzed for chemical composition at Rocky Flats because the experimental program ended before completion of the planned study. Consequently, nominal composition and design dimensions will have to be used.

The chemical formula for polyethylene is $\mathrm{CH}_{2}$. The density was not measured; but its textbook value is $0.95 \mathrm{mg} / \mathrm{mm}^{3}$. For their particular resin, the manufacturer claims a density of $0.944 \mathrm{mg} / \mathrm{mm}^{3}$. Finished cylinders were black in color, the result of adding $2.5 \%$ carbon black to 
the base resin. The manufacturer claims there are $8.612 \times 10^{22}$ atoms of hydrogen per gram of plastic.

Both cylinders were machined to $76.2 \mathrm{~mm}$ radial thickness. The outside diameter of the outer piece was $1.70 \mathrm{~m}$. This surface was the only one not machined; it was smooth enough at manufacture and suitably constant in diameter as to be adequate as wound. Also, it was far enough from the fissile solution that small irregularities would be unimportant. The inside diameter was bored to $1.549 \mathrm{~m}$ diameter $^{29}$. The outside diameter of the inner cylinder was machined to $1.255 \mathrm{~m}$. This surface was considered not sufficiently uniform to bypass machining because it was so close to the fissile solution. The inside diameter of this piece was bored to $1.102 \mathrm{~m}$. This surface might have been left unmachined; but it wasn't.

Each tall cylinder was cut in two. The top half was $1.016 \mathrm{~m}$ tall both inside and out. Both ends of both pieces received face cuts to ensure a good fit and obtain a well-defined geometry. No other lathe operations were necessary for these upper sections. The lower halves were a little more complicated. The outer was $1.029 \mathrm{~m}$ tall; but the inner cylinder stood only $1.016 \mathrm{~m}$. The difference $(13 \mathrm{~mm})$ compensated for the $13-\mathrm{mm}$-thick stainless steel bottom of the inner tank. This design located the joint between top and bottom halves of both inner and outer

${ }^{29}$ The additional significant figure in this diameter reflects the better precision obtained by a machining operation. 
moderator cylinders at the same elevation. Bottom surfaces were the only ones not co-planar with one another; the outer cylinder extended $13 \mathrm{~mm}$ lower than the inner. At this point, four plastic pieces existed.

All four were sectioned vertically to allow a close fitting assembly. Without this, cylinders would not slip over tank flanges. These vertical cuts allowed sections to be moved horizontally under flanges to their final position close to the tank. Once in place, the original cylindrical geometry was restored. On the interior, these cuts were "healed" by welding the plastic back together, as illustrated in Fig. 26. The outer halves were banded together by two plastic strips similar to that often used in packaging. Exact detail of these last machining cuts is neither recalled nor important; the geometry existing during an experiment was simply concentric . cylinders.

One additional lathe operation was needed on both inner and outer upper and lower moderators. A notch was machined to clear the tank's center assembly flange and fastening nuts and bolts. Details of this notch show clearly in Fig. 27. The combined notch was $73 \mathrm{~mm}$ tall by $44 \mathrm{~mm}$ radially.

The inner plastic rested on the bottom of the inner tank. The outer moderator cylinder, however, rested on a stainless steel lifting ring. This was the same thickness $(13 \mathrm{~mm})$ as the 


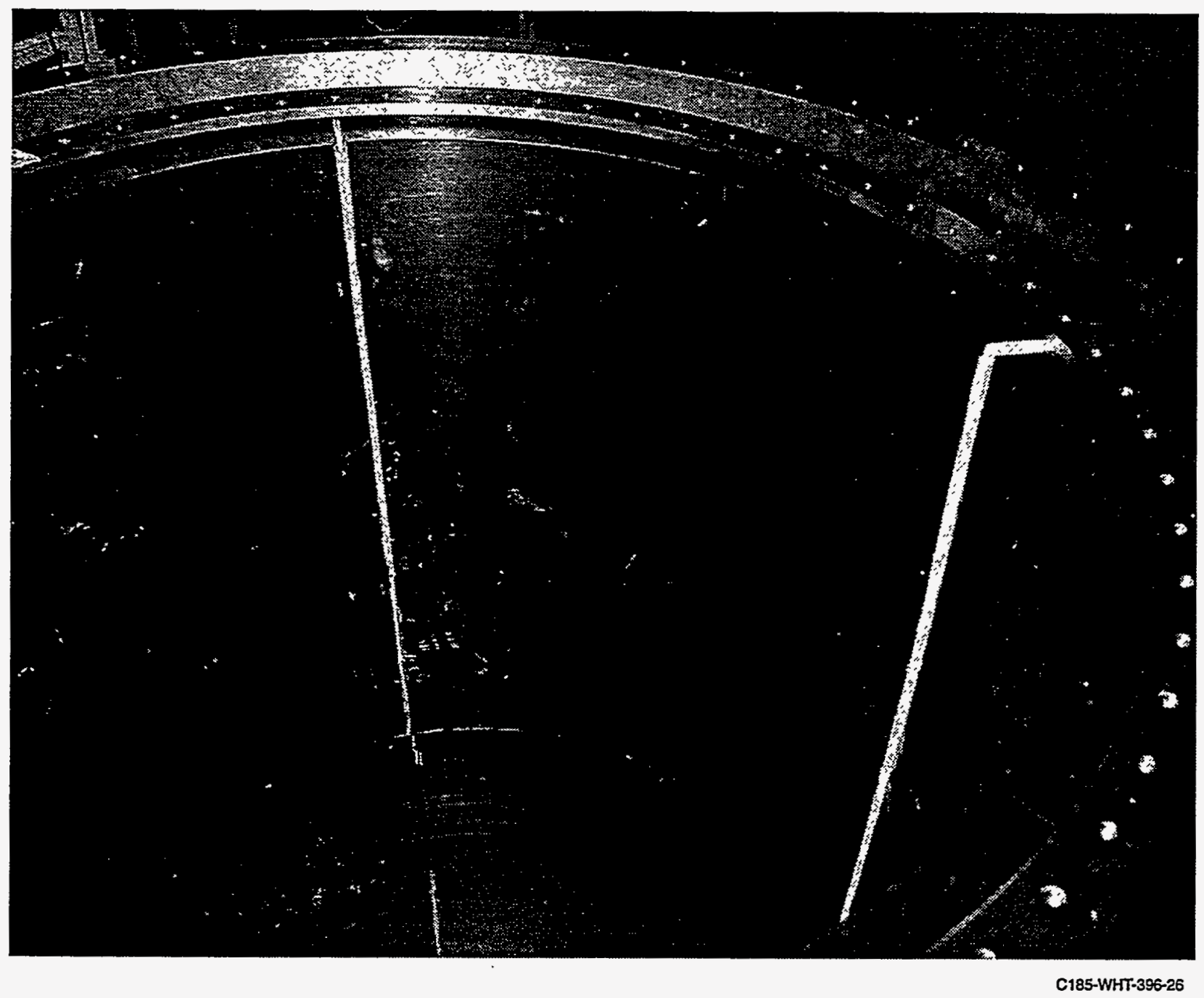

Figure 26. Plastic moderating cylinders were cut apart to allow assembly but then welded back together for strength.

RFP photo \# 35865-14 [1/12/87]. 


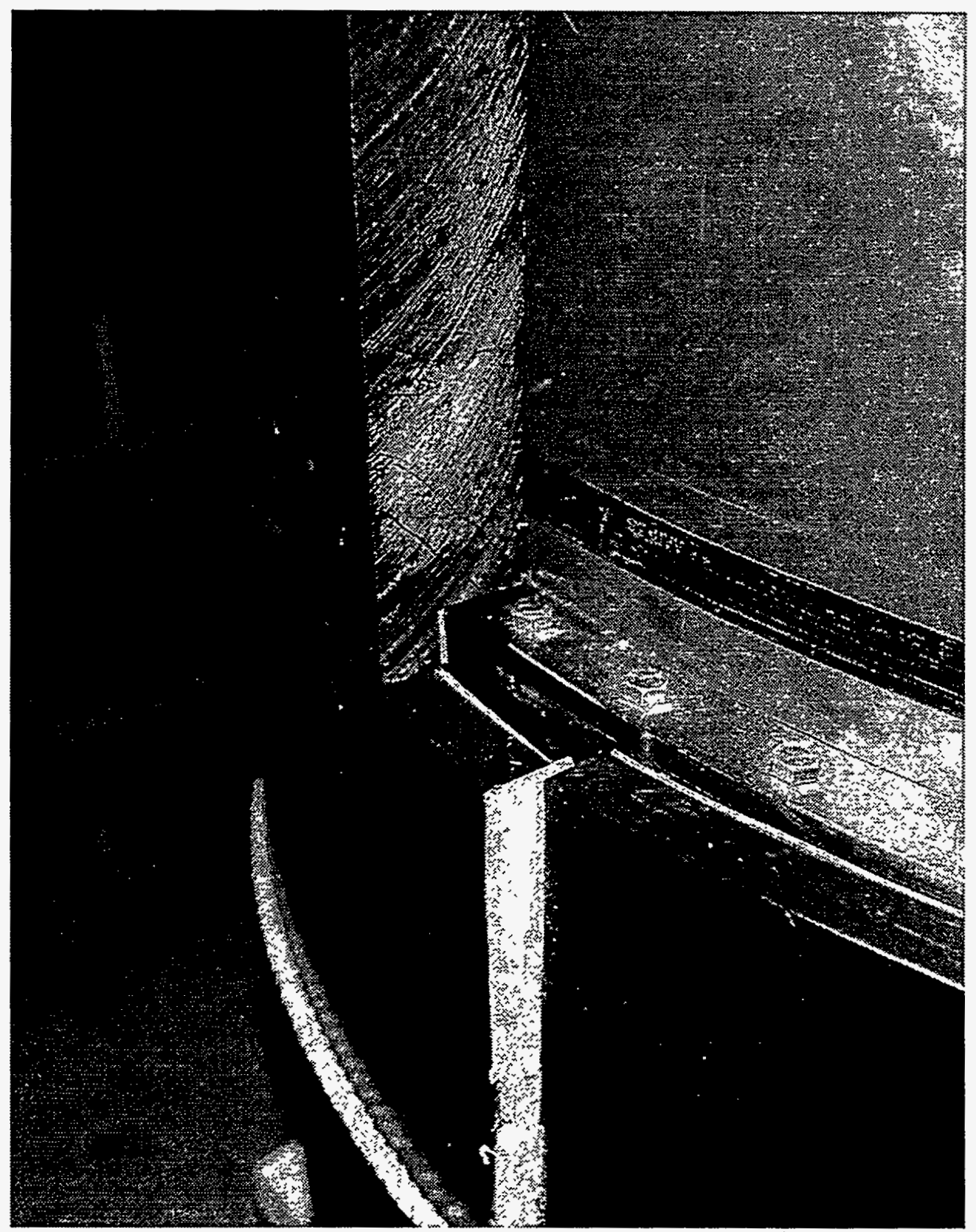

C185-WHT-396-27

Figure 27. Moderator cylinders were notched to fit around tank flanges. RFP photo \# 35866 [1/12/87]. 
bottom of the outer tank. Thus, the bottom surface of the outer moderator was co-planar with the bottom of the fissile solution region. This lifting ring was $1.70 \mathrm{~m}$ outside diameter and $1.55 \mathrm{~m}$ inside.

The overall height of the assembled cylindrical moderator allowed a clearance of $16 \mathrm{~mm}$ below the uppermost flange of the tank. This space provided clearance for nuts and bolts used to hold the lifting cross in place. A cross section drawing of the annular tank and the plastic moderator is presented in Fig. 28. No absorber is shown in this figure for clarity.

\section{Absorber}

Neutron absorbing material was commercial sheet rubber stock called Rad-Stop ${ }^{30}$. This was laminated to surfaces such that neutrons slowed down by the moderator would be absorbed by the rubber. The moderator thickness was selected such that fast fission neutrons formed near the surface of the liquid would be absorbed by the rubber on the far side of the moderator. Neutrons formed deeper in the solution would be thermalized by the solution itself; so another layer of rubber between tank and plastic absorbed these. The result was "sandwiches" of thick plastic laminated on both sides with thin layers of rubber. These sandwiches existed both inside and outside the annular tank.

\footnotetext{
${ }^{30}$ Rad-Stop is a registered trademark of Bisco Products, Inc. of Elk Grove Village, Illinois.
} 


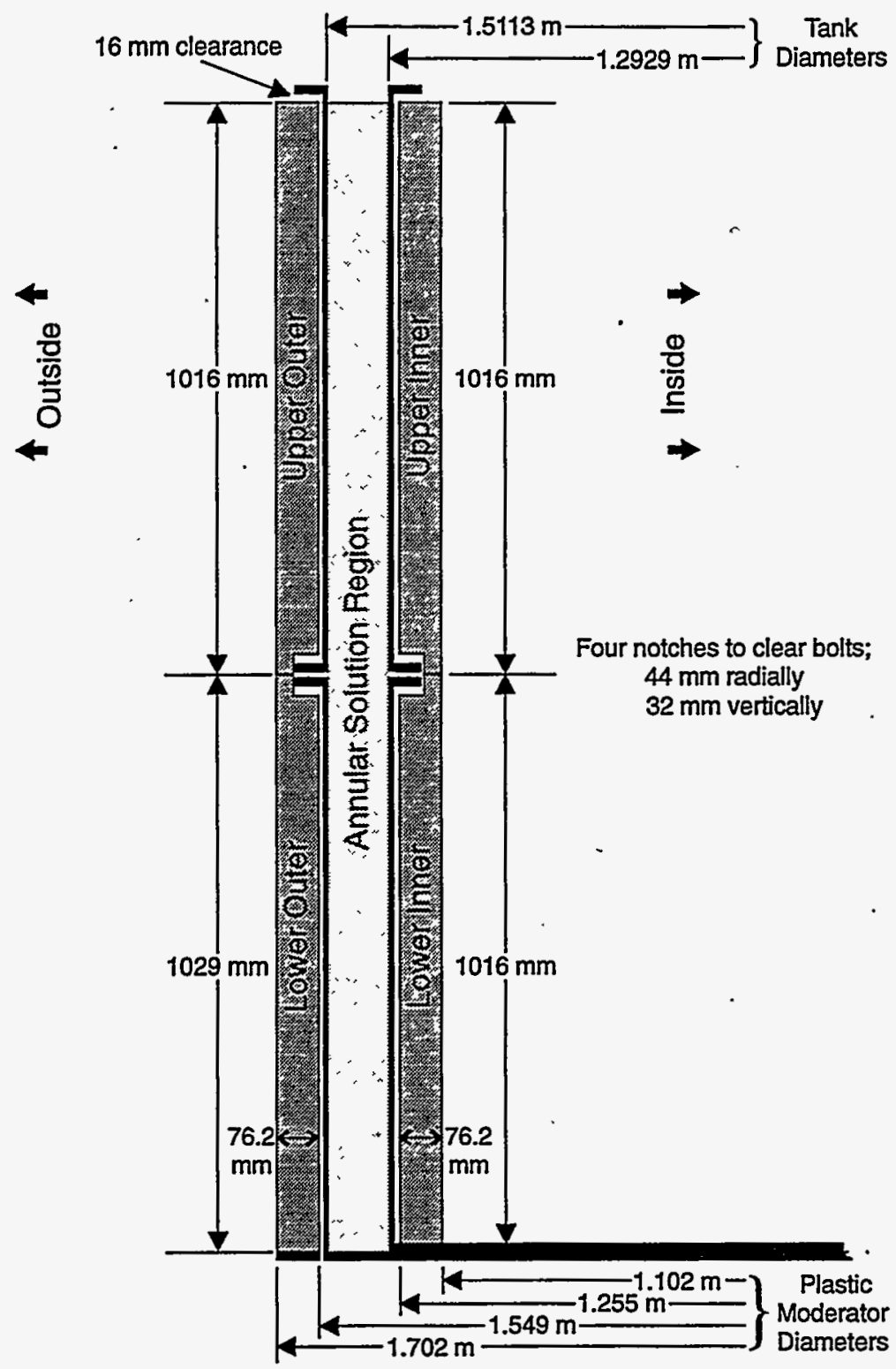

Figure 28. Cross section of the annular tank for the second program showing the polyethylene moderator but not the absorber. 
The manufacturer's Certification of Compliance states that Rad-Stop contains at least 0.6 $\mathrm{mg}$ of natural boron per $\mathrm{mm}^{3}$. The product was a mixture of $50 \%$ boron carbide $\left(\mathrm{B}_{4} \mathrm{C}\right)$ and $50 \%$ silicone rubber. It was never analyzed at Rocky Flats; and the company declined to divulge its elemental composition for proprietary reasons. The suggested composition to assume for calculational purposes is the above distribution of boron carbide and silicone rubber with a density certified at $1.62 \pm 0.01 \mathrm{mg} / \mathrm{mm}^{3}$.

Rad-Stop was delivered in three rolls by manufactured batch. All rolls were $610 \mathrm{~mm}$ wide; but the three came in different lengths: $25 \mathrm{~m}, 57 \mathrm{~m}$, and $38 \mathrm{~m}$. No effort was made to record which material was used where in the experiment. No evidence suggested one batch differed from another in composition.

The sheet rubber was always "wallpapered" onto the convex surface closest to the ideal surface. It was not always attached directly to the polyethylene. This was done for safety and convenience.

One layer was wrapped around the outside of the outer tank. This was banded in place as seen in Fig. 27. Two bands were used per tank section. Banding prevented the rubber from peeling away during an experiment which could have caused an unplanned and significant increase in reactivity. The layer outside the outer moderator was simply stapled to the plastic. 
Commercial steel carpenter's staples were used about every one-tenth meter both vertically and azimuthally. The next layer was between the annular tank and the inner moderator. This rubber was cut to the profile of the surface of each section of the ultimate cylinder and stapled in place to it. Later, upon final assembly, that surface was completely covered with absorber. The last lamination was the innermost one. Rather than staple it to the concave surface of the inner polyethylene, it was wrapped around a paper Sonotube similar to those used in the first program. The diameter of this tube was neither recorded nor recalled. They come in discrete sizes; and photographs and the documented space between it and a nearby component on one experiment suggests either a 0.76 or a 0.81 -m-inside diameter Sonotube may have been used. The former is more likely because purchase of the latter is not recalled.

The height of this Sonotube also must be inferred from photographs. It would appear to be $2.04 \mathrm{~m}$ tall. The wall thickness of the suspected tube probably is $7.6 \mathrm{~mm}$. Rad-Stop was wrapped onto this tube and, then, overwrapped with sheet vinyl $(0.18 \mathrm{~mm}$ thick) to hold it safely in place. Whether or not the rubber was also glued to the Sonotube is not recalled. This poorly documented component is illustrated in Fig. 29. 


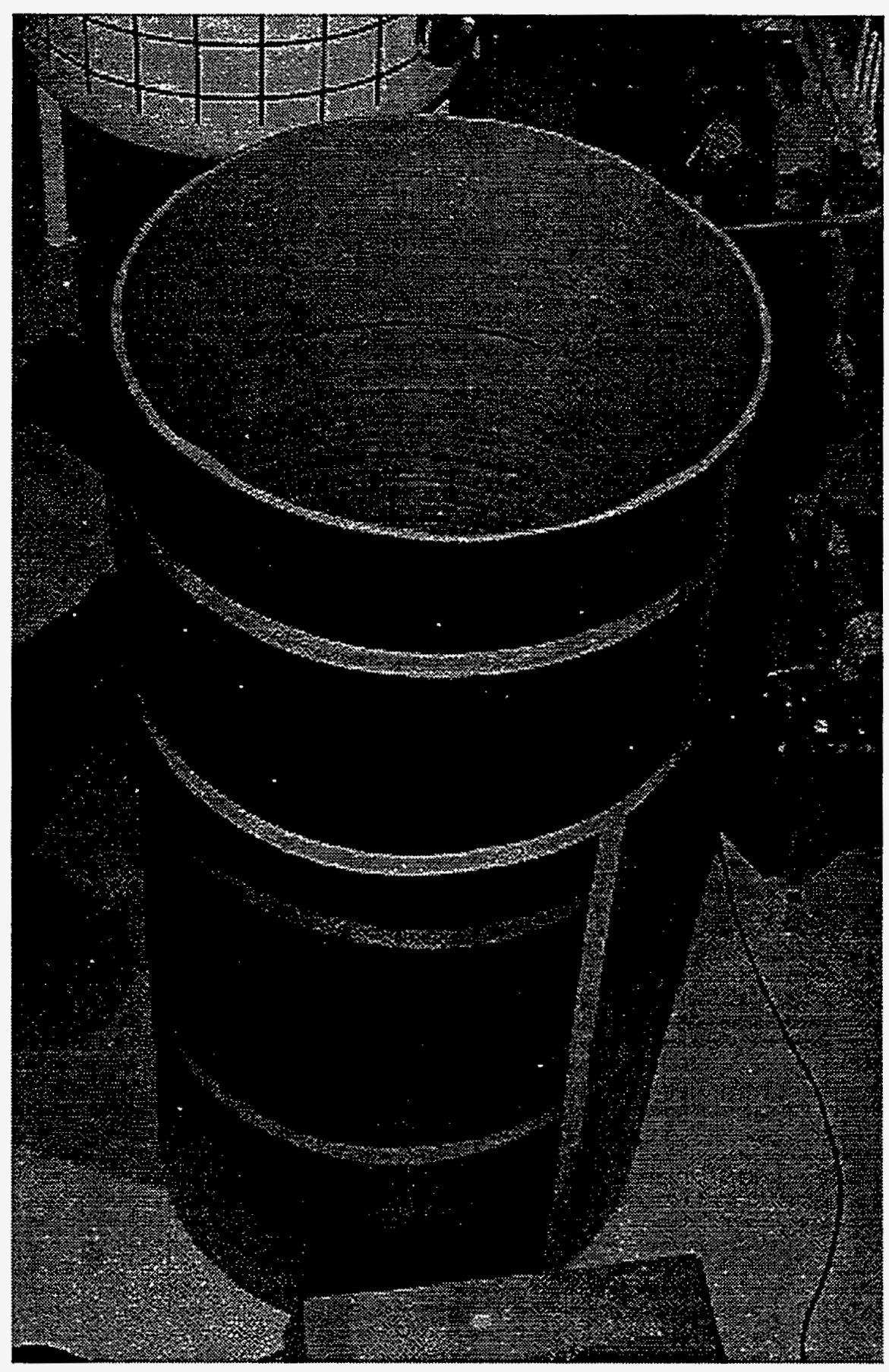

C185-WHT-396-29

Figure 29. The innermost absorber was wrapped onto a paper tube. RFP photo \# 35865-16 [1\12187]. 


\section{CONCRETE REFLECTOR PANELS}

Only experiments of the first program had panels of concrete deliberately placed around the sides of tanks to return neutrons. These simulated walls encountered in any plant and are intended to facilitate criticality safety evaluations of common applications. No top reflection other than normal room return existed. The bottom was reflected by the floor, described in the next section. The flat absorber/moderator slabs were not considered thick enough to constitute anywhere near full reflection.

Seven moveable wall sections were made by pouring wet concrete into wooden forms. This was done April 8, 1980. Later, the wood was removed and discarded leaving the desired concrete reflector panels. All seven were cast $2.44 \mathrm{~m}$ tall by $203 \mathrm{~mm}$ thick. Four were $1.22 \mathrm{~m}$ wide; the other three were $0.91 \mathrm{~m}, 0.61 \mathrm{~m}$, and $0.30 \mathrm{~m}$.

Panels were cast with the forms standing on edge. This accomplished two goals. Workers had less surface to "finish"; and the wall thickness could be more carefully controlled. This important dimension was carefully measured before the pour; and forms were heavily braced to preserve $\mathrm{it}^{31}$. Wire form ties also helped hold this dimension. Form ties weighed about

${ }^{31}$ Note the additional significant figure given for the wall thickness. 
$45 \mathrm{~g}$ each; but about $3 \mathrm{~g}$ were clipped away and discarded with the form material. The four widest panels employed 14 form ties each, the other three, 14, 11, and 3 .

Each panel was strengthened for handling safety by embedded lengths of rebar. Panels would be moved about frequently. All rebar was the typical ribbed steel commercial product in the $13 \mathrm{~mm}$ size. A crossed pattern of vertical and horizontal lengths of rebar was located in the mid-plane of each panel. These were spaced about uniformly in both directions and inset from the edges about the same distance. Vertical pieces were $2.4 \mathrm{~m}$ long. The four wider walls contained 4 of these. The other three panels contained 3, 3, and 2, respectively. All wall sections contained 10 horizontal rebars of lengths appropriate to the wall's width: $1.14 \mathrm{~m}, 0.84$ $\mathrm{m}, 0.54 \mathrm{~m}$, and $0.24 \mathrm{~m}$.

Wherever two rebars crossed, they were tied together by twisting $0.5-\mathrm{m}$-long lengths of 2.4-mm-diameter iron wire. These weighed $13 \mathrm{~g}$ each. Three commercial anchor inserts were cast into the top of each wall along its mid-plane. Two of these were of an uncommon kind (a wound spiral requiring a special thread on the lifting eyebolt) and would be used for actual movement of the walls. They weighed $278 \mathrm{~g}$ each. The third anchor insert was centered in the top surface and would be used for stabilizing the wall sections during experiments. These weighed $123 \mathrm{~g}$ each. 
Summarizing the steel embedded into each of the seven panels, the four widest wall sections contained $21.9 \mathrm{~kg}$ of steel. The next widest reflector contained $16.8 \mathrm{~kg}$, the next, $13.9 \mathrm{~kg}$, and the narrowest, $7.5 \mathrm{~kg}$. All this steel was confined to about the mid-plane of each panel.

The truckload of concrete used to make these panels contained:

$\begin{array}{lc}\text { Portland Type II Cement } & 1412 \mathrm{~kg} \\ \text { Moist Sand } & 3416 \mathrm{~kg} \\ \text { Moist Rock (20 mm average size) } & 4666 \mathrm{~kg} \\ \text { Tap Water at plant } & 607 \mathrm{~kg}\end{array}$

The water-reducing agent, Pozzalith, was probably added to the load; but this fact was not recorded. A simple test was done to determine the moisture content of the sand and the aggregate. Samples of the plant's raw sand and rock were taken the day of the casting. They were weighed "moist" and then dried for several hours at an elevated temperature. Sand lost $2.3 \%$ in weight and rock lost $0.9 \%$; this weight loss was presumed to be water.

A later analysis by the Rocky Flats Analytical Laboratory on the set concrete showed that it contained $1.7 \%$ absorbed water, in reasonable agreement with the simple tests. Set concrete, however, contains water other than just absorbed water. The chemical process binds water of hydration in the complex substance called concrete. This water can be measured by thermogravimetric analysis; and that test revealed water losses of $0.9 \%$ in the temperature range 110 to $300^{\circ} \mathrm{C}$ and another $6.9 \%$ up to $1000^{\circ} \mathrm{C}$. 
A complete and balanced chemical composition was not obtained for this concrete. Rather, the composition may be assumed to be that of any "ordinary" concrete. A few chemical analyses were performed on the ingredients and on the set concrete; but not enough to describe the concrete fully. For example, sand and aggregate were found to contain $74.1 \pm 0.5 \%$ and 88.7 $\pm 0.7 \% \mathrm{SiO}_{2}$, respectively; and carbon was present at $0.040 \%$ and $0.078 \%$. Metallic impurities reported for the plugs may. be assumed for these reflector panels as well. Results for the set concrete found $63 \% \mathrm{SiO}_{2}, 1 \% \mathrm{C}$, and $0.1 \% \mathrm{~S}$. The finished wall panels had a density of 1.85 $\mathrm{mg} / \mathrm{mm}^{3}$.

The three narrower wall sections were weighed when just cast and then, again, two months later. The first was obtained by weighing the freshly-set concrete in the forms and subtracting the weight of discarded form materials. The three weighed 1060, 704, and $346 \mathrm{~kg}$ as cast. Two months later, they weighed 1059,706 , and $345 \mathrm{~kg}$. This data is of questionable value in evaluating water loss during setting because the length of time between pouring and the first weight measurement was not recorded. The anomalous weight gain by the middle panel is attributed to an error in weighing form and scrap material. In all cases, the later weights are assumed more accurate.

The water content of concrete is a very important parameter because hydrogen is such a good moderator. One characteristic of concrete is that its water content is known to change for a 
long time (even years!) as the setting process continues. Although the initial composition of ingredients allows a reasonable estimate of the initial water content, a better measure of that important parameter would be possible if the detailed history of water loss were known. This is believed possible by recording weight loss with time.

Because of its importance, the intent of this program was to determine water content as a function of time. Water in the wet mix was always measured. Then, the weight of the cast piece was measured as soon after pouring as possible. Subtracting the weight of the form material and rubble would give the fractional weight of water in the just-poured concrete. The assumption was that little water escaped in those hours. Any time later that the piece was weighed, a decreased weight would be attributed to the loss of water during setting.

Data recorded for this program did not always provide sufficient detail for this refined evaluation of water content. In 1978, a study of this property of concrete was conducted at Rocky Flats ${ }^{32}$ as part of another study. One figure from the report of that study is repeated here as Fig. 30. Where presented data is inadequate, this curve may be used to approximate the water content of concrete at any time after being poured. This holds for the reflector panels, the plugs (last section), and the floor (next section).

${ }^{32}$ Robert E. Rothe and Inki Oh, "Benchmark Critical Experiments", Nuclear Technology, vol 41, Dec. 1978. 


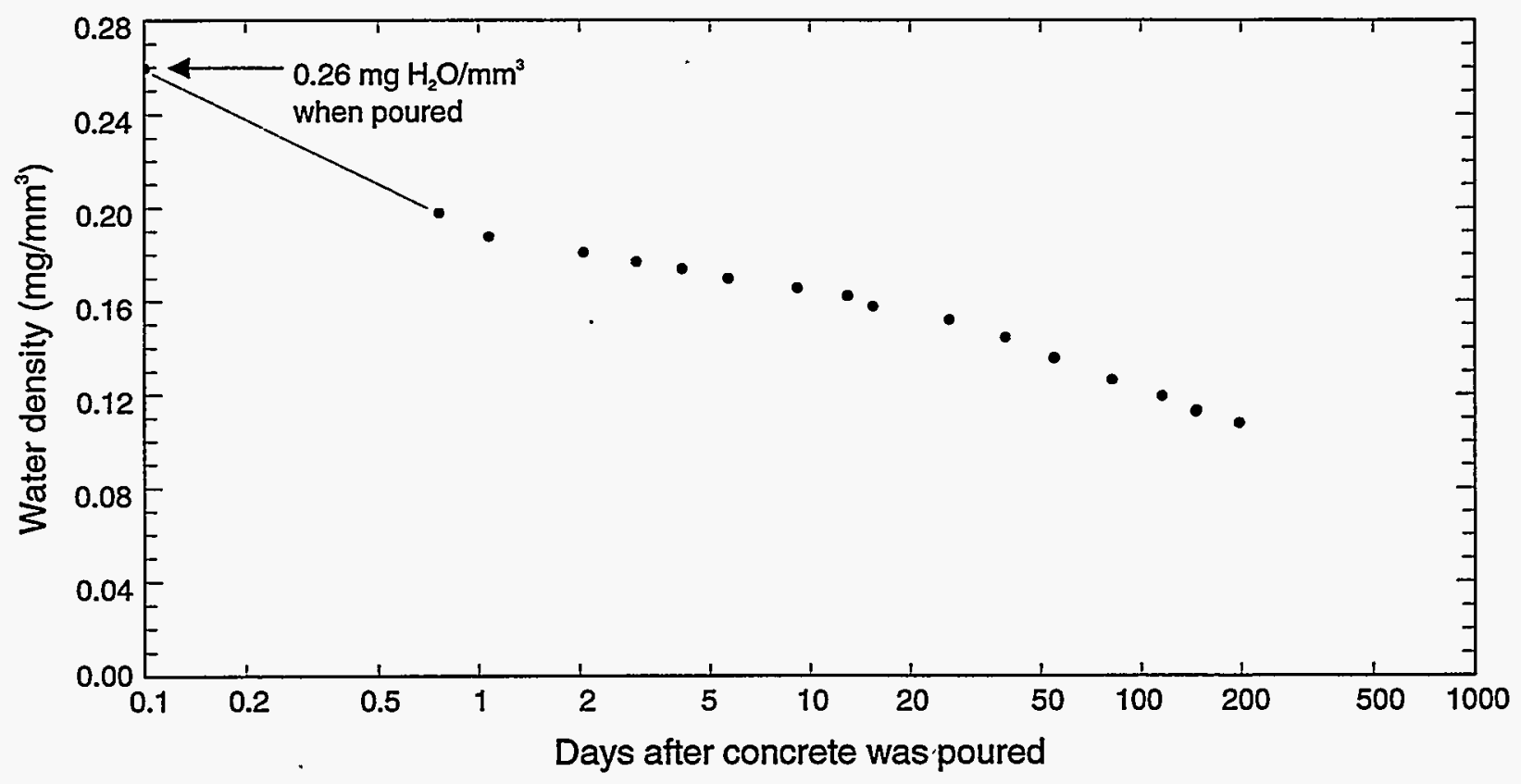

Figure 30. Concrete loses water for a long time after being mixed. Water content of a test concrete block over several months is shown. 
During experiments, reflector panels rested on the floor; but this surrounded the tanks being studied with concrete. Solution lines, needed to carry the fissile liquid into these tanks, were blocked. This complication was solved by raising the narrowest panel $203 \mathrm{~mm}$ by resting an edge on a standard concrete brick, providing the required access at floor level. This perturbation is based on Fig. 31 and is considered negligible. That figure shows the myriad of hoses interconnecting tanks, sight gauges, and manifold for the simplest case; connections to all six tanks were more complicated. 


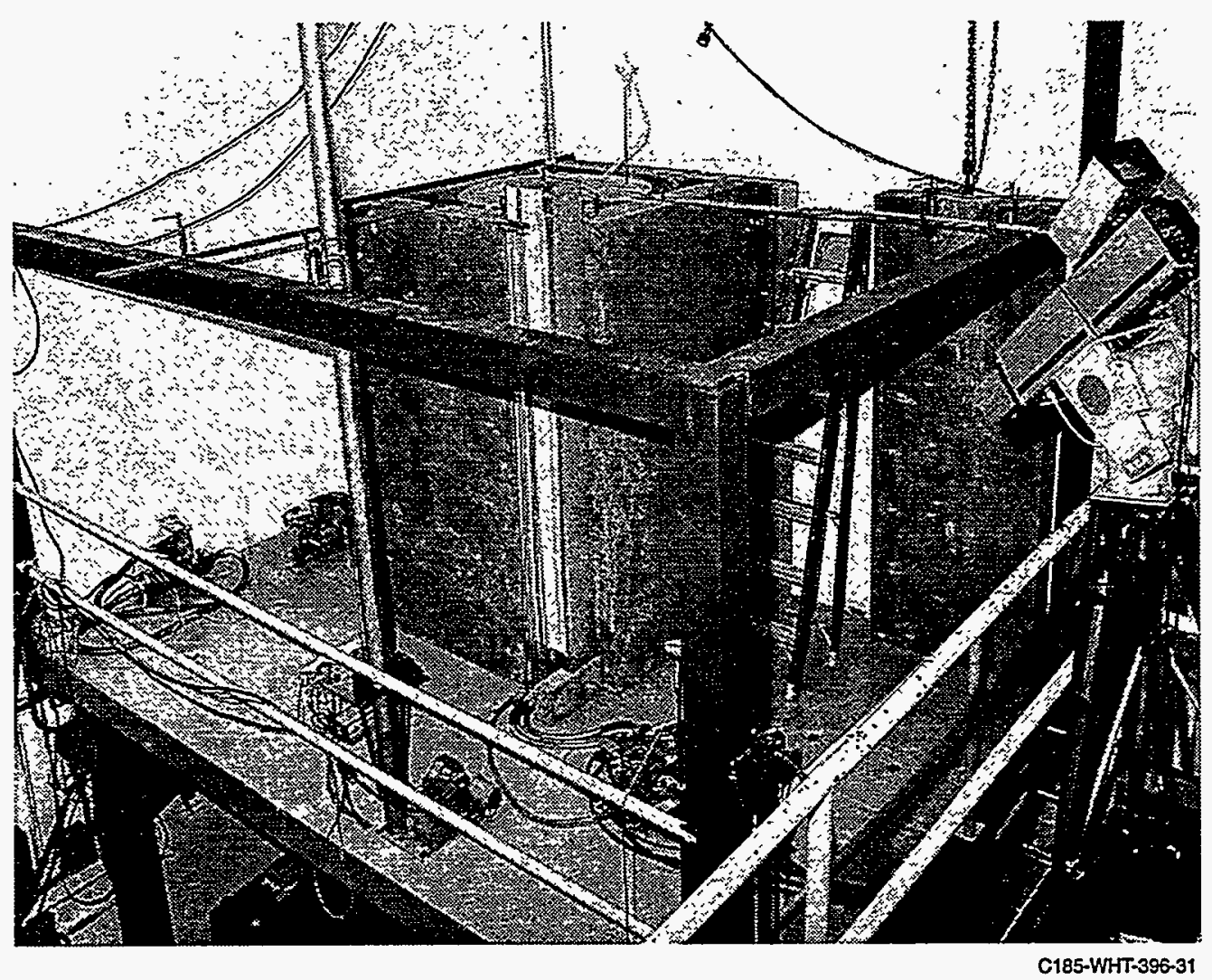

Figure 31. The myriad of plastic hoses directing solution from a single fill line into four or six tanks are not thought to contribute significant reactivity because they are outside the reflector boundary. One panel was raised by a concrete block to connect lines to tanks.

RFP photo \# 26536-1 [1/15/80]. 


\section{ELEVATED' PLATFORM}

Both programs were carried out on the same concrete-floored mezzanine. This was built just prior to the first program in an attempt to increase floor space available to all future programs at the CML. The platform was built in the southeast corner of that room; and it stood immediately above a pair of heavy-duty doors leading to the out-of-doors. Those doors provided access to the Assembly Room for new and possibly heavy equipment.

The platform measured $3.04 \mathrm{~m}$ by $4.88 \mathrm{~m}$ and the top of its concrete floor stood $3.35 \mathrm{~m}$ above the floor of the Assembly Room. The platform floor was composed of eight rectangular panels. Each panel was ordinary concrete poured into a heavy steel channel frame. A heavyduty superstructure supported these eight panels, holding them in contact with one another in a $2 \times 4$ array. Four suitably-sturdy 'legs supported this elevated platform above the floor of the room.

Each of the eight panels measured $1.22 \mathrm{~m}$ by $1.52 \mathrm{~m}$ and was $203 \mathrm{~mm}$ thick. To make each, steel channel stock was welded into a rectangle of those dimensions. The commercial stock is referred to as "C8 x 11.5". It measures $203 \mathrm{~mm}$ across the web and weighs $17.1 \mathrm{~kg} / \mathrm{m}$. Channel flanges faced inward forming a smooth outside vertical surface. Corners were mitered to $45^{\circ}$ and welded. At this point, the frame of the panel looked like a very thick picture frame. 
These floor panels contained rebar embedded in the concrete for added strength. The elevated platform might be called upon to support heavy loads in some applications. All rebar was commercial ribbed steel in the $19 \mathrm{~mm}$ size. It was laid out in a rectangular mesh with the plane of the rebar about $50 \mathrm{~mm}$ above the bottom of the finished slab. Four 1.4-m-long rebars were equally spaced parallel to the long dimension of the frame; and five shorter lengths $(1.2 \mathrm{~m})$ passed at right angles, also, equally spaced. They were tied together with wire at intersections.

A better connection between concrete and frame was ensured by welding 14 short lengths of the same $19 \mathrm{~mm}$ rebar to the inside web of the channel frame. The 14 were about equally spaced around the perimeter at the mid-plane. Each weld stud was $127 \mathrm{~mm}$ long. These are sometimes called "Nelson Weld Studs".

Each floor panel had three holes passing through it. These would be used to pass fissile solution lines, cables, and other experimental equipment from below the floor to the working surface. The location of these holes is not described here because that detail is considered unimportant. They were, however, in a triangular pattern spaced to provide a convenient selection. Each was lined with a $197 \mathrm{~mm}$ length of nominal 50-mm-diameter stainless steel Schedule 10 pipe. The only other steel in a finished floor panel included four heavy-duty lifting 
anchors embedded at corners. These were used to lift floor sections into place on its support superstructure.

The eight frames were weighed prior to pouring concrete. The total weight of steel in each one averaged $122 \pm 1.4 \mathrm{~kg}$.

The concrete was poured on April 10, 1980. The mix contained:

$\begin{array}{lr}\text { Portland Type II Cement } & 1194 \mathrm{~kg} \\ \text { Moist Sand } & 2957 \mathrm{~kg} \\ \text { Moist Rock (20 mm average size) } & 3316 \mathrm{~kg} \\ \text { Tap Water } & 473 \mathrm{~kg}\end{array}$

The concrete supplier measured the water content of their moist sand that day. They found $5 \%$, in agreement with a simple procedure done at Rocky Flats: a can of their sand was dried on a hotplate and found to contain 5\% water, too. At Rocky Flats, the moisture content of the aggregate was found by the same simple method to be $1.7 \%$.

These forms were cast horizontally and upside down. One surface of each form was covered with plywood to yield at least one smooth surface on each panel. That one surface became the working surface when the floor was in place. The other side was simply hand finished by workmen. 
These eight floor panels were supported by a superstructure formed of heavy steel "Wide-Flange I-Beams". All beams stood vertical for best load support. The outside dimensions (to beam centers) of this were $2.54 \mathrm{~m}$ by $4.37 \mathrm{~m}$. This was large enough to allow the $2 \times 4$ array of panels to overhang about equally on all sides. The two long stringers were "W10x45" I-beams. These were $254 \mathrm{~mm}$ tall and weighed $67 \mathrm{~kg} / \mathrm{m}$. A third I-beam, parallel to these two, was centered between them. It would support the edges of the four pair of slabs where they met along the centerline of the floor. It was smaller, "W8x31", measuring $203 \mathrm{~mm}$ high and weighing $46 \mathrm{~kg} / \mathrm{m}$.

Five orthogonal wide-flange I-beams, equally spaced over the length of the long direction, supported the mating faces of four floor panels in each of two rows. Each of the five were, in turn, composed of two lengths, divided by the long center I-beam. These 10 lengths of "W8x31" beam also measured $203 \mathrm{~mm}$ high and weighed $46 \mathrm{~kg} / \mathrm{m}$.

Even though wide-flange I-beams of two heights $(254 \mathrm{~mm}$ and $203 \mathrm{~mm}$ ) were used, they were laid out such that all top-flange surfaces were co-planar. Joints were carefully cut to fit other beams whether they were the same size or not. Short lengths of angle iron were bolted to both webs at these joints to fasten them together. 
The total weight of these 13 pieces of wide-flange I-beam stock of two sizes was $1167 \mathrm{~kg}$. All this was contained in a thick plane whose top surface stood $3.15 \mathrm{~m}$ above the Assembly Room floor.

Finally, the twist mode this otherwise all-rectangular construction was stabilized by horizontal diagonal bracing. Angle iron stock, $50 \mathrm{~mm}$ on a side by $6.4 \mathrm{~mm}$ thick, was welded to the bottom of the W8x31 I-beams wherever they touched along both diagonals.

The horizontal superstructure was supported by four sturdy legs. These were also the same wide flange I-beam stock. The cross section of this structural steel looks very much like the letter "H"; but it is different from a true H-beam. Three of the legs were located under corners of the superstructure; but the fourth leg in the remaining corner would have restricted the opening of one door under the mezzanine. It was relocated a little to accommodate the door. .

Each leg was welded to a $356 \mathrm{~mm}$ square of $13-\mathrm{mm}$-thick steel at the bottom. This formed a pad to distribute weight to the floor more safely. Legs supported the W8x31 beams of the superstructure (not the W10x45 beams); so their lengths, including pads, were $2.95 \mathrm{~m}$. Two diagonal braces of W8x31 beam stiffened each leg in orthogonal directions. 
The working space above the mezzanine had a small amount of structural steel to facilitate stabilization of concrete reflector walls. East and south walls of the Assembly Room would prevent these walls from falling; but the other two directions needed some kind of "fence" to which panels could be tied. Three posts of $152 \mathrm{~mm}$ angle stock (13 mm thick) rose at all corners but the southeast one. These were tied together with two horizontal lengths of the same stock. This construction can also be seen in Fig. 31. The two horizontal members were $2.46 \mathrm{~m}$ above the floor of the mezzanine, just about co-planar with the tops of the nested annular tanks, their internal plugs and external slabs, and the reflector wall sections. Any of these experimental items could be tied to either of these horizontal angle members for seismic stability.

Finally, a pair of yellow-painted pipes formed a safety railing to prevent falling off the platform. These were about 50-mm-diameter light-weight steel pipes bolted to the superstructure. They spanned the full length of the south side of the platform and half the width of the west edge. 


\section{ENVIRONMENT}

Experiments were performed within the Assembly Room. It is a large concrete room containing only a few items large enough and/or close enough to the annular tanks to, sensibly, provide any additional neutron reflection.

The closest large item was an air handling deck. This was only a few meters away from the mezzanine to the west. Its support structure had some significant amount of steel; but this was further away. The air unit itself was closer but of such light-weight sheet metal as to be ignored. This structure supported the room's heating and cooling equipment. The next closest was a Horizontal Split Table, one of the reactivity addition devices used on many other programs. A third large feature of the larger room was a walk-in containment room. Most of the other fissile solution experiments from several other programs were performed there. The purpose of this room was to prevent the spread of contamination upon the inevitable small leaks expected when handling fissile solution. The final component described is the heavy equipment travelling crane built into the room for general us.

The Assembly Room contained other smaller pieces of equipment; but these are considered too small and too far away to be worth description. Large portable tool boxes and normal clutter found around any productive laboratory were, of course, present. 
No materials mentioned in this section of the paper were chemically analyzed for elemental composition. Therefore, material descriptions are given nominally with the code validator required to use typical compositions for the kind of material used.

\section{Assembly Room}

The interior of the Assembly Room measured $11.28 \mathrm{~m}$ in the east/west direction by 10.67 . $m$ in the other. The room was $9.75 \mathrm{~m}$ high. The mezzanine was built in the southeast corner of that room. Concrete walls and ceiling were formed in one, continuous, monolithic (seamless) pour in 1964 . The north wall was $1.52-\mathrm{m}$ thick; but the other three were only $1.22 \mathrm{~m}$. The north wall was made thicker because people occupied rooms to the north; and the small additional shielding would further protect them from radiation during experiments. The thick ceiling varied between $0.61-\mathrm{m}$ and $0.71-\mathrm{m}$ thick. The floor was poured later and was $0.15-\mathrm{m}$ thick but rested directly upon compacted earth. Interestingly, the floor was isolated from the walls by thin rubber pads; so the floor is, indeed, free to creep small amounts over long times without cracking the rest of the structure.

Two layers of crossed steel rebar strengthened the concrete. One layer was about $80 \mathrm{~mm}$ in from the outer surface; the other, the same distance out from the inner. Horizontal rebars were \#8 size on $0.3-\mathrm{m}$ centers. Vertical bars were \#6 size on the same centers. Approximately 7,000 $\mathrm{kg}$ of steel strengthens the concrete. A detailed neutronics calculation would include this material 
in the elemental description of the concrete. Figure 32 is an historic photograph of the Assembly Room under construction and shows many of the features just discussed. The photograph was taken in July or 1964.

Specifications for the concrete poured in 1964 were not unusual for industrial applications. Type I Portland cement was called for using $307 \mathrm{~kg} / \mathrm{m}_{\text {- }}$. The maximum water content in the fresh mix was $30 \mathrm{~kg} / \mathrm{m}_{-}$; and the water had to be pure. Allowed aggregate sizes ranged from 6 to $18 \mathrm{~mm}$; and this rock had to be low in amorphous siliceous materials.

The room had been painted a number of times since being built. These were not just cosmetic; instead, painting was intended to improve the leak-tight integrity of the room. Because of the possibility of a small overpressure at the moment of a hypothetical criticality accident, the room was required to exhibit a very low leak rate due to such an overpressure. The room was repainted inside and out every few years. Most paints were two-component epoxy paints; and the floor, at least, is recalled to have been painted with one such paint called Amercoat@.

The roof was especially difficult to keep leak tight. Paints used were more severely exposed to weather because of standing water and longer exposure to the sun. Another problem contributing to cracking was, ironically, the very test done annually to verify leak-tight integrity. The room was intentionally over pressurized to $1.13 \mathrm{~g} / \mathrm{mm}_{-}$and the net upward force on even 


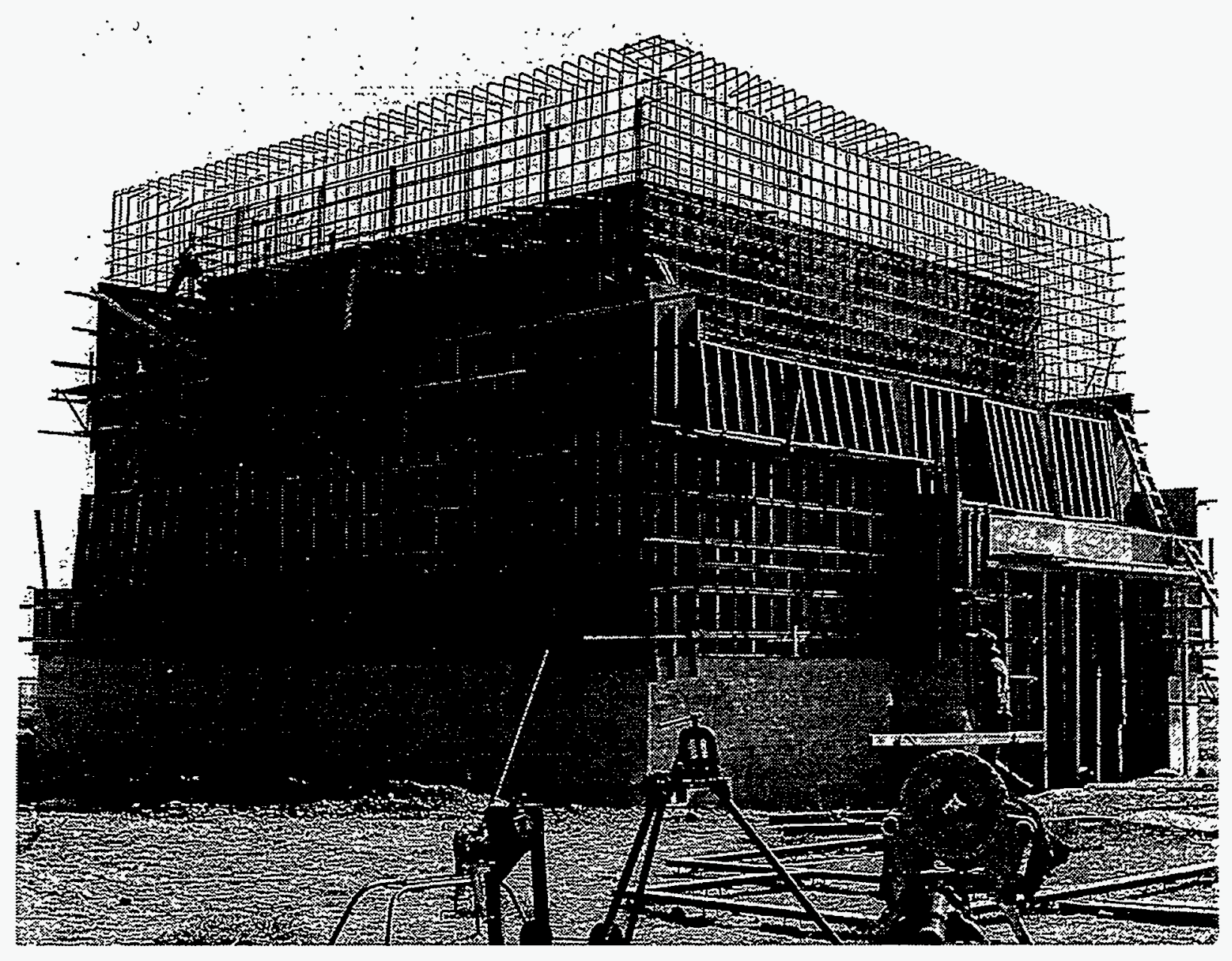

C185-WHT-396-32

Figure 32. The Assembly Room of the Rocky Flats Critical Mass Laboratory was built in the summer of 1964 . This historic photograph reveals several stages of construction.

RFP photo \# 9880-12 [7/23/64]. 
this moderately thick concrete surface came to a surprising $680,000 \mathrm{~kg}$ ! Future facilities requiring maximum containment should probably seek other ways to verify leak tightness than the destructive test imposed here.

Two doorways penetrated this room. One in the north wall at the west end was a 1.07$\mathrm{m}$-wide by 2.44-m-tall passage way used for personnel access. Small experimental components were introduced here too. The passage way extended the full thickness of the north wall plus $1.07 \mathrm{~m}$ (2.59-m total) before making a $90^{\circ}$ turn east. The wall backing the first passage way was also very thick. A similar turn back north after a 1.52-m-long hallway completed a Z-shaped labyrinth. The purpose of this labyrinth was to prevent radiation streaming out of the room in the event of a nuclear criticality accident. It might pass through the closed steel door; but it would not make the two right angle turns to propagate down the hallway.

The second opening was diagonally across the room. It was in the south wall but at the east side. This was an equipment door way connecting directly to the out-of-doors. They are just below the mezzanine used in these programs. The opening was larger to accommodate movement of larger and heavier components: $2.44-\mathrm{m}$ square. This equipment opening was backed by a sliding concrete shield door outside access doors. This massive shield was $1.07-\mathrm{m}$ 
thick. Its 3.05 -m-wide by 2.78 -m-high size effectively would stop any radiation streaming south out of the room due to that same hypothetical accident.

Both door openings were protected against radiation streaming by the methods described above; but two other consequences of the hypothetical accident would must be protected against. One, the formation of a large inventory of radioactive daughter products from the fission process accompanies such an accident. Some of these daughter products would be gaseous and all needed to be contained. Second, a very small explosive blast could, possibly, result. The worst possible explosive yield has been estimated to be much less that a single stick of dynamite. The containment of these two side effects was accomplished at the two openings by the use of strong blast doors with a rubber seal between them and the room. One such door existed at the personnel passage way; and two were used at the heavy equipment opening. Each door was $1.22-\mathrm{m}$ wide by $2.59-\mathrm{m}$ high and $0.10-\mathrm{m}$ thick, although the fairly thick door was constructed as a honeycomb to reduce its weight. All three blast doors were made of steel; and each can be modeled as two 6.4-mm-thick plates on either face separated by 25 linear meters of honeycomb material (steel) $6.4-\mathrm{mm}$ thick by $90-\mathrm{mm}$ wide. Each door weighed about $425 \mathrm{~kg}$.

\section{Air-Handling Unit}

The air handling deck existed in the southwest corner of the room. This all-steel structure was $4.8 \mathrm{~m}$ east/west by $2.4 \mathrm{~m}$ and stood $4.5 \mathrm{~m}$ above the floor. It was constructed of about $30 \mathrm{~m}$ 
of nominally 0.2 -m-sized channel iron. The air handling housing was constructed of very lightweight sheet metal and can be ignored.

\section{Horizontal Split Table}

This is a massive steel table described in detail in the previous paper under this DOE contract: "Experimental Critical Parameters of Plutonium Metal Cylinders Flooded with Water" (September, 1994). That description will not be repeated here because it is believed to be so far away from the mezzanine as to be truly negligible.

\section{Walk-In Hood}

- The fissile solution containment enclosure was several meters away from the mezzanine. Generally, it was about centered north/south and also about centered in the west half of the room. The room was constructed mostly of stainless steel (1.6 mm thick); but it had an estimated $30 \%$ of its surface covered with 13-mm-thick plastic windows. The room was $5 \mathrm{~m}$ north/south by 3 $\mathrm{m}$ and stood $6 \mathrm{~m}$ tall. The nearest point to the experimental annular tanks was approximately 5 m away.

\section{5-Ton Crane}

The room's travelling crane was a typical heavy-duty (5-ton) industrial crane built into the room a short distance below its ceiling. Its massive steel travel I-beams ran east/west with a bridge for 
orthogonal movement. No record was kept of where the bridge nor the crane's winch was situated at the time of the experiments. The crane was used extensively in these experiments. 


\section{SOLUTION HEIGHT}

The height of uranium solution in experimental tanks was the most important parameter in both programs. Four independent methods of determining height were used in different combinations and for different purposes:

$\begin{array}{ll}\text { - } & \text { remote sight gauges } \\ \text { - } & \text { electronic "Level Detector" } \\ \text { - } & \text { storage mass flow meters } \\ & \text { solume data }\end{array}$

Remotely displayed sight gauge heights were the data used to graph safe approaches to criticality for both programs. They were not used to obtain critical height data presented in this paper because other methods were considered more accurate. The first program employed a home-made device called a Level Detector for this. The instrument was not used in the second program because it had been rendered inoperable through repeated exposure to nitric acid fumes. Critical heights for the second program were primarily derived from a commercial Mass Flow Meter.

Sight Gauge - The first program employed up to four sight gauges; the second, one. Each was a vertical length of clear plastic tubing connected to a fitting at the bottom of the tank. The commercial tubing was nominal 13-mm-diameter. They .varied between one and three meters 
from the experiment; so they produced a reasonable indication of the solution level. No obstructions restricted the free flow of solution between tank and tube. Still, they were only considered adequate for graphing reciprocal multiplication curves as criticality was approached. Sight gauges are fairly accurate but not very precise. The meniscus makes them difficult to read; but they are remarkably simple in theory. Not much can go wrong in their use.

Metric scales were mounted vertically alongside the tubing to quantify observations. In the first program, these were merely inexpensive wooden meter sticks with printed scales having $1 \mathrm{~mm}$ increments. They lacked precision; and no effort was made to have zero correspond to the bottom of a tank. Much better scales, engraved metal with $0.5 \mathrm{~mm}$ precision and certified against a linear standard, were employed in the second program.

The level of the yellow-colored uranyl nitrate in the sight gauge was communicated to the experimenters in another room by closed-circuit color television. A camera was positioned a short distance away such that its zoom capability permitted the thickness of the sight gauge to fill about $15 \%$ of the monitor's width. Details of the meniscus were clearly visible.

Two other procedures improved readability. First, the camera always viewed the sight gauge from the same angle, eliminating reading errors resulting from parallax. This was accomplished by mounting the camera on a vertical elevator shaft. The camera could be moved 
up and down with the solution. Any error in reading would at least remain constant throughout an experiment. This careful methodology was enhanced by also adjusting the elevator to locate the solution height at almost exactly the same position on the screen for every observation. This elevator eliminated problems of a camera mounted on a fixed tripod and simply rotated to follow the solution.

The second effort to improve readability involved a concession to the electronic design of television monitors. Their display consists of several thousand horizontal lines scanned onto the screen. A flyback transformer leaves horizontal lines across a screen, visible upon close inspection. These retrace lines would be optically confused with the fiducial markings on the scribed scale. This problem was solved by rotating the television camera $90^{\circ}$ at its elevator mounting. Retrace lines were then orthogonal to markings on the scale. The only consequence of this was that "up" would be to the right (or left) on the screen as viewed by experimenters.

Sight tubes needed to be vented to the atmosphere. This was accomplished by connecting the gauge to a horizontal metal pipe at the top that expelled escaping air directly back into the top of an experimental tank.

Level Detector - This device consisted of a long vertical screw with a gold-plated point attached to its bottom end. The point was electrically insulated from the metal screw. The screw was 
rotated in either direction by a stepping motor attached at the top. An indicator, following the gold point but well above it, transferred the location of the point deep within the tank to a calibrated linear scale mounted above it. The distance between the gold point and the indicator was fixed.

Electronic circuitry programmed a repeated cycle of "searching" for the solution's surface. To illustrate, the gold point began at some level well above the solution. The program turned the motor clockwise, driving the point closer to the solution. The instant the point "found" the surface, the stepping motor stopped. Experimenters could read the height during that pause. A few seconds later, the stepping motor reversed itself and withdrew the point several millimeters above the liquid. There, it stopped again and paused a few seconds more, completing one cycle.

Two details improved precision. A fast-acting solid-state circuit was built to detect surface contact much faster than simple electrical conductivity of a liquid would permit. The stepping motor was also equipped with a brake to reduce coasting once the surface was found.

The Level Detector could even be used during filling. The gold-plated point was long enough to allow solution to raise several millimeters while the probe was in its "read" pause without shorting out the insulating section. Only occasionally did vigorous waves generated by 
the fastest filling rate short out the probe. In these cases, the insulator had to be cleaned and dried before proceeding.

Mass Flow Meter - This is a commercial device $e^{33}$ manufactured locally. Liquid passes through a U-shaped vibrating tube; and the Coriolis force introduces a twist into the tube proportional to the mass passing through it. The magnitude of this twist was converted by the instrument into a very sensitive measure of the mass delivered.

The mass delivered to a critical system, $M$, is related to the solution height, $H$, through other known parameters of the experiment. The cross sectional area, A, of the tank being filled is measured for other experimental purposes. The density, $\mathrm{r}$, of the fissile solution is another parameters needed for experimental purposes. The height can be calculated from:

$$
\mathrm{H}=\mathrm{M} /(\mathrm{r} \nabla \mathrm{A}) \text {. }
$$

This height measurement is completely independent from sight gauge readings.

Two Mass Flow Meters were installed (in parallel) in the solution delivery line connecting the storage tank farm in another room with the experimental tank. They were about three meters away from the experimental tank and connected to it via a small-diameter fill line.

${ }^{33}$ Manufactured by Micro Motion, Inc., 7070 Winchester Circle, Boulder, CO 80301. 
Early stages of an experiment found solution added as fast as one liter per second; so the largercapacity Mass Flow Meter was used. This integrated the mass of solution delivered with a precision of better than $\pm 100 \mathrm{~g}$. Later in the experiment, that rate became too fast to add reactivity safely. The fast-delivery pump was shut down and additional solution added much more slowly. This passed through the second (smaller) Mass Flow Meter; and its mass was integrated from that point until criticality was achieved. The precision of this integration was about $\pm 1 \mathrm{~g}$.

The solution mass in the tank during the slightly super critical condition corresponding to a few-minute-long positive reactor period was simply the sum of the two Mass Flow Meter readouts. Typically, this was on the order of $1000 \mathrm{~kg}$ with a precision of better than $\pm 200 \mathrm{~g} \biguplus$ $0.02 \%$ !). Considering the uncertainty in density and cross sectional area, the precision in a height measurement would be about $\pm 0.6 \%$.

The smaller Mass Flow Meter was also used a second time. It was used to observe precisely subcritical conditions, which would later be used later to interpolate critical cases. After finishing with the super critical case, the smaller Mass Flow Meter was reset to zero and its ability to read solution flow reversed. Then, the few hundred grams of solution removed to render the reactor slightly subcritical was recorded as that liquid flowed back to storage. 
The instruments were caused to yield the height of solution in the tank by setting both readouts to zero just after the solution had filled the line leading to the tank but not yet entered it. Fortunately, this condition could be determined by watching solution fill short lengths of transparent plastic tubing ${ }^{34}$ about three meters from the experimental tank. The line between had a volume of about 1.5 liters; so a very short pulse at the fast rate established. that initial condition. The accuracy of this zero point of the Mass Flow Meters is probably about \pm 0.2 $\mathrm{mm}$.

Storage Tank Volumes - Uranium solution storage tanks in another room were volume calibrated because periodic inventories of the uranium content were required by the government. These data could be used to provide another independent measure of the solution height at criticality.

At the same time the Mass Flow Meters were set to zero, a third person was sent to the storage room. The volume of uranium solution present in the specific tanks feeding that day's experiment was carefully noted. Later, while the assembly was slightly super critical, that same person returned to the storage room $^{35}$ to read the volume remaining in these same tanks. The

34 This tubing was associated with the installation of the two meters themselves; the sensitive devices had to be decoupled from mechanical vibrations.

${ }^{35}$ Two certified experimenters were required to be present during all phases of any critical experiment. This activity was safe because the critical experiments were a distance away and contained in a well-shielded room. 
difference in volumes equalled the volume delivered. This, in turn, equalled the cross sectional area of the experimental tank times the height, another independent measure of that important parameter.

Usually, two or three tanks were needed to supply solution to a typical experiment. Each volume decrease involved two volume readings with an accuracy of about \pm 2 liters each. The net uncertainty, then, in this "volume delivered" was about \pm 5 liters, considerably greater than other methods.

\section{First Program}

Four sight gauges and the Level Detector were used on this first study. When four tanks were nested as in the first configuration, each had a separate sight gauge. If, however, the distribution manifold had been configured that only three of the four were to receive solution in a given experiment, then only three of the four sight gages would display solution. When all six tanks were in use as in the second and third configurations, still only four sight gauges were used. Two pair of tanks were represented by one sight gauge each.

This procedure resulted in many small-diameter solution-filled lines laying about on the floor; but that did not seem to pose a problem. These sight gauges were always located outside the concrete reflector wall panels; so they contributed no reactivity to the experimental system. 
One narrow reflector panel was raised slightly to allow these lines to pass outside. Figure 31 shows this myriad of solution-filled lines during the assembly of one configuration; it was worse when six tanks were used.

Critical heights were obtained from the more-precise Level Detector. It was mounted above the tanks, usually with its probe in the next-to-smallest tank. The back side of the scale and the screw can be seen in Fig. 6 . It had been adjusted vertically such that zero corresponded to the "average tank bottom" ${ }^{136}$ of the tank containing its probe; and, once set, it was not moved relative to the tank.

The solution did not activate the Level Detector until considerable solution had been added to the tank. This was intended to keep the gold point from contacting the tank's metal bottom. If fact, the height at which the gold point first touched solution in the very first experiment was $603 \mathrm{~mm}$ above the bottom. The Level Detector, then, indicated "603 $\mathrm{mm}$ " once started; and it repeatedly sampled the solution level up to the super critical height of $931.53 \mathrm{~mm}$.

The Level Detector was a very precise measuring tool; but its accuracy depended upon the initial setting of zero at the "bottom" of the tank. This was not easy and may not have been

${ }^{36}$ See bold-faced discussion of this point later in this section. 
done in the most useful way. If all tanks bottoms were co-planar and perfectly horizontal, this "bottom" would have been clearly defined. Unfortunately, this was not the case; and even the concept of a tank bottom was ill-defined. Each tank had a $2^{\circ}$ slope to its bottom. All four sizes started at a point $305 \mathrm{~mm}$ above the floor; but, since they differed in diameter, the diametrically. opposite "bottom" was $328,333,337$, and $340 \mathrm{~mm}$ above the floor, respectively. The average bottom is defined to be that height midway between a tank's highest and lowest bottom value. That value for each of the four sizes was $317,319,321$, and $322 \mathrm{~mm}$ above the floor. With the device mounted in the next-to-smallest tank, the Level Detector read zero at $319 \mathrm{~mm}$ height.

Critical height data for the first program presented in this paper assume the following: a) the Level Detector's readout was such that zero corresponded to a point 319 $\mathrm{mm}$ above the floor.

b) all critical heights for any configuration of tanks, relative to the floor of the elevated platform, can be obtained from the relation:

Level Detector value $+319 \mathrm{~mm}$.

Experimental records are ambiguous on some important points; and the author's recollection over 15 years later is not able to resolve all questions. The concern is the possibility that Level Detector heights throughout an experiment were, in fact, not measured above the average tank bottom of the next-to-smallest tank. If not, zero on the Level Detector device (tank 
bottom) may have been slightly different. The consequence of this is that all quoted critical heights could possess a systematic bias. That is, each time the Level Detector was mounted in place for a series of experiments, that set of results may possess a bias. All other measurements in that set will be both precise and accurate relative to that one adjustment. The code validator. should use one or more experiments to determine that bias, if one existed, in the critical height due to this possible flaw. Then, that same correction, if any, should be applied to all other data from the same set.

Three configurations are identified for this program. The Level Detector would have been reinstalled at the beginning of each. Critical heights in this paper are those Level Detector readings recorded in the record books on the day of the experiment. They are believed to correspond accurately to the bottom of the tank as explained; but this caution reflects the author's concern over possibly different conditions.

\section{Second Program}

This study used three of the four height measurement tools in one capacity or another. The Level Detector had been rendered inoperable by this time. Critical height data reported here was derived from both the Mass Flow Meter and from the Sight Gauge. Results by the two methods were sometimes a few millimeters different. This difference will be explained in a later section. Both sets of experimental results are given for completeness. The Storage Tank Volume 
method influenced this data slightly in a few cases. The Sight Gauge was also used to graph the safe reciprocal multiplication approach to criticality.

When the experiment had attained a very slight super critical condition, both the mass data from the two Mass Flow Meters and the height on the Sight Gauge was recorded. Often, a third person was sent to the Tank Storage Room to record the volume data, During this activity, the positive reactor period was generated, measured, and recorded. Typically, this super critical condition was held for ten to twenty minutes.

Next, a very small amount of solution was drained from the system, creating a slightly subcritical system. The goal was to strive for approximately equal reactor periods of opposite sign. The mass passed backwards through the Mass Flow Meter was measured and later converted into a height decrease. The new Sight Gauge reading was also recorded. Sometimes, Sight Gauge heights for the two periods were imperceptibly different! No attempt was made to read again the storage tank volume data; too little had been returned to make an observable change. Typically, this subcritical condition was maintained for another several minutes.

The experiment was ended at this time. The solution was allowed to return to storage. No further measurements of solution height data were made. 


\section{RESULTS}

Reconstructing precise experimental results from data taken a decade or more ago is difficult at best. Fortunately, records at Rocky Flats' CML were quite complete and left little to memory. Still, some important details may not be stated as confidently today as if written only months after the study. The possible bias in critical height data, discussed in another section, is the best example. That bias is probably not present but could be.

Because of this concern, critical conditions presented in this section state clearly changes between experiments. Thus, even if a bias were found, other experiments can be usefully evaluated by including both any observed bias and the changes. To facilitate this approach, experimental results will be described in their actual chronological order rather than, perhaps, some more sensibly ordered sequence.

Results are divided, first of all, into the same two programs considered throughout this paper. For the first; three configurations common to a number of experiments are discussed. In each, the relative placement of tank and reflector remained fixed within the room; and only other components changed are explained. For the second, experiments necessary to determine reactivity shims (suitable DR) are discussed first; and, then, results from varying moderators and absorbers are considered. 


\section{First Program}

The Nested Annular Tank study fell into three configurations. The first involved nesting four tanks of different sizes to form one effectively thick $(152.4 \mathrm{~mm})$ "tank". This assembly was surrounded by concrete reflector wall panels. Once built, neither tanks nor panels were moved. Only the presence or absence of different kinds of plugs and the number of tanks actually filled with solution varied from one experiment to another. No absorber/moderator slabs were used in this set.

The second involved a line array of three nested pairs of tanks. Each "tank" of this array had a nominal combined solution thickness of $76.2 \mathrm{~mm}$. This array was also surrounded by reflector panels, although one end reflector was just the thick concrete wall of the room in which experiments were carried out. Neither tanks nor panels were moved once the array had been built. Various plugs were inserted in one or more tanks; and slabs were used between tanks in some cases. The specific tanks filled also varied.

The last configuration was a simple array of two sets of nested triples of tanks. Thus, the nominal solution thickness of each "tank" was $114.3 \mathrm{~mm}$. These experiments were also reflected; but, this time, walls of the room were not needed to surround the tanks. Again, tanks and reflector panels were not moved once built. Variables included different plugs, the location or absence of slabs, and tanks filled, as before. 
Single "Tank":

The arrangement of concrete reflector panels on the elevated platform is dimensioned in Fig. 33. Circles represent the four tanks. The outer diameter of the largest and inside diameter of the smallest are close to scale. The nest is surrounded by six of the seven reflector panels; the 914-mm-wide wall was stored a short distance from the experimental area. Cast panels might not fit together perfectly; so finished outside dimensions of the "room" were measured. Nominal dimensions would generally be a little smaller. Figure 34 is a photograph confirming this description and illustrating details.

Inside dimensions are most important. These were measured near the tops and bottoms of the reflector enclosure along each wall. Results, presented in the top portion of Table XV, reveal an almost perfectly square reflector with precisely vertical walls. The lower portion of that same table records the closest distance between the outer tank and each wall. This was measured at three heights. The upper should be considered best because it was easily obtained. Still, variations lower are real and illustrate problems in rolling and welding a round tank and casting flat concrete.

The first experiment in this configuration had no plug inside the smallest tank. Even though four were nested, solution was only admitted into the smaller two (tanks \#3 and \#4). The critical height was $929.8 \mathrm{~mm}$. 


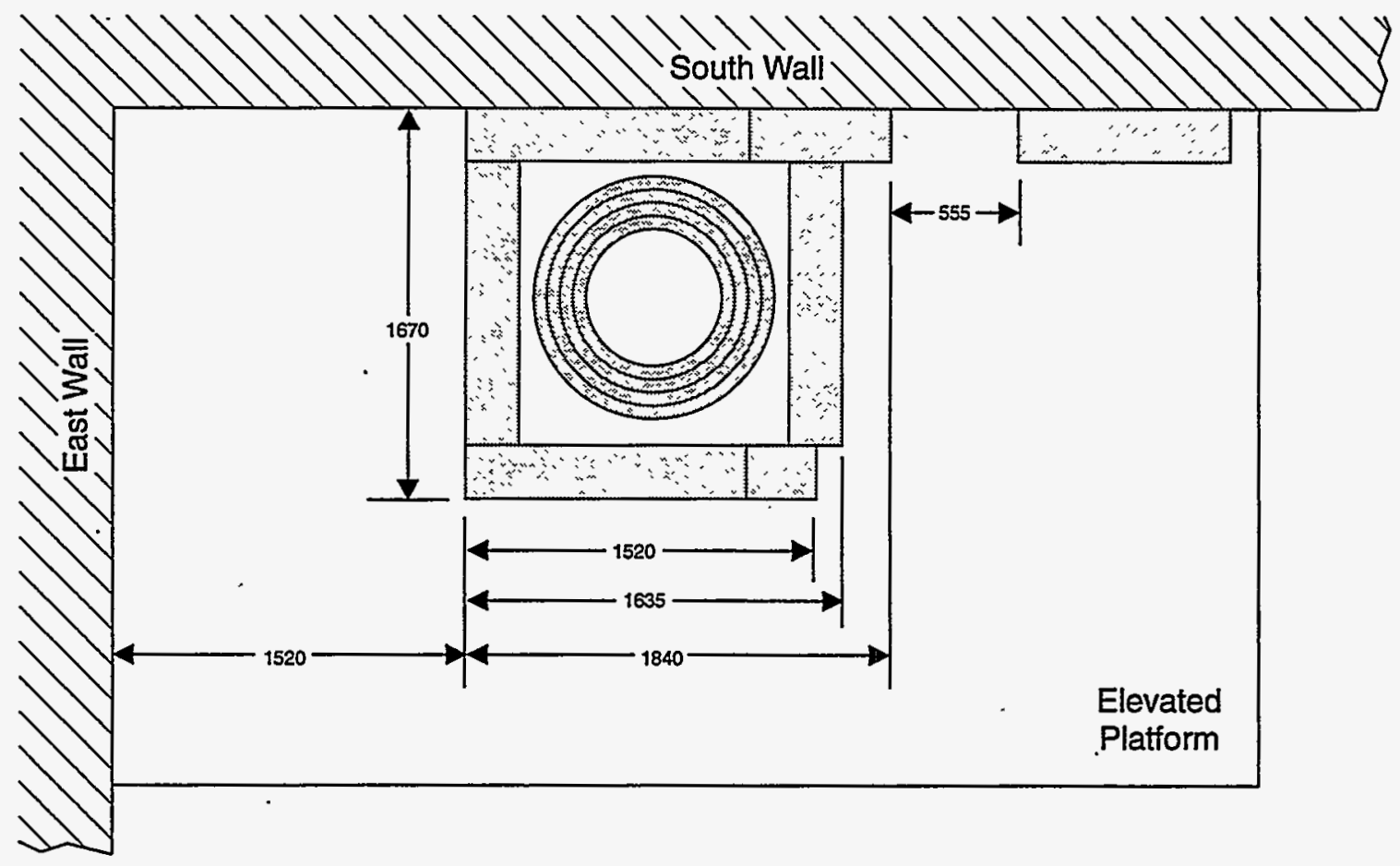

Figure 33. Not all reflector panels were needed to surround four nested tanksof the first configuration. Cast panels did not always fit perfectly; so measured dimensions should be used instead of adding nominal values. 


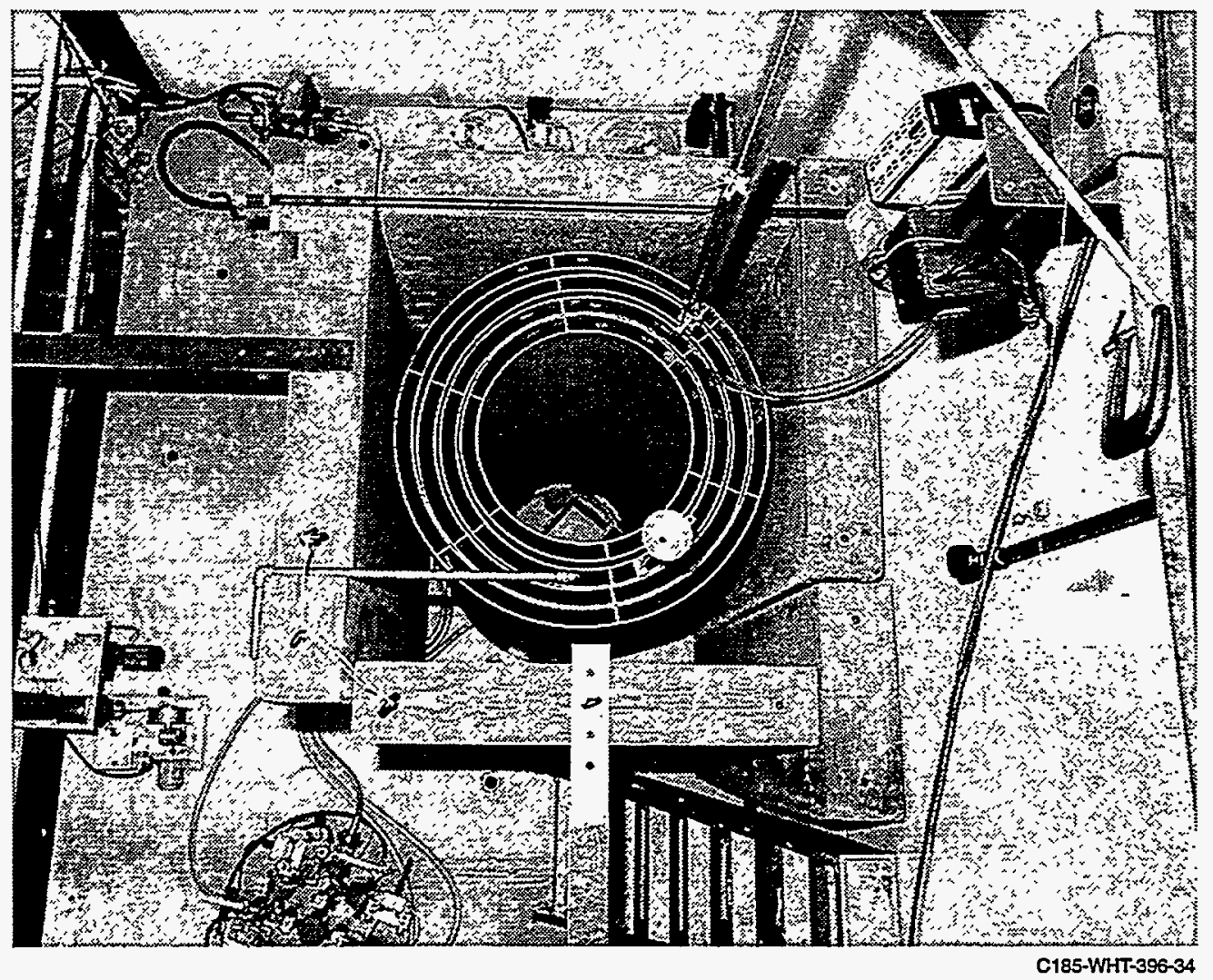

Figure 34. The first configuration viewed from above. RFP photo \# 26536-4 [8/15/80]. 
Table XV. Measured Dimensions of the Reflector Enclosure and Tank Location Within the "Single Tank."

\begin{tabular}{|l|c|c|c|c|c|}
\hline \multirow{2}{*}{$\begin{array}{c}\text { Height } \\
\text { Along } \\
\text { Reflector } \\
\text { Wall }\end{array}$} & \multicolumn{5}{|c|}{ Enclosure Dimensions (mm) } \\
\cline { 2 - 6 } & \multicolumn{2}{|c|}{ North to South Walls } & East to West Walls \\
\cline { 2 - 6 } & $\begin{array}{c}\text { W East } \\
\text { Wall }\end{array}$ & $\begin{array}{c}\text { In } \\
\text { Center }\end{array}$ & $\begin{array}{c}\text { By West } \\
\text { Wall }\end{array}$ & $\begin{array}{c}\text { By North } \\
\text { Wall }\end{array}$ & $\begin{array}{c}\text { By South } \\
\text { Wall }\end{array}$ \\
\hline Top & 1236 & 1236 & 1236 & Missed & Missed \\
Bottom & 1234 & 1234 & 1235 & 1234 & 1234 \\
\hline & \multicolumn{5}{|c|}{ Tank Location Within Enclosure (mm) } \\
\hline & \multicolumn{3}{|c|}{ North } & \multicolumn{3}{|c|}{ East } & South & West \\
\hline Top & 95.4 & 88.5 & 102.4 & 95.6 \\
Middle & 87.0 & 85.9 & 94.5 & 93.2 \\
Bottom & 88.4 & Missed & 100.0 & 100.5 \\
\hline
\end{tabular}


The second experiment actually achieved three critical heights in one procedure. Solution was first pumped into all four tanks yielding a critical height of $271.9 \mathrm{~mm}$. Then, the outermost tank (\#1) was drained, rendering the remaining three subcritical. Additional solution was pumped into only these three until criticality was, again, achieved $(396.4 \mathrm{~mm})$. Finally, solution from tank \#2 was returned to storage producing another subcritical situation. Solution was finally added to the remaining two tanks (\#3 and \#4) to achieve criticality again at $934.6 \mathrm{~mm}$.

This last critical height and the first one should have been the same. The same solution filled the same tanks with all other conditions the same. No confident explanation is offered for the $4.8 \mathrm{~mm}$ difference. The difference is only about $\pm 0.25 \%$; and most physics experiments would be quite satisfied with that high level of repeatability. Experience reveals, however, it to be quite large for this kind of experiment. Typically, critical heights are so sensitive that the distinction between a slightly subcritical condition and one dangerously close to prompt critical would not even be measurable even on this state-of-the-art height-measurement equipment. The reactor period is a vastly more sensitive measure of the proximity to criticality. It can change dramatically with no perceptible change in solution height.

One possible explanation for the $4.8 \mathrm{~mm}$ discrepancy involves a change in the setting of the Level Detector between the two experiments. After the first, the probe of that device was lowered to detect solution at a lower height. The change was made in the belief that no bias 
would be introduced; but that may have been wrong. The change was necessary, however, because lower critical heights were expected for thicker solution regions. The issue of possible Level Detector bias has been discussed elsewhere.

The next experiment with this configuration was the first to contain a plug. The $22 \times 0$ concrete plug which contained no boron was lowered inside the smallest tank. It weighed 122.0 $\mathrm{kg}$ the day of the experiment. Again, three critical heights were obtained from a single experiment. All four tanks filled yielded a critical height of $259.4 \mathrm{~mm}$. The smaller three tanks attained criticality at $356.5 \mathrm{~mm}$; and tanks \#3 and \#4 measured $1064.8 \mathrm{~mm}$ deep when critical. The lower two critical heights are lower than their counterpart measurements in the same tanks without the plug present. This is attributed to the increased reflection introduced by the plug itself. Evidently, very little absorption of neutrons interacting with the opposite side of the tank took place. With fewer tanks, however, the trend reversed. The plug actually reduced acrosstank interactions as expected.

The next study used the same plug; but this time it was wrapped with a thin lamination of pure cadmium metal. An elemental impurity analysis revealed no impurities greater than $0.001 \%$. The metal was $1.59 \mathrm{~mm}$ thick; and the entire lamination weighed $55.2 \mathrm{~kg}$. The metal was glued onto the paper form with small daubs of a commercial product called "Liquid Nails". This was the first experiment to contain a recognized neutron absorber inside the tank. The same 
set of three critical approaches were carried out. Solution in all four produced a critical height of $285.6 \mathrm{~mm}$; and the smaller three, $460.5 \mathrm{~mm}$. With solution in only two tanks the system proved to be well subcritical. The cadmium did effectively interrupt neutron interactions across the tank. The subcritical case was so unreactive, in fact, that the reciprocal multiplication curve became asymptotic to a multiplication of only three!

The next case replaced the cadmium-covered plug with the $22 \times 16$ concrete plug containing $1.2 \%$ boron. This plug weighed $525.0 \mathrm{~kg}$ just before use. Four tanks yielded a critical height of $289.2 \mathrm{~mm}$; and tanks \#2,\#3, and \#4 attained criticality at $445.3 \mathrm{~mm}$. The two smaller tanks were, again, subcritical; but the asymptotic multiplication was a little greater: about four. The lowest critical height was greater than that for the cadmium-wrapped plug, suggesting a uniformly distributed boron absorber might be a better absorber than the cadmium laminated case. On the other hand, the reverse was true for the 3-tank and 2-tank cases. Even the subcritical condition was slightly more reactive $(M=4)$ than the cadmium-lined case $(M=3)$.

The $22 \times 8$ concrete plug having $1.2 \% \mathrm{~B}$ was used next. This is one of the plugs that partially collapsed during casting and now had a cross section different from that planned. It may be assumed essentially solid $(22 \times 0)$ over the critical heights eventually obtained. It weighed $984.3 \mathrm{~kg}$ a few days before use. Solution in four tanks yielded a critical height of $290.6 \mathrm{~mm}$. This is almost identical to the previous case $(289.2 \mathrm{~mm})$; but, then, it ought to be because this 
was a solid plug near the bottom; and the previous case was almost solid and the same material. The 3-tank case achieved criticality at $471.0 \mathrm{~mm}$. The 2-tank case was, again, well subcritical.

The $22 \times 8$ plaster plug containing $1.1 \% \mathrm{~B}$ was inserted next. It weighed $882.8 \mathrm{~kg}$. The critical height with solution in all four tanks was $295.5 \mathrm{~mm}$ and $511.5 \mathrm{~mm}$ when three were filled. Tanks \#3 and \#4 again were well subcritical. Comparing this set with the previous three critical heights reveals these were slightly less reactive. The difference may have been due to the difference between plaster and concrete or (more likely) to the slight difference in boron loading and the effective thickness of the plug near the bottom of the tanks.

The next experiment was the first to contain a concrete plug with the higher $(2.5 \%)$ boron concentration. This was the $22 \times 16$ concrete plug; and it weighed $488.6 \mathrm{~kg}$ just before use. Four tanks produced a critical height of $293.9 \mathrm{~mm}$, whereas tanks $\# 2, \# 3$, and \#4 attained criticality at $483.5 \mathrm{~mm}$. The smaller two were, again, well subcritical. Comparing results with this plug with the similar one at a lower boron concentration (three paragraphs above) yields a surprising observation: critical heights are only slightly greater (2\% and $9 \%$ ) even though the boron concentration is more than doubled!

The next plug used was the thinner plaster one. This $22 \times 16$ plug contained $1.1 \% \mathrm{~B}$ and weighed $468.4 \mathrm{~kg}$ a few days before use. The critical height with all four tanks containing 
solution was $289.6 \mathrm{~mm}$. This time, criticality was achieved with two different sets of three tanks. When the same three tanks were filled as before (\#2 through \#4), the critical height was $463.7 \mathrm{~mm}$. When the smallest tank (\#4) was emptied and solution readmitted into the largest, then tanks \#1,\#2, and \#3 attained criticality at $439.4 \mathrm{~mm}$. One argument in support of this significant decrease is that the plug used intercepted fewer neutrons moving across the tank because it subtended a smaller solid angle.

Both tanks \#2 and \#3 and tanks \#3 and \#4 proved to be subcritical when either pair was filled with solution. Evidently, almost any amount of absorber contained in a plug of almost any thickness was sufficient to render two tanks well subcritical. Still some absorber was necessary because no plug at all and the concrete plug containing no absorber had allowed two tanks to achieve criticality.

This observation was confirmed again by the next experiment. A thin concrete plug containing no boron at all replaced the $1.1 \%$ B plaster one. This $22 \times 16$ concrete plug weighed $554.9 \mathrm{~kg}$ the day before use. Four tanks attained criticality at $255.9 \mathrm{~mm}$. Three (\#2 through \#4) had a critical height of $373.8 \mathrm{~mm}$. Tanks \#3 and \#4 became critical at $795.0 \mathrm{~mm}$ while tanks \#2 and \#3 achieved criticality at $1033.0 \mathrm{~mm}$. Again, the absence of any amount of a recognized absorber allowed criticality to occur in just two tanks. These last two critical heights, however, were a little surprising. If the solid angle subtended argument of the previous paragraph were to 
apply, the middle pair of tanks should have exhibited a lower critical height than the smaller pair. The only explanation offered for the observed opposite result assumes reflection to be most important: The middle pair were further from any reflector, wall, or plug and may have attained that greater critical height because of decreased reflection.

The final set of six approaches to criticality with this configuration ignored earthen plugs altogether. In their place, drums of water were used. Two 55-gallon-sized, painted mild steel, open-topped drums were welded together to form one tall cylinder. These are drums normally used in the manufacture of cheese. Weights of these drums were not recorded; but they appeared to be typical drums of that nominal size. The average outside diameter was $570 \mathrm{~mm}$; and, when lowered onto the same wooden supports used for the earthen plugs, the top of the drum came to within $358 \mathrm{~mm}$ of the top of the tanks. The steel may be assumed to be almost pure iron; an impurity analysis revealed $0.32 \% \mathrm{Mn} \cdot$ and $0.08,0.06,0.043,0.04,0.025,0.019$, and $0.011 \% \mathrm{Si}$, $\mathrm{Al}, \mathrm{C}, \mathrm{Cr}, \mathrm{Ni}, \mathrm{S}$, and $\mathrm{N}$, respectively. The paint pigment was titanium dioxide and contained $10 \%$ Ti. Paint impurities were 0.8 and $0.3 \% \mathrm{Fe}$ and $\mathrm{Al}$ respectively.

For the first three approaches, these drums were filled with ordinary tap water. The water was not analyzed but is not expected to contain significant impurities. Water came to within $6 \mathrm{~mm}$ of the top. With fissile solution in all four tanks, the critical height was $283.2 \mathrm{~mm}$. 
It increased for tanks \#2 through \#4 to $434.8 \mathrm{~mm}$. The water-filled drums rendered tanks \#3 and \#4 well subcritical.

These results are quite similar to cases for earthen materials containing any absorber. Critical heights for four tanks ranged between 285 and $295 \mathrm{~mm}$; and the 3-tank case varied between 445 and $480 \mathrm{~mm}$. The 2-tank nesting was always subcritical with any amount of. absorber. Still, in this water-only case, the water moderator did not intentionally contain any absorber. One qualitative argument supporting this is that the hydrogen in ordinary water is known to be a fair neutron absorber in its own right.

Water for the second three critical approaches had dissolved boron salts to increase absorption. Unfortunately, the boron-loaded solution was not well prepared; so the actual boron content of the water is possibly in question. Preparation began with commercial sodium tetraborate decahydrate, $11.3 \% \mathrm{~B}$. Three mixing containers were filled with $447.2 \mathrm{~kg}$ of water to which $41 \mathrm{~kg}$ of that salt was added. This was sparged by bubbling air in an effort to dissolve all salt. Complete dissolution would have dissolved $4.63 \mathrm{~kg} \mathrm{~B}(11.3 \%$ of $41 \mathrm{~kg})$ in $447.2 \mathrm{~kg}$ of water: $1.03 \%$ B. Not all salt, however, dissolved; sizeable pieces of damp salt settled to the bottom. Even repeated sparging the next day did not complete the task. As a compromise, the over-saturated salt was allowed to rest undisturbed for a few hours. Then, boron solution of unknown concentration was siphoned off the top of the mixing vats into the empty cheese drum. 
This solution was filled to within $23 \mathrm{~mm}$ of the top; and four samples were sent to the laboratory to determine the actual boron concentration achieved. Their results were: $5.3 \pm 0.1 \mathrm{~g} \mathrm{~B}$ per liter of water. The calculated volume of water in drums of this diameter to that height would be about 407 liters. The measured solution concentration suggests that $2.16 \mathrm{~kg}$ of boron (less than half the $4.63 \mathrm{~kg}$ planned) had been dissolved. Assuming these values, the $5.3 \mathrm{~g} \mathrm{~B} /$ liter solution implied the boron-loaded water plug contained $0.48 \% \mathrm{~B}$.

With this borated water plug inside the smallest tank, the critical height for four tanks containing fissile solution was $303.4 \mathrm{~mm}$. The critical height for tanks \#2, \#3, and \#4 was 533.8 mm. Two tanks (\#3 and \#4), again, proved to have almost no reactivity; the asymptotic multiplication was barely more than two. The small amount of boron did increase the critical height as expected but certainly not to any remarkable degree.

Table XVI summarizes results discussed in separate paragraphs above for quick reference.

\section{$\underline{1 \times 3 \text { Array of Nested Pairs: }}$}

The arrangement of concrete reflector panels on the elevated platform is partially dimensioned in Fig. 35. Circles represent tanks. The outside diameter of the largest and inside diameter of the smallest of each pair is roughly to scale. Table XVII is needed to complete the detailed description of this configuration. All seven panels were used; and even this was 
Table XVI. "Single Tank" Composed of Four Nesting Tanks.

\begin{tabular}{|c|c|c|c|}
\hline $\begin{array}{l}\text { Tanks } \\
\text { Filled } \\
(\# 1, \# 2, \# 3, \# 4)\end{array}$ & $\begin{array}{c}\Delta R \\
\text { Net } \\
\text { Radial } \\
\text { Thickness } \\
\text { of Solution } \\
\text { (mm) }\end{array}$ & $\begin{array}{c}\text { Plug } \\
\mathrm{OD}=559 \mathrm{~mm}\end{array}$ & $\begin{array}{l}\text { Critical Solution } \\
\text { Height (mm) } \\
\text { or } \\
\text { Asymptotic } \\
\text { Inverse Neutron } \\
\text { Count Rate }\end{array}$ \\
\hline$\bullet \bullet$ & 76.2 & \multirow{3}{*}{ None } & 929.8 \\
\hline$\bullet \bullet \bullet \bullet$ & 152.4 & & 271.9 \\
\hline$\bullet \bullet$ & $\begin{array}{r}114.3 \\
76.2\end{array}$ & & $\begin{array}{l}396.4 \\
934.6\end{array}$ \\
\hline$\bullet \bullet$ & 152.4 & \multirow[b]{2}{*}{ Solid concrete containing no boron: $1200 \mathrm{~kg}$} & 259.4 \\
\hline$\bullet \bullet$ & $\begin{array}{r}114.3 \\
76.2\end{array}$ & & $\begin{array}{r}356.5 \\
1064.8\end{array}$ \\
\hline$\stackrel{\bullet \bullet \bullet}{\bullet \bullet \bullet}$ & $\begin{array}{r}152.4 \\
114.3 \\
76.2\end{array}$ & $\begin{array}{l}\text { Solid concrete containing no boron: } 1200 \mathrm{~kg} \\
\text { but this concrete cylininer has been wrapped } \\
\text { with a 1.6-mm-lhick layer of pure cadmium metal. } \\
\text { This weighed } 55.2 \mathrm{~kg} .\end{array}$ & $\begin{array}{l}285.6 \\
460.5 \\
0.33\end{array}$ \\
\hline $\begin{array}{ll}\bullet \bullet \bullet \\
\bullet \bullet \bullet \\
\bullet \bullet\end{array}$ & $\begin{array}{r}152.4 \\
114.3 \\
76.2\end{array}$ & $\begin{array}{l}\text { Thin concrete annulus at } 1.2 \% \mathrm{~B}: 525 \mathrm{~kg} \\
\qquad \mathrm{ID}=406 \mathrm{~mm}\end{array}$ & $\begin{array}{l}289.2 \\
445.3 \\
0.25\end{array}$ \\
\hline 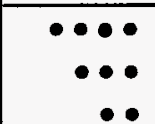 & $\begin{array}{l}152.4 \\
114.3 \\
76.2\end{array}$ & $\begin{array}{l}\text { Thick concrete annulus at } 1.2 \% \mathrm{~B}: 984 \mathrm{~kg} \\
\text { but inner form collapsed during manufacture. } \\
\qquad \mathrm{ID}=203 \mathrm{~mm}\end{array}$ & $\begin{array}{l}290.6 \\
471.0 \\
0.37\end{array}$ \\
\hline$\stackrel{\bullet \bullet}{\bullet \bullet}$ & $\begin{array}{r}152.4 \\
114.3 \\
76.2 \\
\end{array}$ & $\begin{array}{l}\text { Thick plaster annulus at } 1.1 \% \mathrm{~B}: 883 \mathrm{~kg} \\
\qquad \mathrm{ID}=203 \mathrm{~mm} \\
\end{array}$ & $\begin{array}{l}295.5 \\
511.5 \\
0.40\end{array}$ \\
\hline$\because \bullet \bullet$ & $\begin{array}{r}152.4 \\
114.3 \\
76.2\end{array}$ & $\begin{array}{l}\text { Thin concrete annulus at } 2.5 \% \mathrm{~B}: 489 \mathrm{~kg} \\
\qquad \mathrm{ID}=406 \mathrm{~mm}\end{array}$ & $\begin{array}{l}293.9 \\
484.5 \\
0.33\end{array}$ \\
\hline $\begin{array}{l}\bullet \bullet \bullet \bullet \\
\bullet \bullet \bullet \\
\bullet \bullet \\
\bullet \bullet \\
\bullet \bullet\end{array}$ & $\begin{array}{r}152.4 \\
114.3 \\
114.3 \\
76.2 \\
76.2\end{array}$ & $\begin{array}{l}\text { Thin plaster annulus at } 1.1 \% \mathrm{~B}: 468 \mathrm{~kg} \\
\qquad I \mathrm{D}=406 \mathrm{~mm}\end{array}$ & $\begin{array}{l}289.6 \\
463.7 \\
439.4 \\
0.16 \\
0.30 \\
\end{array}$ \\
\hline 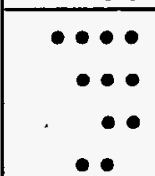 & $\begin{array}{r}152.4 \\
114.3 \\
76.2 \\
76.2\end{array}$ & $\begin{array}{l}\text { Thin concrete annulus containing no boron: } 555 \mathrm{~kg} \\
\qquad I \mathrm{D}=406 \mathrm{~mm}\end{array}$ & $\begin{array}{r}255.9 \\
373.8 \\
795.0 \\
1033.0\end{array}$ \\
\hline$\because \bullet \bullet$ & $\begin{array}{r}152.4 \\
114.3 \\
76.2\end{array}$ & \multirow{2}{*}{$\begin{array}{l}\text { Two steel drums } \\
572 \mathrm{~mm} \text { diameter } \\
\times 1750 \mathrm{~mm} \text { high } \\
\text { welded together } \\
\text { end-to-end. }\end{array}$} & $\begin{array}{l}283.2 \\
434.8 \\
0.29 \\
\end{array}$ \\
\hline 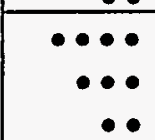 & $\begin{array}{r}152.4 \\
114.3 \\
76.2\end{array}$ & & $\begin{array}{l}303.4 \\
233.8 \\
0.45\end{array}$ \\
\hline
\end{tabular}




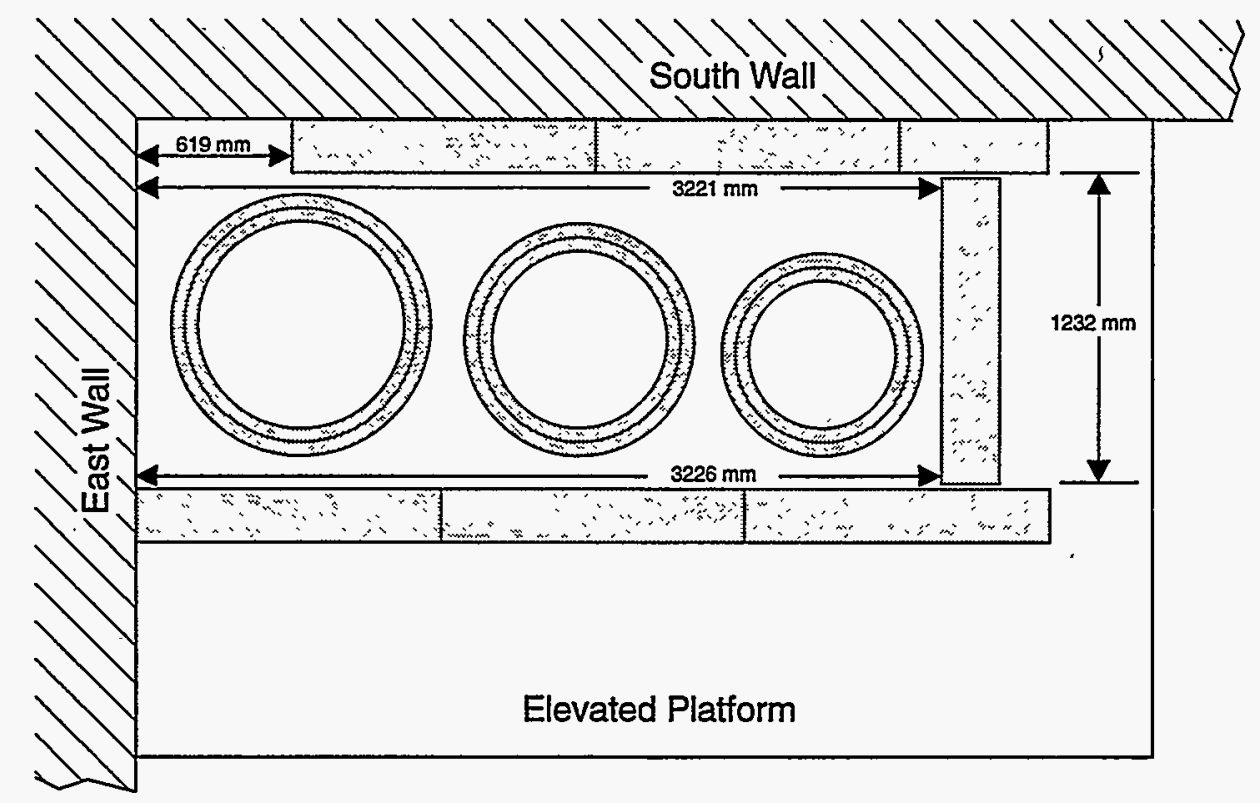

Figure 35. All wall panels were insufficient to surround the $1 \times 3$ array of the second configuration. 
Table XVII. North/South Dimensions for Reflector Wall Panels for the $1 \times 3$ Array of Nested Pairs of Tanks.

\begin{tabular}{|c|c|c|c|c|}
\hline \multirow{2}{*}{$\begin{array}{c}\text { Distance West } \\
\text { from the } \\
\text { East Room } \\
\text { Wall } \\
\text { (m) }\end{array}$} & \multicolumn{2}{|c|}{$\begin{array}{l}\text { South Room Wall } \\
\text { to the Inside Face } \\
\text { at North Reflector } \\
\text { Panels }(\mathrm{mm})\end{array}$} & \multicolumn{2}{|c|}{$\begin{array}{l}\text { Between } \\
\text { Reflector } \\
\text { Panels } \\
\text { (mm) }\end{array}$} \\
\hline & Top & Bottom & Top & Bottom \\
\hline 0.0 & 1429 & 1473 & & \\
\hline 0.6 & 1422 & & 1219 & \\
\hline 1.2 & 1416 & & 1200 & \\
\hline 1.8 & 1416 & & 1178 & \\
\hline 2.4 & 1422 & & 1187 & 1216 \\
\hline 2.6 & & & 1191 & 1195 \\
\hline 2.8 & 1448 & & 1213 & \\
\hline $3.7^{\mathrm{a}}$ & 1451 & 1464 & $1232^{b}$ & 1241 \\
\hline
\end{tabular}

a. Outside the reflector enclosure.

b. Same dimension as in Fig. 35. 
inadequate to surround the large array completely. The east wall of the Assembly Room was used as one reflection face; and Fig. 35 reveals a complication along the south wall. Cast panels might not fit together perfectly; so outside dimensions of the finished reflector enclosure were measured. Nominal dimensions would generally be a little smaller. Figure 36 is a photograph confirming this description and illustrating details.

Inside dimensions of the enclosure are very important. These were measured near the top of the configuration and closer to the floor. Results, presented in Table XVII, reveal another nearly perfect enclosure. Table XVIII records the closest distance between the largest tank of each pair and nearby walls and tanks. This was, again, measured both high and low.

Setting up this array after the single-tank study involved reinstalling the Level Detector. The possibility exists, then, that the bias in solution height data, if present at all, might be different. This caution is discussed elsewhere.

The first experiment in this second configuration had no plugs inside any tank. Fissile solution was admitted into all six tanks; and the critical height was $713.4 \mathrm{~mm}$. The next day, the experiment was repeated; but the smallest two tanks (\#3 and \#4) were left empty. The critical height in the other two pair was $841.8 \mathrm{~mm}$. The next day, only the middle pair of tanks (\#2* and \#3*) was filled; and the critical height was $1425.8 \mathrm{~mm}$. 


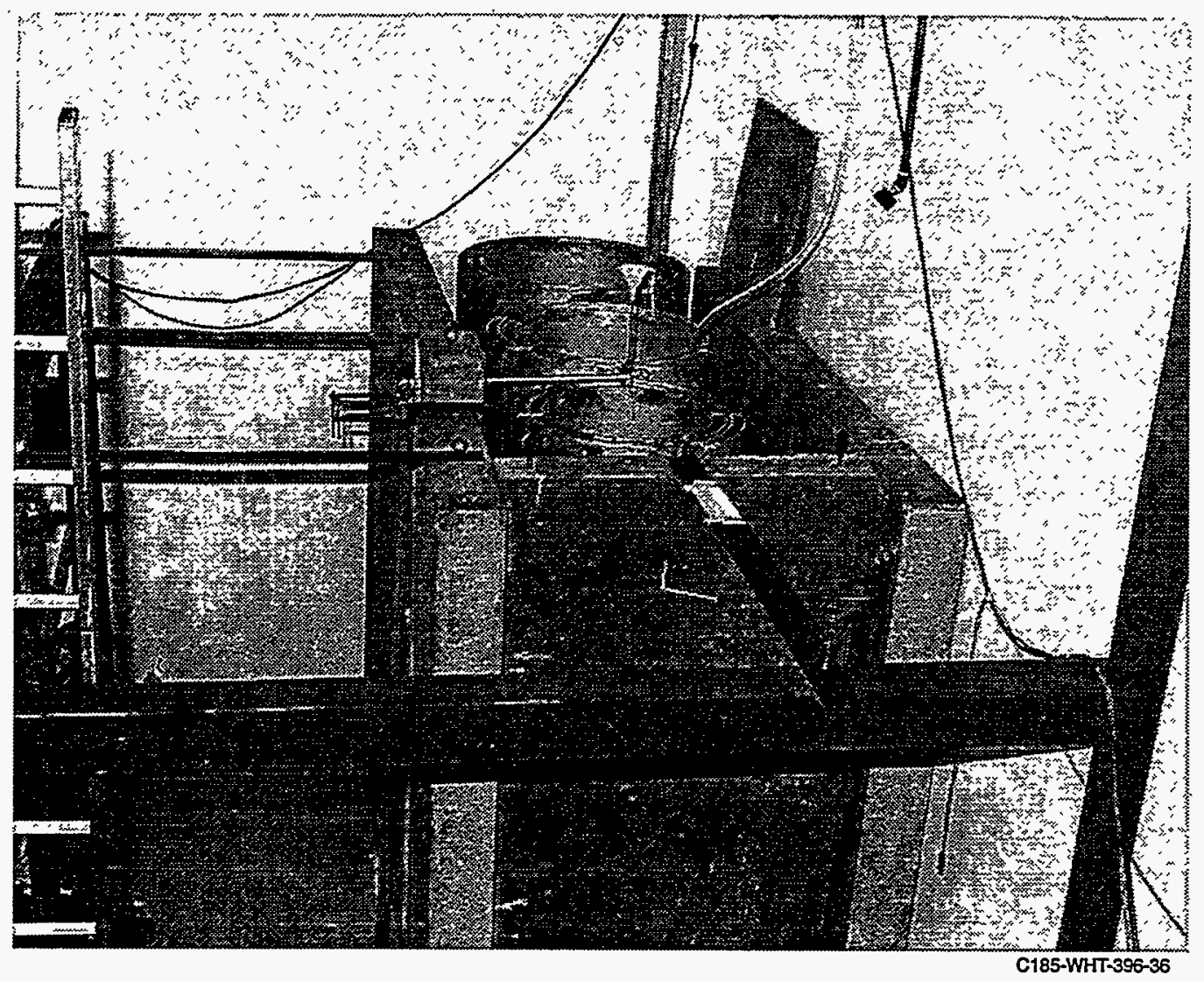

Figure 36. The second configuration without any neutron absorber/moderator components.

RFP photo \# 26692-11 [10/6/80]. 
Table XVIII. Distance Between Nested Pairs of Tanks and Reflector Panels or Neighbor Tanks.

\begin{tabular}{|c|c|c|c|}
\hline From & To & $\begin{array}{l}\text { Top } \\
(\mathrm{mm})\end{array}$ & $\begin{array}{c}\text { Bottom } \\
(\mathrm{mm})\end{array}$ \\
\hline \multirow{4}{*}{ 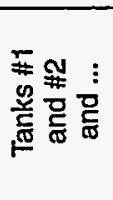 } & East wall of room & 87.3 & 76.2 \\
\hline & North reflector panel & 139.7 & 136.5 \\
\hline & Edge of south reflector panel & 41.3 & 34.9 \\
\hline & Tanks \#2* and \#3* & 147.6 & 158.8 \\
\hline \multirow{3}{*}{ 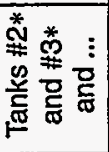 } & North reflector panel & 130.2 & 130.2 \\
\hline & South reflector panel & 133.4 & 130.2 \\
\hline & Tanks \#3 and \#4 & 147.6 & 146.1 \\
\hline \multirow{3}{*}{ 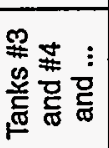 } & North reflector panel & 122.2 & 119.1 \\
\hline & South reflector panel & 271.5 & 277.8 \\
\hline & West reflector panel & 68.3 & 68.3 \\
\hline
\end{tabular}


One final experiment was performed in the absence of absorber. Only the largest tank (\#1) of the largest pair and the middle pair of tanks (\#2* and \#3*) were filled with solution. The critical height for this 3 -tank case was $1181.4 \mathrm{~mm}$. This result seems qualitatively consistent with earlier results from this configuration. The critical height was reasonably less than for the middle pair alone and, yet, significantly greater than for two adjacent nested pair.

The next set of experiments employed plugs within each of the three nested pair. The largest, to the east, received the solid $30 \times 0$ concrete plug containing $1.2 \% \mathrm{~B}$. Space between this plug and the inside of tank $\# 2$ was measured at the top (only) at four points of the compass: north-36 mm, east-28 mm, south-5 mm, and west-20 mm. The center pair ( $\# 2^{*}$ and $\# 3^{*}$ ) received the thick $24 \times 10$ concrete plug containing $1.2 \% \mathrm{~B}$. This was one of the plugs whose top surface slumped a little during casting; so the top of the earthen material was $120 \mathrm{~mm}$ below the top of the paper form. Space between this plug and the inside of tank \#3* was measured at the top at the same four points: $41,7,46$, and $79 \mathrm{~mm}$. Finally, the smallest pair (\#3 and \#4) received the thick walled $22 \times 8$ concrete plug containing $1.2 \%$ B. This plug had also slumped during casting placing its top $170 \mathrm{~mm}$ below the paper. Space between this and the inside of tank \#4 was measured at the same points: $0,5,14$, and $16 \mathrm{~mm}$. 
Two experiments were performed with these plugs. When all six tanks were filled, the critical height was $1346.4 \mathrm{~mm}$. The next day, the smallest pair was kept empty; and the critical height in the other four was $1626.8 \mathrm{~mm}$.

The next change was to exchange the concrete plugs within the two smaller pair of tanks for the only two plaster plugs. The $30 \mathrm{x} 0$ concrete $(1.2 \% \mathrm{~B})$ plug remained untouched inside tank \#2. Tanks \#2* and \#3* received the $22 \times 8(1.1 \% \mathrm{~B})$ plaster plug while the $22 \times 16(1.1 \% \mathrm{~B})$ plaster plug filled the smaller pair. Again, distances between plug and tank were measured at the top only at the four points of the compass: $64,70,60$, and $67 \mathrm{~mm}$ for the center tank and $6,15,7$, and $0 \mathrm{~mm}$ for the western pair. When all six tanks received solution, the critical height was $1331.4 \mathrm{~mm}$; and when only the larger four were filled, that height increased to $1645.6 \mathrm{~mm}$.

This last measurement had about reached the limit of the SCRAM valves to withstand the hydrostatic head of high-density fissile solution exerting pressure against valve seats. Solenoids holding valves closed hummed loudly. Rather than risk initiating a SCRAM by the incremental return of a small amount of solution to obtain a negative reactor period (the usual procedure), more solution was added to obtain a second (shorter) positive reactor period. Then, these date were used to extrapolate the critical case for which the period would be infinite. 
Only one experiment in this $1 \times 3$ array configuration used the concrete plugs containing the highest concentration of boron. The $1.2 \%$ B plugs were temporarily set aside and replaced by the following set. The largest pair of tanks received the $30 \times 18$ concrete plug having $2.5 \% \mathrm{~B}$. This plug's inner form was a length of steel culvert. The central pair received the $22 \times 16$ concrete plug also having $2.5 \% \mathrm{~B}$. This was the only plug at that boron loading that did not have a steel culvert for its inner form. The smallest pair of tanks received the $22 \times 0$ concrete plug with no boron loading but with the lamination of pure cadmium metal around it. This plug had been used in previous experiments. Once again, the space between plug and tank was measured at the top: $15,30,7$, and $30 \mathrm{~mm}$ for tank $\# 2 ; 62,62,62$, and $70 \mathrm{~mm}$ for tank $\# 3^{*}$; and $8,0,8$, and $15 \mathrm{~mm}$ for tank \#4. The single critical height for this case when all six tanks were filled was $1269.9 \mathrm{~mm}$. That was the only experiment using these heavily-boron-loaded plugs.

The next experiment reconstructed the assembly just prior to the last one. That is, the $30 \times 0(1.2 \% \mathrm{~B})$ concrete plug and both $1.1 \% \mathrm{~B}$ plaster plugs were inserted inside tanks. Reflectors and tanks had not been moved. The purpose of this reassembly was to measure repeatability. The result was a critical height of $1322.1 \mathrm{~mm}$ to be compared with the earlier value: $1331.4 \mathrm{~mm}$. The only recorded difference between experiments, performed 55 days apart, was the spacing between plugs and tanks resulting from reassembly. This evidently accounted for the observed decrease. Current and previous spacings in millimeters at the top at the four compass points, were: 


\begin{tabular}{llll} 
Tank & \multicolumn{1}{c}{ Plug } & \multicolumn{1}{c}{ Current } & . Previous \\
\#2 & 30x0 concrete (1.2\% B) & $34,46,7,3$ & $36,28,5,20$ \\
$\# 3 *$ & 22x8 plaster (1.1\% B) & $62,69,70,66$ & $64,70,60,67$ \\
$\# 4$ & $22 \times 16$ plaster (1.1\% B) & $13,14,2,0$ & $6,15,7,0$
\end{tabular}

The more than $10 \mathrm{~mm}$ difference in critical heights for this repeatability experiment may be due to these slight differences in plug placements; but that question has not been studied computationally.

The same array was used next to study the effect of placing bottles of high concentration fissile solution between tanks. This simulated working conditions within a production building where people might walk close to an annular tank holding full bottles of fissile solution. Four 4liter bottles of uranyl nitrate solution were used for this study. The bottles were commercial polyethylene products weighing $370 \mathrm{~g}$ each. They were $146.8 \mathrm{~mm}$ in diameter. Two were filled with $351.64 \pm 0.70 \mathrm{gU} / \mathrm{liter}$ uranyl nitrate solution having a density of $1.4889 \pm 0.0004 \mathrm{mg} / \mathrm{mm}^{3}$. These weighed $5447 \mathrm{~g}$ and $5598 \mathrm{~g}$ because they were filled to slightly different heights. The other two were filled with $86.60 \pm 0.28 \mathrm{gU} /$ liter uranyl nitrate solution having a density of $1.1205 \pm$ $0.0004 \mathrm{mg} / \mathrm{mm}^{3}$. These weighted $3686 \mathrm{~g}$ and $3861 \mathrm{~g}$.

Racks made from a commercial, painted, thin-gauge steel, slotted angle stock were bolted together to hold bottles during the experiment. Both racks happened to weigh $4640 \mathrm{~g}$ each. Each had four vertical legs $1.5 \mathrm{~m}$ tall bolted to short horizontal lengths that also supported the bottles. 
The rack for the high concentration solution located the bottoms of its two bottles $310 \mathrm{~mm}$ and $850 \mathrm{~mm}$ above the floor. The other rack located its bottles $309 \mathrm{~mm}$ and $846 \mathrm{~mm}$ above the floor. Racks did not have diagonal bracing to prevent twisting. Instead, they were pressed against the tanks. The rack containing the two bottles of high concentration solution fit almost perfectly between the largest and center pair of tanks. The other rack was between the other pair of tanks; but these were not perfectly centered because space between did not allow that. Instead, this rack was pressed against the tanks just south of center. Records do not indicate which bottle of each pair (they differed slightly in weight) sat on which shelf. Each bottle was encased in a single light weight plastic bag for contamination control purposes.

When all six tanks received uranium solution, the critical height was $1127.8 \mathrm{~mm}$. The existence of these four bottles (A total of 16 liters of uranium solution!) had decreased the critical height by almost $100 \mathrm{~mm}$. The study continued by draining solution from tanks $\# 1$ and $\# 2$ and resuming the approach toward criticality with the other four tanks. A quite long $(+12.4$ minute) positive reactor period was attained at a solution height of $1451.3 \mathrm{~mm}$; but the system experienced a SCRAM due to the great hydrostatic pressure while attempting to achieve a negative period. The critical height claimed for this one case is a little less precise that all other cases; so it is quoted with less precision: $1451 \mathrm{~mm}$. 
The same array was used one more time to evaluate the reduction in tank-to-tank interaction by inserting plaster absorber/moderator slabs within the array. The weights of the four $1.1 \%$ B plaster slabs a few days before use, including plywood forms, were $275.6,266.1$, 121.9 , and $117.0 \mathrm{~kg}$. Solution-carrying hoses needed to pass between tanks; so slabs between tanks were raised $38 \mathrm{~mm}$ by resting on small blocks of wood $(38 \times 89 \times 76 \mathrm{~mm})$. This cleared hoses on the floor but raised the slabs above the reflector as seen in Fig. 37. The other two slabs were not elevated as seen in the same figure.

In one experiment, both thicker slabs were about centered in the space between nested pairs of tanks. One was between tank \#1 and tank $\# 2^{*}$; the other, between $\# 2^{*}$ and \#3. Slabs were held in place by small wedges of wood. The $117.0 \mathrm{~kg}$ slab was placed inside the enclosure but against the west wall. This is the experiment photographed in Fig. 37. Distances between tanks, slabs, and the end reflector panel are listed below from east to west:

Tank \#1 to closest face of $275.6 \mathrm{~kg} \mathrm{slab} \ldots . . .32 \mathrm{~mm}$, Opposite face of $275.6 \mathrm{~kg}$ slab to Tank \#2*... $35 \mathrm{~mm}$, Tank \#2* to closest face of $266.1 \mathrm{~kg}$ slab .... $33 \mathrm{~mm}$, Opposite face of $266.1 \mathrm{~kg}$ slab to Tank \#3 .... $25 \mathrm{~mm}$, Tank \#3 to closest face of $117.0 \mathrm{~kg} \mathrm{slab} . . . .25 \mathrm{~mm}$, and $117.0 \mathrm{~kg}$ slab to inside face of west panel ... $0 \mathrm{~mm}$.

Even with all six tanks receiving solution, this set-up simply had too much absorber. The reciprocal multiplication curve became flat at a multiplication of only about four. 

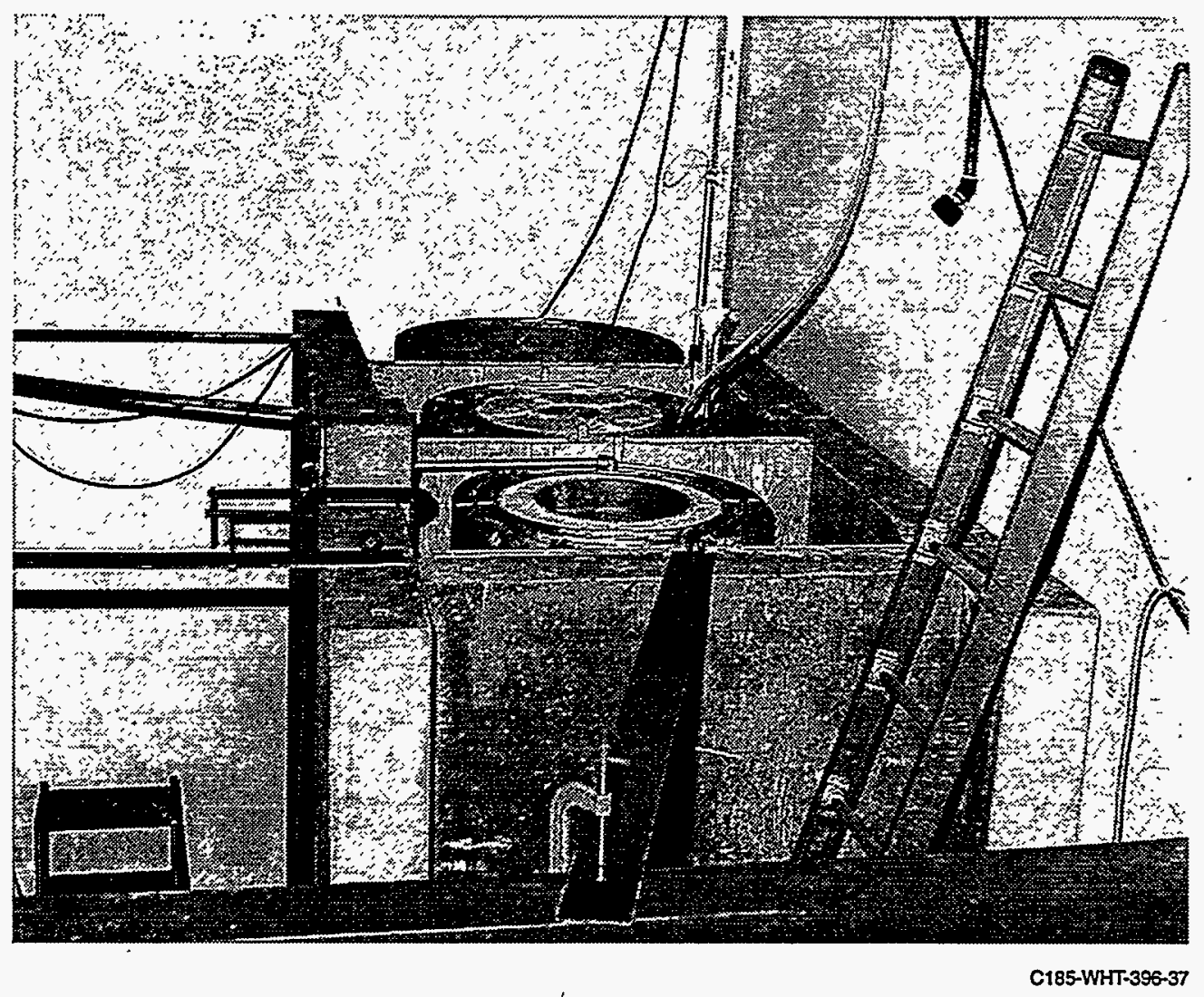

Figure 37. The second configuration with both plugs and slabs within the array.

RFP photo \# 27021-2 [1/15/81]. 
The next experiment had the same arrangement of tanks and plugs; but slabs were totally rearranged. All three from the previous measurement were removed; and only the thinner two were positioned between the nested pairs of tanks. Neither thick slab appeared anywhere in the array. Specifically, distances between tanks and slabs were, from east to west:

Tank \#1 to closest face of $121.9 \mathrm{~kg}$ slab ..... $48 \mathrm{~mm}$, Opposite face of $121.9 \mathrm{~kg}$ slab to Tank \#2* ... $48 \mathrm{~mm}$, Tank \#2* to closest face of $117.0 \mathrm{~kg} \mathrm{slab} . . .46 \mathrm{~mm}$, and Opposite face of $117.0 \mathrm{~kg}$ slab to Tank \#3 .... $46 \mathrm{~mm}$.

When solution was admitted to all six tanks, almost the entire holding of high-concentration uranium solution (about 1060 liters) at the Rocky Flats CML had been pumped into the array. By the time the solution height reached $1690 \mathrm{~mm}$, the multiplication had reached about 40 . A linear extrapolation of the reciprocal multiplication curves showed that criticality would occur at about $1760 \mathrm{~mm}$. Insufficient liquid remained in the storage tanks, however, to approach closer. This one experiment (only), then, has its critical height inferred from an extrapolation of its reciprocal multiplication curve. This curve and that extrapolation are reproduced in Fig. 38. The two curves $(\theta$ and $x)$ represent count rate data from two different radiation detectors; and the extrapolation above $1690 \mathrm{~mm}$ is shown dashed. The uncertainty of this one critical height is larger than those bounded by super critical and subcritical reactor periods, probably about \pm 3 mm. 


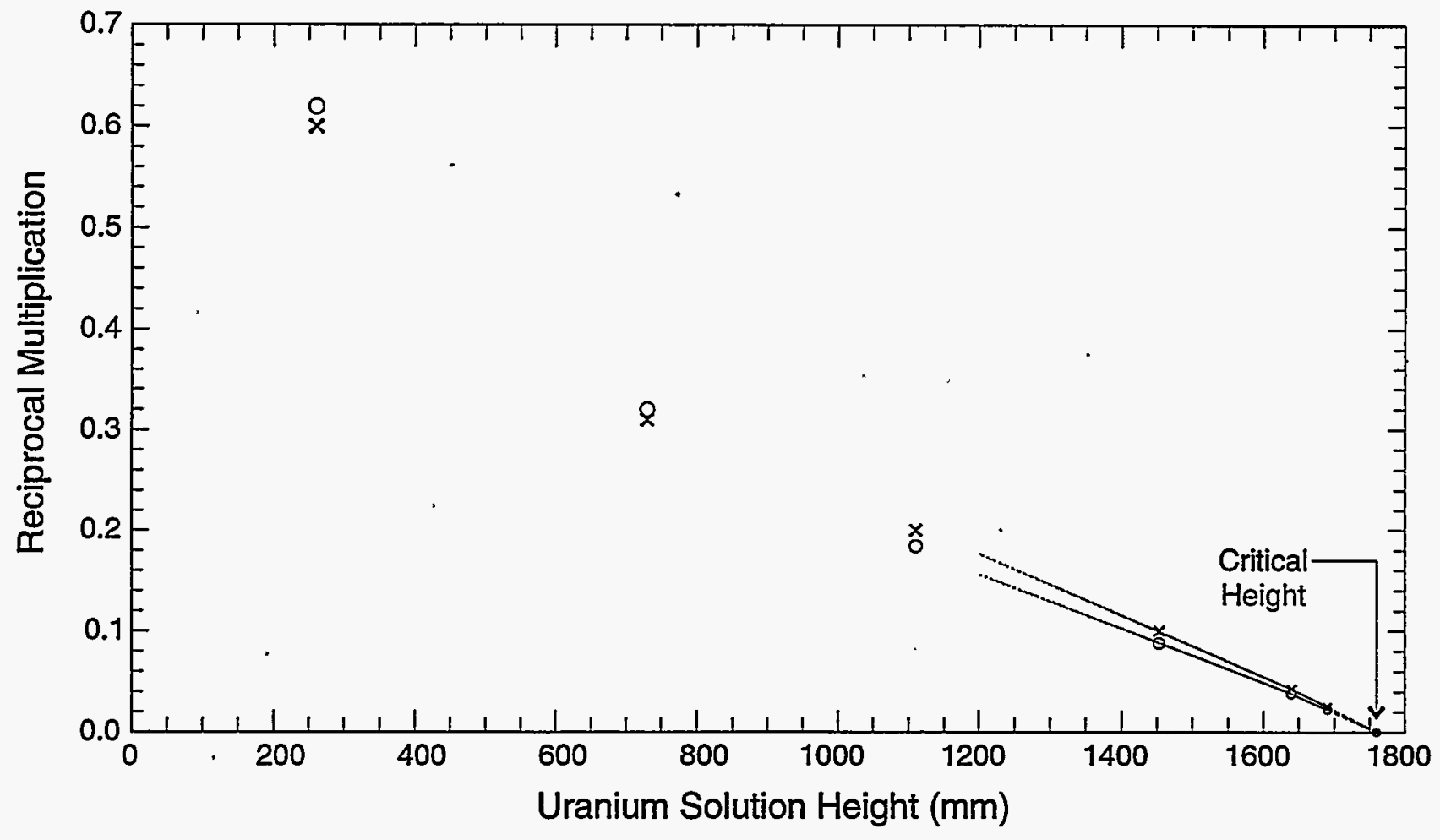

Figure 38. The critical height for one experiment had to be inferred from an extrapolation of the reciprocal multiplication data because the supply of high-concentration uranyl nitrate solution had been exhausted. Criticality corresponds to the ordinate equals zero. 
The only change for the next experiment was to remove the plug from the center pair of nested tanks. Both other pair still contained plugs; and the two slabs remained between the three nested pair. The goal was to increase reactivity and achieve a lower critical height $(895.1 \mathrm{~mm})$ with solution in all six tanks. Solution was drained from the largest pair (\#1 and \#2); and the critical height in the remaining four tanks was $1032.2 \mathrm{~mm}$.

The last experiment at this $1 \times 3$ tank array configuration found the $24 \times 101.1 \%$ B plug returned to the interior of the central nested pair. Unfortunately, spacings between plug and tank were not measured this time. Other than that, all plugs and tanks were as they had been for the previous several experiments. All flat slabs were removed and stored.

The new feature for this last experiment was the presence of hemispheres of $93.17 \%$ enriched ${ }^{235} \mathrm{U}$ metal between the tanks. This was quite similar to the earlier experiment which had bottles of fissile solution in similar locations. People might carry containers of fissile metal close to an annular tank. The same racks were rebuilt to support these uranium metal pieces. Each hemisphere was composed of 13 nested hemispherical metal shells. The effective density of the nested metal was $18.1 \mathrm{mg} / \mathrm{mm}^{3}$; the density of each shell was $18.664 \mathrm{mg} / \mathrm{mm}^{3}$. Nested shells were bagged in plastic for contamination control and placed in thin cubical aluminum cans (152 $\mathrm{mm}$ on a side, $1.6 \mathrm{~mm}$ thick, weighing $527 \mathrm{~g}$ ). Hemispheres were oriented face down (pole 
up) $610 \mathrm{~mm}$ above the floor. The hemisphere between the largest pairs of tanks weighed 8.154 $\mathrm{kg}$; the other one weighed $8.161 \mathrm{~kg}$.

Table XIX summarizes results for the $1 \times 3$ array discussed in separate paragraphs above for quick reference.

$\underline{1 \times 2 \text { Array of Nested Triples: }}$

Only three experiments were performed with this configuration; but each yielded two critical heights. The two included all six tanks filled and solution admitted to only the three smaller tanks. The first pair had the arrangement of tanks, reflector panels, plugs, and slabs dimensioned in Fig. 39. The other two involved removal of components only with no other changes. The second pair had all slabs removed but plugs remained; and the last pair had all plugs and all slabs absent. This last pair formed just two sets of nested tanks closely reflected by concrete wall panels.

Most dimensions on the figure were made at the top because experience with both previous configurations revealed little difference at top or near the floor; all components stood quite vertical. Those few measurements near the floor are enclosed in parentheses. 
Table XIX. Results for $1 \times 3$ Array.

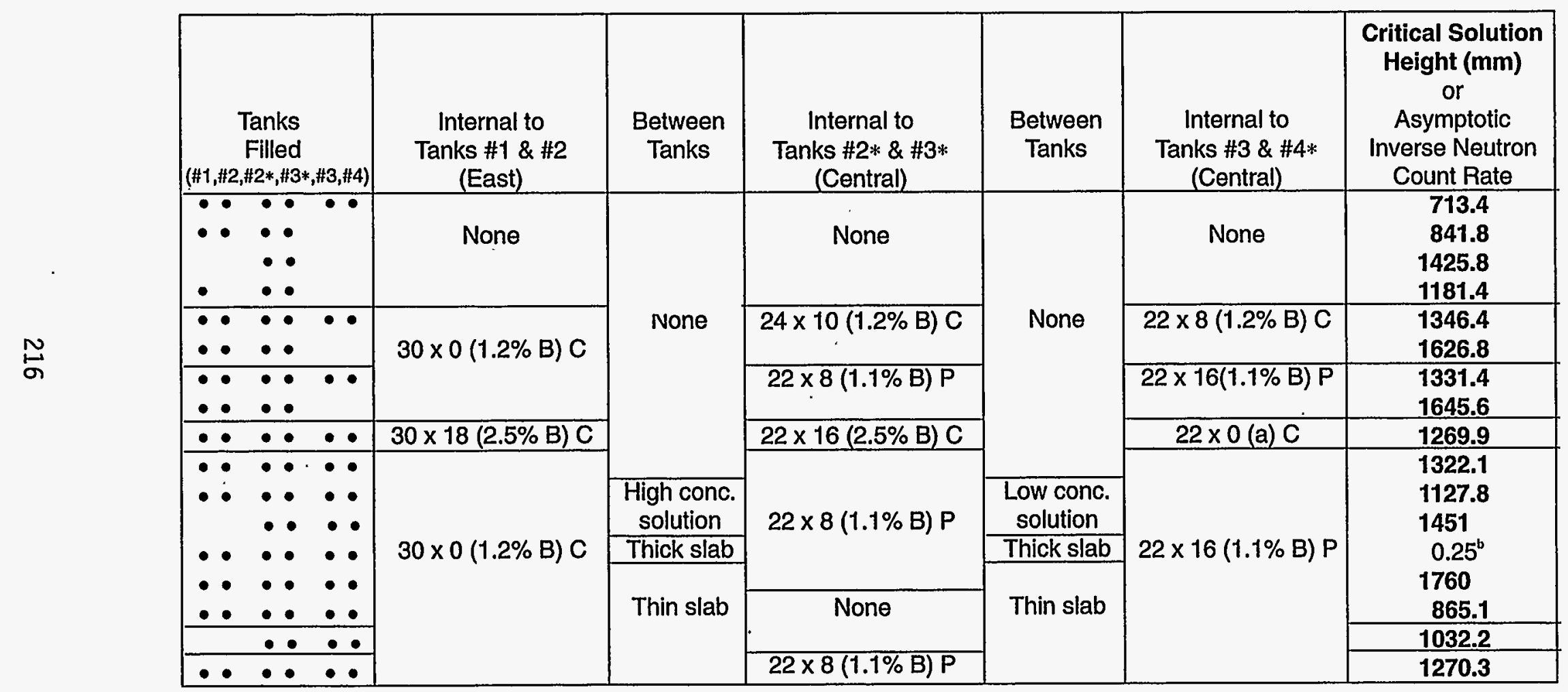

a. Concrete plug contained no boron but was wrapped with sheet cadmium metal.

b. A thin slab pressed against the west reflector panel. 


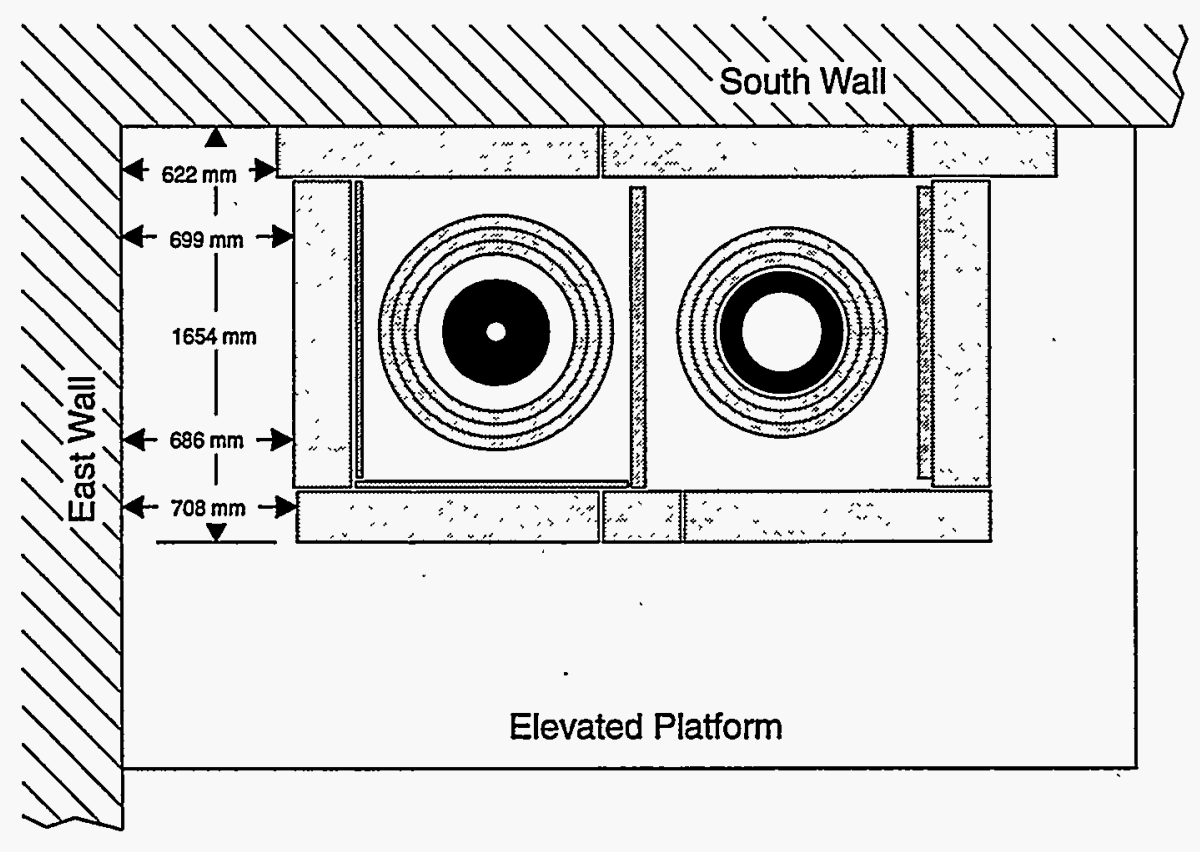

Figure 39. The most complicated case for the $1 \times 2$ array of the third configuration included two plugs and four slabs. Other experiments simply had components removed. 
The thick-walled plug inside the larger set of tanks to the east was the $22 \times 8$ plaster plug containing $1.1 \%$ B. Space between this plug and tank $\# 2 *$ was measured at the top (only): 61 , 36,75 , and $91 \mathrm{~mm}$. The thinner plug inside the other set was the $22 \times 16$ plug of the same material. Space between this and tank \#4 was: $13,10,0$, and $5 \mathrm{~mm}$.

A thick slab separated the two tank sets; and the other thick slab pressed against the west wall. The two thinner plaster slabs were placed against the east and north walls as shown in the figure. No distinction was recorded as to which slab of either thickness was used where. Table XX details the locations of these sets of tanks relative to reflector panels and slabs.

As stated earlier, only four sight gauges were used to indicate the solution height in the six tanks. Tanks \#1 and \#2 and tanks \#3 and \#4 shared common gauges. Another installation of the Level Detector was required at the beginning of this configuration; so the possibility exists that a new bias may need to be established for this set of results.

When fissile solution was admitted to all six tanks assembled as shown in Fig. 39, the critical height was $462.7 \mathrm{~mm}$. Solution was drained from the larger three, rendering the system well subcritical. More solution was added to those until a new critical height of $553.2 \mathrm{~mm}$ was established. 
Table XX. Distance Between Nested Triples of Tanks and Reflector Panels or Neighboring Tanks.

\begin{tabular}{|c|c|c|}
\hline From & To & $\begin{array}{l}\text { Top } \\
(\mathrm{mm})\end{array}$ \\
\hline \multirow{7}{*}{ 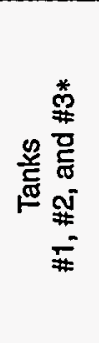 } & East reflector panel & 93 \\
\hline & Closest face of east thin slab & 33 \\
\hline & North reflector panel & 148 \\
\hline & Closest face of north thin slab & 97 \\
\hline & South reflector panel & 53 \\
\hline & Nested Tanks \#2*, \#3, and \#4 & 133 \\
\hline & East face of thick slab between tanks & 25 \\
\hline \multirow{6}{*}{ 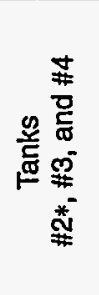 } & North reflector panel & 185 \\
\hline & West reflector panel & 133 \\
\hline & Closest face of west thick slab & 49 \\
\hline & South reflector panel & 123 \\
\hline & Nested Tanks \#1, \#2, and \#3* & 133 \\
\hline & West face of thick slab between tanks & 31 \\
\hline
\end{tabular}


All slabs were removed for the next experiment. This left plugs inside the tanks with a close concrete reflector still in place. The critical height for solution in all six tanks was 417.4 $\mathrm{mm}$; and the smaller three yielded $554.1 \mathrm{~mm}$.

The final experiment at this configuration had no plugs and no slabs. Only the tanks within the reflector remained. The critical height with all tanks full was $359.7 \mathrm{~mm}$. It raised to $448.7 \mathrm{~mm}$ for only the smaller three tanks.

Table XXI summarizes the results for this third configuration for quick reference.

Training Experiments:

The $1 \times 2$ array configuration sat upon the elevated platform drained of solution for over a year while other activities took place at the CML. When one Experimenter announced his planned retirement, a replacement was needed. Another individual was partly trained but needed experience at performing critical experiments to complete his training. The existing configuration was reactivated to allow the needed experience.

The tanks and east and south reflector panels had remained untouched since the last experiment. Only the other four reflector pieces and slabs had been moved to a more convenient 
Table XXI. Experimental Critical Heights for the $1 \times 2$ Array of Nested Tank Triples.

\begin{tabular}{|c|c|c|}
\hline \multirow{2}{*}{$\begin{array}{c}\text { Component } \\
\text { Arrangement }\end{array}$} & \multicolumn{2}{|c|}{ Critical Height (mm) } \\
\cline { 2 - 3 } & All tanks & $\# 2 *$ \#3, \#4 \\
\hline $\begin{array}{l}\text { Plugs \& slabs as } \\
\text { shown in Fig. 39 }\end{array}$ & 462.7 & 553.2 \\
\hline Slabs removed & 417.4 & 554.1 \\
\hline $\begin{array}{l}\text { Slabs \& plugs } \\
\text { removed }\end{array}$ & 359.7 & 448.7 \\
\hline
\end{tabular}


location. They were supported between the north edge of the east reflector panel and the superstructure above the platform. This collection of eight components were simply stacked like books on a shelf. The east panel about bisected the unused components; but neither their exact placement nor order stored was recorded.

Solution heights during this training program were obtained from the Sight Gauge by the trainee because it was the most direct and straightforward method. The Mass Flow Meter had been purchased and installed but not yet tested; so no results quoted here were derived from that. The trainee observed the calibrated scale alongside the Sight Gauge. A second scale had been used to relate the first to actual heights in the tanks: one meter above the floor was observed to correspond to $587 \mathrm{~mm}$ on the Sight Gauge scale. The tank bottom was ill-defined because of its slope; but the following formula can be used to obtain critical heights from Sight Gauge readings:

$$
\begin{aligned}
\text { critical height } & =\text { observed Sight Gauge value }+413 \mathrm{~mm} \\
& - \text { height of tank bottom above floor. }
\end{aligned}
$$

The trainee filled all six tanks and the smaller set of three several times but was not allowed to achieve criticality. Finally, he was allowed to attain the critical condition in the one set of three under the watchful eye of the Senior Experimenter. Two successive experiments, with no changes between, yielded readings (applicable to the above formula) of $428 \mathrm{~mm}$ in both cases. Fewer significant figures are presented because the result is considered less precise. 
Next, the calibrated scale was lowered so that its bottom roughly corresponded to the "bottom of the tank". The trainee was allowed to perform three more critical experiments using the same set of three tanks with no changes between. All three yielded critical heights of 513.5 $\mathrm{mm}$. These observations should be considered less accurate (tank bottom ill defined) as well as less precise (inherent difficulties with the Sight Gauge method).

Finally, the trainee watched the Senior Experimenter fill all six tanks using the Level Detector as the height measurement device. This critical height was $373.5 \mathrm{~mm}$. Records do not detail the Level Detector's installation; so this result is questionable.

"High Power" Study:

Another year later, this same array was used for still another purpose. This goal was to establish a fairly high neutron flux to evaluate some radiation detection equipment for Rocky Flats. That flux would be about a factor of ten greater than most past experiments. This higher power level would be obtained by allowing the flux to grow in the slightly super critical state until the desired level had been achieved. Then, enough solution would be drained from the tanks to keep the system very close to precisely critical at the elevated flux level.

Only the three smaller tanks were filled on two occasions over this two-week-long study following the above procedure. Critical heights are neither accurate nor precise; and the details of 
the critical system are not well-documented because critical measurements were not the goal. Still, the recorded critical heights were about 462 and $463 \mathrm{~mm}$.

\section{Second Program}

The Shielded Annular Tank study fell into two categories. The first was an attempt to identify the nearly ideal radial solution thickness, DR, which would yield a critical height somewhere near the top of this annular tank configuration. This proved to be a difficult task as discussed later. This phase of the study involved several thin laminations of stainless steel described elsewhere as reactivity shims. Because the tank was to be surrounded with thick regions of materials which happen also to be good neutron reflectors, no external reflector panels were intentionally placed close to the tank. Still, proximity to nearby walls and other effective reflectors is described in detail.

The second category concerned experiments with a particular set of shims. Variables between experiments included the absence or presence and the location of the neutron absorber and moderator materials. This program was unexpectedly halted before the planned study had been completed. Many more cases would have been studied but for this untimely termination. The only variations studied involved the interior regions of moderator and absorber materials and movement of certain components away from concentricity. No changes to the exterior moderator/absorber sandwich were made. 
Another constant was the location of the tank within the Assembly Room. Once installed, it was never moved. The outside surface of the moderator/absorber exterior sandwich was $1.02 \mathrm{~m}$ from the south wall of the Assembly Room and $2.54 \mathrm{~m}$ from the east wall. Other stationary components included:

$\sum$ the wooded platform which elevated the tank above the floor,

$\sum$ the circular metal disk under the exterior sandwich,

$\sum$ the fill/drain line which passed through the mezzanine floor $1.91 \mathrm{~m}$ from the south wall and $2.72 \mathrm{~m}$ from the east,

$\sum$ the Sight Gauge and its television camera, and

$\sum$ the stainless steel annular ring inside the larger tank that located the smaller tank precisely concentric.

The only components which may have been moved between experiments included:

$\sum$ the innermost layer of absorber rubber,

$\sum$ the inner upper polyethylene with its layer of rubber stapled in place,

$\sum$ the location of a free-standing shim within the annulus,

$\sum$ the lifting cross,

$\sum$ the vent to the Sight Gauge, and

$\sum$ the neutron source and its long, thin, hollow tube. 
Uranium solution heights were to be obtained from both the Sight Gauge and the Mass Flow Meter data; but the latter was not converted until years later. This proved to be a mistake because the two methods yielded different results by several millimeters. Generally, calculated heights derived from Mass Flow Meter data yielded values 10 to $25 \mathrm{~mm}$ greater than the Sight Gauge results. This important fact is discussed at length in the Uncertainties section. Results from both methods are presented here for completeness.

Finding the precise bottom of the tank was a major problem. To do so, the first increments of solution pumped toward the experimental tank was halted just before the solution entered the tank. Both Mass Flow Meters were set to zero here. The arbitrarily installed Sight Gauge scale was also observed to read $63 \mathrm{~mm}$ at this moment. That fixed correction to subsequent height readings was confirmed months later near the end of this second program. Thus, the tank bottom was confidently believed to correspond to $63 \mathrm{~mm}$ on the Sight Gauge with good accuracy but not great precision. Any subsequent height would be determined by subtracting $63 \mathrm{~mm}$ from reading the Sight Gauge's calibrated scale. A second measure of this important parameter could be obtained from the Mass Flow Meter data by dividing the mass delivered into the tank by the solution density multiplied by the cross sectional area of the tank. 
Solution heights obtained from the Sight Gauge and from the Mass Flow Meter are completely independent of one another. On other studies using this device ${ }^{37}$ the two methods agreed very well with one another. Such agreement was not the case in this study; and that is why results from both methods are presented.

\section{Radial Thickness Search:}

The first experiment began with $\mathrm{DR}=109.22 \pm 0.25 \mathrm{~mm}$. No reactivity shims were employed. Consequently, both wall thicknesses were $6.35 \pm 0.1 \mathrm{~mm}$ as machined. Both interior and exterior sandwiches were present the full height of the tank. Each sandwich was composed of a thick plastic annulus laminated on the outside surface with one layer of flexible, boron-loaded rubber. Another layer of the same rubber inside that completed the sandwich. Dimensions for these components are detailed in another section. The lifting cross was bolted in place to prevent the inner tank from floating.

The critical height for this first experiment was $605.6 \mathrm{~mm}$ as determined from the Sight Gauge. Years later, the mass data was converted to a critical height of $616.2 \mathrm{~mm}$. These results and data for the next several experiments are presented in Table XXII. Both heights, regardless of how determined, were much lower than expected. Reasons for this surprise are discussed

${ }^{37}$ The Poisoned Tube Tank paper to be published next in this series under contract with the DOE. 
Table XXII. Critical and Other Solution Heights ${ }^{a}$ Due to Changes in the Radial Solution Thickness Resulting from Use of Reactivity Shims.

\begin{tabular}{|c|c|c|c|c|c|c|c|c|}
\hline \multicolumn{3}{|c|}{ Shims Usec } & \multirow[b]{2}{*}{$\begin{array}{c}\Delta R \\
(m m)\end{array}$} & \multirow{2}{*}{$\begin{array}{c}\text { Annular } \\
\text { Tank } \\
\text { Area } \\
\left(\mathrm{m}^{2}\right)\end{array}$} & \multirow[b]{2}{*}{$\begin{array}{c}\text { Reactor } \\
\text { Period } \\
\text { (min) }\end{array}$} & \multicolumn{2}{|c|}{ Solution Height } & \multirow{2}{*}{$\begin{array}{c}\text { Difference } \\
\text { in } \\
\text { Methods } \\
\text { (mm) }\end{array}$} \\
\hline $\begin{array}{l}E \\
E \\
\mathscr{E} \\
\dot{\forall} \\
\end{array}$ & $\begin{array}{l}E \\
E \\
\mathbb{E} \\
\stackrel{E}{E} \\
\end{array}$ & $\sum_{\tilde{E}}^{E}$ & & & & $\begin{array}{c}\text { Mass Flow } \\
\text { Meter } \\
(\mathrm{mm})\end{array}$ & $\begin{array}{l}\text { Sight } \\
\text { Gauge } \\
(\mathrm{mm})\end{array}$ & \\
\hline & none & & 109.22 & 0.48101 & $\begin{array}{c}\text { below } \\
-10.4 \\
+7.7 \\
\text { (critical) }\end{array}$ & $\begin{array}{c}532.7 \\
\text { missed }^{c} \\
617.6 \\
(616.2)\end{array}$ & $\begin{array}{c}522.0 \\
604.5 \\
607.0 \\
(605.6)\end{array}$ & $\begin{array}{l}+10.7 \\
+10.6\end{array}$ \\
\hline - & & & 104.46 & 0.45829 & $\begin{array}{c}-16.1 \\
+17.2 \\
\text { (critical) }\end{array}$ & $\begin{array}{c}780.8 \\
783.2 \\
(781.9)\end{array}$ & $\begin{array}{c}770.5 \\
772.0 \\
(771.2)\end{array}$ & $\begin{array}{l}+10.3 \\
+11.2\end{array}$ \\
\hline$\bullet$ & & - & 100.96 & 0.44403 & $\begin{array}{c}-48 \\
\text { not recorded } \\
-13.9 \\
\text { (critical) } \\
\end{array}$ & $\begin{array}{c}981.9 \\
983.3 \\
985.8 \\
(982.8) \\
\end{array}$ & $\begin{array}{c}965.5 \\
967.0 \\
969.0 \\
(966.3)\end{array}$ & $\begin{array}{l}+16.4 \\
+16.3 \\
+16.8\end{array}$ \\
\hline$\stackrel{\bullet}{\circ}$ & $\stackrel{\bullet}{x}$ & - & 94.67 & 0.41663 & subcritical & 824.2 & 837.0 & -12.8 \\
\hline 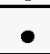 & $\bullet$ & & 98.10 & 0.43089 & subcritical & 1355.2 & 1337.0 & +18.2 \\
\hline
\end{tabular}

a. Height comparisons for 3 critical and 2 subcritical experiments are separated by horizontal lines in the table. Heights enclosed in parentheses were never measured directly but were obtained by the method discussed in the text.

b. Comparisons below the critical height of an eventually critical system are labeled "below" while subcritical systems even with a full tank are labeled "subcritical".

c. Whenever an important height measurement was missed, the difference in height between the positive and negative reactor periods obtained by the other method was used to interpolate the critical height for the case with the missing measurement. 
elsewhere. Calculations following that surprise suggested that none of the three shims designed for the purpose would increase the critical height anywhere near the goal; so their use was bypassed.

Instead, the 4.76-mm-thick shim was hastily purchased, formed, and installed. Since this was expanded outward to press against the inner wall of the outer tank, that wall thickness became, effectively, $11.11 \mathrm{~mm}$ thick. The inside wall was still $6.35 \mathrm{~mm}$ thick. The radial solution annular thickness had been reduced to $\mathrm{DR}=104.46 \mathrm{~mm}$ by this shim.

Even this shim did not produce a critical height near the top of the tank! Critical heights by the two methods were 771.2 and $781.9 \mathrm{~mm}$. The bias between the two methods seemed to be constant over the last two experiments at 10 to $11 \mathrm{~mm}$; but, again, the critical height was surprisingly low.

This was the only experiment where the period data was obtained in the reverse order from the usual procedure. When the source had been fully removed, a very long but negative (slightly subcritical) reactor period developed. This was taken as the subcritical point before a little more solution was added to achieve a positive period. 
Somewhat out of desperation, all three thin shims initially purchased were installed. These pressed against the outside surface of the inner tank. The total thickness was $3.51 \mathrm{~mm}$. Thus, the effective thickness of the inner tank's wall was now $9.86 \mathrm{~mm}$, while the outer tank remained $11.11 \mathrm{~mm}$ thick. The radial thickness had reduced to only $\mathrm{DR}=100.95 \mathrm{~mm}$.

Inexplicably, the critical height still was less than half the tank's height! The radial solution thickness was more than $8 \mathrm{~mm}$ smaller than predicted. The two methods yielded critical heights of 966.3 and $982.6 \mathrm{~mm}$. The difference had increased about 50\%; but that problem was overshadowed by the still-lower-than-expected critical height.

Figure 40 illustrates the dilemma at this point. Critical heights for three values of DR (dots) were extrapolated to lesser values in search of a shim which might attain criticality near the top of the tank. Reasonable extrapolations, encompassed by the shaded region, suggested that a quite-thick shim was still required. The $6.29-\mathrm{mm}$ shim (upward arrow) seemed reasonable, was readily available, and, so, was adopted.

That shim was free-standing within the solution region. It was first positioned roughly tangent to the 4.76-mm-thick shim already expanded against the outer tank. In an attempt to locate this egg-shaped shim more precisely, the distance between it and the inner tank's wall was measured azimuthally at $45^{\circ}$ intervals. Clockwise, starting at the north, these were: $86.3,69.5$, 


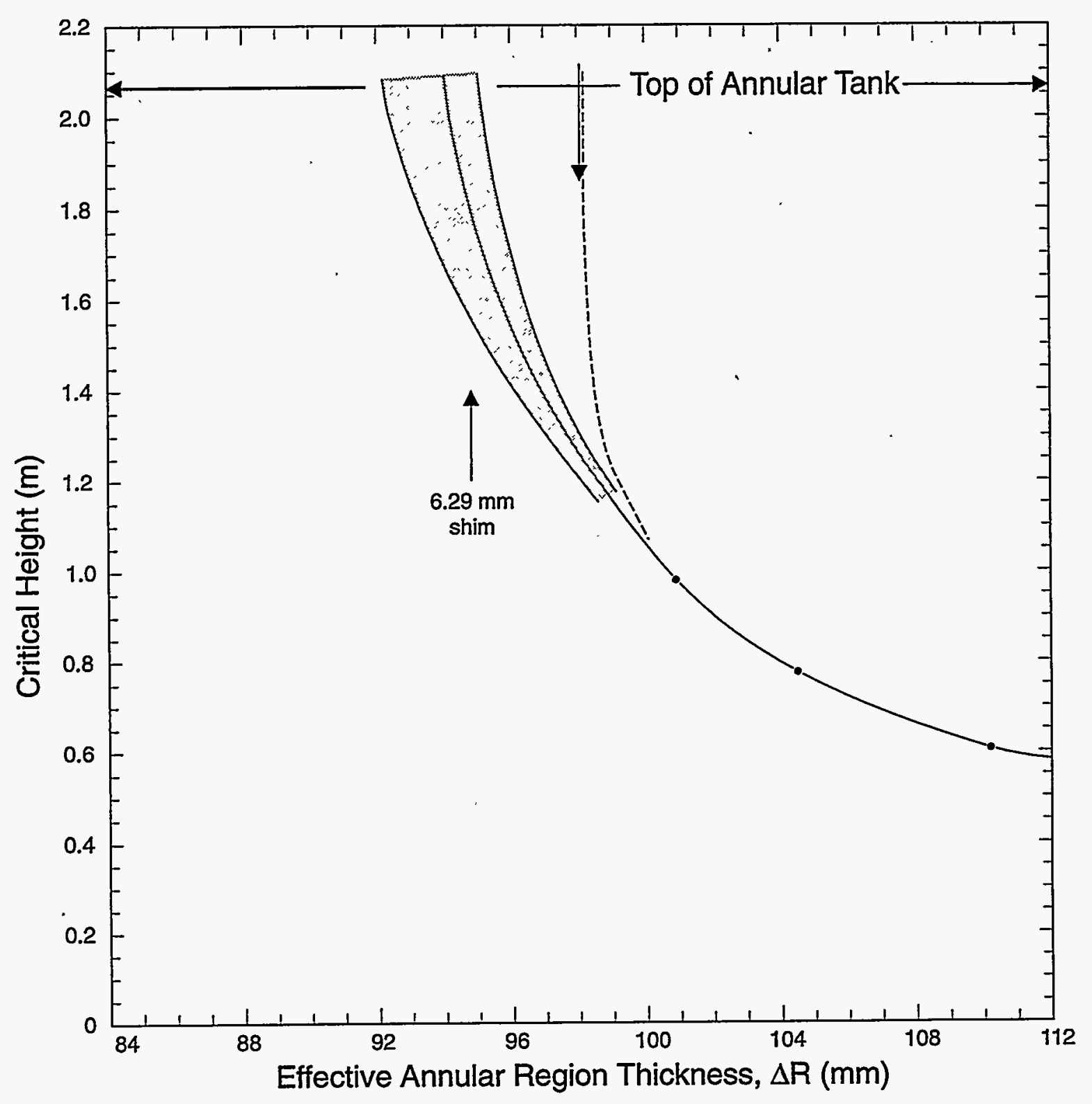

Figure 40. The first three experiments yielded critical heights (dots) less than one meter. Reasonable curves extrapolating these data formed the shaded region and suggested a 6.29-mm-thick shim (upward arrow) was still required. That shim and the next case (downward arrow) proved too thick. The ideal shim fell between 98 and $100 \mathrm{~mm}$. 
$56.3,52.4,43.8,37.5,38.9$, and $54.5 \mathrm{~mm}$, respectively. This shim reduced the effective DR to $94.67 \mathrm{~mm}$ but did not affect the effective thickness of either tank wall.

Instead of producing the desired results, this geometry proved to be dramatically subcritical! The multiplication of the solution filled tank even proved to be extremely low. The system was now quite non-reactive. This result was equally surprising as the earlier low critical heights. Evidently, the desired shim thickness had been only coarsely bounded by cases studied to date.

The now-contaminated set of three thin shims was carefully removed, washed once to remove uranium solution, wrapped for contamination control, and stored. The free-standing shim was roughly centered in the solution region, no longer tangent to one tank surface. The spacing between the outside surface of the inner tank and the inside surface of the shim was (clockwise, starting from north, at $45^{\circ}$ azimuthal increments): $69.3,45.7,45.7,56.7,74.5,75.8,73.3$, and $66.7 \mathrm{~mm}$. This construction left a thick shim against the outer tank wall, an even-thicker shim free standing about centered within the solution region, but no shim against the inner tank. The effective thickness of the two combined solution regions increased to $\mathrm{DR}=98.10 \mathrm{~mm}$; and the effective thickness of the inner wall was returned to its manufactured $6.35 \mathrm{~mm}$. 
Incredibly, this experiment also was subcritical with very little reactivity. Apparently, the knee of the curve in Fig. 40 was much, much sharper than anticipated. In summary, whereas one experiment, $\mathrm{DR}=98.10 \mathrm{~mm}$, was very unreactive, a slight radial increase to $\mathrm{DR}=100.95$ mm yielded an extremely low critical height. Apparently, the sought-for ideal DR remained elusive. The downward arrow in the figure represents this last case; and the dashed curve shows one possible fit to observed data. The knee is incredibly sharp.

The search for an ideal radial thickness was terminated, recognizing the difficulty of achieving the goal. Five large reactivity shims had already been contaminated with uranium solution. Many more, it seemed, might be required to satisfy the search. This last configuration of shims was retained for the several experiments of next phase.

\section{Absorber/Moderator Variations:}

Experimental results from this set of experiment are presented in two related tables. Table XXIII gives critical heights for numerous changes in components between successive experiments. These changes are tabulated in Table XXIV and also discussed in detail in each paragraph describing each experiment. The first table, again, presents both Sight Gauge readings and heights derived from Mass Flow Meter data. All recorded comparisons are tabulated whether near criticality or not to provide many comparisons between the two methods. Farfrom-critical heights are indicated in the table by the word "below" in the Reactor Period column. 
Table XXIII. Critical and Other Solution Heights ${ }^{\mathrm{a}}$ Due to Changes in Placement of Components for the Last Configuration of Table XXII.

\begin{tabular}{|c|c|c|c|c|}
\hline $\begin{array}{l}\text { Component } \\
\text { Changes } \\
\text { Described in } \\
\text { Table XXIV }\end{array}$ & $\begin{array}{l}\text { Reactor } \\
\text { Period }^{\mathrm{b}} \\
\text { (min) }^{\text {(min }}\end{array}$ & $\begin{array}{l}\text { Solution } \\
\text { Mass Flow } \\
\text { Meter } \\
(\mathrm{mm})\end{array}$ & $\begin{array}{l}\text { Height } \\
\text { Sight } \\
\text { Gauge } \\
\text { (mm) }\end{array}$ & $\begin{array}{l}\text { Difference } \\
\text { in } \\
\text { Methods } \\
\text { (mm) }\end{array}$ \\
\hline$A$ & Subcritical & 1301.1 & 1337 & -35.9 \\
\hline B & $\begin{array}{c}\text { Below } \\
-18.3 \\
+22.4 \\
\text { (Critical) }\end{array}$ & $\begin{array}{c}1538.3 \\
1543.7 \\
1544.7 \\
(1544.3)\end{array}$ & $\begin{array}{c}1512.5 \\
\text { missed }^{6} \\
1520.1 \\
(1520)\end{array}$ & $\begin{array}{l}+25.8 \\
+24.6\end{array}$ \\
\hline C & $\begin{array}{c}\text { Below } \\
\text { Below } \\
\text { Below } \\
-12.9 \\
+8.6 \\
\text { (Critical) }\end{array}$ & $\begin{array}{c}747.4 \\
1645.6 \\
1664.7 \\
1667.5 \\
1670.4 \\
(1668.7)\end{array}$ & $\begin{array}{c}737 \\
1632 \\
1651 \\
1655.1 \\
1657.5 \\
(1656)\end{array}$ & $\begin{array}{l}+10.4 \\
+13.6 \\
+13.7 \\
+12.4 \\
+12.9\end{array}$ \\
\hline$D$ & $\begin{array}{c}\text { Below } \\
\text { Below } \\
\text { Below } \\
-18.0 \\
+7.4 \\
\text { (Critical) }\end{array}$ & $\begin{array}{c}1559.7 \\
1660.0 \\
1710.5 \\
1710.6 \\
1714.0 \\
(1711.6)\end{array}$ & $\begin{array}{l}1538 \\
1638.5 \\
1689 \\
\text { missed }^{\circ} \\
1692.1 \\
(1690)\end{array}$ & $\begin{array}{l}+21.7 \\
+21.5 \\
+21.5 \\
+21.9\end{array}$ \\
\hline$E$ & $\begin{array}{c}\text { Below } \\
-6.5 \\
+9.87 \\
\text { (Critical) }\end{array}$ & $\begin{array}{c}1663.6 \\
1699.6 \\
1704.0 \\
(1702.3)\end{array}$ & $\begin{array}{c}1653 \\
1690 \\
1694 \\
(1692.4)\end{array}$ & $\begin{array}{r}+10.6 \\
+9.6 \\
+10.0\end{array}$ \\
\hline$F$ & $\begin{array}{c}-5.8 \\
+3.9 \\
+2.81 \\
\text { (Critical) }\end{array}$ & $\begin{array}{c}1705.4 \\
1701.6^{d} \\
1711.9 \\
1708.1^{d} \\
1713.1 \\
1709.3^{d} \\
(1708.0) \\
(1704.2)^{d} \\
\end{array}$ & $\begin{array}{l}1686 \\
1691.9 \\
1686 \\
(1686)\end{array}$ & $\begin{array}{l}+19.4 \\
+15.6^{d} \\
+20.0 \\
+16.2^{d} \\
+27.1 \\
+23.3^{d}\end{array}$ \\
\hline & $\begin{array}{c}-5.4 \\
+5.4 \\
\text { (Critical) }\end{array}$ & $\begin{array}{c}1694.4 \\
1700.9 \\
(1697.7)\end{array}$ & $\begin{array}{c}1689 \\
1695 \\
(1692)\end{array}$ & $\begin{array}{l}+5.4 \\
+5.9\end{array}$ \\
\hline G & $\begin{array}{c}\text { Below } \\
\text { Below } \\
-4.73 \\
+6.69 \\
\text { (Critical) }\end{array}$ & $\begin{array}{c}1607.7 \\
1658.0 \\
1708.7 \\
1715.4 \\
(1712.6)\end{array}$ & $\begin{array}{c}1585.5 \\
1637 \\
1688.5 \\
1694 \\
(1692)\end{array}$ & $\begin{array}{l}+22.2 \\
+21.0 \\
+20.2 \\
+21.4\end{array}$ \\
\hline$H$ & $\begin{array}{c}\text { missed }^{\circ} \\
+5.1 \\
\text { (Critical) }\end{array}$ & $\begin{array}{c}1706.2 \\
1711.4 \\
(-1708)\end{array}$ & $\begin{array}{c}1695 \\
1699.5 \\
(\sim 1697)\end{array}$ & $\begin{array}{l}+11.2 \\
+11.9\end{array}$ \\
\hline
\end{tabular}


a. Each horizontal set of comparisons separated by horizontal lines was obtained from a single experiment. Heights enclosed in parentheses were never measured directly but were obtained by the method described in the text.

b. Comparisons below the critical height of an eventually critical system are labeled "below" while subcritical systems even with a full tank are labeled "subcritical".

c. Whenever an important height measurement was missed, the difference in height between the positive and negative reactor periods obtained by the other method was used to interpolate the critical height for the case with the missing measurement.

d. Smaller font entries in this one experiment only correspond to a possible bias in the mass flow meter data. Full font entries derived from masses a much as $2.45 \mathrm{~kg}$ too large. Height data for both assumptions are provided. 
Table XXIV. Changes in Components Between Experiments Described in Table XXIII.

A. Innermost layer of absorber (on paper tube) removed and the 6.23-mm-thick shim relocated tangent to the shim on the outer tank just east of north.

B. Same as A plus the inner upper plastic moderator has been removed along with the absorber stapled to its surface.

C. Same as B except that the innermost layer of absorber (on paper tube) has been returned and is roughly centered inside the tank.

D. Same as C except that the "floating" 6.23-mm-thick shim has been relocated to be close to centered in the solution region.

E. Exactly the same as D. Records suggest that the mass flow meters were not set to zero until the sight gauge read $602 \mathrm{~mm}$ (solution already $539 \mathrm{~mm}$ deep in tank). All mass flow meter data have had $539 \mathrm{~mm}$ added to heights determined from this device. This $539 \mathrm{~mm}$ adjustment applies to this one experiment only!

F. Same as $D$ and $E$ except that the innermost absorber (on paper tube) has been intentionally positioned non-concentric with the tank. The maximum space between it and the tank was $203 \mathrm{~mm}$ while the minimum was $41 \mathrm{~mm}$.

G. The innermost absorber (on paper tube) is recentered so configurations D and $E$ are reestablished. A rolling cart is positioned against the east side of the tank and one 150-mm cube of fissile solution is centered on the top shelf of the cart.

$H$. The same as $G$ except that the cube of solution is adjacent to the tank rather than centered on the shelf. 
Critical heights obtained by interpolation are enclosed in parentheses and never represent an actually achieved state of the apparatus.

The first experiment in this sequence simply had the innermost layer of neutronabsorbing rubber removed. This is referred to as case " $\mathrm{A}$ " in both tables. The paper tube to which this was attached was simply withdrawn to increase reactivity by restoring across-tank neutron interactions. The free-standing shim was, again, tangent to the outer tank along one element; but this time shim-to-wall spacings were not measured. Even these drastic actions yielded a still subcritical and quite unreactive system.

The next change, case "B", was certain to produce a critical system and it did. The inner upper plastic moderator was removed from the system along with the absorber rubber stapled to it. To summarize, the interior of the annular tank contained only the lower half of the plastic and the rubber stapled to its outer surface; all the rest had been removed. The exterior sandwich, however, remained intact.

As expected, the reciprocal multiplication curve behaved as two distinctly different curves. Over the lower half, the multiplication approached that of a subcritical system. Above, however, the curve became dramatically more reactive and predicted criticality. The critical height measured by the Sight Gauge was $1520 \mathrm{~mm}$, while that calculated from Mass Flow Meter 
data was $1544.3 \mathrm{~mm}$. The difference, $24.6 \mathrm{~mm}$, was larger than previously observed. It also remained roughly constant over the full height suggesting that the difference was characteristic of the whole experiment and not a function of height in the tank.

The next experiment found the innermost rubber and its paper tube returned and centered inside the tank, case " $\mathrm{C}$ ". Only the inner upper plastic and its stapled rubber were still absent. This increased the critical height, as expected, to 1656 and $1668.7 \mathrm{~mm}$ by the two methods. The difference had returned to the more familiar 12 to $13 \mathrm{~mm}$.

The 6.23-mm-thick shim was again centered in the annular region for case " $\mathrm{D}$ ". The critical height increased to 1690 and $1711.6 \mathrm{~mm}$ by the two methods. Evidently, comparing this and the previous case, the off-center shim was more reactive than the centered case because it produced a thicker solution region - one uninterrupted by stainless steel - over most of the circumference of the annular region. Conversely, the centered shim was less reactive because no solution region was allowed to attain that great thickness any where. The difference between the two methods remained fairly constant over the whole experiment at about 21 to $22 \mathrm{~mm}$.

The next experiment, "E", was a repeat of the previous one but only a few hours later. Few conditions could have changed from morning to afternoon. The critical height by the Sight Gauge method for the afternoon measurement was only $2.4 \mathrm{~mm}(0.14 \%)$ different from the 
morning one. The difference is reasonable for the claimed precision of the method. The height derived from Mass Flow Meter data, however, differed by a surprisingly large $9.3 \mathrm{~mm}$. This suggests that the very precise Mass Flow Meter data may lack accuracy, whereas the Sight Gauge information may be more accurate even though less precise.

Several days later, the next configuration was also measured both morning and afternoon. This repetition served two purposes. Two persons were being trained as Experimenters; and they needed multiple opportunities to achieve criticality. Secondly, the morning experiment suffered an uncertain error in recording Mass Flow Meter data. An $2.45 \mathrm{~kg}$ "drift" was noted in the log book. This drift was neither explained in the records nor recalled ten years after the fact. This problem was of sufficient concern to warrant the repeat measurement that afternoon.

That specific configuration, "F", was the same as the previous except that the innermost rubber and its paper tube were located off center on purpose. The maximum space between the rubber and some unspecified component concentric with the tank was $203 \mathrm{~mm}$ while the minimum was $41 \mathrm{~mm}$. That unspecified component probably was the inside surface of the innermost plastic moderator; but that is not certain. It cannot be the tank because the moderator, alone, is thicker than the minimum $41 \mathrm{~mm}$. The dimensions, however, are inconsistent with either assumption as to the nominal șize of the paper tube chosen for this innermost rubber layer. Elsewhere, two possible diameters were proposed based on photographs and commercial sizes 
available: 0.76 and $0.81 \mathrm{~m}$. Adding two thicknesses of paper and two rubber thicknesses to either diameter would leave air spaces of 309 and $258 \mathrm{~mm}$ respectively. Neither is consistent with observed $244 \mathrm{~mm}(203+41 \mathrm{~mm})$.

Critical heights for the morning run of experiment "F" were $1686 \mathrm{~mm}$ by the Sight Gauge method and either 1708.0 or $1704.3 \mathrm{~mm}$ by the Mass Flow Meter data. The first assumes the $2.45 \mathrm{~kg}$ drift, the other does not. The afternoon run by the Sight Gauge method was $0.36 \%$ larger at $1692 \mathrm{~mm}$. The other method was about the same percentage lower than the morning's data: $1697.7 \mathrm{~mm}$.

The last two experiments, "G" and "H", found all components again concentric with one another. The new feature was the presence of a cube of fissile solution located on a standard laboratory rolling cart such as found throughout Rocky Flats. That cube was centered on the top shelf of the cart for experiment "G"; and it was pushed to the side of the cart, in contact with the tank, for the other.

The cube of solution was not well described in record books because it was a component borrowed from another program. The following is based on recollection. The container was welded of $1.6-\mathrm{mm}$-thick stainless steel into a cube $152 \mathrm{~mm}$ on a side (outside dimension). The 
liquid was uranyl nitrate solution at a high concentration. That concentration is not recorded; but assuming the same concentration as in the present program would not be unreasonable.

The rolling cart was formed of thin gauge stainless steel. It was rectangular $(1.2 \times 0.6 \mathrm{~m})$ and had two shelves. The upper shelf was about $0.8 \mathrm{~m}$ above the floor; and the location of the lower shelf is unimportant.

Critical heights by the two methods for the centered case were $1692 \mathrm{~mm}$ and $1712.6 \mathrm{~mm}$. The case with the cube touching the outermost rubber produced conflicting results. The critical height by one method increased $(1697 \mathrm{~mm})$; but it decreased by the other $(1708 \mathrm{~mm})$. That the centered and contiguous cases were so similar to one another, however, suggests that the annular tank was so well shielded by the materials exterior to the annulus that little could influence critical conditions. This was as predicted in the design of the entire program.

Mass Flow Meter data for the subcritical period of the last case was missed; so the resulting critical heights are a little more ambiguous.

The comparison of the two methods of measuring heights reveals an interesting point. Mass Flow Meter data generally predicted heights either 10 to $13 \mathrm{~mm}$ or 20 to $25 \mathrm{~mm}$ greater 
than Sight Gauge data. That difference seemed to be constant over the full height of an experiment. Few exceptions to this unexplained observation are found.

One possible explanation for a systematic error in Mass Flow Meter data may be the presence of small air bubbles entrained in the U-shaped tube of the device itself. Bubbles would lower the density of the solution; and this, in turn, would elevate the derived critical height. A 10 $\mathrm{mm}$ error out of a $2000 \mathrm{~mm}$ critical height could be accounted for by only a $0.5 \%$ error in the density of the solution. Such an error is entirely possible.

Since the difference between the two methods remained fairly constant over an experiment, the bubbles (if the cause of the error) apparently remained trapped throughout each measurement once formed. 


\section{UNCERTAINTIES}

General:

Uncertainties reported in this paper have one of three meanings depending upon application. Which is used is made clear in the text. When the result of a statistically significant sampling, the uncertainty is the conventional standard deviation calculated for the average. Examples include many measurements reported in the Tanks, Reactivity Shims, Moderators and Absorbers, and other sections of this paper. For example, many measurements of reactivity shim thicknesses were made and accurate averages and precise standard deviations could be reported.

The second kind of uncertainty is best exemplified by the critical solution heights reported here. Certainly, multiple measurements were not made; that would have been both expensive and risky. These uncertainties are simply good guesses at the confidence placed in the quoted value. Sometimes this uncertainty was smaller than others; but each case is discussed individually in the Results Section. A discussion of the uncertainty in a solution height measurement is presented later in this section.

Occasionally, only a very few measurements of some parameter were made. The number was too few for a good statistical analysis but more than one. In these cases, the average was traditional; but the uncertainty was estimated in still a third way. Decades of experience in 
scientific measurement suggest the following observation: the range observed for a small set of measurements is often a good estimate of about three times the standard deviation of a much larger set on the same parameter. This notion is not at all mathematically rigorous.

Even when uncertainties are not specifically given, the number of significant figures expressed signify confidence in the value. For example, annular solution region thicknesses were very carefully measured because of their extreme sensitivity on criticality. Many non-destructive measurements were made on the tank used in the second program to refine that parameter. The shim-free value of $109.22 \pm 0.25 \mathrm{~mm}$ is quite certain and that precise. On the other hand, a parameter stated to be $1.9 \mathrm{~m}$ implies a good likelihood that the true value lies between about 1.85 and $1.95 \mathrm{~m}$. The 1.9-m-thick concrete walls of the Assembly Room are a good example.

\section{Solution Height:}

A common requirement of many experiments involving liquids is the measurement of the height of that fluid. That is true even outside the field of nuclear criticality safety. This seemingly simple task is really not so simple as it appears. The solution has a top surface and the container has a bottom plane. Usually, this plane is horizontal. The sought-for height is the difference between these two elevations. The top surface of the liquid, under the influence of gravity, is certain to be flat and horizontal. The bottom might not be so easy to define even in the absence of other problems discussed below. In the Shielded Annular Tank study, a slight tilt 
during setup could affect this parameter. Other programs at Rocky Flats have been plagued by warped bottoms caused by welding. The Nested Tank study had a built-in problem because of the intentional $2^{\circ}$ slope.

In addition to having a well-defined bottom, it is imperative to know when that bottom is attained. The top surface of a tank of solution is easy to see; the "bottom" is much more difficult to find. It was impossible to see solution enter the tank via closed circuit television in both programs. The plan was to locate the bottom by indirect means. In both programs, the goal was to pause the fill sequence just before solution entered the tank. This would be declared "the tank bottom". The fill line was much smaller than the tank; so a few-millimeter error in this pause was believed better than biasing the experiment with even a little solution in the tank. This was difficult.

Both top and bottom, however, are equally important to identify and measure. To site an unrelated example, the length of an object can be measured with the most carefully calibrated scale possible read most precisely; but, if the scale had not been carefully placed at the foot of the object, the length measurement would be no better than that placement. The human tendency exists to expend more care in measuring the top than in finding the bottom. Criticality is more exciting than an empty tank. This is an example of poor technique. 
In addition to having a well-defined bottom and knowing when that bottom had been attained, the next hurdle in the task of critical height measurement was the measurement of both top and bottom heights. This task also involves several components or issues. One is to have the height measurement device truly represent the status of the liquid in the tank; and the second is to read that representation with the equipment set up for that purpose.

The Sight Gauge was always a meter or more away from the $\operatorname{tank(s)}$; so a horizontal transfer of the actual height in the tank to the indicated height on the Sight Gauge was questionable. Bubbles either in the tank or in the plastic tube could alter the effective density of the solution. Pockets of higher-concentration solution or salt crystals attached to the wall of the plastic tube had the same effect. Both phenomena would cause the indicated height to differ from the true height. Even if this problem were overcome, the solution meniscus complicated readings. Parallax from closed-circuit television readings and retrace lines caused by the flyback transformer have already been discussed but did compound the problem.

The Mass Flow Meter could have been an almost perfect device for measuring solution heights; but it wasn't. It required a precise knowledge of the true density of the solution; and the same density had to exist in the meter and in the tank. It also demanded a well-defined determination of the tank's bottom for proper "initialization". Finally, a precise measure of the cross sectional area of the right-circular geometry being filled was required. All these were 
difficult hurdles; but the device may have been plagued by air bubbles. This has already been discussed and appears to have been some problem in the Shielded Annular Tank study.

Solution height measurements in these two programs is a good example of a fundamental dilemma in scientific research. It also illustrates the distinction between accuracy and precision very well. This detailed discussion of uncertainties in height determinations is only important because of the extreme sensitivity of the reactor period at or near criticality to the actual amount of solution present. A few grams of solution out of a thousand kilograms produce a marked change in this period. That corresponds to a few parts per million!

A few experiments were repeated just to evaluate repeatability of results. These were disappointing even though agreement within about $0.1 \%$ was found. The possibility exists for much better reproducability. Even the flagrant differences between the two methods of the second program were smaller than one percent! Still, much better agreement could have been attained.

Specifically, one assembly of plugs, tanks, and reflector panels, using $1.1 \% \mathrm{~B}$ plaster plugs and the cadmium-wrapped one, was reassembled. The second result was a critical height of $1322.1 \mathrm{~mm}$ compared with the first-assembled $1331.4 \mathrm{~mm}$. The more than $10 \mathrm{~mm}$ difference in critical heights is attributed to undetectable (and, therefore, unreported) differences in building the 
two assemblies. This could include the azimuthal orientation of one or more plugs within their respective tanks, the precise location of these same plugs within the tanks, and/or differences in the tilt of a plug as it rested inside a tank.

This one repeatability run illustrates an important point with respect to the uncertainty of all of these results. Any given construction of tanks, plugs, reflectors, and other hardware would have a critical height identifiable to within, say, $\pm 0.01 \mathrm{~mm}$ ! That is, the addition or removal of that small quantity of solution would have a pronounced effect upon the observed reactor period with no uncertainty as to when a system was super critical or subcritical. That same identical construction, absolutely untouched between runs, would have a repeatable critical height of, perhaps, $\pm 0.5 \mathrm{~mm}$. Undetected very minor changes in the assembly -possibly changed by the addition and removal of the weight of the solution itself - would be responsible for this change. The total reconstruction of a supposedly identical assembly, as in the case under consideration here, produced the observed $10 \mathrm{~mm}$ difference in critical heights. The critical systems are so sensitive to such a very large number of unrecognized parameters that the detailed reporting of these parameters would be essentially impossible.

\section{Elemental Composition:}

Some material compositions were measured at Rocky Flats by analytical methods on multiple samples drawn from a larger lot. The boron content of Gerstley Borate is one example. 
Multiple samples from several lots were analyzed more than once and also according to their nominal sieve size. This was done so carefully because of the importance of the boron content of this mineral. Measurement by size was important because of the possibility that a particular plug might have contained more powered material than chunk sized. Fortunately, the boron was uniformly distributed by particle size.

Other materials are simply reported by their common name; and elemental composition should be obtained from the literature. An example is the elemental composition of the polyethylene plastic used in the second program. In a few cases, manufacturer's certification of composition is provided in the belief that those documents represent the material well. The stainless steel used in the Shielded Annular Tank study is one example.

An analytical determination of elemental composition is not always better than assuming an industry-wide standard composition. This possibly arguable assertion is defended on human factors considerations. When multiple sampling is not possible, expensive, and/or difficult to obtain, analytical results are often deduced from a single sample. This is subject to possible inhomogeneity (the sample may not represent the whole); and even a perfect analysis could yield wrong results due to human error, laboratory bias, or contaminated laboratory hardware. A single sample is subject to unavoidable analytical uncertainties. 
Most analytical measurements of elemental compositions are not much better than $\pm 1 \%$; some are much less certain. Impurity measurements can be uncertain by a factor of two. Any error in laboratory technique worsens the result. Even a perfectly homogeneous sample could yield wrong results.

On the other hand, common materials readily available from a number of sources and manufactured under strict production controls are probably much better described by the industry-wide standard composition than by any single analysis of a single sample. Alloys of stainless steel, steel, and polyethylene plastic fall into this category. Uncommon materials, ones with little manufacturing controls, or materials prepared in the field (such as concrete and plaster) should be sampled and analyzed. The plugs and slabs of the first program are excellent examples.

Precision in elemental composition is more important for components which are a major influence on reactivity. Close in and larger items need better understanding of their composition. Concrete reflector wall panels immediately adjacent to an array would need to be analyzed; while concrete walls a great distance away may be described more approximately. The composition of the concrete walls of the Assembly Room is probably not very important. 


\section{Counting Statistics:}

Both programs employed reciprocal multiplication data in a number of ways. This information is certainly very dependent on the chosen relative geometry between the fissile material, the radiation detectors, and the changing solution levels. Still, the relative data in similar experiments are related provided these geometries do not change. Typically, the numerator, $\mathrm{C}_{\mathrm{o}}$, resulted in about 2500 neutrons being counted in a fixed interval of time; and the related uncertainty would be \pm 50 neutrons. The asymptotic multiplication for subcritical cases was usually about four; so the denominator, $\mathrm{C}(\mathrm{H})$, would be 10,000 neutrons counted over the same interval. The uncertainty, then, in these asymptotic reciprocal multiplication values would be about $\pm 4.5 \%$.

Multiplication values at heights close to criticality had greater certainty. At criticality, for example, $\mathrm{C}(\mathrm{H})$ approached infinity; so the uncertainty in the reciprocal multiplication simply equaled the uncertainty in $\mathrm{C}_{0}: \pm 2 \%$. 


\section{A DESIGN CHALLENGE}

Two problems made the second of these two programs difficult to accomplish successfully. One of these is theoretical in nature and would not have been eliminated by any other design. The second was a design flaw that could easily have been avoided by more thoughtful planning.

\section{Theoretical:}

A large-sized solution annulus is similar in many respects to a large-sized solution slab. Both are effectively infinite (in a neutronic sense) in two dimensions and relatively thin in the third. The critical thickness of an infinite slab of solution accidently spilled onto the floor of a large room, for example, is quite thin. It also depends strongly upon the concentration of the solution. An annular tank capable of holding a reasonable amount of solution such as a storage tank in a production setting would be tall enough to approach infinity and have an even-larger circumference which also approaches infinity. Its radial thickness is, likewise, quite thin.

The solution annulus may be viewed simply as the solution slab rolled into a cylinder about an axis parallel to the slab but offset a distance from it. That offset would be the radius of the annulus. The reactivity, $r$, of both geometries is very sensitive to the thickness of the third 
dimension. That is, changes in reactivity, dr, depends strongly on d(slab thickness) in one case and on $d(D R)$ in the other.

The major difference between a solution slab and an annulus is neutron interaction. The . slab does not interact with itself anywhere. Fission neutrons leaving its surface do not return. A solution annulus is different. Fission neutrons from one region can interact with fissionable nuclei on the other side of the annulus. That 'obvious fact formed the initial rationale for the Shielded Annular Tank study.

A significant ramification of this observation is that the manufacture of a tall annular tank of large-diameter, capable of achieving criticality near its top with a fissile solution near its minimum-critical-volume concentration, is essentially impossible. First, the pre-experiment selection of the target radial thickness to manufacture would be difficult. Calculational methods are not yet good enough to predict that dimension with adequate precision; and, if the thickness somehow were known, the experiment, itself, would not be needed in the first place.

Second, the manufacturer requires some tolerance in this dimension. No one could construct a tank to precisely any given radial thickness. This problem was recognized during the design phase of this program and discussed with potential manufacturers. They requested tolerances of about \pm 3 to $4 \mathrm{~mm}$, common in the construction of tanks. Design needs dictated a 
tolerance smaller than $\pm 0.2 \mathrm{~mm}$ ! The two camps were far apart! The selected manufacturer successfully attempted to achieve smaller tolerances by welding a much-thicker plate of stainless steel into a nominal right circular cylinder and, then, machining the cylinder to the needed radial dimensions. Even the machining operation was staged to reduce warpage through heating. Progressively smaller cuts were made with the tank allowed to cool between.

The third problem concerns the relative importance of the sign of this very small allowed machining tolerance, e. The criticality of a tank with a radial thickness of DR $+e$ over a significantly large area would be distinctly different than that of a tank where a large portion had a radial thickness of $D R-e$ or where the variation between $+e$ and $-e$ alternated between adjacent small areas. Stated differently, an infinite flat solution slab with a large area incrementally thicker than the rest of the slab has criticality determined by only the thickness of that region. Conversely, an infinite solution slab with a large area incrementally thinner than the rest of the slab would be unaffected by the thinner region; its critical thickness would be that of the slab everywhere else. Figure 41 illustrates this point.

\section{Practical:}

The sensitivity of DR on criticality was recognized as just that and only that by this author during the design stage of the program. The need to adjust radial thickness by very small amounts was so obvious that three different thicknesses of reactivity shims were purchased. 

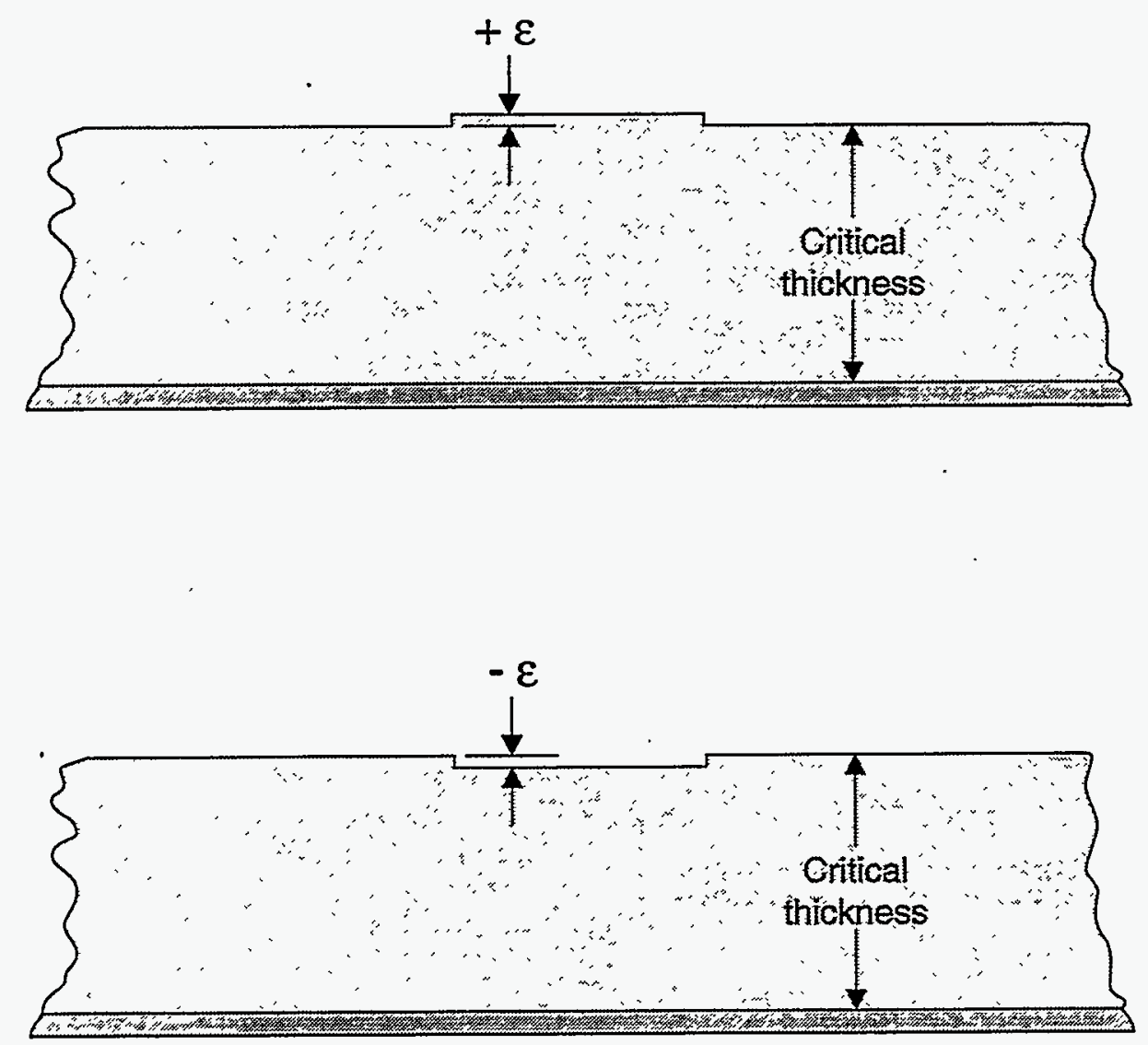

Figure 41. An infinite slab of fissile solution with a thicker region over a large but finite area has criticality determined by that thickness regardless of the thickness of the slab. A similar slab with a large - but thinner - area is unaffected by the depression.

Criticality is determined by the thickness of the infinite slab. 
Three were ordered because the thickness needed was not obvious. To facilitate this plan, the annular tank was intentionally designed to be too thick. Criticality would occur at some low height; that was expected. Then, some combination of one or more reactivity shims were to be installed to yield criticality near the top of the tank.

This approach did not work as has been explained in other sections. The reason for this failure was recognized only after a number of reactivity shims had been installed and contaminated - too late to redesign the entire experiment.

The design flaw was the failure to recognize that a reactivity shim of any given thickness actually affected two important dimensions, not just one. In addition to decreasing the radial thickness of the solution by exactly its thickness, the shim also increased the thickness of the tank wall it was adjacent to. The now-thicker wall formed a thicker reflector to the solution annulus. Subsequent calculations revealed this to be a significant consideration. In fact, the planned decrease in reactivity due to a decrease in DR was offset $50 \%$ (!) by the increase in reactivity due to additional reflection. Mathematically,

$$
r(\text { system })=r(D R=109.22 \mathrm{~mm})-\mathrm{dr}(\text { due to change in } \mathrm{DR})+\ldots \mathrm{dr} \text { (due to reflector })
$$

where $r$ is the reactivity and $d r$ is the change in that parameter due to the introduction of the shim. This conclusion is illustrated in Fig. 42. 

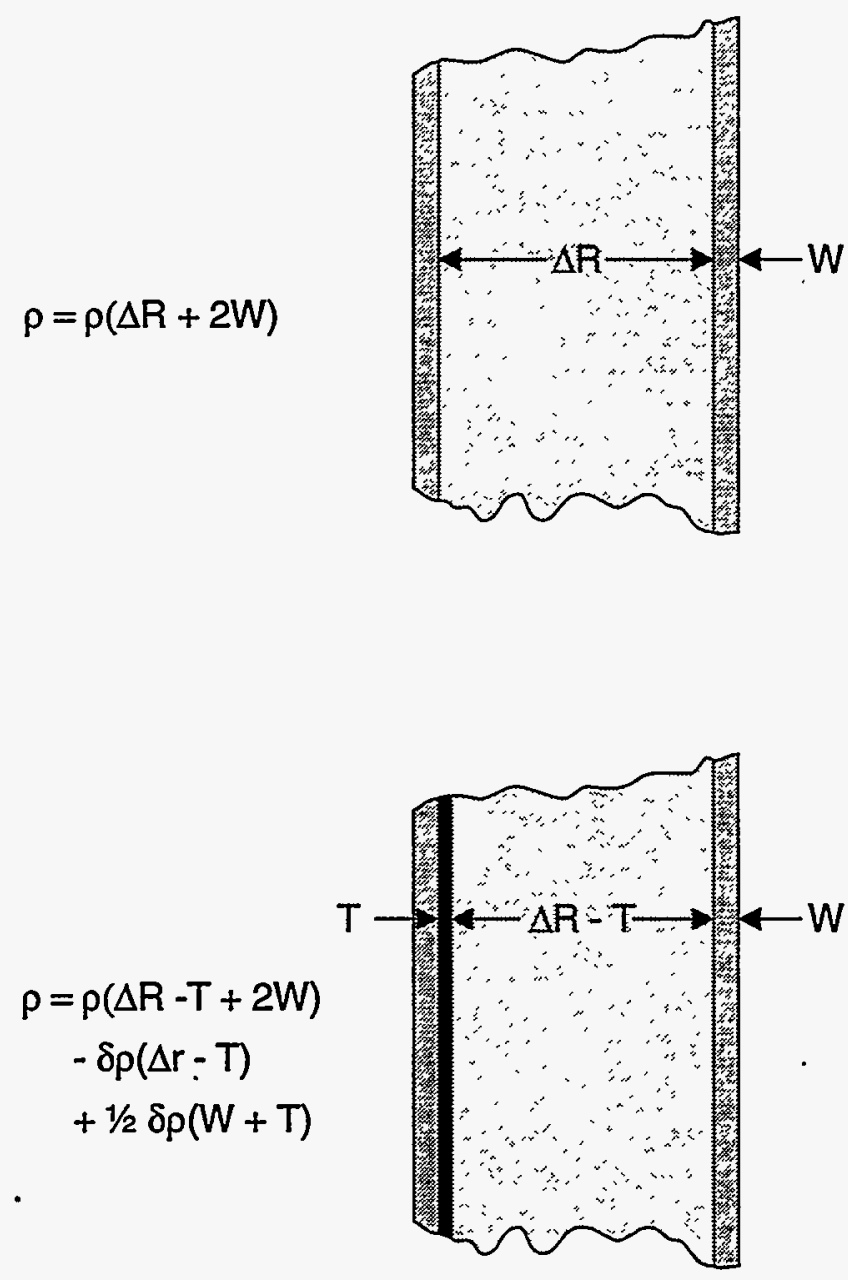

Figure 42. A reactivity shim reduces reactivity of a slab or annulus because it reduces the solution thickness; but half that decrease is offset by the increased reflection of the thicker wall. 
The realization of this error was quickly followed by the understanding that a much better design was possible. Rather than start with a tank intentionally too thick, the better design would start with a tank a little too thin. This tank would clearly be subcritical when filled. Then, thin reactivity shim stock could have been wrapped around the outside of the tank until sufficient additional reactivity had been added as reflector to produce the desired critical height. Another advantage of such an approach would be that the machined surfaces and their precise geometries would not be compromised by less-precise rolled metal shims. Finally, such shim material could remain uncontaminated, greatly reducing the cost of post experiment activities. 


\section{PREPARATION OF A NEUTRON-ABSORBING CONCRETE}

The goal was to formulate a recipe for concrete and plaster containing some reasonable amount of boron. The wet mix had to be poured into forms to make panels for use in experiments. The task seemed simple: substitute any commercial compound rich in boron for a portion of one or more ingredients found in normal concrete. Several materials came quickly to mind. Boron carbide is $73 \%$ boron and a fine powder; it would easily mix homogeneously. It was rejected because it was expensive. Ordinary Borax, a commercial laundry product, is sodium tetraborate and, therefore, rich in boron too. It was considered as a viable alternative. Boron oxide, $\mathrm{B}_{2} \mathrm{O}_{3}$, is $31 \%$ boron, very inexpensive, and readily available. Many other boron compounds were discovered during a search for such materials; but they were rejected because of the apparent suitability of boron oxide.

Sand is a principal component of concrete. Sand is silicon dioxide. The plan was to replace a portion of the ordinary sand with a suitable amount of boron oxide, substituting one oxide for another. Dry ingredients would be mixed first. Then, water would be added and mixed as usual whenever making concrete. Finally, the wet mix would be cast into forms and allowed to set. The plan seemed obvious to this author - a nuclear physicist, not a concrete engineer. 
A test mix was planned to determine just how much water would be needed because of the slight change in dry ingredients. Craftsmen from Rocky Flats were asked to prepare a test case of about half a cubic meter. Dry ingredients were mixed in a wheelbarrow sufficient to yield about $2 \%$ boron in the final mix.

A normal amount of water for ordinary concrete was added; but the new mix behaved strangely. It seemed too dry; so more water was added. Soon, the craftsman was observed shielding his face from intense heat emanating from the wheelbarrow. He was turning the mix with a shovel by one hand extended from his body. Moments later, the wet mix appeared to set in an instant. One shovel full set right on the shovel. Heat from the operation made standing alongside the wheelbarrow quite uncomfortable.

The next morning, the set concrete was examined. One fist-sized chunk was picked up. Although it held shape under its own weight, it easily crumbled in the fist, falling through the fingers back to the rest of the rubble. This boron-loaded concrete had almost no strength whatsoever.

Local concrete firms were contacted about this strange phenomenon; and they most courteously advised this author to pursue nuclear physics, a respectable profession. They explained that concrete engineers were well aware of problems associated with changing the $\mathrm{pH}$ 
of concrete. Acids do not add well to concrete. Boron oxide forms boric acid when mixed with water. Experts could have predicted the results of the test.

The problem was investigated a little further at Rocky Flats -more out of curiosity than anything else. Small batches having a variety of boron contents were prepared and cast in paper cups. Batches ranged from boron free to about $3 \%$ boron. Water content was also varied as well as the amount of cement in each batch. Figure 43 shows the results of this investigation. The upper half displays the casting shortly after being removed from the paper cup. The lower half presents the consequences of handling with bare hands! These tests were repeated with plaster because both earthen materials would be used in experiments. Results were similar.

The advantage of Gerstley Borate and other borate compounds available commercially is that they are completely benign in concrete. They do not appear to have any gross effects on the setting properties of concrete. Some later testing on the strength of $15 \mathrm{~mm}$ diameter by $30 \mathrm{~mm}$ tall cylinders did show some reduction in strength. Because of this and the earlier findings, plugs were designed to be lifted by the bottom steel plate; and slabs of plaster would be contained by their forms. 


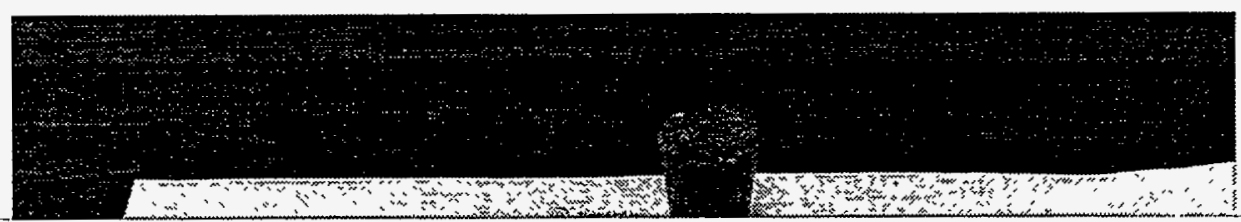

Rocky Flats investigated a means of measuring one important parameter of Raschig rings without touching them. That parameter was the boron content of the glass for which the Standard set a minimum value. The non-destructive assay technique involved a collimated neutron source and shielded neutron detector. The two were diametrically opposed from one another when mounted on the ring-filled tank being measured. Source neutrons entered the counter through a hole in the shield only after passing through the tank containing the bed of Raschig rings. If a suitable amount of boron was present in the path of the neutrons (the desired case), the beam would be diminished by absorption. If either rings were missing or boron had somehow been preferentially leached from the glass, the flux reduction would not be as great.

The prototype device featured a rotational capability that allowed the source and counter to move azimuthally around a tank keeping the two always diametrically opposed. The same hardware provided for vertical movement too. Thus, the device was capable of scanning all portions of a right circular cylinder.

The method is obviously dependent upon the diameter of the tank under study; but this parameter could be factored into the calibration. The physics of this was quite straightforward; but the practical application was not. The many different diameters for tanks found at Rocky Flats following decades of case-by-case installations necessitated a wide variety of mounting rigs. 
Furthermore, ring-filled tanks at the plant often have external ports on their sides serving a myriad of purposes. Assaying around these ports was also difficult.

Years later, when Rocky Flats began to introduce shielded annular tanks, the same physics concept was reconsidered. Fortunately, the need to maintain surveillance on moderating and absorbing materials could be factored into the design of these tanks. A fixed outside diameter was mandated; and a cylindrical surface free of ports and penetrations was engineered into the plant-standard design. This safety study was reported in the literature ${ }^{39}$. Still later, an improvement was made for a recent application. The improvement is to position the neutron source interior to the inner tank's shield. This design reduced greatly the distance across which the neutron beam might diverge; and it cut in half the number of layers of material penetrated. This safety study was published in an internal report ${ }^{40}$.

${ }^{39}$ D. A. Freier, "Tank Evaluation System: Shielded Annular Tank Application", RFP-4165. October 4, 1988.

${ }^{40}$ D. A. Freier and B. P. Anderson, "TES (Tank Evaluation System) Evaluation of Building 371 Caustic Waste System SATs (Shielded Annular Tanks). Technical Investigations, EG\&G Rocky Flats Plant, 93-002. May, 1993. 


\section{ACKNOWLEDGMENTS}

The author gratefully acknowledges several people involved in these two programs in many ways. Most have become close friends in the many years since the experiments were performed. Sadly, some are now deceased. Grover Tuck (deceased), Dr. Inki Oh (deceased), Warren R. (Bob) Sheets, and George Goebel were the principal experimental assistants for the first program, although Dr. John S. Pearson and Dr. Stephen H. Manglos joined the team late in the series. A short ancillary series designed to study criticality detection and alarms - but using the annular tank equipment - employed the assistance of Dr. Robert E. Miles. Electronic instrumentation of the Reactor Control Console was maintained by Bob Sheets and Douglas E. Payne (deceased).

The second program found Dr. R. David Sachs, Dr. Miles, and, later, Dr. James M. Wu as principal assistants. The author is especially grateful to these three assistants for their extraordinary efforts at a difficult time. He had experienced a nearly fatal mountain climbing accident early in the program; and the team put forth the extra effort necessary to continue the study. The electronic instrumentation of the Reactor Control Console was maintained by Howard C. Bachman (retired). Finally, Mr. Gilbert J. Garcia attended to the important safety aspects of handling the potentially dangerous radioactive and contaminating materials for both programs. 
Christine E. White composed the many figures and tables for this lengthy paper. She did so under difficult conditions. She and the author live and work in different states. Hand-drawn drafts were mailed to her initially. Iterative improvements were mailed back and forth with only occasional telephone calls for clarification. Results illustrate her talents clearly. 


\section{ADDENDUM}

This addendum is necessary because of the long time taken to write this paper (18 months) and because of the even longer time since the experimental work was performed - the first work began in 1980. Information in this section was discovered during searches of written records for other data. When such discoveries occurred early in the writing, they could easily be incorporated into subsequent text. Later discoveries, affecting earlier text, became more difficult to include. Reorganizing completed text was attempted but became increasingly laborious. New findings modified previously written text. Tables and figures had to be renumbered

\section{Addendum \#1: MODERATORS and ABSORBERS}

The final cross section assumed for the $22 \times 8$ plug is that the top of the sagged earthen material is $165 \mathrm{~mm}$ below the top of the paper tube and that the inner form has been filled with the boron-loaded concrete to a depth of about $1.07 \mathrm{~m}$. This is, at best, an approximation to the actual situation.

[This paragraph pertains to the subsection headed: "Internal Moderation and Absorption - first program". It will be inserted after the paragraph beginning with the words: "Two other plugs (22x8 and $24 \times 10 \ldots . . . "]$ 


\section{Addendum \#2: MODERATORS and ABSORBERS}

The manufacturer's claim for Rad-Stop gives the following elemental composition:

$\begin{array}{ccccc}\text { Si } & \text { O } & \text { H } & \text { C } & \text { B } \\ 20.6 & 16.5 & 2.6 & 22.4 & 38.0\end{array}$

which adds up to 100.1 weight-percent. This advertizing brochure claims a density of 1.62 $\mathrm{mg} / \mathrm{mm}^{3}$ and a stock thickness of $3.18 \mathrm{~mm}$.

[This general comment applies to the portion of this section concerned with the second experimental program.]

\section{Addendum \#3: SOLUTION HEIGHT}

The Mass Flow Meter is a very precise instrument; but great care must be taken to obtain accurate data. Microbubbles formed in the uranium solution by the impeller of the centrifugal pump could have reduced the effective density of the liquid. These bubbles, trapped in the Ushaped vibrating tube of the device itself, could yield inaccurate heights calculated from the mass data. This seems to be the case since critical heights calculated from the Mass Flow Meter data were several millimeters higher than that indicated by the less-precise Sight Gauge method. The position adopted for this paper is that the Sight Gauge data is probably more reliable even though the Mass Flow Meter recorded masses to the nearest gram - a precision in about one part in a million! Still, critical heights by both methods are recorded for completeness.

The problem did not exist, apparently, in other later programs using the Mass Flow Meter. In particular, critical heights for the Poisoned Tube Tank paper (to be published next in the series of Rocky Flats experiments) evidently were free of this difficulty. There, heights 
obtained by a number of methods were determined and compared almost immediately after the experiment; and no such large differences were uncovered.

[This general comment may modify slightly several sections of the paper. It is included in the Uranium Height section only because that is the section that describes the device.] 


\section{A NON-DESTRUCTIVE ASSAY METHOD}

The Shielded Annular Tank is a relatively new design for the critically safe storage of

fissile solutions. Prior to that concept, borosilicate glass Raschig rings served the nuclear industry well (for half a century) as a fixed nuclear absorber in storage tanks. Such important concepts need safety standards to ensure continued safety. The Shielded Annular Tank is subject to ANSI/ANS 8.21-1995 ${ }^{38}$. The American National Standard, ANSI/ANS 8.5, sets safety standards for Raschig rings. That includes not only specifications covering manufacture and initial use but also the need for periodic reinspection of rings to make certain they are not losing their ability to absorb neutrons.

Such reinspections are costly and potentially dangerous. Rings will have been immersed in fissile solution for many months to years when the reinspection required by the Standard is due. The glass will be heavily contaminated. If the surface has been etched by the fluid stored, that contamination may be deeply embedded. The expense stems from problems in handling contaminated objects; and the danger arises out of the potential for spreading contamination and inflicting cuts from broken pieces.

38 American National Standard: "American National Standard for Use of Fixed Neutron Absorbers in Nuclear Facilities Outside Reactors", ANSI/ANS-8.21-1995. 
Rocky Flats investigated a means of measuring one important parameter of Raschig rings without touching them. That parameter was the boron content of the glass for which the Standard set a minimum value. The non-destructive assay technique involved a collimated neutron source and shielded neutron detector. The two were diametrically opposed from one another when mounted on the ring-filled tank being measured. Source neutrons entered the counter through a hole in the shield only after passing through the tank containing the bed of Raschig rings. If a suitable amount of boron was present in the path of the neutrons (the desired case), the beam would be diminished by absorption. If either rings were missing or boron had somehow been preferentially leached from the glass, the flux reduction would not be as great.

The prototype device featured a rotational capability that allowed the source and counter to move azimuthally around a tank keeping the two always diametrically opposed. The same hardware provided for vertical movement too. Thus, the device was capable of scanning all portions of a right circular cylinder.

The method is obviously dependent upon the diameter of the tank under study; but this parameter could be factored into the calibration. The physics of this was quite straightforward; but the practical application was not. The many different diameters for tanks found at Rocky Flats following decades of case-by-case installations necessitated a wide variety of mounting rigs. 
Furthermore, ring-filled tanks at the plant often have external ports on their sides serving a myriad of purposes. Assaying around these ports was also difficult.

Years later, when Rocky Flats began to introduce shielded annular tanks, the same physics concept was reconsidered. Fortunately, the need to maintain surveillance on moderating and absorbing materials could be factored into the design of these tanks. A fixed outside diameter was mandated; and a cylindrical surface free of ports and penetrations was engineered into the plant-standard design. This safety study was reported in the literature ${ }^{39}$. Still later, an improvement was made for a recent application. The improvement is to position the neutron source interior to the inner tank's shield. This design reduced greatly the distance across which the neutron beam might diverge; and it cut in half the number of layers of material penetrated. This safety study was published in an internal report ${ }^{40}$.

${ }^{39}$ D. A. Freier, "Tank Evaluation System: Shielded Annular Tank Application", RFP-4165. October 4, 1988.

${ }^{40}$ D. A. Freier and B. P. Anderson, "TES (Tank Evaluation System) Evaluation of Building 371 Caustic Waste System SATs (Shielded Annular Tanks). Technical Investigations, EG\&G Rocky Flats Plant, 93-002. May, 1993. 


\section{ACKNOWLEDGMENTS}

The author gratefully acknowledges several people involved in these two programs in many ways. Most have become close friends in the many years since the experiments were performed. Sadly, some are now deceased. Grover Tuck (deceased), Dr. Inki Oh (deceased), Warren R. (Bob) Sheets, and George Goebel were the principal experimental assistants for the first program, although Dr. John S. Pearson and Dr. Stephen H. Manglos joined the team late in the series. A short ancillary series designed to study criticality detection and alarms - but using the annular tank equipment - employed the assistance of Dr. Robert E. Miles. Electronic instrumentation of the Reactor Control Console was maintained by Bob Sheets and Douglas E. Payne (deceased).

The second program found Dr. R. David Sachs, Dr. Miles, and, later, Dr. James M. Wu as principal assistants. The author is especially grateful to these three assistants for their extraordinary efforts at a difficult time. He had experienced a nearly fatal mountain climbing accident early in the program; and the team put forth the extra effort necessary to continue the study. The electronic instrumentation of the Reactor Control Console was maintained by Howard C. Bachman (retired). Finally, Mr. Gilbert J. Garcia attended to the important safety aspects of handling the potentially dangerous radioactive and contaminating materials for both programs. 


\begin{abstract}
APPENDIX
The complete report reproduced on the following several pages is copied verbatim from its original written in the fall of 1987 . No new information has been added nor deletions made. The document was an attempt on the part of criticality safety personnel to use unpublished data described in the body of this report to validate the then-current computational techniques used in nuclear criticality safety evaluations.
\end{abstract}

This appendix may contain some differences from the present paper. The reason is that both documents came from the same collection of unreduced data generated in the $1980 \mathrm{~s}$. The present paper was composed a decade later; but the appendix document was written with a different perspective and for a different purpose. Units of measure differ as do style and wording.

This author apologizes for additional effort needed to reconcile the two; but the appendix was not published in any retrievable format at the time. The risk of losing a possibly valuable work obviously closely associated with the current paper was great; so, it is included as an appendix. 
THE VALIDATION OF A

\title{
FISSILE SOLUTION STORAGE METHOD
}

\section{FOR USE AT ROCKY FLATS}

\section{THE SHIELDED ANNULAR TANK}

\author{
Robert E. Rothe \\ Robert E. Miles \\ Jerry N. McKamy \\ R. David Sachs \\ James $\mathrm{N} . \mathrm{Mu}$
}

September, 1987

\author{
Critical Mass Laboratory \\ Rockwell International \\ Rocky Flats Plant
}




\section{IECHNICAL SUMMARY}

A program of eleven critical approach measurements have been performed in an effort to verify. the nuclear criticality safety of a new method of storing fissile solution at the Rocky Flats Plant (RFP). The method is referred to as "the shielded annular tank", and future production tanks of this type will be composed of right circular annular cylinders containing the fissile solution. The critically-safe thickness of this annular region can be maximized - thereby improving the storage efficiency of the method (percentage of a room's floor space available to the storage of fissile solution) - by surrounding both the interior and exterior of the annular regions with layers of effective neutron moderators and neutron absorbers. These combine to form the "shield" preventing neutronic interaction between one region of the annulus and a diametricaliy-opposed region or with another nearby tank.

The measurements were performed at the Critical Mass Laboratory (CML), Building 886, operated by Rockwell International at the RFP facility. This laboratory was designed for such a purpose, and allows the performance of critical measurements with assured safety to people and environment. To date, over 1600 measurements have been performed at this laboratory. This program was conducted at the CML during 1986 and 1987 with all critical approach measurements being performed during 1987 . 
Each configuration was described very accurately as computer input for the nuclear criticality safety computational code known as KENO. This code calculates a quantity known as "the neutron reproduction factor" (or keff). In a critical system, the value of this factor is known to be accurately and precisely 1.000. The purpose of calculating each configuration is to validate the computational code in that application (the KENO code will also yield a calculated factor of 1.000). Any difference between the measured and calculated values of this factor is taken to be the "bias" of the computationar method. Any nonconservative bias must necessarily be taken into consideration when applying these calculations to safety evaluations of plant operations, such as the use of shielded annular tanks for the safe storage of plutonium solution in production areas at RFP.

To minimize uncertainties in the determination of this bias, the configuration at criticality must be measured both very accurately and precisely. Thus, the geometry of the annular tanks, the moderator, and the absorber regions must be determined very carefulity. Next, the elemental composition of the materials in these geometrical regions must be equally well defined, for the KENO code depends on accurate specification of geometry and composition for its calculation of keff. 
Every one of the critical approach measurements which did, in fact, achieve criticality was tested against the computer code in this fashion. The average bias in keff is $0.0061 \pm 0.0025$. Some calculations yielded keff values siightly in excess of unity (slightly conservative), while some were slightly less than 1.0 (slightly nonconservative); but the average bias of the computational method is less than 2.5 times the standard deviation of the statistically determined neutron reproduction factor. This fact constitutes a validation of the KENO code in such applications.

With the KENO code thus validated, a computational results to design a production tank for use in many and varied applications within the RFP mission were verified. The results of this study are also reported in this document, and the curmination of this effort is that the dimensions of a shielded annutar tank have been defined for critically-safe use in many applications throughout the plant. These dimensions have been approved by the Manager of Nuclear and Facilities Safety as acceptable from a criticality safety point-of-view. Other safety disciplines have reviewed the proposed production tank in light of their special safety considerations. 
INTRODUCTION

This report begins with a technical summary which describes why the measurement/computational program was undertaken. The summary concludes with the conclusion that the purpose was successfully accomplished and that a critically-safe tank has been approved for use in production areas at RFP. Several sections describe the measurement program in detail. The tank, the moderator, the absorber, and nearby neutronically-important items are described and defined. The fissile solution used in the study is described to prove that the concentration of the fissile isotope was sufficient to approximate the minimum critical volume concentration - necessary for a conservative computer validation study. The laboratory methods employed on each experiment are described next. The measured results and their uncertainties are presented in another section. These were used to validate the Monte Carlo (statistical) computational code, KENO, in this type of situation. Then, the validated code was used to design a production tank for use at RFP, and this is described in another section. The conclusion of this report contains the validated statement that an alternate method of storing fissile solution at RFP has been designed and approved. 
The computer code validation procedure begins with a set of precise critical mass measurements reported here. This is accomplished by constructing a test tank which approximates the proposed tanks to be used in production areas in all respects except one. The height, diameter. and wall thickness of the test tank closely resemble a typical production tank. The composition of the tank and the neutron-moderating plastic and plastic and neutronabsorbing rubber are identical to those proposed for a production tank. The one exception lies in the radial thickness of the annular region designed to contain the fissile solution. In the test case, this was selected to be so large that criticality could occur even at low heights within the tank. In fact, the need to be able to add or subtract small reactivity increments (called reactivity "shims"). was recognized early on, and the annular thickness of the test tank was set such that criticality would occur at a low height within the tank. Then, these shims were to be used to increase that critical height until, hopefully, criticality would occur. with an essentially full tank. In the production tank. this radial thickness will be selected to be considerably smaller such that criticality would never occur under any reasonable circumstance. 
[7]

The validation study continued by measuring test configuration which departed from the proposed production tank design, and then validating the computer code in these cases, too. For example, moderator and absorber components were intentionally omitted. In no case did the KENO computer code compute a Ref significantly different from unity for any "measured critical system. Thus, the code is validated for all cases studied. 


\section{APPARATUS}

The fissile solution was uranyl nitrate salt, $\mathrm{UO}_{2}\left(\mathrm{NO}_{3}\right)_{2}$ - $6 \mathrm{H}_{2} \mathrm{O}$, dissolved in dilute nitric acid. The uranium concentration in the solution was well within the broad range known as "the minimum critical volume concentration", generally recognized to extend from 300 to $400 \mathrm{~g}$ U/7iter. The solution used in this program had a concentration of $367 \mathrm{~g}$ U/liter. The bulk density of the uranium solution was $1.5 \mathrm{~g} / \mathrm{cm}^{3}$, the [H]/[U] atomic ratio was 62 , and the total impurities were $<1500 \mathrm{ppm}$ by weight with no significant portion of that being elements with high thermal neutron absorption cross sections. The solution contained nitric acid necessary to maintain the uranium salt in solution. The concentration of nitric acid was $0.58 \mathrm{M}$.

The annular region which ultimately contained the fissile solution was formed by nesting two stainless steel concentric tanks of different diameters. The outside diameter of the smaller tank (151.130士.013 cm) was enough smaller than the inside diameter of the outer tank (129.286 $\pm .000 \mathrm{~cm}$ ) that an annular region $10.922 \mathrm{~cm}$ thick would 
be formed when the two tanks were perfectly concentrically nested: The height of the inner tank was shorter than the outer tank $(208.28 \mathrm{~cm})$ by the thickness of the outer tank's bottom plate; thus, the tops of the two nested tanks were coplanar. The walls of both tanks were $0.63 \mathrm{~cm}$, and both tanks had the same thickness bottom plate: $1.3 \mathrm{~cm}$. The bottom plates on each tank held the right circular geometry true, but stiffening rings were used at the top and midheight of each tank to maintain the geometry over the whole height. These rings were welded in place early in construction, but all final dimension machining was done after all welding. Rings measured $1.3 \mathrm{~cm} \times 5.0 \mathrm{~cm}$ in cross section. Room doorway limitations did not permit either tank to enter the room as a single unit. Each was segmented horizontaliy at about its mid-plane. The top halves of both tank assemblies were $104.14 \mathrm{~cm}$ high. Top and bottom segments of both inner and outer tanks were bolted together using an 0-ring to assure leak tightness. All metal components of both tanks were composed of type 304 L stainless steet.

Neutrons created by the fission process are too energetic to be absorbed readily by a neutron poison, so the inside of the inner tank and the outside of the outer tank were surrounded by cylindrical regions of high density $c=$ $0.95 \mathrm{~g} / \mathrm{cm}^{3}$ ) polyethylene, a plastic high in hydrogen content and, therefore, a good neutron moderator. Both cylindrical 
regions were quite similar in height and thickness, but differed in radial dimension to suit each specific location. The polyethylene regions were spiral-wound as layer-uponlayer laminations of hot polyethylene filament material until the desired thickness was built up over an 2.3-m length. The finished cylindrical moderator regions were then machined from these "blanks". The outer polyethylene moderator was machined to a $169 \mathrm{~cm}$ outside diameter and a $155 \mathrm{~cm}$ inside diameter. The average thickness of the cylindrical region was $7 \mathrm{~cm}$. The height was cut to $204 \mathrm{~cm}$ but this, too, was sliced at mid-plane to permit access to the test room. The similar dimensions for the inner polyethylene moderator (also sliced at mid-plane) were: $124 \mathrm{~cm}$ outside diameter, $108 \mathrm{~cm}$ inside diameter, $8 \mathrm{~cm}$ annular thickness, and $203 \mathrm{~cm}$ tall. All these plastic dimensions are intentionally given with low precision because internal stresses formed during manufacture caused the final cylindrical components to vary considerably in any dimension by 3 or $4 \mathrm{~mm}$. To complicate the geometrical description of these cylinders further, each of the four sections (top and bottom of the inside and outside moderator) had to be sliced vertically in order to permit assembly around a tank already in $\mathrm{place}$. Outer polyethylene components were merely sliced into two hemi-cylinders. Interior components were sliced vertically into three setments. Later, after each cylindrical set was reinstalled around or within the 
appropriate tank, vertical seams were welded with polyethylene welding rod stock to fill saw keft gaps and to return seismic integrity to the completed assembly. Vertical cuts lessened the already low dimensional precision on these regions. This dimensional variability in the polyethylene moderator regions had been anticipated, so the radial dimensions were set to leave considerable $(1.3 \mathrm{~cm})$ air gaps between the polyethylene and the adjacent stainless steel wall of a tank. Furthermore, the mid-plane between the top and bottom segments of either cylindrical region were machined to form a step which prevented any neutron streaming through gaps in the material. All polyethylene contained $2 \%$ by weight carbon black (pure carbon).

Neutrons moderated to thermal and epithermal energies have a high potential for causing a fission if they encounter another fissile nucleus, but they also have a very high probability of being absorbed should they encounter a boron nucleus first. Thus, each of the two polyethylene regions is further 1 aminated inside and out by a $0.32-\mathrm{cm}-$ thick wrap of silicone rubber. This rubber was manufactured to contain over $50 \%$ boron carbide $\left(B_{4} C\right)$. The isotopic ratio $B 10 / B^{11}$ within normal elemental boron is 0.238 , and the isotope $B 10$ has a very strong affinity for absorbing thermal neutrons. Consequentiy, the B10 nuclei within the rubber are an effective and efficient absorber of neutrons which otherwise might go on to cause a fission. The rubber came in flexible sheet 
material which was wrapped around convex surfaces. COne would have difficulty in "pushing out" such a flexible material such that it would hold in place against any concave surface.) The outermost layer of this neutronabsorbing material was wrapped onto the outside surface of the outer polyethylene moderator. It was stapled to the plastic. The next layer of rubber was wrapped around the outside surface of the outer (larger diameter) stainless steel tank. Thus, this layer was separated by a few $\mathrm{mm}$ of air from its nearest polyethylene cylinder. The next inner layer of boron-loaded rubber was stapled to the outer surface of the inner polyethylene moderator cylinder. Here, the assembly sequence required that the rubber be cut to sheets the same size as each segment of an interior moderator; it could not simply be wrapped after assembiy. The innermost layer of rubber was wrapped onto a heavy-duty cardboard tube normally used as a form for casting cylindrical concrete bridge pieces. The diameter of this paper tube was a few centimeters smaller than the inside diameter of the inner polyethylene region. making for an easy slip fit. The elemental composition of the boron-loaded rubber material is given in a table in a later section, along with the elemental compositions of all materials as input to the computer.

The radial spacing between the two nested stainless steel tanks was intentionally selected to be so wide that criticality would occur below the mid-plane of the annular 
region. Then, the critical height of subsequent systems could be increased by the installation of wraps of thin stainless steel to either the outside of the inner stainless steel tank or to the inside of the outer tank. These shims would reduce the effective annular spacing between the tanks by increasing the effective wall thickness. Several shims were used in various locations within the annular region throughout the program; all were stainless steel. A 4.87-mm-thick shim was rolled to a diameter slightly less than the inside of the larger tank. After lowering into the tank, a set of screw drive devices were used to expand the fairly thick shim such that it fit fairly tightly against the inside wall of the outer tank. Intimate contact did not exist everywhere because of imperfections in the rolling process and the stiffness of the material, and the exact location and extent of such air gaps was not possible to assess. Still, the model of a tight-fitting shim is assumed to be a very good approximation. The outside surface of the inner tank was also wrapped with such shims. These were much thinner, but three were used to build up the needed thickness. The thickness of the individual layers was $0.744,1.219$, and $1.511 \mathrm{~mm}$. If used, they were always used together for a total thickness of $3.474 \mathrm{~mm}$. The quality of fit appeared to be much better, and the possible existence of air gaps need not even be considered. A third shim, $6.23 \mathrm{~mm}$ thick, 
was also used on some experiments. This shim was rolled to an outside diameter of $142.75 \mathrm{~cm}$, clearly intermediate between diameters defining the solution annulus. The purpose for this was to abrogate the concern for solution build-up in air gaps by intentionally having a large quantity of solution on either side of a shim. Various measurements used the above reactivity shims in various combinations.

The environment of a measurement is important because nearby materials can introduce neutron reflection. The shielded annular tank measurement system, described above, rested on a platform $39 \mathrm{~cm}$ above a $20-\mathrm{cm}$-thick concrete deck. Concrete walls to the south and east were $1.9 \mathrm{~m}$ and $3.5 \mathrm{~m}$ from the tank centerline, respectively; both walls were $1.2 \mathrm{~m}$ thick. Other concrete surfaces of the room were so far away as to be ignorable. The inner tank containing its polyethylene and rubber regions was prevented from floating in the fissile solution by a heavy-duty "lifting/hold-down cross". This was composed of crossed I-beams welded in the shape of a plus sign. Both tanks were bolted to it. This cross weighed $100 \mathrm{~kg}$.

The photographs of Figures 1 to 7 show various aspects of the components described in this section. The first three portray overall views, while the remainder emphasize details. 


\section{FIGURE 1}

Upper three-quarter view of the completely assembled configuration ready for a measurement. The cross is bolted in. place, and is used for lifting components and to keep the inner tank from tending to float. All moderator polyethylene plastic and absorber rubber is present, although two rubber layers are hidden from view by other components. The annular space for the solution is seen most sharply at both sides of the photograph about halfway up the picture. Because no reactivity shims are present for this case, the full annular thickness exists. The funnel was used to guide a small, Cf252 neutron source into position. This was needed for the reciprocal multiplication technique used for a safe approach to criticality. 



\section{FIGURE 2}

Measurements were made on a thick concrete mezzanine elevated $3.4 \mathrm{~m}$ above the floor of the room. This view, looking east, shows proximity to nearby walls. The center-most absorber (wrapped onto a paper tube) and the steel cross are absent from this photograph. 


\section{$\underline{\text { FIGURE } \underline{3}}$}

Steel banding held the absorber rubber in place against the outside of the outer tank where staples could not be used. The mid-plane segmenting is clearly visible. 


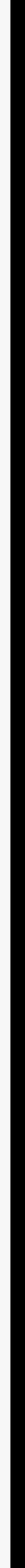




\section{FIGURE 4}

The tank was elevated above the concrete floor to reduce neutron reflection from that surface. The outer layer of rubber is not present for this study. The devices near the top of the tank on either side are equipment associated with a neutron attenuation method of determining the presence of shielding materials. This program was also studied on these tanks during the critical measurement program, but their results are not included in the text. 


\section{FIGURE 5}

A detail of the polyethylene installation near mid-plane. The steps machined in the plastic provided clearance for the mid-plane flanges and prevented neutron streaming. Steel banding was used to draw slight mismatches (resulting from internal stresses in the polyethylene during forming) into better geometrical alignment. The rope at the bottom left of the photograph would not remain after banding. 


\section{FIGURE 6}

A detail of the innermost boron-loaded rubber. This sheet was wrapped onto a cardboard tube that fit loosely inside the inner polyethylene moderator region. A single sheet of thin vinyl plastic $(0.15 \mathrm{~mm}$ thick) was wrapped and taped over the rubber holding it in place. Staples could not be trusted to hold in the paper tube. 



\section{FIGURE_ 7}

Detail showing the segmenting of the inner polyethylene moderator plastic. The horizontal mid-plane seam can be seen, but the fit is very good because both surfaces were machined. Vertical seams were welded using polyethylene welding rod. 



\section{PROCEDURE}

The reciprocal multiplication technique (1/M) was used for a safe approach to criticality. Here, the test apparatus described in the previous section is completely assembled in a mechanically sound and seismically stable manner, but with the total absence of any fissile solution. Additionally. radiation sensitive devices, such as neutron proportional counters and neutron- and gamma-sensitive ionization chambers, are carefully located at appropriate places near the apparatus.

A neutron source $(C f 252)$ is placed inside a thin-walled hollow sealed tube close to the bottom of and in the solution annular region. The count rate seen by each of the detectors at their distance from the source and with all the various materials interposed is taken to be the initial count, $C_{0}$. for the critical approach measurement in question. When fissile solution is introduced to this "initial system". the detector count rate increases to $C(h)$ at solution height ,h. due to the increased number of nuclear fissions taking place as criticality is approached. This count rate approaches infinity at criticality and cannot be graphed, but the reciprocal approaches zero. Thus, the reciprocal multiplication is tracked carefuliy as that parameter decreases with increasing solution height. The critical solution height would be that at which $1 / M=0$. 
When count rates get very high, a detector phenomenon known as "dead time" complicates the continued use of this technique as the final few liters of fissile solution are pumped into the tank to establish criticality. The technique is abandoned for the carefulty controlled attainment of criticality. Instead, the neutron source is withdrawn from the solution, and small quantities of solution are added to the tank in alternating incremental steps. During all of this, the "power level" (as shown by the ionization chamber detection channels) is carefully monitored until the neutron population is seen to e-fold (increase) over a period of a few minutes. At this point, the configuration is slightly above criticality. This solution height is noted. Next, a small amount of solution is drained away until the neutron flux decreases with about the same magnitude of an e-folding period. Again, this now-subcritical height is noted. Finally, the critical height quoted in this report is that interpolated between these two heights, one slightly above and one slightiy below criticality.

Figure 8 is an example of such a 1/M curve. The dots, themselves, show the actual solution heights at which the reciprocal multiplication was measured and recorded. The solid line shows the actual approach to criticality employing this technique. The dashed lines show the use of the data to provide a continuous estimate of the projected critical height. (For safety, at least two certified persons each recorded data from at least two detection channels; only one point is shown in this example for clarity.) 
[31]

Fissile solution was introduced into the tank by the positive action of pumping the solution against the force of gravity. This precluded the inadvertent passage of unwanted solution to the tank. Three pumps, each having variable rates, were used such that the act of making solution additions was always under full control. Still. "fail-safe" scram valves would act should an accident occur, allowing the solution to pass into critically-safe holding tanks. 


\section{RESULTS AND UNCERTAINTIES}

Table I presents the critical height of the fissile solution in the annular region for those measurements for which criticality was achieved. The increase in critical height as various reactivity shims were introduced is shown in Figure 9. The goal was to so "shim" the reactivitycontrolling parameters as to achieve criticality with a tank whose annular region was relatively deep. This proved to be a rather difficult task for reasons to be explained later in this section, but the critical heights actually achieved proved to be quite adequate for the computer code validation purpose of the measurement.

A detailed analysis of the nuclear physics pertinent to a critical configuration such as these studied in this program revealed that the critical thickness of an already very tall solution annulus would be imperceptibly thicker than the critical thickness of an even taller solution annulus. The task is made even more difficult by the need to place one tank within another, neither being absolutely perfect in fabrication, such that the annular spacing should be absolutely the same constant at all heights and azimuths. The ideal tank cannot be built, even in the best-equipped and qualified machine shop. 
Table I. Critical Solution Heights for Various Tank Parameters

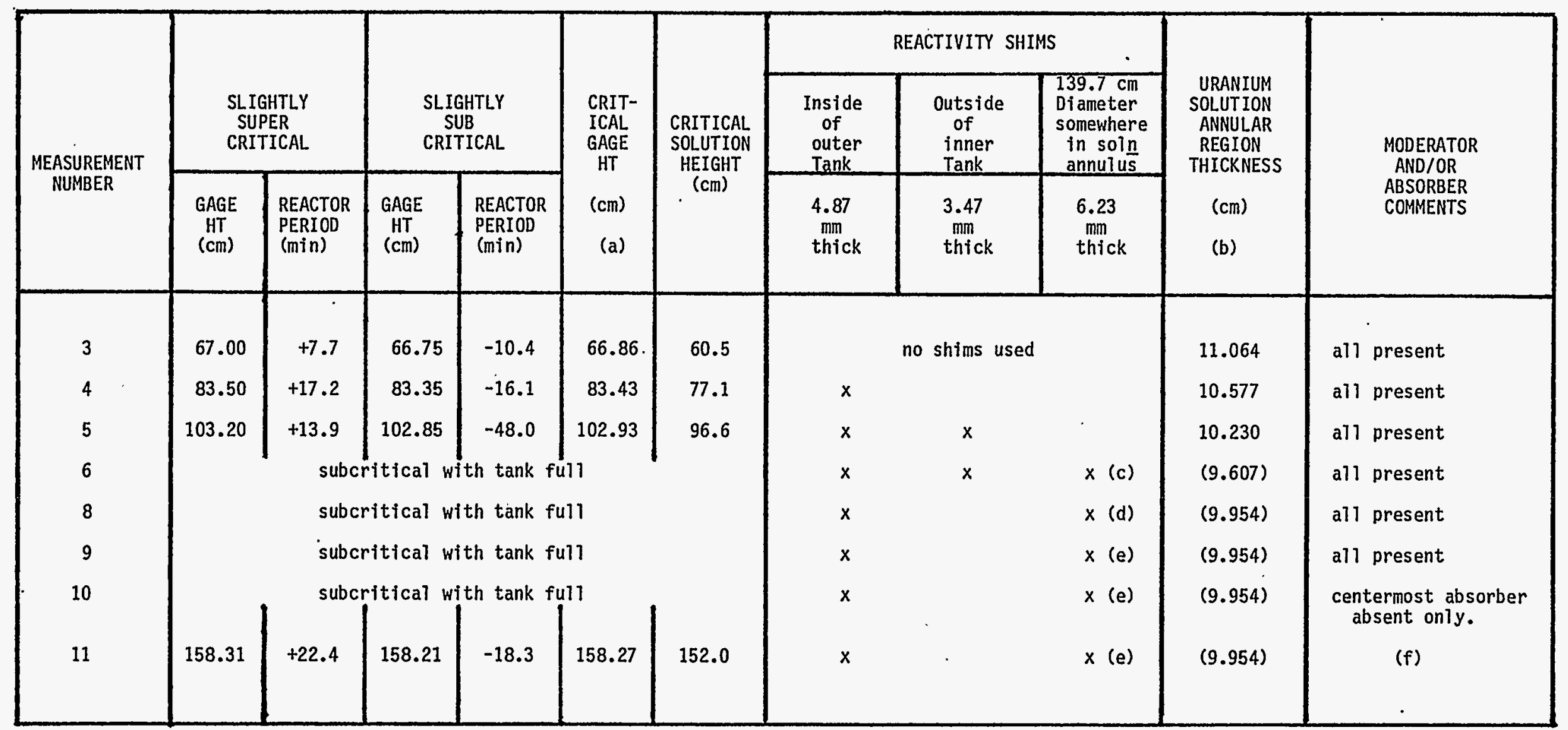

See footnotes on next page 
Tabie 1 (Cont.)

Critical Solution Heights for Various Tank Parameters

Page 2

(a) The solution height gage read $6.3 \mathrm{~cm}$ whenever solution first wet the bottom of the tank.

(b) Solution thicknesses in parentheses are the total of two solution regions separated by the 139.3-cm-diameter reactivity shim situated in the annulus as specified by footnotes (c). (d), and (e).

(c) 6.23-mm-thick shim touching the 4.87-mm-thick shim.

(d) 6.23-mm-thick shim roughiy centered in solution annular region.

(e) 6.23-mm-thick shim touching the outer tank (4.87-mm-thick shim absent).

(f) Center most absorber absent as well as the top half of the inner polyethylene moderator and the absorber layer stapled thereto. 


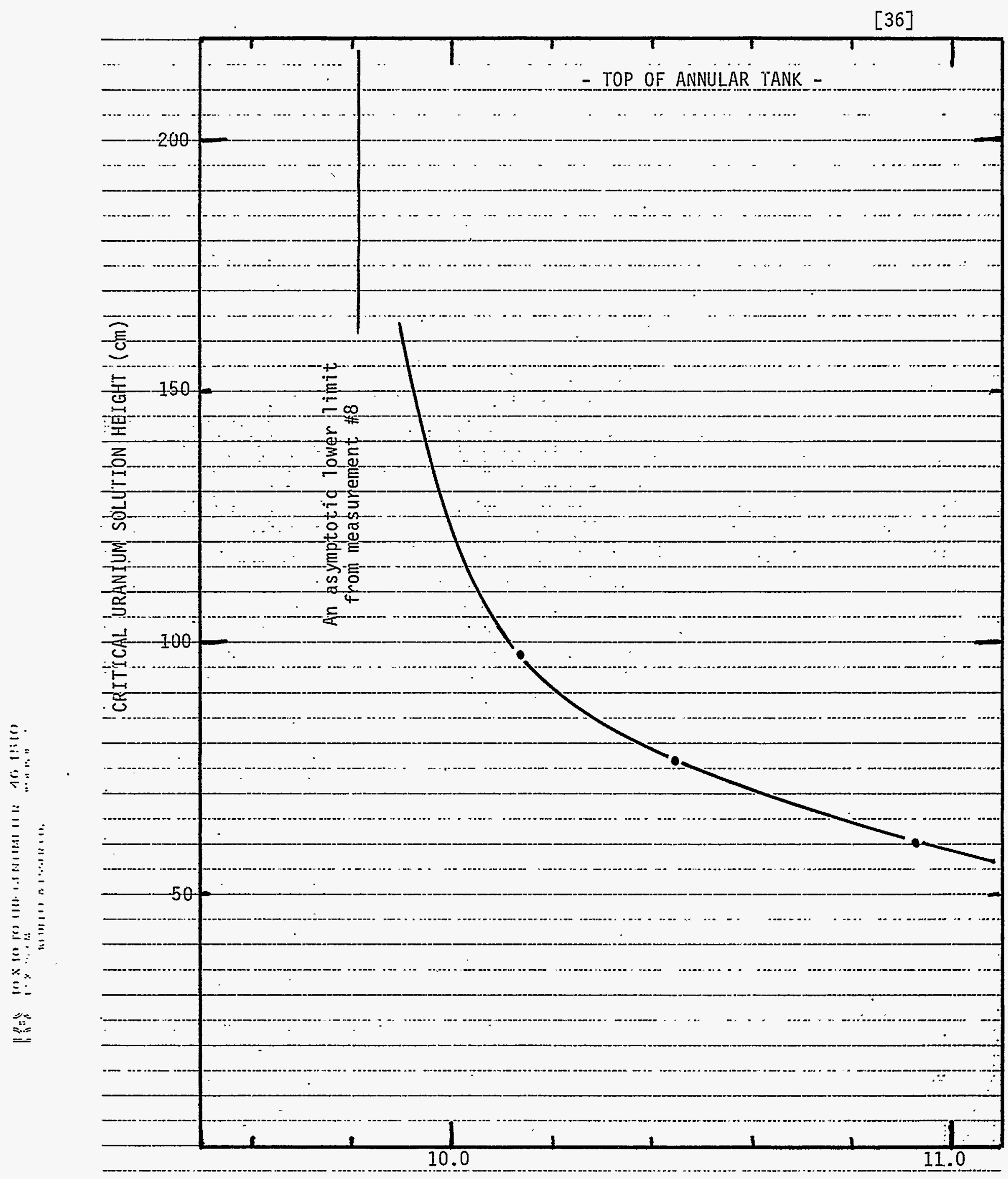

URANIUM SOLUTION ANNULART THICKNESS $(\mathrm{cm})$ FIGURE- 9 
Another nuclear physics consideration is important to the slope of the curve of Figure 9 at any solution height above that for which no shim existed. That curve would be dramatically steeper if the only important phenomenon was the decrease in the annular thickness of the solution thickness. In reality, however, the introduction of any "shim" into the solution region not only decreased the thickness of that region, but it effectively increased the thickness of the nearby stainless steel wall. The reduction in solution thickness is certainly a reactivity removal, but the added reflection due to the effectively thicker wall is a reactivity addition shim. The former effect is about twice the impact of the latter, so the net effect of the stainless steel shims described in the previous section is to increase the critical solution height as expected. Fortunately, production tanks - the goal of this program - do not demand anywhere near the radial thickness constancy of the test tank. A production tank must remain well-subcritical at all times under all conditions. Thus, its annular thickness would lie far away from the steeplysloped asymptote sought for in Figure 9. Ordinary good care during fabrication would easily yield a perfectly safe tank in spite of the obvious necessity to design tolerances into a manufacturing specification. Additionally. RFP's inspection procedure upon receipt would provide another chance to determine the suitability of a manufactured tank before installation. 
The neutron "shjelds" are very important components to this design, and the omission or removal of one such shield can sharply increase the reactivity of a production tank. One measurement - with full shields in place - was very far from criticality with a given set of shims within the annular region. The next measurement repeated the same configuration except that the upper half of the inner moderator and absorber were removed. The $1 / M$ curve during the filling up to the mid-plane of the tank very closely followed the $1 / M$ curve of the previous (well-subcritical) measurement. The curve deviated sharply from the earlier one as the solution height continued to increase above about mid-plane until criticality was achieved only a short distance above mid-plane. Figure 10 shows the $1 / \mathrm{M}$ curves for both these measurements. The slope- of the $1 / M$ curve near criticality demonstrates the strong significance of each shield component of a shielded annular tank. One corollary stemming from these same two measurements can be recognized. In some large-geometry critical configurations, the possibility exists that geometrically-smaller portions of the same configuration may achieve criticality independent of the presence of possibly much larger portions of the same configuration which are even well-subcritical. This phenomenon may be described as a system being "piece-

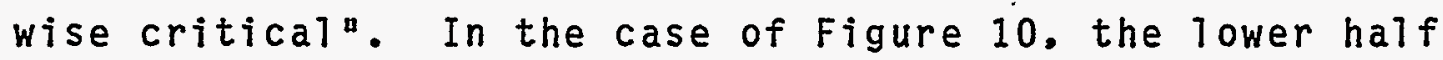


of the tank behaved as though the whole tank was subcritical all the way to the top, but the few tens of centimeters above the nominal mid-plane of the tank behaved as though the critical assembly achieved criticality without much interaction with the well-subcritical portion below.

This notion of "piece-wise criticality" has relevance to the precision of the annular solution region thickness at various azimuths around the tank and heights. If a significant azimuthal segment of an annular tank had a slightiy thicker annular thickness over a considerable height, that portion of the tank could become "piece-wise critical" even though all remaining portions of the cylindrical annulus might still be slightly subcritical. Piecewise critical means that two nearby regions of an overall critical configuration are not so well coupled neutronically that subcritical portion(s) have any or no effect on the criticality of the other (self-critical) portion.

The uncertainty in the dimensions of machined metal components is very small because the importance of precision to the code validation process was recognized in the planning stages of this program. Typically, the dimensional tolerances on each such component are $\pm 0.2 \mathrm{~mm}$. The uncertainty in the annular spacing between the two tanks is understandably larger because it is the result of assembling several components. Still, radial spacing measurements made 
at four vertical heights up the tank and at sixteen azimuths around the tank for each height reveal the radial thickness spacing to be constant to better than $\pm 1.0 \mathrm{~mm}$ almost everywhere. A precisely machined annular disk at the bottom of the larger tank assured the best possible location of the smaller tank within it for this constant annular spacing.

The polyethylene plastic moderator is the least precise component of this entire program. Each radial and height dimension has an uncertainty of about $\pm 4 \mathrm{~mm}$. This is so because of internal stresses in the material during manufacturing and their evolution with time and machining.

The elemental analysis of the fissile solution is another significant source of measurement uncertainty. Analytical laboratory techniques were used such that the precision of accurate measurements. (no bias) of the uranium concentration is almost $\pm 1 \%$. Unfortunately, analytical techniques do not exist for an equaliy precise measurement of the hydrogen content of the fissile solution. This important parameter not only has a fairly large uncertainty $( \pm 5 \%)$, but the value quoted is probably not extremely accurate either. The reason for this latter problem is that one never knows the true distribution of free or ionically bound hydrogen in the solution, and analytical techniques respond differently to each. Neutrons scatter from hydrogen nuclei independent of their.chemical 
binding status. Even though hydrogen is determined about five times less precisely than the uranium content, hydrogen effects the KENO computational results three times more strongly than does the uranium. Because of the uncertainty in the precise knowledge of the solution composition, the KENO computations for several cases were run with slightly different solution descriptions. Statistically different values of keff were obtained for these different solution descriptions, and this fact was taken into consideration when validating the code for use in designing productionstyle tanks.

The apparatus used to measure the actual height of the solution via a sight gauge at any point within the tank was very precise $( \pm 0.2 \mathrm{~mm})$, but the ability to determine where the bottom of the tank would occur on that same sight gauge (relative height measurement devise) was less precise ( \pm $0.6 \mathrm{~mm})$. Therefore, the precision quoted for any critical height measurement in this report is about $\pm 2 / 3 \mathrm{~mm}$. Of course, the relative precision between measurements within this program would have the $\pm 0.2-\mathrm{mm}$ precision because neither the tank bottom nor sight gauge moved between measurements. 


\section{VALIDATION OF COMPUTATIONAL METHOD}

The basic geometrical description of the shielded annular tank (SAT), based on measurements made prior to the first critical approach, is summarized in Table II, with material atom densities given in Table III. The KENO5A input for this shielded annular tank defined in Tables II and III is listed in Table IV.

This basic model was used as a KENO5A validation model for the first SAT critical measurement. Three additional critical measurements were made for systems that differed in radial thickness and/or the deletion of certain regions, and validation models were developed to compute keff for these systems also. A summary of the four critical measurements and corresponding keff values computed is given in Table V. In three of four cases, the computed value was within $0.5 \%$ of the measured value of unity. Even the fourth case differed by only $1.5 \%$, and this was very sensitive to the accuracy of measured parameters. This agreement for these four measurements provides excellent assurance of the validity of the calculational method. The calculated results were quite insensitive to possible inaccuracies in the amount, thickness, compositions, and exact placement of the neutron absorbing rubber and the neutron moderating polyethylene plastic. 
An uncertainty of $20 \mathrm{~g} / 7$ iter in the uranyl nitrate solution concentration causes a $1 \%$ change in the computed keff value. Uncertainties in modeling the stainless steel walls of the annulus and the shims inside the annulus have a significant effect on the computer keff values, although these components were modeled quite carefully. Uncertainties in the hydrogen concentration are al so believed to have a significant effect on the computed keff values. In conclusion, modeling uncertainties are believed to be responsible for a $\pm 1 \%$ to $\pm 2 \%$ uncertainty in the computed keff value for any given SAT measurement. In light of these modeling uncertainties, the KENO5A code calculational method for the SAT is well validated by these measurements. 
Table II. Geometrical Measurements and Physical Constants for the Shielded Annular Tank Validation Study (dimenstions in $\mathrm{cm}$ and density in $\mathrm{g} / \mathrm{cm}^{3}$ )

INNER TANK

radius

wall thickness

bottom thickness

$=63.731$, top $=63.689$

height

material

density

bottom $=0.83975$, top $=0.94607$

1.2319

bottom $=103.37$, top $=103.38$

304L stainless stee]

7.9

\section{OUTER TANK}

radius

wall thickness

bottom thickness

height

tank material

tank density

$$
\begin{aligned}
& \text { bottom }=75.634, \text { top }=75.697 \\
& \text { bottom }=0.2751 \text {, top }=0.2555 \\
& 1.2319 \\
& \text { bottom }=103.37, \text { top } 103.38 \\
& 304 \text { L stainless steel } \\
& 7.9
\end{aligned}
$$

ANNULAR WIDTH

$$
\begin{aligned}
& \text { bottom }=10.975 \\
& \text { bottom }=10.966 \\
& \text { bottom }=11.064 \\
& \text { top }=10.925 \\
& \text { top }=10.925 \\
& \text { top }=11.057
\end{aligned}
$$

(from inner and outer tank differences)

(average of 16 measured values)

(maximum of 16 measured values)

(from inner and outer tank differences)

(average of 16 measured values)

(maximum of 16 measured values) 
Table II (Cont.)

Geometrical Measurements and Physical Constants...

Page 2

SHIELD MATERIALS

\begin{tabular}{|c|c|c|c|c|}
\hline $\begin{array}{l}\text { material } \\
\text { (density) }\end{array}$ & where used & radius & height & thickness \\
\hline $\begin{array}{l}\text { polyethyl ene } \\
(0.944)\end{array}$ & $\begin{array}{l}\text { inner-1 ower } \\
\text { inner-upper } \\
\text { outer-1 ower } \\
\text { outer-upper }\end{array}$ & $\begin{array}{l}54.50 \\
54.50 \\
76.91 \\
76.99\end{array}$ & $\begin{array}{l}103.37 \\
103.38 \\
103.37 \\
103.38\end{array}$ & $\begin{array}{l}7.62 \\
7.62 \\
7.66 \\
7.58\end{array}$ \\
\hline $\begin{array}{c}\text { boron-7 oaded } \\
\text { rubber } \\
(1.6191)\end{array}$ & $\begin{array}{l}\text { inner most } \\
\text { inner-lower } \\
\text { inner-upper } \\
\text { outer-lower } \\
\text { outer-upper } \\
\text { exterior-low } \\
\text { exterior-up }\end{array}$ & $\begin{array}{l}46.67 \\
62.12 \\
62.12 \\
76.33 \\
76.35 \\
84.57 \\
84.57\end{array}$ & $\begin{array}{l}206.75 \\
103.37 \\
103.38 \\
103.37 \\
103.38 \\
103.37 \\
103.38\end{array}$ & $\begin{array}{l}0.63 \\
0.32 \\
0.32 \\
0.32 \\
0.32 \\
0.32 \\
0.32\end{array}$ \\
\hline $\begin{array}{c}\text { paper } \\
\text { tube } \\
\text { [ce]1u1ose] } \\
(0.9)\end{array}$ & & 45.72 & 206.75 & 0.95 \\
\hline
\end{tabular}


Table III. Composition and Atom Densities for the Shielded Annular Tank Components

$$
\begin{aligned}
& \text { Rubber (density }=1.6191 \mathrm{~g} / \mathrm{cm}^{3} \text { ) } \\
& \text { 7.1528-3 } \\
& 1.0057-2 \\
& \text { 2.5156-2 } \\
& \text { 1.8187-2 } \\
& 3.4279-2 \\
& \text { Cellutose (density }=0.9 \mathrm{~g} / \mathrm{cm}^{3} \text { ) } \\
& \text { Atom Densities } \\
& \text { (atoms/barn-cm) }
\end{aligned}
$$

$\begin{array}{ll}U-234 & 1.0 \\ U-235 & 93.17 \\ U-236 & 0.43 \\ U-238 & 5.4 \\ H & \\ N & \\ O & \end{array}$


Table IV. Basic KEN05A Calculational Model of the Shielded Annular Tank

SAT, EXP\#I,BASIC MODEL, NO SHIMS, ANN=4.32B, 4. 30 T, CONC $=367 G / \mathrm{L}, \mathrm{H}=60.5 \mathrm{CM}$ REEAL PARA LIE=41 TME=IOO $\$ Y P G=1500$ GEN=400 TBA=2 NUB=YES ENO PARA REAE ARRAY NUX $=i$ NUY=I NUZ=6 FILL 651234 ENC FILL END ARRAY READ MIXT MIX=1 1102.033710 6100 $2.0067-3$ 8100 i.6721-2 MIX=2 ILOZ 2.5156-2 5100 3.4279-2 6.100 1.8187-2 8100 1.0057-2 $141007.1528-3$ $M I X=31102 \quad 7.9044-261004.0734-2$ IX=4 200 1.0 MIX=5 301 1.0 $M I X=5 \quad 92400 \quad 9.4478 I-6 \quad 9250 z \quad 2.9454-4$ 92509 5.8196-4 92600 4.02806-6 $92852 \quad 2.7395-5 \quad 92853<.2764-5$ 1162 $5.51316-2 \quad 7100 \quad 2.21766-3$ $8 I 003.743036-2$ END MIXT REAC GEOM UNIT 1

CYLINDER $0 \quad 145.72 \quad 27.0-32.27$ CYLINDER 1 1 $46.6727 .0-32.27$ CYLINUER 2 I $47.30 \div 27.0-32.27$ CYLINDER 0 I $54.50 \quad 27.0-32.27$ CYLINOER 3 . 1 - $62.12 \quad 27.0-32.27$ CYLINEER $2^{2 \cdots} 1$ - $62.4427 .0-32.27$ CYLIFDER $0 \quad 163.7327 .0 \quad-32.27$ CYLINDER 4 I $64.5727 .0-33.5$ CYLINDER 6 I $75.63 \% 27.0-33.5$ CYLINDER $4 \quad 176.333 \quad 27.0 \quad-34.73$ CYLINDER $2 \quad 1 \quad 76.653 \quad 27.0-34.73$

CYLIFDER 0 O $76.9127 .0 \quad-34.73$

CYLINDER 3 I $84.5727 .0 \quad-34.73$ CYLINDER 2. $184.8927 .0-34.73$ CUBOID 0 I $4 \mathrm{P}$ :00.0 $27.0-34.73$ UNIT 2

CYLINDER CYLINUEK CYLINDER CYLINDER

CYLINDER CYLINDER CYLINDER CYLINEER CYLINDER CYLIHDER

CYLINEER

CYLINDER CYLINDER CYLINUER CUBGID UNIT 3

CYLINOER CYLINDER CYLINUER CYLINDEE CYLINDER CYLINDER CYLINUER CYLINDER CYLINDER CYEINOER CYLINDER CYLINDER CYLINOER CYLINDER CUEOID

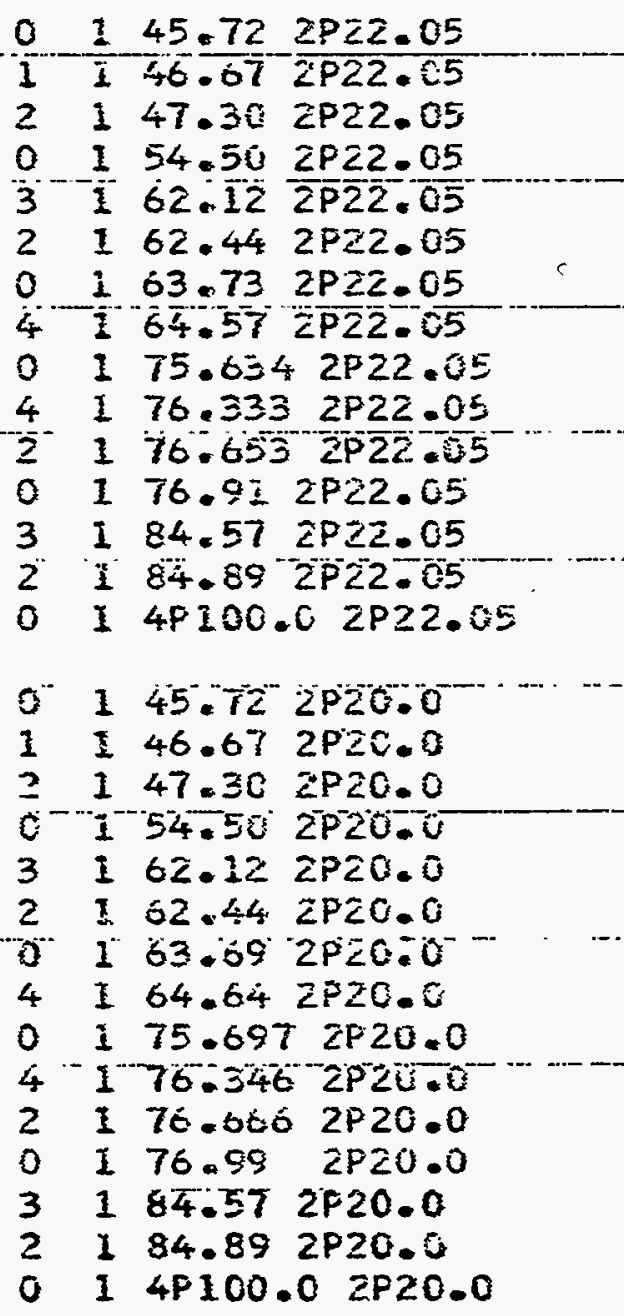

UNIT 4

CYLINDER $0 \quad 145.72 \quad 2 P 31.69$

CYLINDER I I 46.67 2P31.09

CYLINDER $2^{1} 1^{4}: 30$ 2P31.69

CYLINUER O $\$ 54.50 \quad 2 F 31.69$

CYLINDER $3162.122 P 31.69$

CYLINDER 2 1 62.44 2P3I.69

CYLINOER $01163.692 P 31.69$

CYLINOER 4 \$ 64.64 ZP®1.69

CYLINEER O 1 75.697 2P31.69

CYLINDER 4 i.76.346 ZP3i.69

CYLINDER 2176.665 2P31.69

CYLINSEK 0 i 76.99 2P3I.69

CYLINDER $3 \quad 184.57$ 2F31.09

CYLINDER 2 I 84.89 2FEI.69

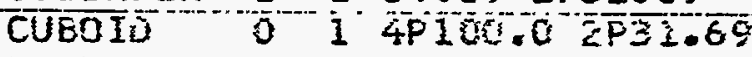

UNIT 5

CYLINDER $4 \quad 119.00 .0-2.54$

CYLINOER 9 i $40.00 .0-2.54$

CYLINDER $4 \quad 184.850 .0-2.54$

CUBOID O I 4PI00.0 $0.0-2.54$

UNIT 6 .

CUEOJD 014 P 3 C.C C.O -38.0

CUBOID $4 \quad 1$ 4P30.0 $0.0-18.2$

CU8015

CUEOID D $14 P 75.0$ C.0 $-3 E .0$

CUBEIP 0 I $85.0-75.0$ 2P75.0 0.0 -

CUธี่อบ

CUECIO

CUECID

ENE GEOM

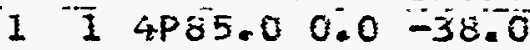

$0 \pm 4 P I O C .0$ 0.5 -38.0

$514 P 100.00 .0-68.0$

READ START NST $=0$ NBX $=1$ END START

READ BOUNOS ALL $=V A C$ END BOUNDS

END UATA

END 
Table V. KEN05A Calculational Results for the Shielded Annular Tank Program

\begin{tabular}{|c|c|c|}
\hline $\begin{array}{c}\text { MEASUREMENT } \\
\text { NUMBER }\end{array}$ & $\begin{array}{c}\text { MEASURED } \\
\text { CRITICAL } \\
\text { HEIGHT } \\
(\mathrm{cm})\end{array}$ & $\begin{array}{c}\text { CALCULATED } \\
k_{\text {eff }} \\
\text { AND } \\
\text { STANDARD } \\
\text { DEVIATION }\end{array}$ \\
\hline 3 & 60.5 & $.98948 \pm .00127$ \\
4 & 77.1 & $.99479 \pm .00117$ \\
5 & 96.6 & $.99765 \pm .00119$ \\
11 & 152.0 & $.99347 \pm .00132$ \\
\hline
\end{tabular}




\section{DESIGN OF PRODUCTION IANK}

The shielded annular tank (SAT) study, was conceived to produce a tank design that offers the advantages of high volume, relatively-high floor space efficiency, reduced neutron doses to operators, low maintenance costs, and easy shielding verification in a proven technology design. This section reports results of the calculational study which resulted in the determination of the final design parameters for the production SAT. The KENO-IV computer code with the 16-group Hansen-Roach cross section set was used for all calculations.

The basic approach to the design was to start with the standard unshielded annular tank already in use and improve upon its design characteristics. Three straightforward steps can be taken to improve the annular tank design. First, increase the annular thickness to the maximum subcritical thickness for a water-reflected single tank. Secondly, isolate the tanks neutronically from all other fissile material. Thirdiy, minimize the thermalneutron return to the tanks to allow high concentration solution to be safely stored in the tank.

Figure 11 shows the parameter study used to determine the thickness of the annular solution region for the SAT. Curves of keff vs annular thickness for each of three different reflector conditions are shown. The data are 


\section{('u!) snjnuu}

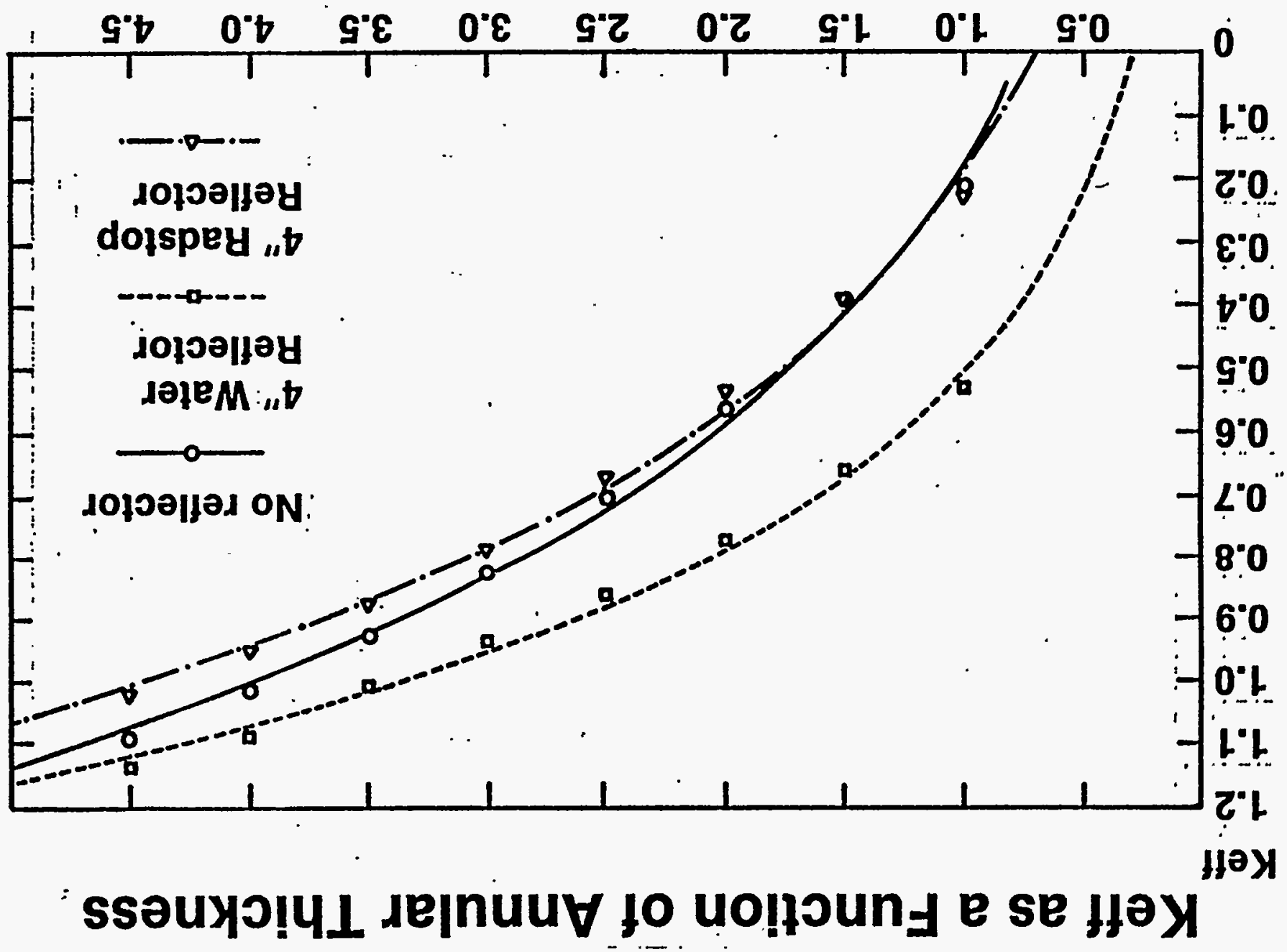

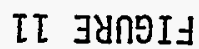


for a single 152.4-cm-diameter by 213.3-cm-high annular tank filled with $150 \mathrm{~g}$ Pu/liter metal/water mixture. The reflectors used in this study were water, the boron-loaded rubber commercially identified as Radstop $\otimes$, and air (no reflector). (Radstop is a product of the Bisco Company, and consists of a borated silicone rubber with a boron loading of $\left.0.6 \mathrm{~g} \mathrm{~B} / \mathrm{cm}^{3}\right)$. $10.2 \mathrm{~cm}$ of each material was placed on the inner and outer surfaces of the tank. The water-reflected tank is clearly the most reactive. with the Radstop-reflected tank the least reactive, as expected. At an annular solution thickness of $7.62 \mathrm{~cm}$, the waterreflected tanks have a keff of 0.95. Therefore, that thickness $\left(3^{n}\right)$ was selected as the maximum subcritical annular solution thickness for the SAT. Note that this value is conservative because the Radstop-reflected tank at the same thickness has a keff of only 0.80 .

The next step is to neutronically isolate the tank from other fissile material. Isolation is achieved by adding a layer of hydrogeneous material to the surfaces of the tank. Figure 12 shows the effect of different moderators on the reactivity of the system. In this study, an infinite array of tanks with all tanks in contact was modeled. Each tank in the array had the same diameter and height dimensions as the single tank described in the previous paragraph. In this case, a 7.62-cm-thick metal/water mixture having $200 \mathrm{~g}$ Pulliter was used. and a 1 -mm-thick sheath of Radstop was 


\section{Keff as a Function of Moderator Thickness for Several Different Moderators}

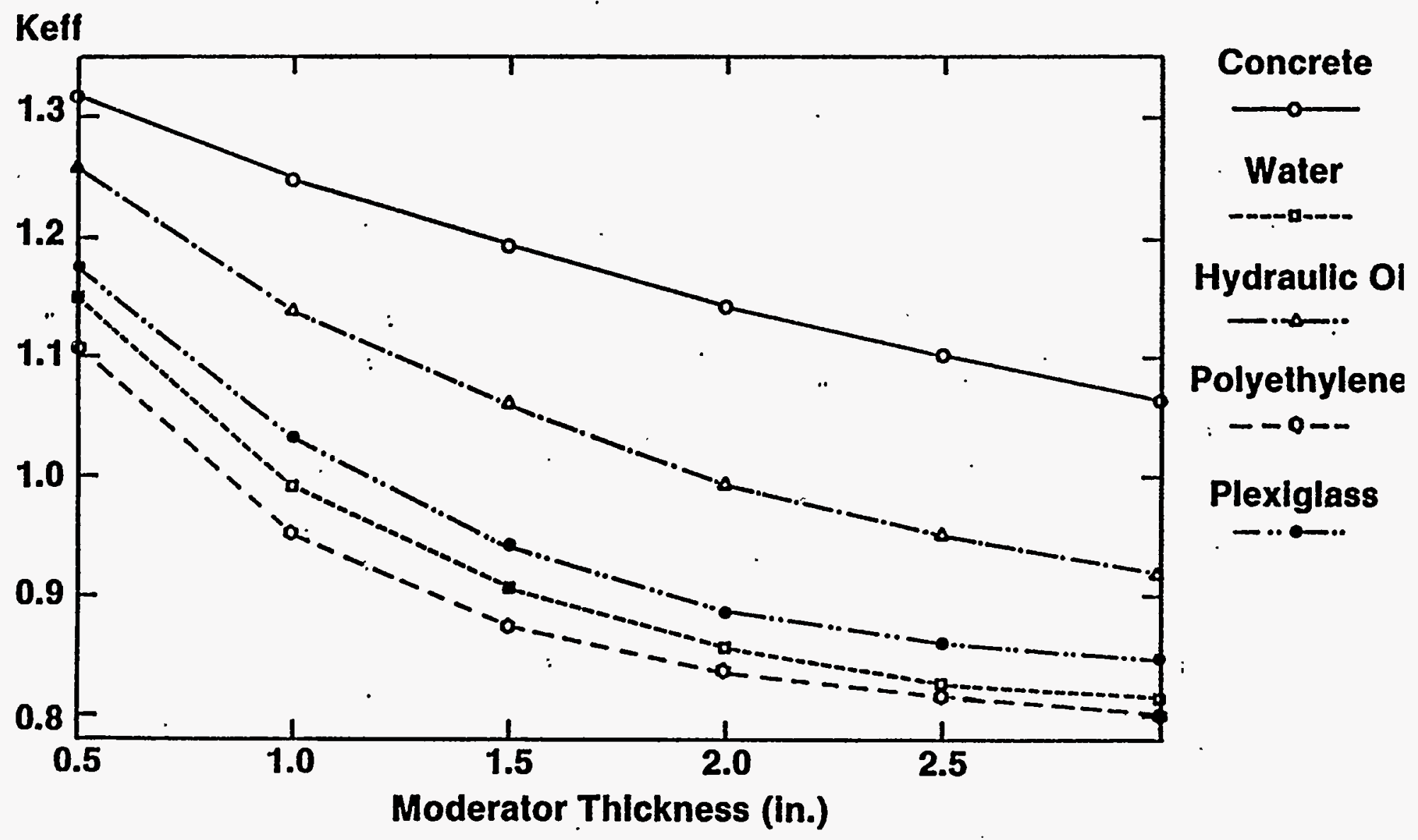


placed on each side of the moderator, forming a sandwich. The reactivity of the system decreased as a function of both hydrogen content and moderator thickness. For the SAT, a 6.35-cm-thick polyethylene moderator was selected. This choice of moderator resulted in a keff for this system of 0.81 .

Finally, the thermal neutron return to the solution region must be minimized to maximize the solution concentration stored in the tank. Figure 13 shows the data used to determine the final thickness of the Radstop used in the production model of the SAT. Again, the data in Figure 13 are for an infinite array of tanks in contact, each with a 7.62-cm-thick solution annulus. The $3 \mathrm{~mm}$ thickness of Radstop was chosen as the most efficient thickness to incorporate into the tank.

The end result of this calculational study was a production shielded annular tank whose design characteristics are shown in Table VI, expressed in English and metric units mixed. The tank is illustrated in Figures 14 and 15. The lead was added to the shield design to reduce gamma radiation dose to workers.

Finally. Figure 16 illustrates the effectiveness of the neutron absorber sandwich. The data shown in Figure 16 are based on the design parameters listed in Table VI with the exception that the solution concentration is allowed to change. The SAT array remains subcritical for solution concentrations up to $1000 \mathrm{~g}$ Pu/liter. This fact demonstrates the ability of the neutron absorber sandwich to isolate each tank and minimize thermal neutron return. 
FIGURE 13

\section{Keff as a Function of Radstop Thickness for Several Different Moderator Thicknesses}

\section{Keff}

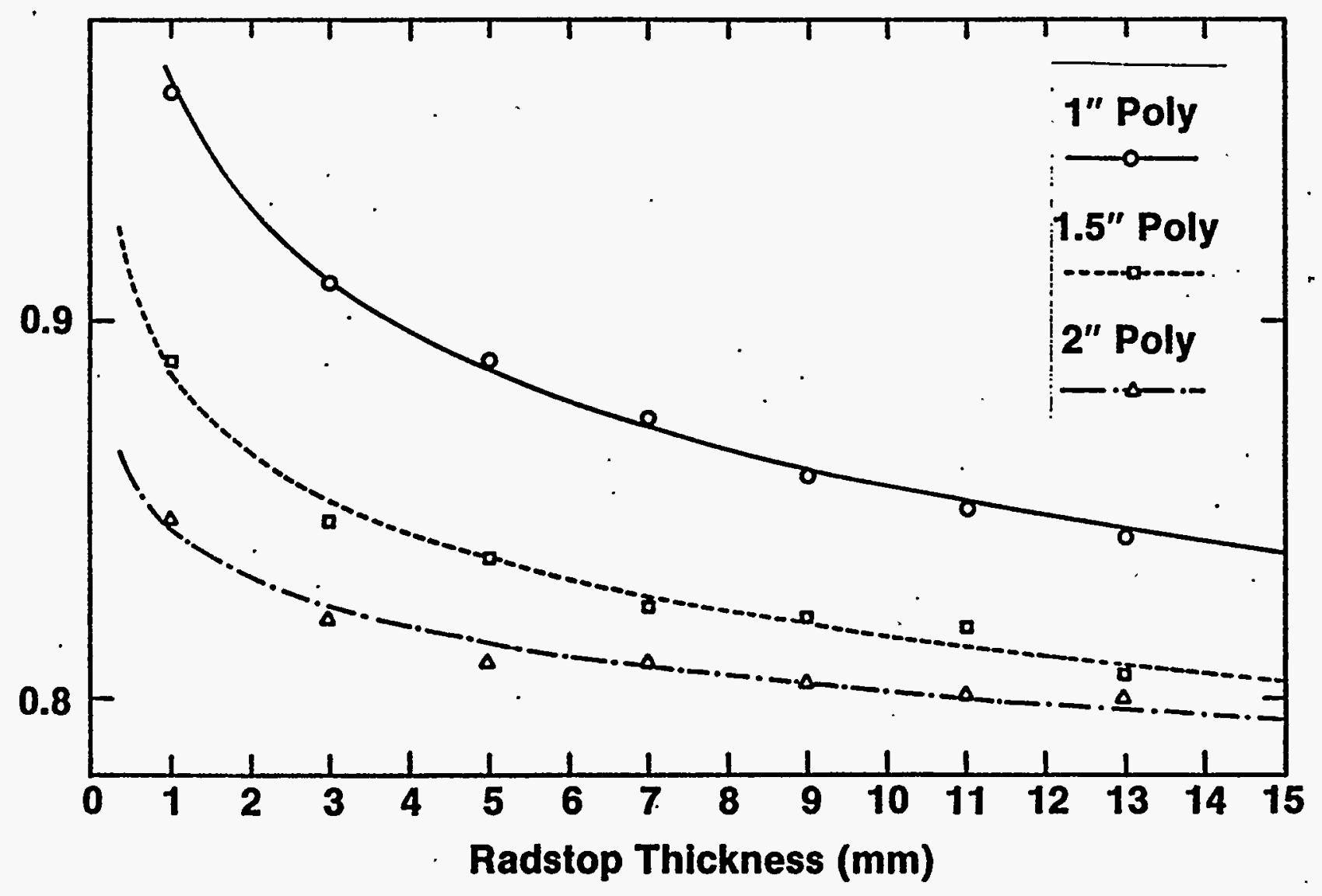


FIGURE 14

\section{Cross Section of Shielded Annular Tank}

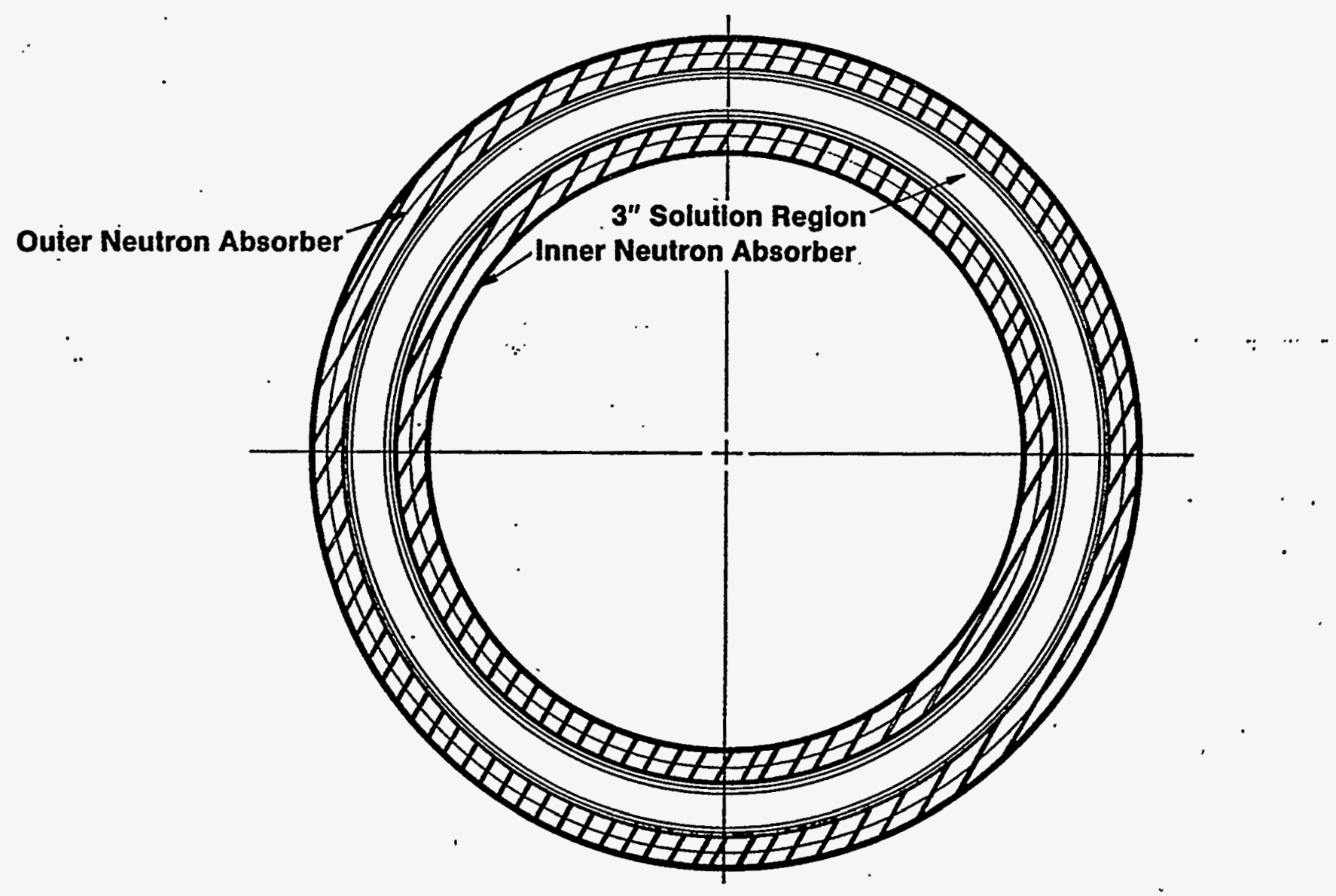


FIGURE 15

\section{Neutron Absorber Sandwich}

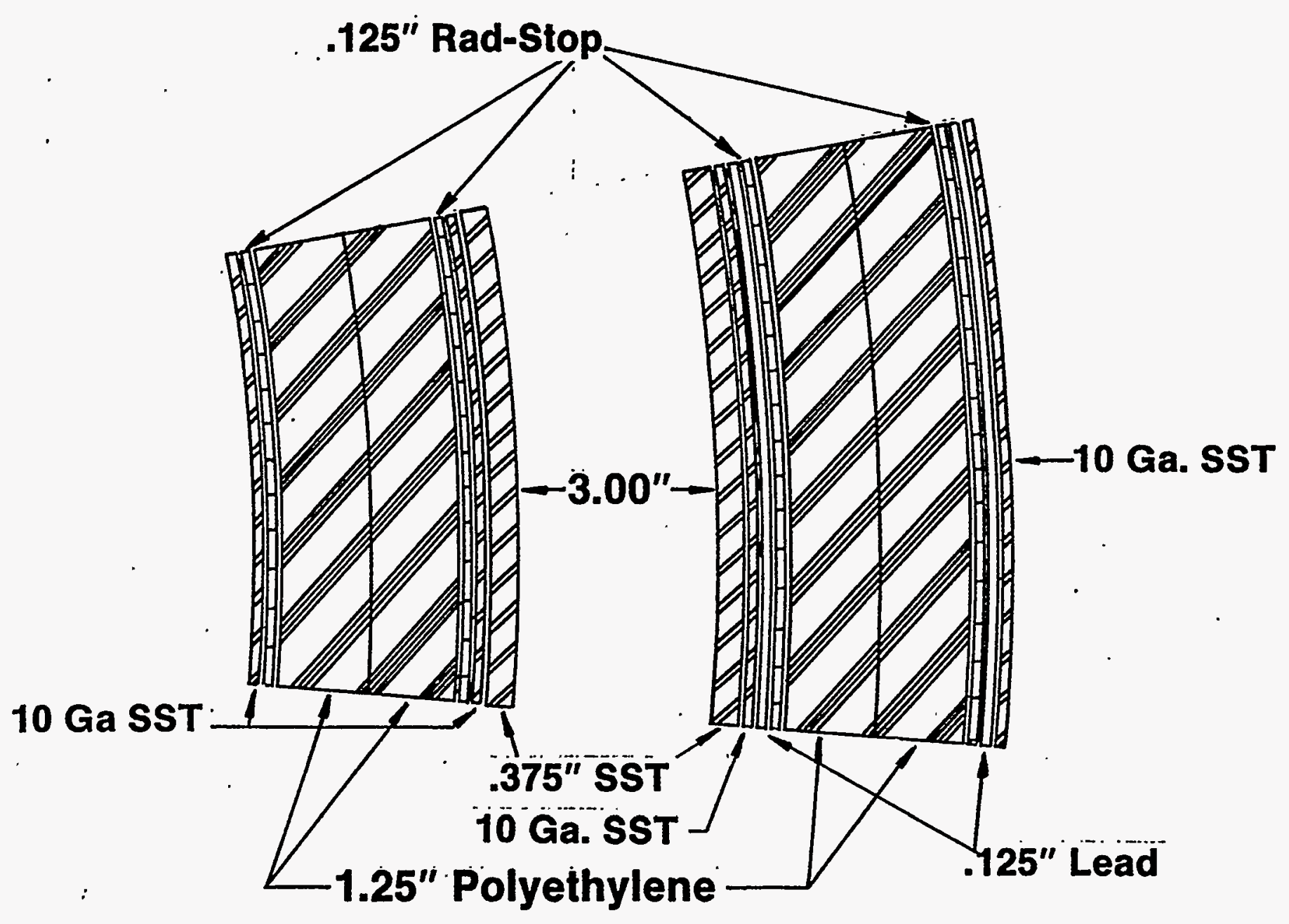


FIGURE 16

\section{Keff as a Function of Solution Concentration}

Keff

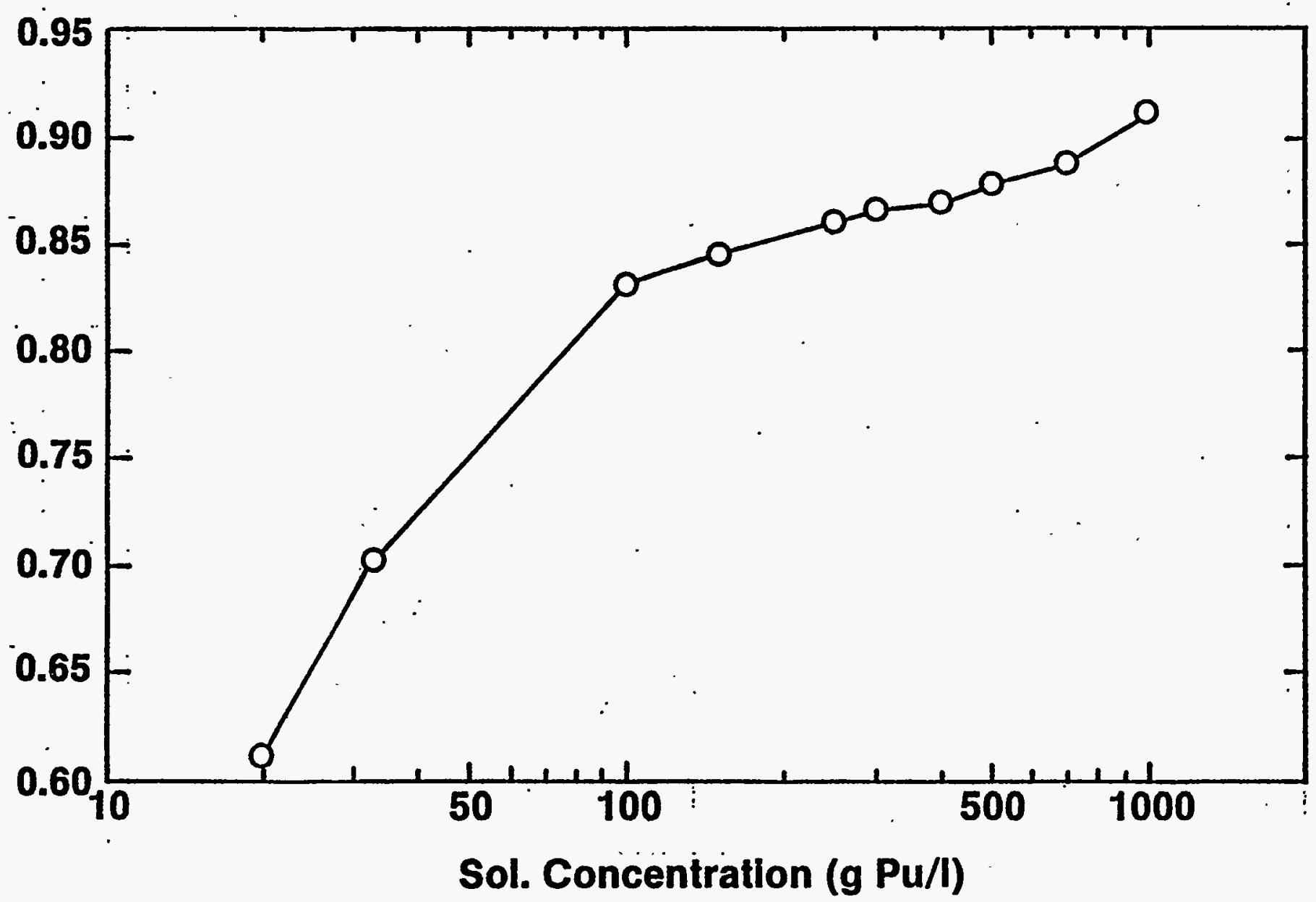




\section{Nominal SAT Model}

- 7' high, 60" OD

- 3" solution annulus

- 2.5" polyethylene moderator

- 1/8" radstop absorber

- $200 \mathrm{~g} \mathrm{Pu} / \mathrm{l}$ solution

- Infinite array

- $20 \mathrm{Kg} \mathrm{Pu}$ as "sludge" 
[60]

CONCLUSION

The shielded annular tank is a viable design for the storage of large quantities of fissile solution with confidence in the criticality safety of the method. The computational code (KENO) used to set design parameters for such a tank to be used in production applications throughout the plant has been validated against a series of precisely-performed criticality measurements. No significant bias was found thus, Nuclear and Facilities Safety considers the calculational technique approved for use in designing such a tank for use at Rocky Flats. 


\section{REFERENCE}

1. "American National Standard, Use of Borosilicate Glass Raschig Rings as a Neutron Absorber in Solutions of Fissile Materiai". ANSI/ANS-8.5-1986, prepared by the American Nuclear Society Standards Committee Working Group ANS-8.5, January 3, 1986. 
KEN05A Models used to validate other measured cases.

SAT, EXP\#2,BASIC MODEL, ANN=4.32B,4.30T,CONC $=367 \mathrm{G} / \mathrm{L}$, SHIM $=.457$ IN, H=77.1CM READ PARA $L I B=41$ TME $=100$. NPG $=1500 \quad G E N=400$ TBA=2 NUB=YES END $P A R A$ READ $\triangle R R A Y$ NUX=I NUY $=I$ NUZ=6 FILL $6512=4$ END FILL END ARRAY READ NIXT MIX=1 $1102.03371061002 .0067-3$ 8100 $1.6721-2$ MIX=2 102 $2.5136-251003.4275-2$ 6100 $1.8187-2$ 8100 $10057-2141007.1528-3$ MIX=3 $11027.9044-261004.0734-2$ MIX=4 200 I. 0 MIX=5 3011.0 $M I X=6 \quad 92400 \quad 9.44781-6 \quad 92508 \quad 2.9454-4 \quad 92509 \quad 5.8196-4 \quad 92600 \quad 4.02806-6$ $928522.7395-592853 \quad 2.2764-5$ 1 $6025.91316=271002.21766-3$

$81003.743036-2$ END MIXT

REED GEOM

\section{UNIT I}

CYLINDER

CYLINDER

CYLINDER

CYLINDER

CYLINOER

CYLINOER

CYLINDER

CYLINDER

CYLINDER:

CYLINDER

CYLINDER

CYLINDER

CYEINDER

CYLINGER

CUEOIO

UNIT 2

CYLINDER

CYLINDER

CYLINDER

CYLINDER

CYLINDER

CYLINDER

CYLINDER

CYLINDER 4

CYLINDER

CYLINGER

CYLINDER

CYLINDER

CYLINOER

CYCINDER"

CUBOID

UNIT 3

CYLINDER

CYLINOER

CYLINDER

- CYLINTER'

CYLINDER.

CYLINDER

CYLINDER

CYLINDER

CYLINOER

CYLINDER

CYLINDER

CYLINDER

CYLINDER

CYLINDER

CUBOID

$$
\begin{array}{lllll}
0 & 1 & 45.72 & 43.62 & -32.27 \\
1 & 1 & 46.67 & 43.62 & -32.27 \\
2 & 1 & 47.30 & 43.62 & -32.27 \\
0 & 1 & 54.50 & 43.62 & -32.27 \\
3 & 1 & 62.12 & 43.62 & -32.27 \\
-3 & 1 & 62.44 & 43.62 & -32.27 \\
0 & 1 & 63.73 & 43.62 & -32.27 \\
4 & 1 & 64.57 & 43.62 & -33.5 \\
6 & 1 & 75.147 & 43.0 .2 & -33.5 \\
4 & 1 & 76.333 & 43.62 & -34.73 \\
2 & 1 & 76.653 & 43.62 & -34.73 \\
0 & 1 & 76.91 & 43.62 & -34.73 \\
3 & 1 & 84.57 & 43.62 & -34.73 \\
2 & 1 & 84.89 & 43.62 & -34.73 \\
0 & 1 & 49100.0433 .62-34.73
\end{array}
$$

$0 \quad 145.72 \quad 2 P 13.74$

$1 \frac{1}{1} 46.07 \frac{4513 \cdot 74}{2 P 13.74}$

$2 \pm 47.30 \quad 2 P 13.74$

- $154.50 \quad 2 P 13.74$

3 1 62.12 2PI3.74

$162.44 \quad 2 P 13.74$

$163.73 \quad 2 \mathrm{P} 13.74$

$124.572 P 13.74$

- $175.147 \quad 2$ P 13.74

$4 \quad 175.850 \quad 2 P 13.74$

2176.333 2P13.74

$0 \quad 176.91$ 2PI3.74

$3184.572 \mathrm{P} 13.74$

2 i $84.892 \mathrm{PI} 3.74$

$0 \div$ 4P 100.0 2P 3.74

$0^{-1} 45.72 .2 P 20.0^{-}$

$11.46 .672 P 20.0$

$2147.3 \mathrm{C} 2 \mathrm{P} 2 \mathrm{O} . \mathrm{O}$

0 i $54.50 .2 P 20.0$

$3162.12 \quad 2 \mathrm{P} 20.0$

$2162.442 \mathrm{P} 20.0$

0 I $63.69^{-2 P 20.0}$

$4164.64 \quad 2 P 20.0$

$0175.210 \quad 2 P 20.0$

$4.76 \div 3462 P 20.0$

$2176.666 \quad 2 \mathrm{~F} 20.0$

a 176.99 2P20.0

$3184.57 \quad 2 \mathrm{P} 20.0$

2184.89 2P20.0

$014 P \pm 00.0 \quad 2 P 20.0$
UNIT 4

CYLINDER $\quad 0 \quad 145.72 \quad 2 P 31.69$

CYLINDER I $146.67 \quad 2$ P31.69

CYLINDER 2 'I 47.30 2P3I.69

CYLINDER 0154.50 2P31.6\%

CYLINOER 3162.12 2P31.69

CYLINDER 2 i 62.44 2P31.69

CYLINDER $\quad 0 \quad 163.69$ 2P3I.69

CYLINDER 4164.64 2P31.69

CYIINDER O 75.230 2P 1.69

CYLINDER $4 \quad 176.346 \quad 2 P 31.69$

CYLINOER 2 1 76.666 2P31.69

CYLINDER O 1 16.99 ZP31.69

CYLINDER $3 \quad 184.57$ 2P31.69

CYLINDER 2.184 .89 2P31.69

CUBOID 0 1 4P100.0 2P31.69

UNIT 5

CYLINDER $4 \quad 1$ 19.C $0.0-2.54$

CYLINDER 0 1 $40.00 .00-2.54$

CYLINDER 4 I $84.890 .0-2.54$

CUBOID 0 1 4P100.0 $0.0-2.54$

UNIT 6

CUBOID $014 P 30.00 .0-18.0$

CUBOID 4 I 4 P30.0 $0.0-18.2$

CUBOIO 0 I 4P30.0 $0.0-38.0$

CUBOID $0114 P 75.00 .0-38.0$

CUBOID $0.185 .0-75.0 .2 P 75.0 .0 .0-38$.

CUBCIO I I 4 PB5.0 C.6 -38.0

CUBOID 014 P $100.00 .0-38.0$

CUBOID 5 1 $48130.0 .0 .0-68.0$

END GEOM

READ START NST $=0$ NBX $=i$ END START

READ BOUNDS ALL=VAC ENO BOLNOS

END DATA

FNก 


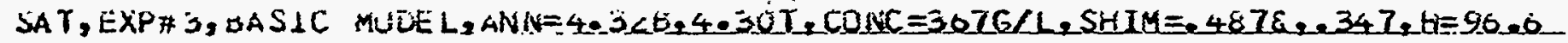
RE AL PAKA $L I B=\angle I$ TME $=1 C 0$ NPG $=1500$ GEN=400 TBA=Z NUB=YES END PARA rEAU AKR AY NUX=1. NUY=i NUL=0 FILL 05 i 234 ENU FILL ENU ARKAY

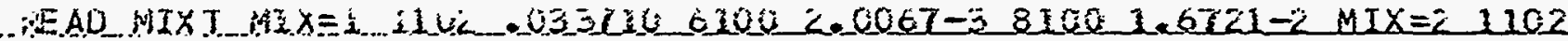

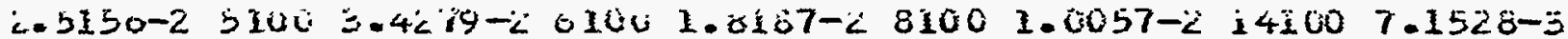

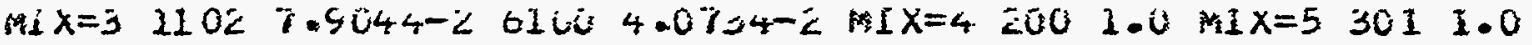

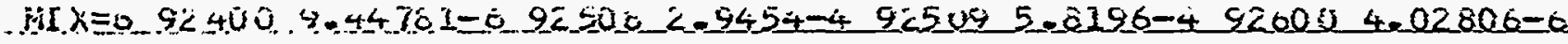

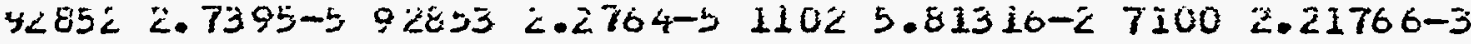

$8 I$ LS $3.743530-\angle$ END MIXT

- XIESO GEOM

Uivir 1

CYLINEER U 4 45.72 6 E. $1-32.27$

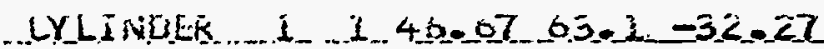

LYLINDEK $214 \% .5065 .1-32.27$

CYLINDER \& $134.50 \mathrm{03} .1-32.27$

CYLIINDER - 3 i 6.2.12 $63.1-32.27$

CYLINUER \& 1 C. 2.44 OE. $1-32.27$

CYLINDER $Q$ I 13.73 O3.1 -32.27

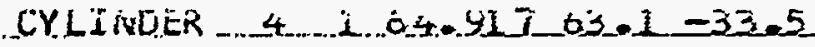

CYLINDER 6 I $75.17763 .1-33.5$

CYLINDER 4 I $70.33303 .1-34.73$

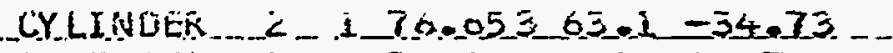

CYLIMUER \& 170.51 0j.1 -34.73

CYLINDER \& $184.5763 .1-34.73$

CYLINUER 2 $1 . .1$ a4. 19 0 $3.1-34.73$

CUVISIO

UVIT Z̈

i) $14 \mathrm{p} 100.063 .1-34.73$

CYLINDER . C. I 42.7Z ZP4.0C

UNIT 4

CYLINDER \& i 45.72 2P31.64

CYLINUEK 1 I 40.07 2P4 - UU

CYLINUER $2 \quad 147.30<P 4 . U U$

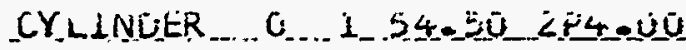

CYLINLER I 1 OOL.IZ Z̈P4.OC

CYLINDER $2 \mathrm{~L} 02.44$ ZP4.00

CY.LINÜER ...6 i_0.3.73 2F4.00

CYLINDER 4164.917 ¿P4. UO

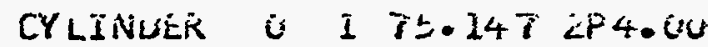

CYLINUER . 4...I 7.2.E5O $\angle P 4.00$

CYLINDER 2 I 70.33 $2 P 4.00$

CYLINDER $O+70.9 I$ ZF4.0O

CYLINOE $\quad 3 \quad 184.57 \angle P 4.00$

CY LINUER $\angle$ i 84.39 2P4.UL

CUBUIL O 14 PIUU.U ZP4.00

UNIT 3

CYLINUER

1 4P100 00 2P4.00

CYLINGEK

CYLINDER

CYLINLER

CYLINUEK

CYLINEER

CYLINOEX

CYLINUER

CYLINOER

EYLINDER

CYLiLULER

CYLINUER.

CYLINLER

CYLINDER

WUOIL

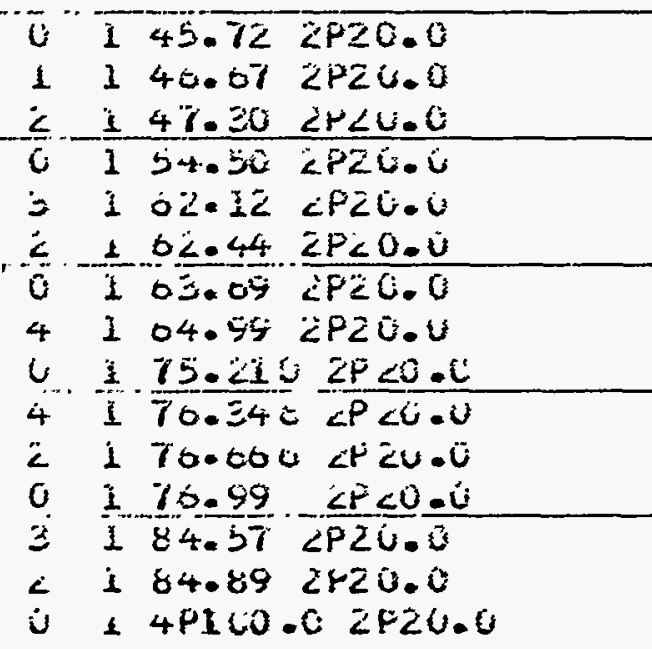

CYLINUER

$1+40.07$ EPJi-09

CYLINUER Z I 17.30 CP31.09

CYLINDER U 124.50 ¿PS1.09

CYLINDER 3

CYLINEER Z $10 \angle 04$ LPEi.OS

CYLINLER $Q$ i 103.05 ZP3 1.69

CYLINUER ... 4 i O4. OS $\leqslant F 31.09$

EYLINUER $Q$ \& $75 . \angle I U 2 P 31.0 \%$

UYLINDDER 4 i 70.340 2P31.09

SYLINOEK . 2 . 70.060 2P 31.09

CYLINDER $\&$ I TO.59 2PEI.09

CYLINUER S 184.57 ZPE1.09

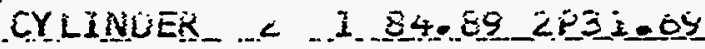

CUEOIO O I 4PIUE.0 2 PSLOOS

LEV IT 5

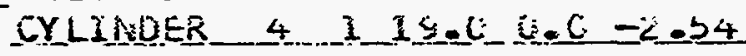

CYLINDER $G=46000.0-2.54$

CYLINUEK 4 I $84.6 \% \mathrm{COL}-2.54$

CUEUID . ... U i 4 El $10.0 .0 .0-2.54$

UNIT 6

CUBEID O $\quad$ S P3G.O O.G -18.0

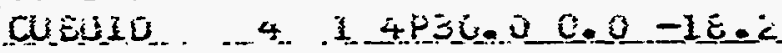

CUEOLD 5 \& 4 P 3 U.U $0.0-50.0$

CUBUID O I 4 Pै75.0 0.L -30.6

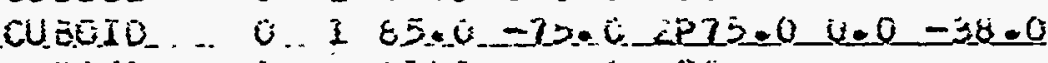

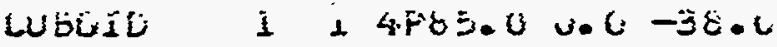

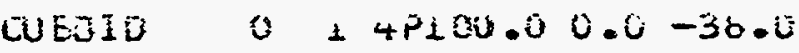

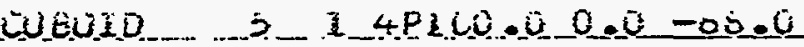

END GEOM

KEAL SIART RST 0 NEX=1 ENU STAKT

KEAD EUUNOS ALL=VAC EVIV BUGIVOS.

ENU LIATA

END 
SAT, EXP\#4,BASIC MODEL, ANNULUS $=4.32 B, 4.30 \mathrm{~T}, \mathrm{CONC}=367 \mathrm{G} / \mathrm{L}, \mathrm{SHIM}=.4768 .6225$ READ PARA LIB $=41$ TME $=100$ NPG $=1500$ GEN $=400$ TBA $=2$ NUB $=Y E S$ END PARA READ ARRAY NUX $=1$ NUY $=1$ NUZ=6 FILL $651212 z \quad 34$ END FILL END ARRAY READ MIXT MIX=1 $1102.0337106100 \quad 2.0067-3 \quad 8100 \quad 1.6721-2$ MIX=2 1102 2.5156-2 $5100 \quad 3.4279-2 \quad 6100 \quad 1.8187-2 \quad 8100 \quad 1.0057-2 \quad 14100 \quad 7.1528-3$ MIX=3 $11027.9044-26100 \quad 4.0734-2$ MIX=4 200 1.0 MIX=5 3011.0 MIX=6 $92400 \quad 9.44784-6 \quad 92508 \quad 3.6722-4 \quad 92509 \quad 5.0928-4 \quad 92600 \quad 4.02808-6$ $928523.10286-592853 \quad 1.91302-5 \quad 11025.511897-2 \quad 7100 \quad 2.22068-3$ $81003.593159-2$ END MIXT

READ GEOM

UNIT I

CYLINOER $\quad 0 \quad 145.72 \quad 33.5 \quad-32.27$

CYLINDER $\quad 0 \quad 146.67 \quad 33.5 \quad-32.27$

CYLINOER 0 I $47.30 \quad 33.5 \quad-32.27$

CYLINDER $0 \quad 154.50 \quad 33.5 \quad-32.27$

CYLINDER $3 \quad 162.12 \quad 33.5 \quad-32.27$

$\begin{array}{llllllll}\text { CYLINDER } & 2 & 1 & 62.44 & 33.5 & -32.27\end{array}$

CYLINDER $\quad 0 \quad 163.73 \quad 33.5 \quad-32.27$

CYLINDER $4 \quad 164.57 \quad 33.5 \quad-32.27$

$\begin{array}{lllllllll}\text { CYLINDER } & 6 & 1 & 70.75 & 2 P 33.5 & \text { ORIGIN } & 2.70 & 0.0\end{array}$

$\begin{array}{llllllll}\text { CYLINDER } & 4 & 1 & 71.3725 & 2 P 33.5 & \text { ORIGIN } & 2.70 & 0.0\end{array}$

CYLINDER. $6 \quad 175.158 \quad 2 P 33.5$

$\begin{array}{llllll}\text { CYLINDER } & 4 & 1 & 76.333 & 33.5 & -34.73\end{array}$

$\begin{array}{llllllll}\text { CYLINDER } & 2 & 1 & 76.653 & 33.5 & -34.73\end{array}$

CYLINDER $0 \quad 176.91 \quad 33.5 \quad-34.73$

$\begin{array}{lllllll}\text { CYLINOER } & 3 & 1 & 84.57 & 33.5 & -34.73\end{array}$

CYLINDER. 2 I $34.8933 .5-34.73$

CUBOID 0 I 4P100.0 $33.5-34.73$

UNIT 2

CYLINDER $\quad 0 \quad 145.72 \quad 2 P 18.8$

CYLINDER $00 \quad 146.67 \quad 2 P 18.8$

CYLINDER 0 1 $147.30 \quad 2 P 18.8$

CYEINDER $0 \quad 154.50 \quad 2 P 18.8$

CYLINDER $3 \quad 162.12 \quad 2 P 18.8$

CYLINDER 2 2 $162.44 \quad 2 P 18.8$

CYLINOER $\quad 0 \quad 163.73 \quad 2 P 18.8$

CYLINDER $4 \quad 164.57 \quad 2 P 18.8$

CYLINDER $6 \begin{array}{lllll}6 & 70.75 & 2 P 18.8 & \text { ORIGIN } 2.70 & 0.0\end{array}$

$\begin{array}{lllllll}\text { CYLINDER } & 4 & 1 & 71.3725 & 2 P 18.8 & \text { ORIGIN } 2.70 & 0.0\end{array}$

CYLINEER $6 \quad 175.158 \quad 2 P 18.8$

CYLINEER $44 \quad 176.333 \quad 2$ PI8.8

CYLINDER $2 \quad 176.653 \quad 2 P 18.8$

CYLINDER $\quad 0 \quad 176.912 P 18.8$

$\begin{array}{lllll}\text { CYLINDEP. } & 3 & 1 & 84.57 & 2 P 18.8\end{array}$

CYLINDER 2184.89 2P18.8

CUBOTD $\quad 0 \quad 14$ P100.0 2P18.8

UNIT 3

CYLINDER $\quad 0 \quad 145.72 \quad 2 P 26.6$

CYLINDER 01146.672 P26.6

CYLINDER 0 I $47.30 \quad 2$ P26.6

CYLINDER $\quad 0 \quad 154.50 \quad 2 P 26.6$

CYLINDER $01162.12 \quad 2 P 26.6$

CYLINDER 0 1 162.442 2P26.6

CYLINDER $0 \quad 163.692 P 26.6$

CYLINOER $4 \quad 164.64 \quad 2 P 26.6$

CYLINDER 61170.75 2P26.6 ORIGIN 2.700 .0

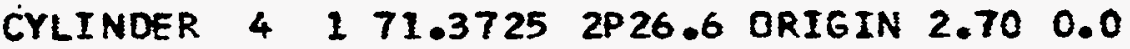

CYLINDER $6 \quad 175.2212$ P26.6 


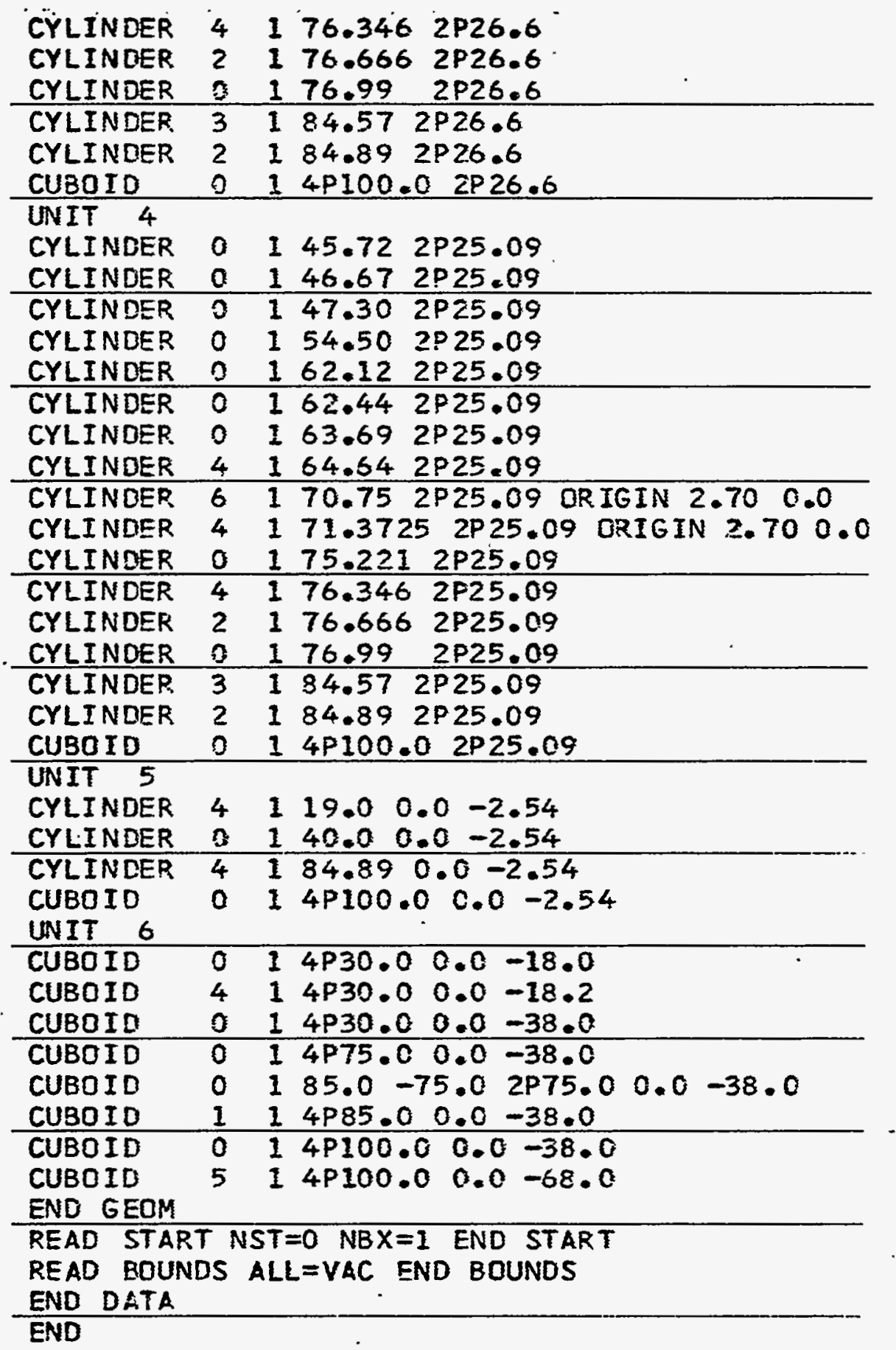

